\title{
Fostering monitoring and regulation of learning
}

Citation for published version (APA):

Van Loon, M. H. G. (2014). Fostering monitoring and regulation of learning. [Doctoral Thesis, Maastricht University]. Datawyse / Universitaire Pers Maastricht. https://doi.org/10.26481/dis.20140508ml

Document status and date:

Published: 01/01/2014

DOI:

10.26481/dis.20140508ml

Document Version:

Publisher's PDF, also known as Version of record

\section{Please check the document version of this publication:}

- A submitted manuscript is the version of the article upon submission and before peer-review. There can be important differences between the submitted version and the official published version of record.

People interested in the research are advised to contact the author for the final version of the publication, or visit the DOI to the publisher's website.

- The final author version and the galley proof are versions of the publication after peer review.

- The final published version features the final layout of the paper including the volume, issue and page numbers.

Link to publication

\footnotetext{
General rights rights.

- You may freely distribute the URL identifying the publication in the public portal. please follow below link for the End User Agreement:

www.umlib.nl/taverne-license

Take down policy

If you believe that this document breaches copyright please contact us at:

repository@maastrichtuniversity.nl

providing details and we will investigate your claim.
}

Copyright and moral rights for the publications made accessible in the public portal are retained by the authors and/or other copyright owners and it is a condition of accessing publications that users recognise and abide by the legal requirements associated with these

- Users may download and print one copy of any publication from the public portal for the purpose of private study or research.

- You may not further distribute the material or use it for any profit-making activity or commercial gain

If the publication is distributed under the terms of Article $25 \mathrm{fa}$ of the Dutch Copyright Act, indicated by the "Taverne" license above, 


\section{Fostering Monitoring and Regulation of Leaming}

Mariëtte van Loon 
The research reported in this dissertation was carried out at

Mastricht University in Leminum!

in the School of Health Professions Education

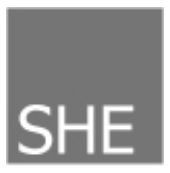

in the context of the research school

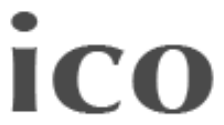

and was funded by

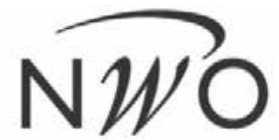

Nederlandse Organisatie voor Wetenschappelijk Onderzoek

(C) Mariëtte Henrica van Loon, Maastricht 2014

ISBN 9789461593269

Production: Datawyse | Universitaire Pers Maastricht 


\title{
Fostering Monitoring and Regulation of Leaming
}

\author{
PROEFSCHRIFT
}

ter verkrijging van de graad van doctor

aan de Universiteit Maastric ht

op gezag van de Rector Magnific us, Prof. Dr. L.L.G. Soete, volgens het besluit van het College van Decanen,

in het openbaarte verdedigen

op donderdag 8 mei 2014 om 16:00 uur

door

Mariëtte Henrica van Loon

Geboren op 1 november 1982 te 's-Hertogenbosch

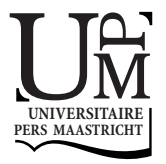




\section{Promotores}

Prof. dr. J. J. G. van Merriënboer

Prof. dr. T. van Gog, Erasmus Universiteit Rotterdam

\section{Copromotor}

Dr. A. B. H. de Bruin

\section{Beoord elingsc ommissie}

Prof. dr. T. Dornan, voorzitter

Dr. H. H. L. M. Donkers

Prof. dr. F. G. W. C. Paas, Erasmus Universiteit Rotterdam

Prof. dr. M. S. R. Segers

Prof. dr. J. D. Vermunt, Cambridge University 


\section{Contents}

Chapter 1

Introduction

Chapter 2

The Effect of Delayed-JOLs and Sentence Generation on Children's Monitoring Accuracy and Regulation of Idiom Study

Chapter 3

Effects of Reflection and Sentence Generation on Adolescents' Restudy

Selections and Monitoring when Learning Idioms

Chapter 4

Can Students Accurately Evaluate their Understanding of Cause-and-Effect

Relations? The Effects of Diagram Completion on Monitoring Accuracy

Chapter 5

Activation of Inaccurate Prior Knowledge Affects Primary-School Students'

Metacognitive Judgments and Calibration

Chapter 6

Refutations in Science Texts Lead to Hypercorrection of High-Confidence

Misconceptions

Chapter 7

General Discussion

Summary

Glossary

Samenvatting (Summary in Dutch)

Dankwoord (Acknowledgements)

Curriculum Vitae

List of SHE Dissertations

List of ICO Dissertations 


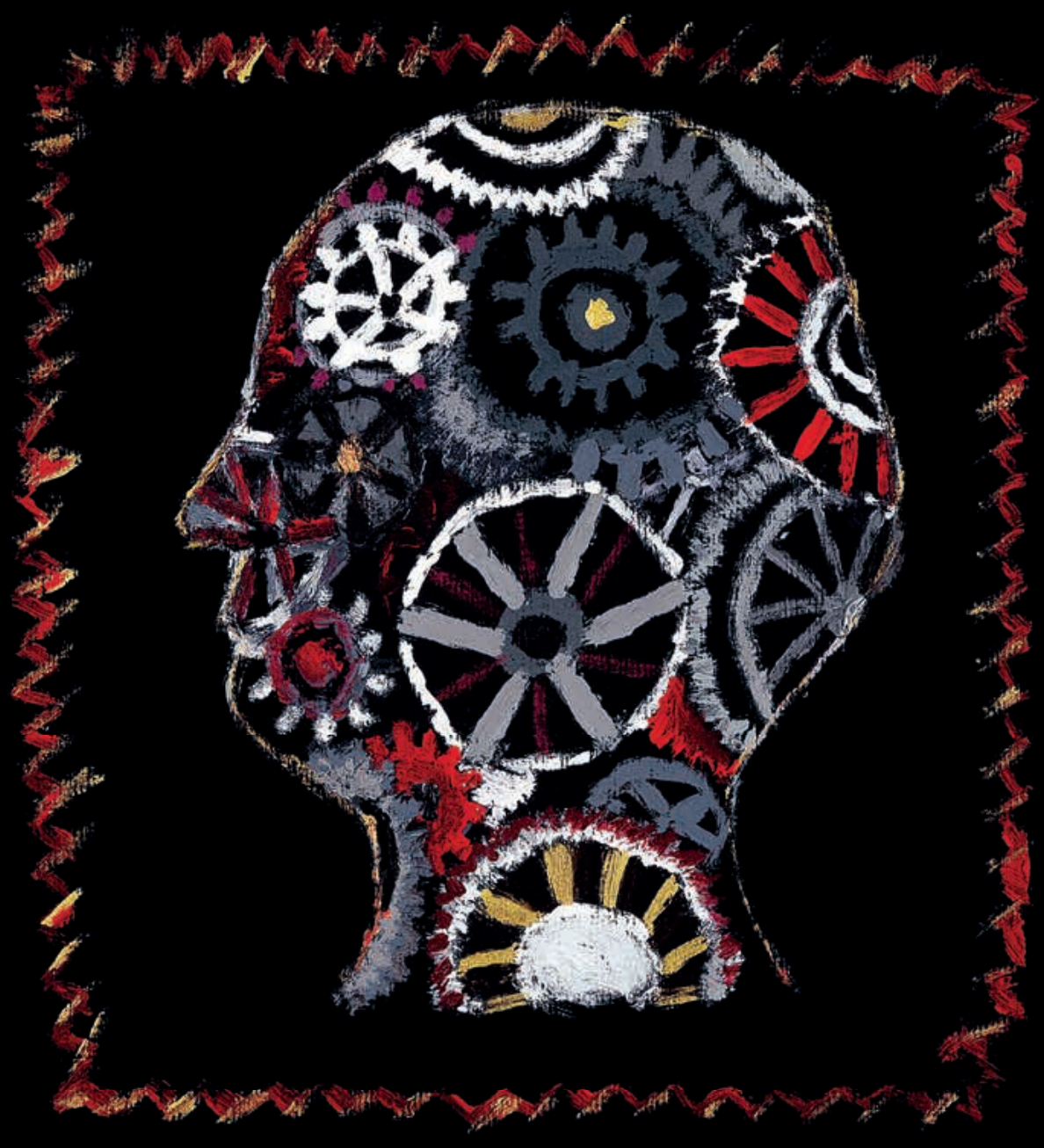




\section{HAPTER 1 Introduction}

Metacognition, which can best be described as "knowing about knowing" is an important research topic in educational sciences. It is obvious that metacognition plays a considerable role during learning. Imagine Tom, a secondary-school student who has to prepare French and Biology homework for the next day. In addition he needs to study for a History and a Physics examination later that week. When doing homework and learning for exams, it is important that Tom accurately monitors his actual level of understanding of studied materials. Based on his monitoring, he should then recognize and prioritize appropriate next study tasks and homework tasks, and allocate study time to these tasks (Zimmerman, 1998).

The term metacognition was first used by Flavell (1976), who described it as: "I am engaging in metacognition if I notice that I am having more trouble learning $A$ than $B$; or if it strikes me that I should double check C before accepting it as a fact (p. 232)". Long before Flavell described the concept of metacognition, however, philosophers were already contemplating "knowing about knowing". More than two-thousand years ago, Aristotle argued that thinking is different from perception. In the first textbooks on Psychology, which were written in the $19^{\text {th }}$ century, much attention is paid to the question 'how do we know what we know'? Wilhelm Wundt (1874) tried to measure this by using introspection methods; he argued that these methods would provide insight into a person's subjective experience of the world. William James (1890) described in his The Principles of Psychology that humans can alter their lives by altering their attitudes of mind.

One century later, a theoretical framework for metacognition was proposed by Nelson and Narens (1990). Their framework, depicted in Figure 1, provides insight into the relation between metacognition (the meta-level) and cognition (the object-level), and the interplay that exists between monitoring and regulation processes. In Figure 1 it can 
be seen that cognition influences metacognition through monitoring, and that metacognition influences cognition through regulation.

Since Nelson and Narens developed their framework, scientific research on monitoring and regulation has increased substantially. For instance, statistical problems when measuring monitoring accuracy were addressed (Schraw, Kuch, \& Gutierrez, 2013); and there evolved an interest into the neurocognitive bases of metacognitive monitoring and regulation (Chua, Schacter, \& Spering, 2009). Research on metacognition during study of educationally relevant materials was mainly conducted with college students, tasks were chosen so that these participants did not have any prior knowledge about the content (Maki, 1998; Thiede, Anderson, \& Therriault, 2003). However, even though this research provided valuable theoretical knowledge and insights, so far, important questions remain about how this fundamental research can be applied for young learners in educational contexts.
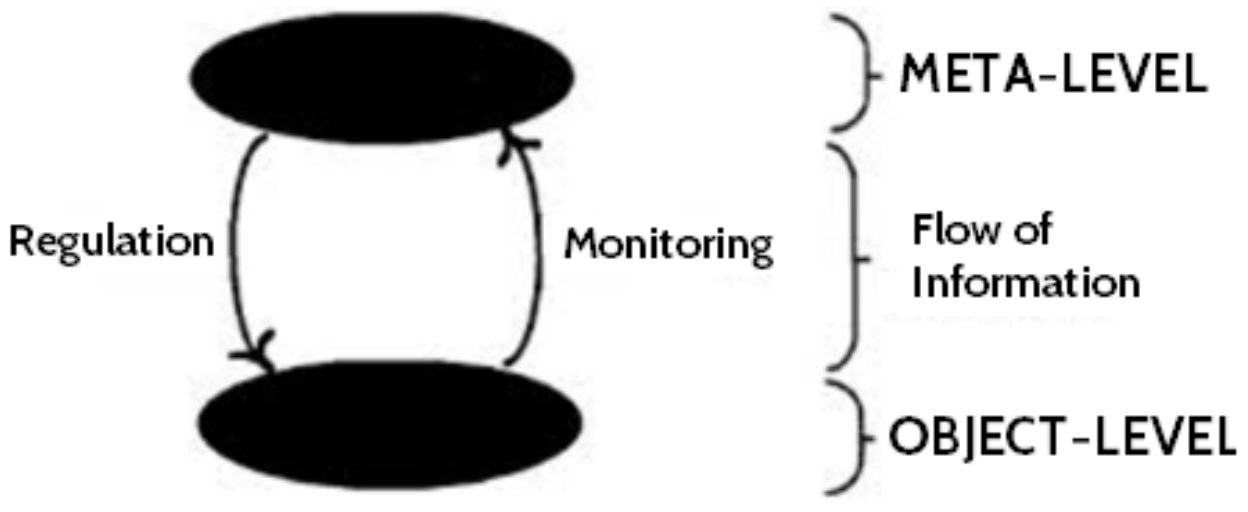

Figure 1. The theoretical framework of metacognition, adapted from Nelson and Narens (1990).

Many subjects in primary and secondary education require learning from textual materials. Such textual materials can take various forms, for example, students can be required to understand figurative language; to study the meaning of difficult definitions; or to study causal relations between concepts presented in expository science texts. When studying these various text materials, learners continually need to monitor their learning and regulate their own learning progress to reduce the discrepancy between their learning goals and their perceived current level of learning (e.g., Nelson \& Narens, 1990; Thiede \& Dunlosky, 1999).

Monitoring accuracy is a predictor of learning outcomes: Only when students monitor their learning accurately, can they engage in effective self-regulated learning (Dunlosky \& Ariel, 2011; Metcalfe \& Finn, 2008), and optimize their test performance and academic achievement (Ertmer \& Newby, 1996; Thiede et al., 2003). Unfortunately, when 
studying text, both adults' and young learners' monitoring accuracy is very low (Dunlosky, Rawson, \& Middleton, 2005; Lipko, Dunlosky, Hartwig, Rawson, Swan, \& Cook, 2009; Lipko, Dunlosky, \& Merriman, 2009). If learners cannot accurately monitor their learning, they cannot effectively decide which information needs further study, and consequently, learning outcomes are likely to be suboptimal. Indeed, inaccurate monitoring has been demonstrated to lead to underachievement (Dunlosky \& Rawson, 2012).

The first aim of this research is to investigate how instructions can improve monitoring and regulation of text study for young learners (age 9 - 15). Because monitoring accuracy and subsequent regulation are not only dependent on effects of instructions, but may also depend on individual differences between learners, the second aim is to address how age differences and individual differences in the level of prior knowledge are related to monitoring accuracy and regulation of study. Before describing the research and explaining the specific research questions, in this Introduction I will first explain measurement of monitoring and regulation; then I explain how instructions might be promising to improve monitoring and regulation; and thereafter I describe how individual differences in age and prior knowledge potentially affect monitoring and regulation.

\section{Measuring Monitoring and Regulation}

\section{Measurement of Monitoring Accuracy}

Figure 2 shows that, at different moments in the learning process, learners can be asked to monitor their learning by providing monitoring judgments. In most research on monitoring accuracy, learners are asked to monitor their current state of learning by providing judgments of learning (JOLs). Research on the accuracy of JOLs typically asks learners to read a set of texts. After reading, participants make predictive judgments, that is, for each of the read texts they predict how well they will do on a future test about the content of that text. When providing JOLs about studied texts, the higher the JOLs are, the more confident the learner is that $s /$ he will provide correct responses when tested on the studied texts. Note that monitoring judgments do not always need to be elicited during acquisition of knowledge; learners can also be asked to monitor their learning in advance of learning, by activating prior knowledge and providing a judgment about their confidence in the accuracy of their activated prior knowledge. Furthermore, learners can be asked for monitoring judgments after learning, when tested for retrieval of knowledge, by indicating confidence in the accuracy of the test responses. These retrospective judgments are called self-score judgments (SSJs). Figure 2 shows the monitoring judgments and the time they are elicited in the studies described in this dissertation (in 
advance of learning; during acquisition of knowledge; and when tested for output of knowledge).

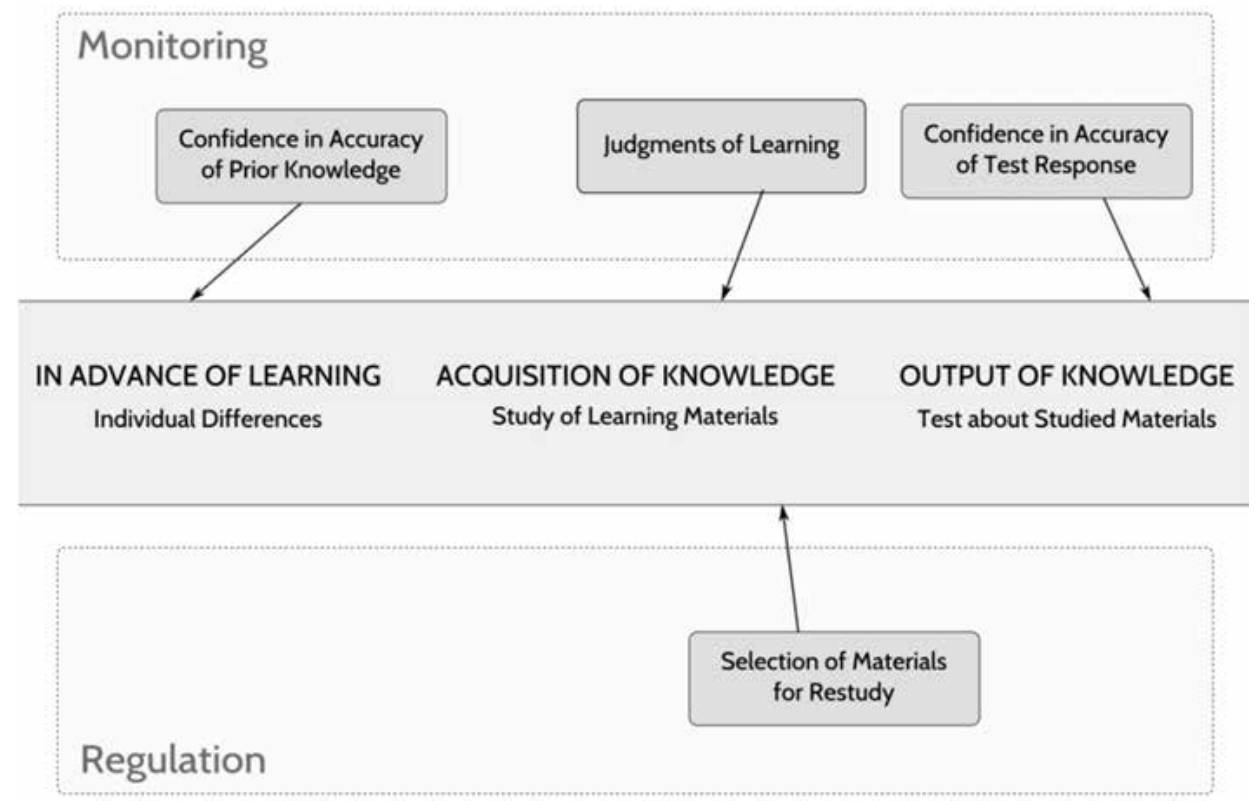

Figure 2. Measurement of monitoring judgments and regulation of study.

For analyses of monitoring accuracy, a distinction can be made between relative accuracy and absolute accuracy (Schraw, 2009). Relative accuracy is indicated by the correlation between a learner's monitoring judgment and actual performance; values can range between -1 to +1 . This measure of relative accuracy indicates whether a person can discriminate between studied materials that are more or less likely to be recalled on a test. A highly positive correlation between judgments and performance shows accurate monitoring, whereas a value of zero indicates that there is no association between predictions and performance. Unfortunately, relative monitoring accuracy is often low, that is, a low correlation between subjective monitoring judgments and objective performance scores is commonly reported in the literature (for a review, see Thiede, Griffin, Wiley, \& Redford, 2009).

More recently, research on monitoring accuracy started to use measures of learners' absolute accuracy, also referred to as calibration accuracy (Dunlosky \& Lipko, 2007). When investigating absolute accuracy, the absolute difference between monitoring judgments and performance is calculated. In contrast to measures of relative accuracy that indicate the strength of the relation between monitoring judgments and actual performance, absolute accuracy measures provide an indication about learners' 
level of overconfidence or underconfidence. For instance, when a learner predicts to have $30 \%$ correct on a test about topic $A$ and has an objective score of $10 \%$ correct; predicts to have $80 \%$ correct on a test about topic B and has a test score of $60 \%$; and predicts to have $100 \%$ correct about topic $C$ and has a score of $80 \%$, the correlation between predictions and performance is +1 , indicating perfect relative accuracy. However, when calculating absolute accuracy it appears that this learner is overconfident; his predictions of performance are higher than the objective credit that he will receive for his test performance. Research shows that learners tend to be overconfident when judging learning and predicting test performance. Even when their test responses are not awarded any credit, learners often predict that these responses will be correct (Dunlosky \& Lipko, 2007; Koriat, 2011; Lipko et al., 2009).

In sum, learners' relative and absolute monitoring tends to be inaccurate, indicating that they: (a) have difficulties discriminating between information which has and which has not yet been well-learned, and (b) expect to receive credit for their incorrect test responses.

\section{Mea surement of Regulation of Study}

Inaccurate monitoring has harmful effects on the effectiveness of self-regulated learning, because, when monitoring is inaccurate, it is unlikely that learners' regulation of study is adaptive (Bjork, Dunlosky, \& Kornell, 2013). When learners are asked to regulate their learning, they are often asked to indicate which materials need further study, as visible in Figure 2. The relation between JOLs and restudy selection is usually indicated by the correlation between these two measures, and typically, this correlation is highly negative (Son \& Metcalfe, 2000; Thiede \& Dunlosky, 1999), indicating that learners decide to select materials for which they provided low JOLs more often for restudy than the materials for which their JOLs were high. In order to make adaptive study selections (i.e., leading to the best possible learning outcomes), learners should decide to further study the materials that are not yet well-known and drop study materials that they already know well (Thiede \& Dunlosky, 1999). Research shows that learners with inaccurate monitoring tend to drop materials from study that are not yet well learned (Dunlosky \& Thiede, 2004; Kornell \& Bjork, 2008), indicating maladaptive regulation.

\section{Improving Monitoring and Regulation}

How do we know what we know? Even though Wilhelm Wundt recommended introspection methods to access memory, more recent memory research shows that we do not have direct access to our memory traces, and that we therefore cannot base 
monitoring judgments on detecting the presence and the strength of our memory traces (Benjamin \& Bjork, 1996). Instead, metacognitive judgments are inferential, and monitoring of learning is based on a variety of heuristics, or cues (Brunswik, 1956; Koriat, 1997). For instance, beliefs about the working of memory can be used as a cue for monitoring. For example, when a learner predicts that he will not remember French vocabulary because he believes that his memory is not functioning well that day, this belief is used as a cue for his monitoring judgments. Or when a learner judges that he will better remember the Biology study materials that were repeatedly covered in class than the materials which were just discussed once, he uses the number of presentations of materials as a cue for monitoring judgments. Other examples of cues are the ease of processing information (Koriat, Ackerman, Lockl, \& Schneider, 2009), or perceived familiarity with the topic of study (Griffin, Jee, \& Wiley, 2009). Cues have varying degrees of validity in predicting test performance, and when the used cues have perfect validity in predicting test performance then the accuracy of metacognitive judgments is guaranteed (Benjamin \& Bjork, 1996). Monitoring accuracy is low when monitoring judgments are based on superficial cues, which are not valid predictors of test performance. When students use these invalid cues as a basis for their monitoring judgments and study selections, monitoring accuracy and effectiveness of regulation are not expected to be optimal. There are indications that monitoring and regulation can improve when instructions help learners to activate valid cues about their learning and knowledge (Nelson \& Dunlosky, 1991).

Most research that aimed to improve monitoring accuracy tried to focus learners' attention on valid cues. Research on improvement of monitoring when studying textual information mainly focused on improvement of relative monitoring accuracy (instead of on improvement of absolute accuracy) of JOLs during acquisition of knowledge. Learning materials in these studies typically consisted of very simple text materials, referred to as paired-associates, for instance, by asking learners to remember word-pairs such as 'Ocean-Tree' (Nelson \& Dunlosky, 1991). Robust research findings show that the timing of the JOLs is an important factor when aiming to improve monitoring for these types of paired-associate materials (Nelson \& Dunlosky, 1991). Monitoring was shown to be more accurate when learners were asked to give the JOL a few minutes after learning than when giving JOLs immediately during study. Relative accuracy, indicated by the correlation between JOLs and test performance, was .90 when JOLs were provided after a short delay, compared with only .38 for immediate JOLs. This robust research finding has been called the delayed-JOL effect (Nelson \& Dunlosky, 1991). Delayed JOLs are more accurate than immediate JOLs, because the accessed cues are more valid when predicting performance after studying. That is, people attempt to retrieve information from longterm memory and this retrieval process is also needed at the test. In contrast, when monitoring immediately during learning, studied information is still active in working 
memory and because this information may not be remembered (i.e., stored in long-term memory), immediate judgments are not necessarily indicative of future test performance (Rhodes \& Tauber, 2011).

Usually, in education, text materials are more meaningful and also more complex than paired-associate materials. To study more complex, educationally relevant text materials, learners not only need to process information literally to remember exact details, but also need to integrate the studied content with contextual information and with their prior knowledge. Thus, studied information needs to be processed on a higher level, with a focus on gist, or the essence, the deeper meaning of a text (Graesser, Singer, \& Trabasso, 1994; Kintsch \& Van Dijk, 1978; Van Den Broek \& Kendeou, 2008). For instance, learners might need to understand the gist of figurative language in the text, such as idiomatic phrases, in order to understand the meaning. Or, when studying expository science texts, such as biology texts, learners' understanding of the gist of such a text largely depends on comprehension of the relation between concepts.

When learners are monitoring their learning of complex materials, monitoring is usually inaccurate because learners have difficulties using valid cues which provide them with indications of their understanding of the gist (Anderson \& Thiede, 2008). Only delaying the JOLs is not sufficient to attend learners to deeper understanding of the gist of studied texts. Even though delayed-JOLs can improve monitoring for learning tasks in which literal retrieval of studied information is needed, monitoring usually remains inaccurate when delayed-JOLs are made after study of more complex materials of which learners need to understand the gist (Dunlosky \& Lipko, 2007; Maki, 1998). Instructions that might be effective to direct learners to these valid cues related to gist understanding are generation instructions (Anderson \& Thiede, 2008; De Bruin, Thiede, Camp, \& Redford, 2011; Thiede \& Anderson, 2003; Thiede, Dunlosky, Griffin, \& Wiley, 2005), which ask learners to focus on the connections between the studied information and contextual information, and integration of information in prior knowledge. For adults, generating summaries (Anderson \& Thiede, 2008; Thiede \& Anderson, 2003), or generating keywords about studied texts (Thiede et al., 2005) were effective tasks to improve monitoring accuracy. Presumably, because these strategies supported learners to selftest whether they could make connections between studied information and contextual information, these generation tasks focus their attention on the gist. Moreover, the timing of the generation task proved to be an important factor when aiming to improve monitoring and regulation. When performing a generation task immediately after study, learners can still access the literal details they just read in the text. However, memory for these literal details decays more rapidly than memory for the gist of a text (Kintsch, Welsch, Schmalhofer, \& Zimny, 1990). Therefore, immediate generation tasks do not inform learners about their long-term memory representation for the gist. By contrast, 
when the generation task is delayed until after study, learners are better able to access the gist representation from memory (Thiede et al., 2005).

Prior research mainly addressed effects of generation instructions on JOLs of adult learners during study of expository text, and results of effects of generation instructions on monitoring accuracy are somewhat diverse (Thiede et al., 2009). Moreover, it is not yet clear whether generation instructions can improve monitoring and regulation when young learners study educationally relevant text materials. This indicates the need to research how generation instructions can be suitable when young learners study a variety of text formats, such as learning figurative language and study of complex science texts containing cause-and-effect relations.

\section{Ind ividual Differences}

\section{Age Differences}

There are indications that developmental differences affect monitoring, and the effect seems to depend on task complexity (De Bruin et al., 2011; Krebs \& Roebers, 2010). Monitoring simple tasks, such as study of word pairs has been demonstrated to be relatively accurate at a young age; children six years of age could more accurately predict their recall after a delay rather than immediately after study (Schneider, Visé, Lockl, \& Nelson, 2000). Effects of developmental differences seem to be more apparent when investigating children's regulation of study for simple materials such as word-pairs. Findings indicate that sixth-grade learners show better regulation abilities than fourthgrade learners (e.g., Dufresne \& Kobasigawa, 1989; Krebs \& Roebers, 2010): Ten and twelve year olds spent more time studying the hard items than they spent studying the easy items, demonstrating an age-related improvement in the efficient allocation of study time.

Developmental differences also seem to affect monitoring accuracy when studying more complex materials; between the ages of 9 and 12, monitoring might become more accurate and learners seem to become less overconfident (Krebs \& Roebers, 2010, 2011; Schneider \& Pressley, 1997). Little is known about improving monitoring accuracy by means of generation strategies; a study by De Bruin et al. (2011) in which children had to study expository text, showed that both $6^{\text {th }}$ and $7^{\text {th }}$ grade learners' monitoring accuracy improved after generating keywords, but that this generation instruction was not suitable to improve $4^{\text {th }}$ graders' monitoring accuracy.

Thus, even though monitoring for paired-associate learning tasks can be accurate for young children, it is unclear whether young children's monitoring accuracy can be improved when studying more complex materials, and it is yet unclear whether young 
learners have the ability to use their monitoring judgments as input to guide subsequent regulation of study (Dufresne \& Kobasigawa, 1989; Zimmerman \& Martinez-Pons, 1990).

\section{Prior Knowledge}

A second important factor that is expected to affect monitoring and regulation when studying texts is learners' prior knowledge: Prior knowledge has a large influence on what learners understand and remember when learning from text (Alexander \& Jetton, 2000). Several studies have shown that activating prior knowledge before studying has positive effects on learning (e.g. Ozuru, Dempsey, \& McNamara, 2009). However, research has largely disregarded the role prior knowledge plays when monitoring learning and when regulating study. Inaccurate prior knowledge may hinder learning because it is hard to change (Van den Broek, \& Kendeou, 2008), and inaccuracy of prior knowledge may be especially problematic when learners use their prior knowledge in monitoring. When learners believe that their prior knowledge is correct and complete, this might lead to overconfidence and premature termination of study.

\section{Overview of the Dissertation}

The reported research aims to directly influence the accuracy of monitoring and regulation of study by implementing generation instructions and by varying the timing of the judgments and the instructions.

Moreover, it is investigated how individual differences that are apparent before learning (age differences and prior knowledge) and factors that are important during learning (the format of studied texts) affect the learning process and monitoring and regulation when young learners from grade 3 (approximately 9 years old) to grade 9 (approximately 15 years old) study text.

This dissertation starts with three studies investigating the effects of novel generation instructions on monitoring and regulation: Sentence Generation (in Chapters 2 and 3) and Diagram Completion (in Chapter 4). It is presumed that these instructions will be promising to improve relative and absolute monitoring accuracy, and subsequent regulation for young learners. Furthermore, because the timing of generation instructions seems to affect monitoring accuracy and regulation (Thiede et al., 2005), effects of immediate and delayed generation instructions will be compared. In the last two studies in this dissertation, learners are asked to activate their prior knowledge before they studied text materials and provided JOLs and restudy selections.

In Table 1, the specific research questions for the five studies are listed, as well as an overview of the text materials that are used, the independent variables (effects of 
instructions and individual differences), and outcome measures. Furthermore, Figure 3 shows the overview of the variables that are researched and reported in this dissertation.

Table 1. Overview of Research Questions Addressed in this Dissertation

\begin{tabular}{|c|c|c|}
\hline Study Materials & Independent Variables & Outcome Measures \\
\hline \multicolumn{3}{|c|}{$\begin{array}{l}\text { Chapter 2: How do the timing of JOLs and sentence generation instructions affect monitoring accuracy and } \\
\text { regulation of study? }\end{array}$} \\
\hline Idiomatic phrases & $\begin{array}{l}\text { o Timing of judgments } \\
\text { (immediate/delayed) } \\
\text { o Generation instruction (sentence } \\
\text { generation) } \\
\text { o Grade level }\end{array}$ & $\begin{array}{l}\text { o Relative monitoring accuracy } \\
\text { o Regulation of Study }\end{array}$ \\
\hline
\end{tabular}

Chapter 3: Can sentence generation and reflection instructions improve study selections and reduce overconfidence?

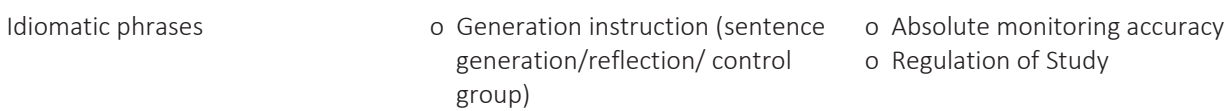

Chapter 4: How do diagram instructions and the timing of these instructions affect monitoring accuracy and regulation of study when studying cause-and-effect relations?
Science texts containing cause-and- o Generation instruction (diagram o Relative monitoring accuracy effect relations generation) o Regulation of Study
o Timing of the generation instruction (immediate/delayed)

Chapter 5: How does inaccurate prior knowledge affect overconfidence and regulation of study?
Key concepts
o Accuracy of prior knowledge
o Grade level
o Absolute monitoring accuracy
o Regulation of Study

Chapter 6: How do inaccurate prior knowledge, confidence in prior knowledge, and text format affect learning, overconfidence, and regulation of study?
Texts containing contradictions to
- Accuracy of prior knowledge
o Confidence in prior knowledge
- Correction of inaccurate prior common misconceptions
o Text format (standard/refutation)
- Absolute monitoring accuracy
o Regulation of Study

Chapter 2: "The Effect of delayed-JOLs and sentence generation on children's monitoring accuracy and regulation of idiom study", describes the first experimental study, which investigates how relative monitoring accuracy and regulation of study can be improved when learning idiomatic phrases. Effects of the timing of the JOLs and effects of a novel sentence generation instruction are investigated. Furthermore, effects of age differences on monitoring and regulation are taken into account, by testing fourth-graders (approximately 10 years of age) and sixth-graders (approximately 12 years). To acquire more insight into effects of instructions on the monitoring process, analyses of JOL reaction times are used. 
Chapter 3: "Effects of reflection and sentence generation on adolescents' restudy selections and monitoring when learning idioms", specifically focuses on learners' restudy selections and absolute monitoring accuracy. Because it is assumed that generation tasks are more suitable than asking learners to directly access valid cues through reflection, this study aims to investigate whether sentence generation is more suitable than commonly used reflection instructions to improve self-regulated learning. Three experimental conditions are used; adolescent learners (ninth-graders, approximately 15 years) receive reflection prompts after study, generate sentences after study, or receive control instructions.

Chapter 4: "Can students accurately evaluate their understanding of cause-andeffect relations? The effects of diagram completion on monitoring accuracy", aims to extend the research on monitoring and regulation at sentence level (reported in Chapters 2 and 3) to more complex materials. This chapter presents research on monitoring accuracy when adolescents (ninth-graders, approximately 15 years) study texts containing cause-and-effect relations. The study aims to improve monitoring accuracy using a novel generation instruction: Diagram completion. Furthermore, the study reports effects of the timing of this diagram completion instruction on monitoring. Learners are asked to complete causal diagrams immediately after reading, to complete them after a delay, or receive control instructions.

In Chapter 5, titled "Activation of inaccurate prior knowledge affects primary-school students' metacognitive judgments and calibration", it is investigated whether activation of inaccurate prior knowledge before study contributes to primary-school children's overconfidence and suboptimal regulation of study. Primary-school children are first asked to activate prior knowledge, and then study the meaning of complex definitions. Furthermore, developmental differences are taken into account by comparing calibration accuracy of third- and fourth-graders (nine - ten years old) with an older age group consisting of fifth- and sixth-graders (ten - twelve years old).

Chapter 6, titled 'Refutations in science texts lead to hypercorrection of highconfidence misconceptions', describes a study in which adolescents (eight-graders, approximately 14 years) are activating prior knowledge about common misconceptions and then studied science texts about these topics. The study investigates whether explicit refutation of inaccurate prior knowledge supports learners to correct inaccurate prior knowledge that is held with high confidence. Further, it is investigated whether reading refutation texts improves monitoring and regulation more so than reading standard texts.

In Chapter 7, the findings of the studies reported in this thesis are discussed, along with theoretical and practical implications, limitations, and directions for future research.

The dissertation ends with a summary of the most important research findings of the studies described in this thesis, both in English and in Dutch. 
Finally, because definitions about metacognition and its measurement are not standardized, a glossary is included to clarify the terminology in this dissertation with regard to monitoring judgments, control processes, instructional interventions and measures.

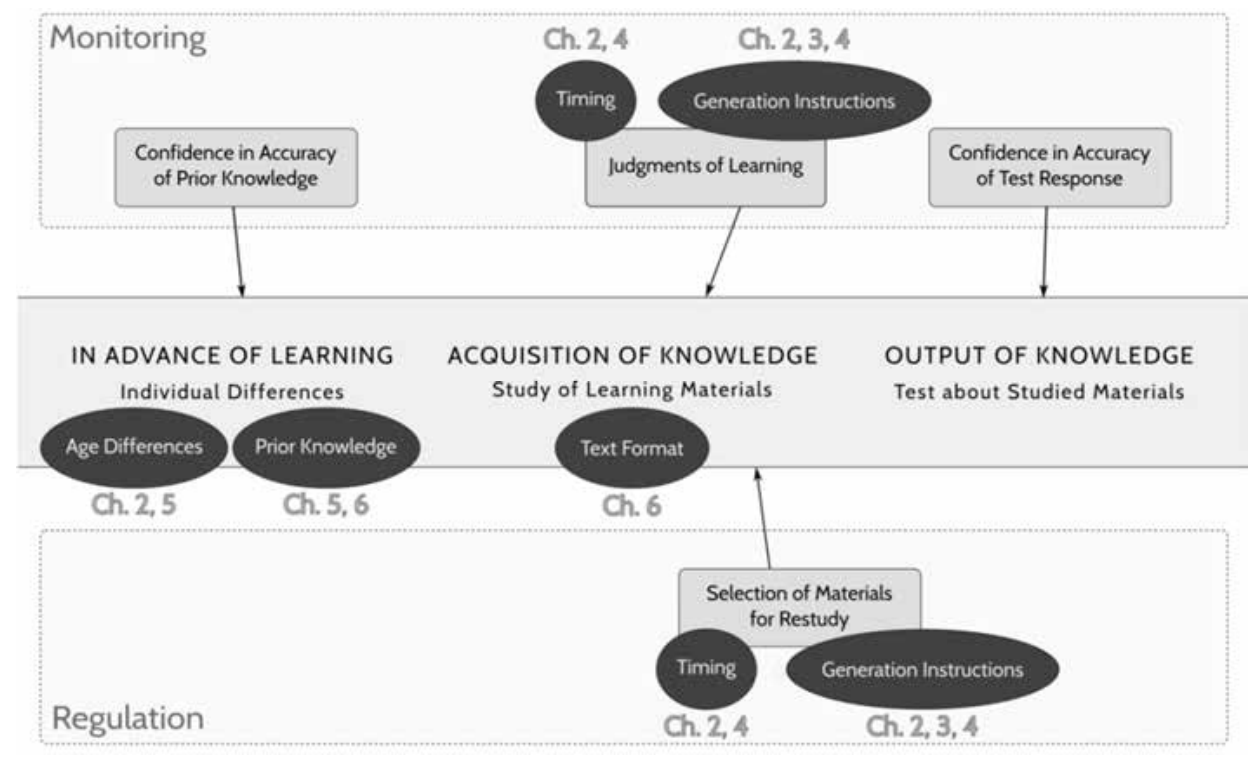

Figure 3. Overview of measures of monitoring and regulation used in this dissertation and the factors that are expected to affect monitoring, regulation, and learning. 


\section{References}

Alexander, P. A., \& Jetton, T. L. (2000). Learning from text: A multidimensional and developmental perspective. In M. L. Kamil, P. B. Mosenthal \& P. D. Pearson (Eds.), Handbook of Reading Research (Vol. 3, pp. 285-310). Mahwah, NJ: Erlbaum.

Anderson, M. C. M., \& Thiede, K. W. (2008). Why do delayed summaries improve metacomprehension accuracy? Acta Psychologica, 128(1), 110-118. doi: 10.1016/j.actpsy.2007.10.006

Ariel, R., Dunlosky, J., \& Bailey, H. (2009). Agenda-Based Regulation of Study-Time Allocation: When Agendas Override Item-Based Monitoring. Journal of Experimental Psychology-General, 138(3), 432-447. doi: 10.1037/a0015928

Benjamin, A. S., \& Bjork, R. A. (1996). Retrieval fluency as a metacognitive index. In L. M. Reder (Ed.), Implicit Memory and Metacognition: The 27th Carnegie Symposium on Cognition (pp. 309-338). Hillsdale, NJ: Erlbaum.

Bjork, R. A., Dunlosky, J., \& Kornell, N. (2013). Self-regulated learning: beliefs, techniques, and illusions. Annual Review of Psychology, 64, 417-444. doi: 10.1146/annurev-psych-113011-143823

Brunswik, E. (1956). Perception and the Representative Design of Psychological Experiments: University of California Press.

Chua, E. F., Schacter, D. L., \& Sperling, R. A. (2009). Neural Correlates of Metamemory: A Comparison of Feelingof-Knowing and Retrospective Confidence Judgments. Journal of Cognitive Neuroscience, 21(9), 17511765. doi: 10.1162/jocn.2009.21123

De Bruin, A. B. H., Thiede, K. W., Camp, G., \& Redford, J. (2011). Generating keywords improves metacomprehension and self-regulation in elementary and middle school children. Journal of Experimental Child Psychology, 109(3), 294-310. doi: 10.1016/j.jecp.2011.02.005

Dufresne, A., \& Kobasigawa, A. (1989). Children's spontaneous allocation of study time: Differential and sufficient aspects. Journal of Experimental Child Psychology, 47, 274-296.

Dunlosky, J., \& Ariel, R. (2011). The Influence of Agenda-Based and Habitual Processes on Item Selection During Study. Journal of Experimental Psychology-Learning Memory and Cognition, 37(4), 899-912. doi: 10.1037/a0023064

Dunlosky, J., \& Lipko, A. R. (2007). Metacomprehension: A brief history and how to improve its accuracy. Current Directions in Psychological Science, 16(4), 228-232. doi: 10.1111/j.1467-8721.2007.00509.x

Dunlosky, J., \& Rawson, K. A. (2012). Overconfidence produces underachievement: Inaccurate self evaluations undermine students' learning and retention. Learning and Instruction, 22(4), 271-280. doi: 10.1016/j.learninstruc.2011.08.003

Dunlosky, J., Rawson, K. A., \& Middleton, E. L. (2005). What constrains the accuracy of metacomprehension judgments? Testing the transfer-appropriate-monitoring and accessibility hypotheses. Journal of Memory and Language, 52, 551-565. doi: 10.1016/j.jml.2005.01.011

Dunlosky, J., \& Thiede, K. W. (2004). Causes and constraints of shift-to-easier-materials effect in the control of study. Memory \& Cognition, 32(5), 779-788. doi: 10.3758/BF03195868

Ertmer, P. A., \& Newby, T. J. (1996). The expert learner: Strategic, self-regulated, and reflective. Instructional Science, 24, 1-24. doi: 10.1007/BF00156001

Flavell, J. H. (1976). Metacognitive aspects of problem-solving. In L. B. Resnick (Ed.), The nature of intelligence (pp. 231-236). Hillsdale, NJ: Lawrence Erlbaum Associates.

Graesser, A. C., Singer, M., \& Trabasso, T. (1994). Constructing inferences during narrative text comprehension. Psychological Review, 101(3), 371-395. doi: 10.1037//0033-295x.101.3.371

Griffin, T. D., Jee, B. D., \& Wiley, J. (2009). The effects of domain knowledge on metacomprehension accuracy. Memory \& Cognition, 37(7), 1001-1013. doi: 10.3758/MC.37.7.1001

James, W. (1890). Principles of Psychology. New York: Henry Holt. 
Kintsch, W., \& Van Dijk, T. A. (1978). Toward a model of text comprehension and production. Psychological Review, 85(5), 363.

Kintsch, W., Welsch, D., Schmalhofer, F., \& Zimny, S., 133-, \& 159. (1990). Sentence recognition: A theoretical analysis. Journal of Memory and Language, 29, 133-159.

Koriat, A. (1997). Monitoring one's own knowledge during study: A cue-utilization approach to judgments of learning. Journal of Experimental Psychology-General, 126(4), 349-370. doi: 10.1037/00963445.126.4.349

Koriat, A. (2011). Subjective confidence in perceptual judgments: A test of the self-consistency model. Journal of Experimental Psychology: General, 140(1), 117-139. doi: 10.1037/a0022171

Koriat, A., Ackerman, R., Lockl, K., \& Schneider, W. (2009). The easily learned, easily remembered heuristic in children. Cognitive Development, 24(2), 169-182. doi: 10.1016/j.cogdev.2009.01.001

Kornell, N., \& Bjork, R. A. (2008). Optimising self-regulated study: The benefits-and costs-of dropping flashcards. Memory, 16(2), 125-136. doi: 10.1080/09658210701763899

Krebs, S. S., \& Roebers, C. M. (2010). Children's strategic regulation, metacognitive monitoring, and control processes during test taking. British Journal of Educational Psychology, 80(3), 325-340. doi: $10.1348 / 000709910 \times 485719$

Krebs, S. S., \& Roebers, C. M. (2011). The impact of retrieval processes, age, general achievement level, and test scoring scheme for children's metacognitive monitoring and controlling. Metacognition and Learning. doi: 10.1007/s11409-011-9079-3

Lipko, A. R., Dunlosky, J., Hartwig, M. K., Rawson, K. A., Swan, K., \& Cook, D. (2009). Using standards to improve middle school students' accuracy at evaluating the quality of their recall. Journal of Experimental Psychology: Applied, 15(4), 307-318. doi: 10.1037/a0017599

Lipko, A. R., Dunlosky, J., \& Merriman, W. E. (2009). Persistent overconfidence despite practice: The role of task experience in preschoolers' recall predictions. Journal of Experimental Child Psychology, 103, 152-166. doi: 10.1016/j.jecp.2008.10.002

Maki, R. H. (1998). Predicting performance on text: Delayed versus immediate predictions and tests. Memory \& Cognition, 26(5), 959-964. doi: 10.3758/bf03201176

Metcalfe, J., \& Finn, B. (2008). Evidence that judgments of learning are causally related to study choice. Psychonomic Bulletin \& Review, 15(1), 174-179. doi: 10.3758/pbr.15.1.174

Nelson, T. O., \& Dunlosky, J. (1991). When peoples judgments of learning (JOLs) are extremely accurate at predicting subsequent recall: The "Delayed-JOL effect". Psychological Science, 2(4), 267-270. doi: 10.1111/j.1467-9280.1991.tb00147.x

Nelson, T. O., \& Narens, L. (1990). Metamemory: A theoretical framework and new findings. Psychology of Learning and Motivation, 26, 125-141. doi: 10.1016/S0079-7421(08)60053-5

Nelson, T. O., \& Narens, L. (1994). Why investigate metacognition? In A. P. Shimamura (Ed.), Metacognition: Knowing about Knowing. (Vol. xiii, pp. 1-25). Cambridge, MA, US: The MIT Press.

Ozuru, Y., Dempsey, K., \& McNamara, D. S. (2009). Prior knowledge, reading skill, and text cohesion in the comprehension of science texts. Learning and Instruction, 19(3), 228-242. doi: 10.1016/j.learninstruc.2008.04.003

Rhodes, M. G., \& Tauber, S. K. (2011). The Influence of Delaying Judgments of Learning on Metacognitive Accuracy: A Meta-Analytic Review. Psychological Bulletin, 137(1), 131-148. doi: 10.1037/a0021705

Schneider, W., \& Pressley, M. (1997). Memory Development Between Two and Twenty. Mahwah, NJ: Lawrence Erlbaum Associates.

Schneider, W., Vise, M., Lockl, K., \& Nelson, T. O. (2000). Developmental trends in children's memory monitoring - Evidence from a judgment-of-learning task. Cognitive Development, 15(2), 115-134. doi: 10.1016/s08852014(00)00024-1

Schraw, G. (2009). A conceptual analysis of five measures of metacognitive monitoring. Metacognition and Learning, 4, 33-45. doi: 10.1007/s11409-008-9031-3 
Schraw, G., Kuch, F., \& Gutierrez, A. P. (2013). Measure for measure: Calibrating ten commonly used calibration scores. Learning and Instruction, 24, 48-57. doi: 10.1016/j.learninstruc.2012.08.007

Son, L. K., \& Metcalfe, J. (2000). Metacognitive and Control Strategies in Study-Time allocation. Journal of Experimental Psychology: Learning, Memory and Cognition, 26, 204-221. doi: 10.1037/02787393.26.1.204

Son, L. K., Schwartz, B. L., \& Kornell, N. (2003). Implicit metacognition, explicit uncertainty, and the monitoring/control distinction in animal metacognition. Behavioral and Brain Sciences, 26(3), 355-356. doi: $10.1017 /$ S0140525X03400083

Thiede, K. W., \& Anderson, M. C. M. (2003). Summarizing can improve metacomprehension accuracy. Contemporary Educational Psychology, 28, 129-160. doi: 10.1016/S0361-476X(02)00011-5

Thiede, K. W., Anderson, M. C. M., \& Therriault, D. (2003). Accuracy of metacognitive monitoring affects learning of texts. Journal of Educational Psychology, 95(1), 66-73. doi: 10.1037/0022-0663.95.1.66

Thiede, K. W., \& Dunlosky, J. (1999). Toward a general model of self-regulated study: An analysis of selection of items for study and self-paced study time. Journal of Experimental Psychology: Learning, Memory and Cognition, 25(4), 1024-1037. doi: 10.1037/0278-7393.25.4.1024

Thiede, K. W., Dunlosky, J., Griffin, T. D., \& Wiley, J. (2005). Understanding the delayed-keyword effect on metacomprehension accuracy. Journal of Experimental Psychology: Learning, Memory and Cognition. doi: 10.1037/0278-7393.3.1.6.1267

Thiede, K. W., Griffin, T. D., Wiley, J., \& Redford, J. (2009). Metacognitive monitoring during and after reading. In D. J. Hacker, J. Dunlosky \& A.C. Graesser (Eds.), Handbook of Metacognition in Education (pp. 85-106). New York: Routledge.

Van Den Broek, P., \& Kendeou, P. (2008). Cognitive processes in comprehension of science texts: The role of coactivation in confronting misconceptions. Applied Cognitive Psychology, 22(3), 335-351. doi: 10.1002/acp.1418

Wundt, W. H. (1874). Gründzuge der physiologischen Psychologie. Leipzig: Engelmann.

Zimmerman, B. J. (1998). Academic studying and the development of personal skill: A self-regulatory perspective. Educational Psychologist, 33(2-3), 73-86. doi: 10.1207/s15326985ep3302\&3_3

Zimmerman, B. J., \& Martinez-Pons, M. (1990). Student differences in self-regulated learning: Relating grade, sex and giftedness to self-efficacy and strategy use. Journal of Educational Psychology, 82(1), 51-59. 


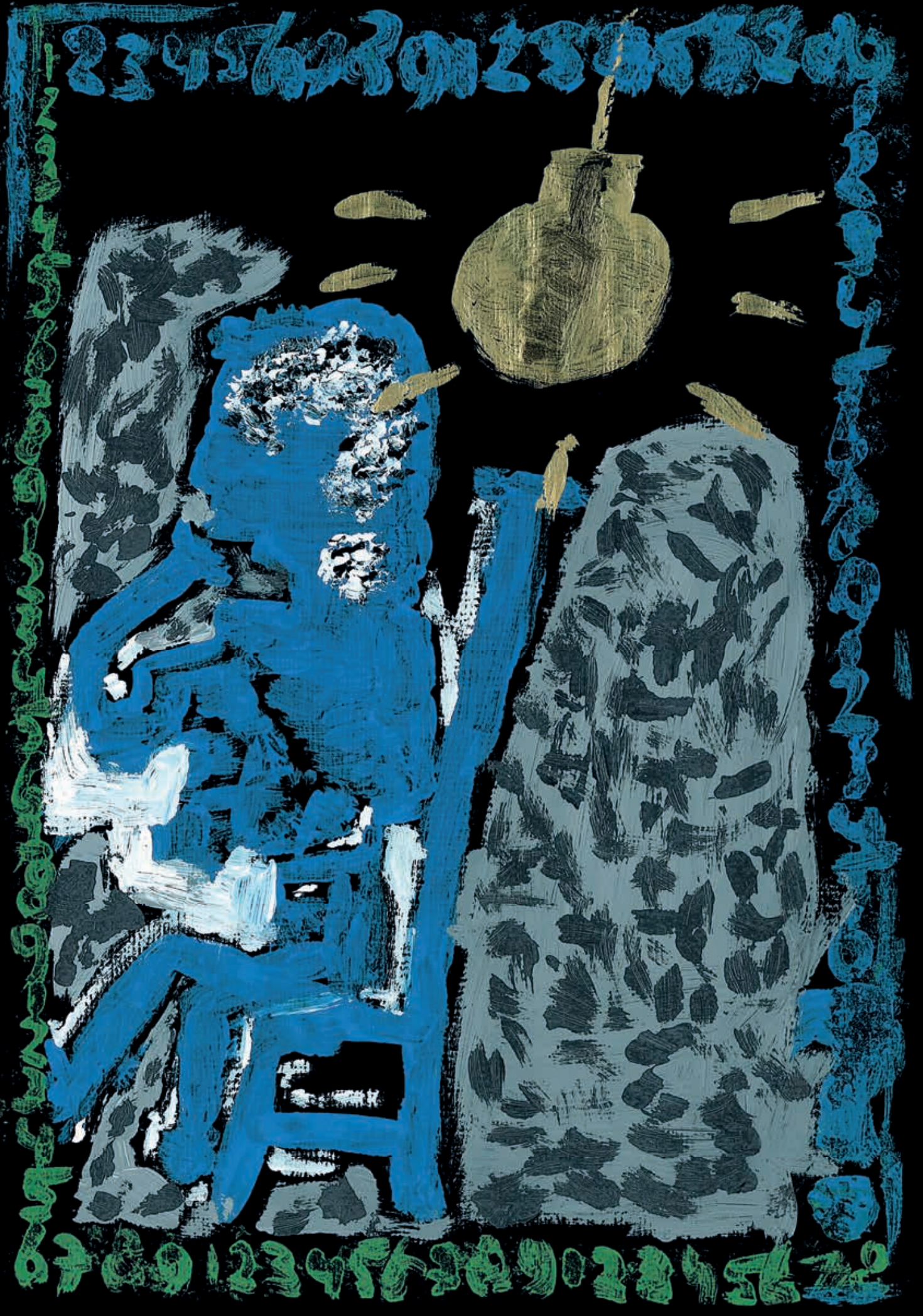




\title{
C HAPTER 2 \\ The Effect of Delayed-J OLs and Sentence Generation on Children's Monitoring Accuracy and Regulation of Idiom Study
}

\begin{abstract}
When studying verbal materials, both adults and children are often poor at accurately monitoring their level of learning and regulating their subsequent restudy of materials, which leads to suboptimal test performance. The present experiment investigated how monitoring accuracy and regulation of study could be improved when learning idiomatic phrases. Elementary school children (fourth and sixth-graders) were instructed to predict their test performance by providing judgments of learning (JOLs). They provided JOLs immediately after studying each idiom, after studying all idioms, or after studying all idioms followed by generating sentences in which the idioms were used. Correlations between JOLs and test performance showed that delayed-JOLs and delayed-JOLs with sentence generation were more accurate than immediate JOLs. JOLs after sentence generation also improved regulation of study compared to delayed-JOLs only. Analyses of JOL reaction times suggest that delayed-JOLs led children to retrieve the literal meaning of the idiom, whereas JOLs after sentence generation led children to focus on connections between studied information, contextual information, and prior knowledge. Sentence generation presents a promising method to improve regulation of study, and thus idiom learning.
\end{abstract}

This chapter has been published as: Van Loon, M.H., De Bruin, A. B. H., Van Gog, T., \& Van Merriënboer, J. J. G. (2013). The effect of delayed-JOLs and sentence generation on children's monitoring accuracy and regulation of idiom study. Metacognition and Learning, 8, 173-191. doi: 10.1007/s11409-013-9100-0 


\section{The Effect of Delayed-J OLs and Sentence Generation on Children's Monitoring Accuracy and Regulation of Idiom Study}

Children frequently study verbal materials, both in the classroom and when doing homework. Previous research has found that monitoring and regulation play an important role in learning (e.g., Dunlosky \& Metcalfe, 2009; Nelson \& Narens, 1990; Thiede, Anderson, \& Therriault, 2003). During self-regulated study, learners attempt to reduce the discrepancy between their learning goals and their perceived current state of learning (e.g., Nelson \& Narens, 1990; Thiede \& Dunlosky, 1999). Monitoring refers to assessing this current state of learning (Dunlosky \& Metcalfe, 2009), which is -ideallyused to regulate further study activities. That is, learners should monitor how well they have learned materials, and based on that information, make a decision on whether they will study these materials further or discard them (Thiede \& Dunlosky, 1999). More accurate monitoring has been shown to lead to more effective restudy decisions when regulating further study (Metcalfe \& Finn, 2008a). In turn, more effective regulation leads to higher test performance and better academic achievement (Ertmer \& Newby, 1996; Thiede et al., 2003).

Unfortunately, when studying textual materials monitoring accuracy is often low, implying that learners often cannot distinguish between what they do and do not understand. Correlations between predicted and actual test performance usually do not exceed .25 (see the review by Dunlosky \& Lipko, 2007; Maki, 1998). As a result, regulation of study is likely to be ineffective, and therefore test performance might be suboptimal (Thiede et al., 2003). Recently, there has been increased interest in improving metacognitive skills, both in adults and young learners (e.g., Dunlosky \& Lipko, 2007; Huff \& Nietfeld, 2009; Lipko, Dunlosky, \& Merriman, 2009; Von der Linden, Schneider, \& Roebers, 2011).

\section{Improving Monitoring Accuracy through Long-Term Memory Retrieval}

To improve monitoring and regulation of study, it is essential to understand how poor monitoring skills can be explained. According to Koriat's (1997) cue-utilization framework, monitoring is based on a variety of cues, and accuracy is often low because judgments are based on superficial cues, such as ease of processing (Koriat, Ackerman, Lockl, \& Schneider, 2009), familiarity with the topic of study (Griffin, Jee, \& Wiley, 2009), or inaccurate prior knowledge (Van Loon, De Bruin, Van Gog, \& Van Merriënboer, 2013). Since superficial cues are not valid predictors of test performance, monitoring might not be accurate when students use these as a basis for judgments. 
Instead, when learners are required to activate valid cues about their learning, their predictions of test performance improve (Nelson \& Dunlosky, 1991; Thiede \& Anderson, 2003). One of the most influential studies on the improvement of monitoring accuracy is the delayed Judgment of Learning (JOL) experiment by Nelson and Dunlosky (1991). Participants were asked to provide JOLs after studying unrelated word pairs: They had to predict the likelihood of recall of each target word on the future test. Learners made JOLs either immediately after studying each item or after a delay, when a short interval was situated between study and JOLs. The delayed-JOLs improved monitoring accuracy to a great extent: The gamma correlation (Nelson, 1984) between predicted and actual test performance was .90, compared with only .38 for immediate JOLs. Presumably, for immediate JOLs retrieval of targets that remained active in working memory is dominant. Delayed-JOLs are more accurate, because when predicting performance after studying, people attempt to retrieve the target from long-term memory. Since retrieval from longterm memory is also needed on the test, the delayed-JOL instruction provides learners with valid cues, which in turn leads to more accurate judgments (Nelson \& Dunlosky, 1991; see Rhodes \& Tauber, 2011, for a meta-analysis).

\section{Improving Monitoring Accuracy through Delayed Generation}

Even though delayed-JOLs can improve monitoring for associative learning tasks, monitoring usually remains inaccurate when delayed-JOLs are made after study of more complex and educationally relevant materials (Dunlosky \& Lipko, 2007; Maki, 1998). When taking a test about complex materials, such as expository texts or figurative language, learners have to show that they understand information instead of simply retrieving the studied target (Thiede et al., 2003). Thus, retrieval of literal information from long-term memory does not necessarily provide learners with valid cues about performance.

Models explaining the understanding of content-rich materials agree that complex information can be processed literally, but importantly, can also be processed on a higher level with a focus on gist (Graesser, Singer, \& Trabasso, 1994; Kintsch \& Van Dijk, 1978; Van Den Broek \& Kendeou, 2008). To accurately understand complex, content-rich materials, the reader should not only focus on literal processing of information but also on gist, in order to integrate the novel information with contextual information and with prior knowledge (Kintsch, 1988; Levorato, Nesi, \& Cacciari, 2004; Perfetti, 2007). For example, when learners study about blood circulation, they may have prior knowledge about the heart, lungs, and arteries, and have an understanding of the dynamics of oxygen transportation. The novel information about blood circulation needs to be linked to this prior knowledge in order to reach understanding. Because integration of studied 
information with prior knowledge is important for learning of content-rich materials, to improve monitoring learners should not only focus on literal retrieval, but also on cues that give them indications about gist, that is, understanding of the target (Anderson \& Thiede, 2008; Thiede et al., 2003).

Research has shown that generation instructions are an effective way to help learners focus on the gist (Anderson \& Thiede, 2008; De Bruin, Thiede, Camp, \& Redford, 2011; Thiede \& Anderson, 2003; Thiede, Dunlosky, Griffin, \& Wiley, 2005). For instance, instructing learners to generate summaries (Anderson \& Thiede, 2008; Thiede \& Anderson, 2003), or keywords about a text (De Bruin et al., 2011; Thiede et al., 2005) can focus their attention on connections between studied information, contextual information, and prior knowledge. These cues, indicating their understanding of the gist, are still available when learners provide JOLs and therefore lead to more accurate judgments (Thiede \& Anderson, 2003). It is important to note, though, that these generation tasks only have a beneficial effect on monitoring accuracy when these are delayed after study (Thiede et al., 2003, 2005). Memory for textbase representations decays more rapidly than memory for gist (Fletcher \& Chrysler, 1990; Kintsch, Welsch, Schmalhofer, \& Zimmy, 1990, Thiede \& Anderson, 2008). When generating keywords or summaries is done immediately after study, details from the text are more activated within working memory (Cowan, 1999). Therefore, when performing a generation task immediately after study, learners can rely more on the accessibility of details from the text. When learners generate keywords or summaries after a delay, such details have decayed and they need to base their judgments more on the gist of texts stored in longterm memory. The latter provide better cues, due to higher similarity with the test context (Thiede et al., 2005).

\section{Monitoring and Regulation of Study when Leaming Idioms}

A type of complex and educationally relevant verbal learning material that has -to the best of our knowledge- not yet been studied in research on monitoring and regulation, is material containing figurative language, such as idioms. Idioms are metaphorical phrases, such as 'to throw in the towel', whose meaning cannot be derived from the meaning of individual words that make it up (Swinney \& Cutler, 1979). Idioms are an important topic of study, because of their high frequency of occurrence in spoken and written language (Brinton, Fujiki, \& Mackey, 1985; Nippold \& Taylor, 2002; Tabossi, Fanari, \& Wolf, 2009). Theories on idiom learning demonstrated that this metaphorical language can also, as other complex text materials, be processed on two levels. First of all, idioms can be processed on a literal level. An idiom-learning task has characteristics of other associative learning tasks, because learners can literally retrieve the meaning of 
the idiom when presented with the figurative expression. Traditional theories of idiom learning suggest that idioms can be processed in much the same manner as individual words (Bobrow \& Bell, 1973; Swinney \& Cutler, 1979). As single words, each idiom has its own concept node, and one concept can activate multiple connected concept nodes (Cutting \& Bock, 1997).

More recent research suggests that idioms are not only stored as simple word-word associations, and processed with a focus on the literal meaning, but that the mental representation for idioms is much more complex than that for simple words (Langlotz, 2006). Idiom comprehension is to a certain extent comparable to comprehension of expository texts (Langlotz, 2006). When idioms are correctly understood, a learner also needs to focus on processing of the gist of this idiom. An idiomatic phrase is assumed to activate the same lexical items in a mental representation that are involved in the comprehension of non-metaphorical discourse (Sprenger, Levelt, \& Kempen, 2006). When idioms are stored and activated in memory, the idiom is activated with connections to contextual information, and the learner's prior knowledge (Cain \& Towse, 2008; Langlotz, 2006; Levorato \& Cacciari, 1992, 1999). When the idiom's concept node is activated, this activation spreads to the lexical-syntactic level (which are the words of which the idiom consists), and also to the conceptual level (prior knowledge and contextual information). The knowledge about the gist of idioms is stored through these connection patterns (Cutting \& Bock, 1997; Langlotz, 2006; Sprenger et al., 2006). Thus, to understand and use idiomatic expressions, learners should not only focus on retrieval of the literal meaning, but they also have to focus on connections which indicate their understanding of the gist.

Learning idioms is an interesting activity for metacognition research, because it has characteristics of associative learning tasks like study of related word pairs, and also characteristics of content-rich educational materials. If idioms can be processed with or without attention to gist, presumably the nature of idiom learning has implications for monitoring and regulation. As yet, it is unknown how well children can monitor and regulate study when learning idioms. Because idiom learning has characteristics of associative learning tasks, learners' monitoring accuracy and subsequent regulation are expected to benefit from a delayed-JOL instruction when compared with an immediate $\mathrm{JOL}$ instruction. A delayed-JOL instruction is assumed to lead children base JOLs on longterm memory retrieval (Nelson \& Dunlosky, 1991), which provides them with a more accurate indication of future test performance than when making immediate judgments when the information is still present in working memory. Because idioms can be processed with a focus on literal retrieval of the meaning, when judging learning of idioms, an attempt to retrieve the meaning can provide learners with a valid cue regarding future performance. Therefore, delayed-JOLs should be more accurate than 
immediate JOLs, and subsequent regulation should be more accurate following delayedJOLs than following immediate JOLs.

Moreover, to fully understand the gist of idioms, they also need to be connected to prior knowledge and contextual information (Levorato \& Cacciari, 1999; Sprenger et al., 2006). If, for example, a student understands the idiom 'throw in the towel', then the mental representation of the idiom should not only capture the literal meaning, but also the gist of the idiom, because of connections with prior knowledge and possible contexts in which this idiom can be used.

Previous research has shown that sentence generation facilitates memory performance (Graf, 1982). The present study investigates whether sentence generation could also improve metacognitive skills. When a learner has good idiom understanding, he should be able to create a novel sentence in which he correctly uses the studied idiom. Because sentence generation is assumed to focus learners' attention on valid cues regarding gist information, when making JOLs this instruction is expected to have a beneficial effect on monitoring accuracy when compared to immediate JOLs and delayedJOLs without this generation instruction (Anderson \& Thiede, 2008; Thiede et al., 2003). Moreover, we hypothesize that regulation would be more accurate following sentence generation than following immediate JOLs and mere delayed-JOLs.

\section{Reaction Times when Providing J OLs}

As indicated above, immediate JOLs, delayed JOLs, and JOLs after sentence generation are expected to be based on different cues. Measures of reaction times (RTs) when children make JOLs (hereafter referred to as JOL RTs) provide an opportunity to further investigate assumptions about the use of cues.

First of all, retrieval of accessible information from working memory is a faster process than long-term memory retrieval (Conway \& Engle, 1994; Sternberg, 1969). Thus, if children base JOLs on targets that remained active in working memory when monitoring idiom understanding immediately after learning, these immediate JOL RTs should be shorter than JOL RTs for the judgments which are provided after a delay.

When investigating possible differences in cue use between monitoring following the delayed-JOLs with or without sentence generation, it is especially interesting to look at the JOLs at the low end of the scale. When children provide low JOLs, they indicate that they have low confidence to produce the correct meaning of the idiom at the test. Research on JOL RTs shows that low JOLs are usually accompanied by slow JOL RTs, because information which learners attempted to retrieve did not come to mind easily (e.g., Benjamin, Bjork, \& Schwartz 1998; Koriat \& Ma'ayan, 2005; Metcalfe \& Finn, 2008b; Son \& Metcalfe, 2005). Findings by Metcalfe \& Finn (2008b) showed that when learners 
made self-paced JOLs about an associative learning task, RTs for the low JOLs were longer than RTs for higher JOLs.

However, JOL RT research provided evidence that not all delayed-JOLs are necessarily based on a retrieval attempt (Metcalfe \& Finn, 2008b; Son \& Metcalfe, 2005). When investigating delayed-JOLs for an associative name learning task, Son and Metcalfe (2005) found that learners did not spontaneously attempt retrieval, and the low JOLs were provided quickly. Moreover, Metcalfe and Finn (2008b) found that when participants had to provide JOLs under time constraints, low JOLs were provided fast. This finding led to the assumption that two different processes can underlie delayed-JOLs: Retrieval of studied information, and a quick assessment stage in which participants do not attempt to literally retrieve information (Metcalfe \& Finn, 2008b; Son \& Metcalfe, 2005).

In the present study, learners provide self-paced JOLs about the studied idioms. Differences in JOL RTs between the sentence generation and uninstructed delayed-JOL conditions are expected to occur at the low end of the JOL scale. When learners provide JOLs following sentence generation, low JOLs are presumed to result from cues that the idiom could not be connected to prior knowledge and contextual information, instead of from an unsuccessful attempt to retrieve the literal meaning. Therefore we expect low JOLs after sentence generation to be fast. The processes involved in making uninstructed delayed-JOLs are expected to differ from those involved when the person first generates sentences. In line with the assumption that delayed-JOLs are based on a retrieval attempt (Rhodes \& Tauber, 2011), we expect to replicate findings by Metcalfe and Finn (2008b) that low delayed-JOLs are accompanied by slow RTs.

\section{Development of Metacognitive Skills}

For associative learning tasks, the delayed-JOL effect has also been demonstrated in studies with young learners (Koriat \& Shitzer-Reichert, 2002; Schneider, Visé, Lockl, \& Nelson, 2000). It has been shown that monitoring skills for associative learning tasks can develop at a young age; children six years of age could more accurately predict their recall after a delay rather than immediately after study (Schneider et al., 2000). Research on metacognitive skills when learning paired associates showed that age differences are more apparent when investigating children's regulation of study. Findings indicate that sixth-grade learners show better regulation abilities than fourth-grade learners (e.g. Dufresne \& Kobasigawa, 1989; Krebs \& Roebers, 2010). Thus, even though monitoring for associative learning tasks can be accurate for young children, the ability to use JOLs to guide subsequent study does not seem to be developed until around ten years of age (Dufresne \& Kobasigawa, 1989; Zimmerman \& Martinez-Pons, 1990). 
Research on development of idiom learning indicates that children aged seven and over start to develop the ability to understand the meaning of idioms, and idiom comprehension skills continue to develop into adolescence (Brinton et al., 1985; Cain, Towse, \& Knight, 2009). Until present, it is unclear whether developmental differences affect monitoring and regulation of idiom study. To date, most research on metacognition when studying complex verbal materials has focused on adult learning. While there are some studies on paired associate learning in young children (e.g. Schneider et al., 2000), to the best of our knowledge, only a study by De Bruin, Thiede, Camp, and Redford (2011) investigated how monitoring and subsequent regulation of study could be improved when children had to study expository text. They investigated whether generating keywords improved fourth-, sixth-, and seventh-graders' JOL accuracy. De Bruin et al. (2011) showed that generating keywords after a delay improved monitoring accuracy only for sixth- and seventh-graders. For the fourth-graders, there was no effect of the delayed generation task. These findings imply that age differences in monitoring may occur for more complex learning tasks (Brown, Bransford, Ferrara, \& Campione, 1983; De Bruin et al., 2011; Krebs \& Roebers, 2010). De Bruin et al. (2011) asked children, in addition to providing JOLs, to select texts that they would like to restudy. The results showed that participants did use their monitoring to decide which texts to reread, even the fourth-graders. Thus, even though fourth-graders could not accurately monitor their learning, they did use the results of their monitoring to regulate their study.

These findings indicate that, when learning more complex, educationally relevant verbal materials, it is not yet clear whether and how monitoring and regulation can be improved for fourth-graders. Because idiom learning can be considered a complex task, we explored whether sixth-graders would show more accurate monitoring and more accurate regulation than fourth-graders, in line with the findings by De Bruin et al. (2011).

\section{Present Study}

The aim of the present study was to investigate whether a delayed-JOL and a sentence generation instruction improve monitoring accuracy and subsequent regulation of idiom study compared to an immediate JOL instruction. To explore whether developmental differences affect monitoring and regulation of study with an idiom learning task, we tested both fourth- and sixth-graders. JOL RTs were measured in order to acquire information about the effects of instructions on the speed of providing JOLs, which might provide insight into cues used when judging idiom learning.

We tested the following hypotheses: Regarding monitoring accuracy, we expected that delayed-JOLs would be more accurate than immediate JOLs (Hypothesis 1a), that JOLs after sentence generation would be more accurate than delayed-JOLs (Hypothesis 
$1 b)$, and that monitoring would be more accurate for sixth-grade than fourth-grade learners (Hypothesis 1c). Because monitoring accuracy has been shown to affect regulation, we expected that restudy selections would be more accurate following delayed-JOLs than immediate JOLs (Hypothesis 2a), and moreover that restudy selections would be more accurate following sentence generation than following delayed-JOLs (Hypothesis 2b). Furthermore we expected restudy selections to be better for sixth-grade than fourth-grade learners (Hypothesis 2c). With regard to JOL RTs we expected immediate JOLs to be faster than delayed-JOLs and JOLs after sentence generation (Hypothesis 3a), and we expected that the low JOLs would be provided faster following sentence generation than for uninstructed delayed-JOLs (Hypothesis 3b).

\section{Method}

\section{Partic ipants and Design}

Participants were 90 primary school pupils, 49 fourth-grade students (18 boys and 32 girls, $M=9.9$ years, $S D=0.6$ years) and 41 sixth-grade students ( 15 boys and 26 girls, $M$ $=12.0$ years, $S D=0.6$ years). . They were recruited from five elementary schools in the south of the Netherlands. For all participants, parental consent was obtained. The study was based on a 2 (grade level) $\times 3$ (instruction) between-subjects design. For the idiom study task, participants were assigned randomly to one of three groups, which were immediate JOL ( $n=30,17$ fourth-grade, 13 sixth-grade); uninstructed delayed-JOL ( $n=$ 28,15 fourth-grade, 13 sixth-grade); and delayed-JOL after sentence generation ( $n=32$, 17 fourth-grade, 15 sixth-grade). 


\begin{tabular}{|c|c|c|}
\hline \multicolumn{3}{|c|}{ Instructions Idiom Learning Task } \\
\hline $\begin{array}{l}\text { Immediate JOL } \\
\text { Group }\end{array}$ & $\begin{array}{l}\text { Delayed JOL } \\
\text { Group }\end{array}$ & $\begin{array}{l}\text { Sentence Generation } \\
\text { Group }\end{array}$ \\
\hline 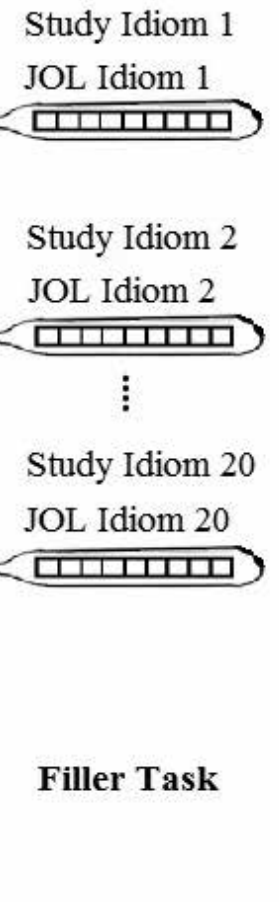 & 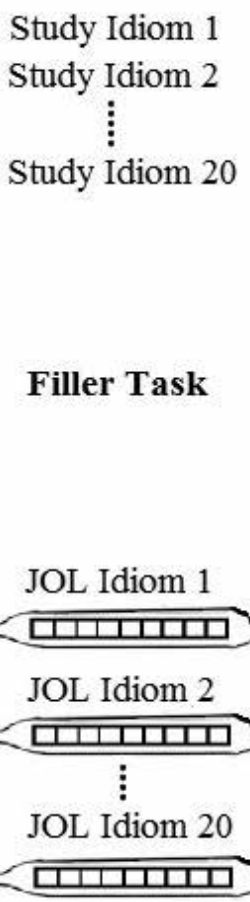 & 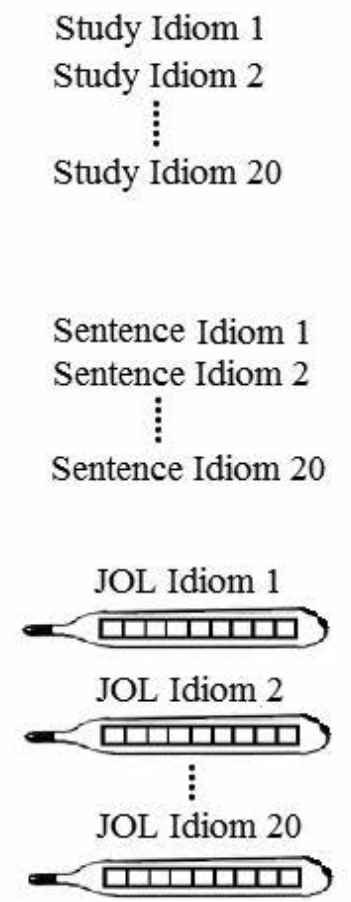 \\
\hline \multicolumn{3}{|c|}{ Restudy Selections } \\
\hline \multicolumn{2}{|c|}{$\begin{array}{l}\text { To crack the whip } \\
\text { Down in the dumps }\end{array}$} & To jump the gun \\
\hline $\begin{array}{l}\text { What is th } \\
\text { What is th }\end{array}$ & $\begin{array}{l}\text { Test } \\
\mathrm{ag} \text { of 'To kick the } \\
\mathrm{ag} \text { of 'To crack th }\end{array}$ & t'? \\
\hline
\end{tabular}

Figure 1. Representation of the procedure of the study. 


\section{Materials}

Idioms. Twenty Dutch idioms with their meanings were selected for the idiom learning task, Table 1 shows examples of the idioms. A pilot study involving 24 elementary school children who did not participate in the final experiment confirmed that these idioms were unfamiliar to students of this age. In this pilot study, learners (10 $4^{\text {th }}$ grade and $146^{\text {th }}$ grade pupils) were asked if they knew the meaning of 35 idioms. These idioms were presented to them without their meaning. They were told to write down the meaning of the idiom if they thought they knew this, and leave a question-mark if they did not know the meaning of the idiom. From the 35 idioms in this pilot study, 20 idioms were selected for the present study. For the selected idioms, none of the $4^{\text {th }}$ grade learners wrote down the correct meaning (of their responses $55.0 \%, S D=23.1$, was a question mark; $45.0 \%$, $S D=23.1$, was an incorrect response). Only 3.6\% $(S D=3.4)$ of the responses of the $6^{\text {th }}$ grade learners was correct (whereas $72.5 \%, S D=16.6$, was a question mark; and $25.0 \%$, $S D=15.5$, an incorrect response).

In the study phase, the idiom with the meaning and an example sentence in which the idiom was used were presented on a laptop computer screen. An example of an English equivalent of the learning task is 'Step on it (idiom) - Hurry up (meaning) - Step on it, the taxi will be here any time and you're not even dressed (example sentence)'.

Table 1. Examples of Dutch Idioms.

\begin{tabular}{lll}
\hline Dutch Idiom & English Translation & Meaning \\
\hline Korte armen hebben & To have short arms & To have a lack of money \\
Een bok schieten & To shoot a goat & To do something stupid \\
De hoogte hebben & To have height & To be drunk \\
Met spek schieten & To shoot with bacon & To brag about something \\
\hline
\end{tabular}

JOLs. When requested to provide JOLs, participants were presented with the idiom on the screen, and the question: "How confident are you that you will be able to provide the meaning of this idiom at the test?" JOLs were given with a mouse click on a thermometer with 9 squares, comparable to the thermometer used by Koriat and Shitzer-Reichert (2002). The scale was depicted as a color drawing of a thermometer ranging from deep blue (the first square, no chance to recall the meaning) to deep red (the ninth square, completely certain to recall the meaning).

Sentence Generation Instruction. Participants were instructed to generate 20 novel sentences in which the 20 previously studied idioms occurred. The idiom was provided on the screen as a cue, and the children were encouraged to generate a meaningful novel 
sentence in which they used the idiom. The children orally produced the novel sentences, the experimenter typed the sentences.

Selection for restudy. Participants were shown a sheet of paper with a $2 \times 10$ array in which each cell was filled by a previously studied idiom. The format of an array was chosen because this places less demands on working memory capacity than an item-byitem format (Thiede \& Dunlosky, 1999). The order of items was randomized, because Ariel, Al-Harty, Was, and Dunlosky (2011) demonstrated that decisions for re-study are influenced by presentation order. Participants were required to mark with a pen, which phrases they would like to re-study, and 0 to 20 items could be selected.

Test. The test consisted of self-paced recall of the 20 idioms, in which participants were asked to type the correct meaning when provided with the idiom.

Apparatus. The idioms, sentence generation task, JOL task, and recall test were presented on a PC compatible laptop and E-prime software (Schneider, Eschman, \& Zuccolotto, 2002) was used for stimulus presentation as well as response and reaction time recording. For each participant, the order of items in the subtasks was randomized anew by the software from study to test.

\section{Procedure}

Figure 1 depicts an overview of the procedure of the study. All children were tested individually in quiet rooms of their schools. Testing time was about 40 minutes per child. The children were instructed that idioms with their meaning would appear on the computer screen together with an example sentence in which the idiom was used. They were told they had to study the idioms so they would be able to show that they comprehended the meaning when cued with the idiom. They were presented with an example of a study trial and an example of a test trial before the idiom learning task started. The study phase was self-paced, that is, the idiom, its meaning, and the example sentence remained on the screen until the participant pressed the space bar. No feedback was provided during idiom learning.

Before providing JOLs, children received an explanation of the thermometer and practiced with an example. Depending on assigned condition, JOLs were provided either immediately after studying each idiom (immediate JOL instruction), after studying all idioms and performing a filler task (delayed-JOL instruction), or after studying and generating sentences for all idioms (sentence generation instruction). Note that following the sentence generation instruction, JOLs were also provided after a delay. Participants in the sentence generation condition first practiced the sentence generation task with an example idiom. After generating an example sentence they received feedback once on the quality of this sentence. Then the actual generation task started. When the children indicated that they could not generate a sentence for an idiom, the experimenter 
encouraged them a maximum of three times to try to generate a sentence. No feedback was provided on the quality of the generated sentences. Participants in the other conditions performed a filler task (a mental rotation task), which was done to create the same delay for all participants between the self-paced study phase and the recall test.

After studying and providing JOLs, interspersed with a sentence generation or filler task depending on assigned condition, participants had the opportunity to select which items they would like to restudy. They were reminded that they had to take a test at a later point, on which they had to correctly recall the meaning of the 20 idioms. Note that they did not actually get to restudy those items because restudy would have intervened between JOLs and recall on the test (Thiede \& Dunlosky, 1999).

The test was self-paced, after pressing the F1 key, the next idiom appeared. After completing the test, all the children were told that they performed well and were thanked for their participation.

\section{Analyses}

Test performance scoring. For 52 participants (57\%), two raters, who were blind to the experimental condition, coded the responses on the test items as incorrect (0), partially correct (0.5), or completely correct (1). Each meaning of an idiom consisted of 1-3 idea units and credit was given for responses that expressed these ideas. Comprehension was emphasized, so if the participant responded with a paraphrase of the original meaning, for example 'make haste' instead of 'hurry up' when cued with 'step on it', this was scored as correct. Partial credit was given if a response expressed one or two but not all of the idea units contained in a definition. The raters agreed on coding $94 \%$ of the time. Because inter-rater agreement was high, one rater scored the test performance of the remaining participants, and these scores were used in the analysis.

Monitoring and regulation accuracy. The gamma correlation was used to measure monitoring accuracy and regulation of study, because this non-parametric statistic is considered the most appropriate measure of relative accuracy (Nelson, 1984). To assess monitoring accuracy, intra-individual gammas were calculated between participants' JOLs and their actual score for each of the 20 idioms. For 6 participants, monitoring gammas could not be computed, because of invariance in test performance (i.e., they had no items correct on the test). For regulation of study, the intra-individual gamma correlation between JOLs and whether an idiom was selected for restudy (yes $=1$, no = 0) was calculated, as operationalized by Thiede et al. (2003). More accurate regulation was indicated by a stronger negative correlation, a gamma of -1 indicates that previous JOLs are adequately translated into the selection of idioms for restudy. For 3 participants gammas could not be computed, because of invariance in restudy selections. 
For monitoring accuracy gammas and regulation of study gammas, the ANOVA assumption of equality of variance was violated. Therefore, gammas were transformed using the Fisher-Z transformation (Fisher, 1915). Note that the Fisher-Z transformation did not change the pattern of results in any substantive manner. For the analyses described below, all reported post-hoc tests are Bonferroni-corrected $t$-tests, and partial eta squared is reported as a measure of effect size.

RT data. To investigate the effects of JOL instructions on JOL RTs, JOLs were coded into three levels: Low (JOL rating 1-3); Intermediate (JOL rating 4-6), and High (JOL rating 7-9). Because of the hierarchical structure of the data (each participant provided $20 \mathrm{JOLS}$, and participants were nested in grade levels), the effect of instructions on JOL RTs was investigated with a mixed model multilevel regression analysis. For this analysis, a random intercept was included for every participant. JOL instruction, Grade level (grade 4 and grade 6) and JOL level (low, intermediate, high) were included as fixed factors, and in addition the interaction JOL Instruction * JOL level was added to the model. JOL RTs were measured in ms, for significant effects the regression coefficients, standard errors, and 95\% confidence intervals are reported.

\section{Results}

Table 2 presents Mean study time, Mean JOLs and Mean of individual Median JOLs for each experimental condition and grade, and JOL skewness is reported with z-scores to provide insight into the JOL distributions. In addition, Table 2 presents the percentage of idioms selected for restudy, and the percentage of correct test performance. In the analyses described below, interaction effects are only reported when significant.

ANOVAs showed no significant difference between the Mean study time per idiom for the different conditions, $F(2,89)=.56, p=.57$. Because the JOL distribution was skewed, Median JOLs were used to investigate whether there was a relation between JOL instructions and JOL magnitudes. ANOVAs exhibited no significant relation between JOL instructions and Median JOLs, $F(2,87)=.70, p=.50$. In addition, there was no significant relation between $\mathrm{JOL}$ instructions and test score, $F(2,87)=.89, p=.41$. 
Table 2. Mean Study Time per Idiom (in Seconds), Mean JOLs, Mean of Individual Median JOLs, JOL Distribution, Selection for Restudy, and Test Performance (Standard Deviations of the Mean in Parentheses)

\begin{tabular}{|c|c|c|c|c|c|c|}
\hline \multirow[b]{2}{*}{ JOLs } & \multicolumn{3}{|c|}{ Fourth Grade } & \multicolumn{3}{|l|}{ Sixth Grade } \\
\hline & Immediate & Delayed & $\begin{array}{l}\text { Sentence } \\
\text { Generation }\end{array}$ & Immediate & Delayed & $\begin{array}{l}\text { Sentence } \\
\text { Generation }\end{array}$ \\
\hline $\mathrm{n}$ & 17 & 15 & 17 & 13 & 13 & 15 \\
\hline Mean Study Time per Idiom & $7.8(2.7)$ & $8.9(4.4)$ & $8.2(2.3)$ & $8.7(2.9)$ & $8.8(3.5)$ & $7.8(3.0)$ \\
\hline Mean JOLs & $5.6(2.2)$ & $5.3(2.8)$ & $5.2(3.0)$ & $5.7(2)$ & $5.8(2.6)$ & $4.8(3.2)$ \\
\hline Median JOLs & $5.5(1.4)$ & $5.2(2.1)$ & $5.2(2.1)$ & $5.6(1.4)$ & $5.7(1.7)$ & $4.8(2.7)$ \\
\hline z-score skewness JOLs & -2 & -0.71 & -0.67 & -2.27 & -1.85 & 1.03 \\
\hline Selection for restudy (\%) & $55.6(20.7)$ & $47(17)$ & $51.8(20.1)$ & $35.8(22.1)$ & $43.8(10.2)$ & $55.3(23.5)$ \\
\hline Correct test performance (\%) & $26.8(23.5)$ & $23.5(19.4)$ & $34.3(23.7)$ & $36(20.5)$ & $33(19.4)$ & $36.8(23.5)$ \\
\hline
\end{tabular}

Note. Mean study time per idiom, Mean JOLs, Mean of individual Median JOLs, z-scores indicating skewness of JOLs, percentage of items selected for restudy, and percentage correct performance for the JOL instructions and grade levels.

\section{Monitoring Accuracy and Regulation of Study}

Table 3 shows the regular and the Fisher-Z transformed gamma correlations for monitoring accuracy. A 3 (JOL Instruction) x 2 (Grade) ANOVA revealed a significant main effect of JOL instruction on monitoring accuracy, $F(2,81)=24.61, p<.001, \eta_{p}{ }^{2}=.39$. Post hoc tests showed higher monitoring accuracy for participants who received the delayedJOL instruction $(p<.001)$ and the sentence generation instruction $(p<.001)$ than for participants who received the immediate JOL instruction. This finding that delayed-JOLs led to more accurate monitoring than immediate JOLs confirms Hypothesis 1a. Results did not show a significant difference between the sentence generation and the delayed$\mathrm{JOL}$ instruction ( $p=.259$; Hypothesis $1 \mathrm{~b}$ ). Moreover, there was no main effect of Grade level on monitoring, $F(1,78)=.09, p=.77$ (Hypothesis $1 c$ ).

Table 3 shows the regular and the Fisher-Z transformed gamma correlations for regulation of study. The 3 (JOL instruction) * 2 (Grade level) ANOVA on regulation of study showed a significant effect of JOL instruction, $F(5,81)=34.87, p<.001, \eta_{p}{ }^{2}=.39$. Post hoc tests showed that the delayed-JOL instruction improved regulation of study when compared to the immediate JOL instruction $(p<.001)$, confirming Hypothesis 2 a. The sentence generation instruction improved regulation of study when compared to both the immediate JOL $(p<.001)$ and the delayed-JOL $(p=.01)$ instructions, confirming Hypothesis $2 b$, which predicted that regulation would be most accurate following sentence generation.

The effect of Grade is not significant, $F(5,81)=1.67, p=.07, \mathrm{n}_{\mathrm{p}}{ }^{2}=.04$, although there is a tendency indicating that regulation of study may be more accurate for sixth-graders 
than for fourth-graders. This finding, although only marginally significant, seems to be in line with Hypothesis 2c, which predicted better regulation for the older age group.

There was no significant effect of JOL instruction on percentage of idioms selected for restudy, $F(2,87)=1.34, p=.27$; nor of Grade on percentage of items selected for restudy, $F(1,88)=2.09, p=.15$. This shows that the above mentioned effects were not due to differences in the number of items selected.

Table 3. Monitoring Accuracy and Regulation of Study

\begin{tabular}{|c|c|c|c|c|c|c|}
\hline \multirow[b]{2}{*}{ JOL Instructions } & \multicolumn{3}{|c|}{ Fourth Grade } & \multicolumn{3}{|l|}{ Sixth Grade } \\
\hline & $\begin{array}{l}\text { Immediate } \\
\text { JOL }\end{array}$ & $\begin{array}{l}\text { Delayed- } \\
\text { JOL }\end{array}$ & $\begin{array}{l}\text { Sentence } \\
\text { Generation }\end{array}$ & $\begin{array}{l}\text { Immediate } \\
\text { JOL }\end{array}$ & $\begin{array}{l}\text { Delayed- } \\
\text { JOL }\end{array}$ & $\begin{array}{l}\text { Sentence } \\
\text { Generation }\end{array}$ \\
\hline \multicolumn{7}{|c|}{ Monitoring Accuracy } \\
\hline Regular Gammas & $.25(.38)$ & $.75(.26)$ & $.78(.24)$ & $.22(.43)$ & $.70(.29)$ & $.89(.09)$ \\
\hline Fisher-Z Gammas & $.31(.49)$ & $1.35(.87)$ & $1.35(.76)$ & $.26(.50)$ & $1.2(.82)$ & $1.7(.67)$ \\
\hline \multicolumn{7}{|l|}{ Regulation of Study } \\
\hline Regular Gammas & $-.14(.37)$ & $-.73(.24)$ & $-.79(.42)$ & $-.41(.3)$ & $-.78(.21)$ & $-.93(.07)$ \\
\hline Fisher-Z Gammas & $-.18(.46)$ & $-1.17(.73)$ & $-1.7(.97)$ & $-.48(.36)$ & $-1.38(.81)$ & $-2.01(.68)$ \\
\hline
\end{tabular}

Note. Regular gamma correlations and Fisher-Z transformed gamma correlations indicating monitoring accuracy and regulation of study for the JOL instructions and the grade levels (standard deviations of the mean in parentheses).

\section{J OLReaction Times}

Figure 2, in which JOL RTs are visible as a function of JOL instructions and JOL levels, provides a visual representation of the results of the analyses described below.

The multilevel regression analysis revealed significant main effects of $\mathrm{JOL}$ instruction, JOL level, and Grade level, and moreover a significant JOL Instruction * JOL level interaction effect. The significant effect of JOL instruction on JOL RTs, $F(2,1773)=$ $120.06, p<.001$, shows, in line with Hypothesis 3a, that immediate JOLs were provided faster than delayed-JOLs ( $b=-1287.89, \mathrm{SE}=87.86, \mathrm{Cl}=-1460.21$ to -1115.57$)$, and JOLS after sentence generation ( $b=-632.22, S E=139.32, \mathrm{Cl}=-905.48$ to -358.97$)$. There was no significant difference between mean JOL RTs following the sentence generation and the delayed-JOL instruction, $p=.192$. 


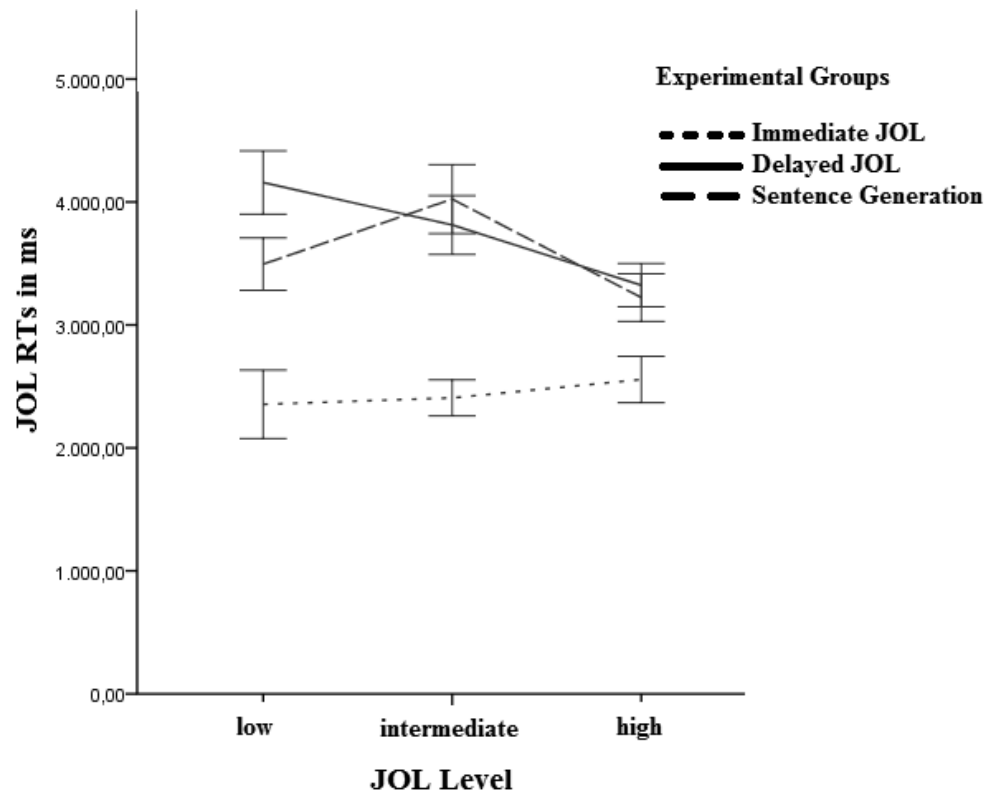

Figure 2. JOL RTs (in ms) as a function of JOL instruction and JOL level. Error bars indicate the 95\% Confidence Interval. JOL RTs are fastest for Immediate JOLs. For the low JOLs, JOL RTs are faster following sentence generation than following uninstructed delayed-JOLs.

Even though we did not have specific hypotheses regarding the effect of grade level on overall JOL RTs, we will report the analyses in order to provide a complete picture of the data. The significant effect of Grade level, $F(1,1773)=46.41, p<.001$, shows JOLs were provided faster by the sixth-graders than the fourth-graders $(b=479.50, S E=.70 .30, \mathrm{Cl}=$ 341.44 to 617.55$)$.

Importantly, as visible in Figure 3, there was an interaction effect between JOL instructions and JOL levels, and this interaction effect was significant, $F(4,1773)=8.91$, $p<.001$. Further investigation of this interaction effect shows, in line with Hypothesis $3 b$, that the JOL RTs differ at the low end of the JOL scale (JOLs $1-3$ ). As expected, for low JOLs there was a significant difference between the delayed-JOL condition and the sentence generation condition, $F(2,479)=36.87, p<.001$. Low JOLs were provided faster following the sentence generation instruction than following the delayed-JOL instruction ( $b=662.97, \mathrm{SE}=164.77, \mathrm{Cl}=339.20$ to 986.74$)$.

\section{Disc ussion}

This study investigated children's metacognitive skills when learning idioms. We aimed to address the question of whether these skills would improve by focusing attention on 
literal retrieval cues and gist cues prior to monitoring. Therefore, we investigated the effects of immediate $\mathrm{JOL}$, delayed-JOL, and sentence generation instructions on monitoring and regulation of fourth- and sixth-grade learners.

First of all, we hypothesized that delayed-JOLs would be more accurate than immediate JOLs (Hypothesis 1a). Results on monitoring accuracy show that, in line with our expectations, providing JOLs after a delay improved monitoring. Also when providing JOLs following sentence generation, monitoring accuracy significantly improved when compared to immediate JOLs. Contrary to our expectations (Hypothesis $1 \mathrm{~b}$ ), monitoring accuracy did not differ between the delayed-JOL and the sentence generation group. Monitoring of idiom study was highly accurate following both instructions: Mean gamma correlations were .73 following delayed-JOLs and .84 following sentence generation. Note that both following delayed-JOL and sentence generation instructions, monitoring judgments were provided after a delay. Thus, the benefits of the sentence generation instruction on monitoring may be attributable to the delayed-JOL procedure. In addition, we expected that JOLs would be more accurate for sixth-graders than for fourth-graders (Hypothesis 1c). This expectation was not confirmed, monitoring accuracy did not differ between the two age groups.

In line with our expectations (Hypothesis 2b), the sentence generation instruction improved regulation of study, compared to both delayed-JOL and immediate JOL instructions. In addition, as predicted by Hypothesis 2a, the delayed-JOL instruction led to better regulation than the immediate JOL instruction. Moreover, the nearly significant effect of grade level on regulation of study implies that regulation was more accurate for sixth-graders than for fourth-graders, in line with our expectations (Hypothesis 2c). Older children tended to regulate study more accurately than the younger ones, by more often selecting idioms for restudy that they had judged as more difficult, and vice versa.

The measurements of JOL reaction times provided additional insights into effects of the three instructions on cue utilization when monitoring idiom learning. Our findings suggest that indeed, the JOL instructions led children to rely on different cues. In line with our expectations, JOLs were made fastest following the immediate JOL instruction (Hypothesis 3a), presumably because immediate judgments were based on monitoring of information that remained available in working memory (Nelson \& Dunlosky, 1991). Moreover, the speed of providing monitoring judgments differed for the low JOLs, with which participants indicated that they had low confidence that they would provide the correct meaning of the idiom at the test. Low JOLs following sentence generation were provided faster than low JOLs following uninstructed delayed-JOLs (Hypothesis 3b). The JOLs following the sentence generation task show the same pattern as the judgments in the speeded JOL condition by Metcalfe and Finn (2008b). These findings suggest that, when monitoring learning following sentence generation, participants did not attempt to retrieve the meaning of the idiom. On the other hand, following the delayed-JOL 
instruction, the RTs for the low JOLs were longer. The slope for JOL RTs following the delayed-JOL instruction shows the same pattern as findings on RTs for delayed-JOLs by Benjamin et al. (1998), and the uninstructed delayed-JOL condition of the research by Metcalfe and Finn (2008b). This suggests that, when children are asked to monitor idiom learning after a delay, they spontaneously attempt to retrieve the meaning. On the other hand, monitoring idiom learning following sentence generation seems to lead learners not to focus on retrieval fluency, but on a different cue. Based on studies by Thiede et al. (2003) and De Bruin et al. (2011), we assume that the sentence generation task leads learners to focus on valid cues related to the ability to connect the idiom with prior knowledge, instead of retrieval fluency cues. The reaction time findings thus seem to provide additional support for the argument that instructions can affect young learners cue utilization.

Our results expand findings on the effect of instructions on metacognitive skills (e.g., De Bruin et al., 2011; Nelson \& Dunlosky, 1991; Thiede et al., 2003) to children's idiom learning. It can be concluded that the delayed-JOL effect that was found with associative learning tasks (Nelson \& Dunlosky, 1991) also applies to more complex and educationally relevant tasks such as studying idioms. The memory retrieval account, which states that JOLs are accurate because they rely on information from long-term memory (Nelson \& Dunlosky, 1991; Rhodes \& Tauber, 2011) provides an explanation for more accurate monitoring when judging idiom learning after a delay. This implies that metacognition for idiom learning has characteristics of metacognition for associative learning tasks. This might also explain why there was no difference in monitoring accuracy between fourthand sixth-graders. Note that the reaction times of the JOLs were longer for the fourthgraders than for the sixth-graders, which might indicate that judging idiom learning was more difficult for the younger learners. However, monitoring accuracy following the delayed-JOL instructions and the sentence generation task was accurate for the fourthgraders as well as for the sixth-graders. This finding is in line with findings by Schneider et al. (2000), who showed that even young elementary school students can monitor learning of paired associates very well when judging their memory after a delay.

Importantly, our findings that sentence generation led to more accurate regulation of study than the delayed-JOL instruction, indicate that sentence generation does not only improve language learning (Graf, 1982), but can also have a beneficial effect on metacognition. Our findings on the beneficial effect of sentence generation can be explained by the nature of the idiom learning task. In addition to having characteristics of associative learning tasks in which target information can be retrieved literally, idiom learning also has characteristics of more complex and educationally relevant text comprehension tasks. Because idiom processing can be gist-based, with a focus on connections with contextual information and prior knowledge (Cain \& Towse, 2008; Langlotz, 2006; Levorato \& Cacciari, 1999; Sprenger et al., 2006), the sentence generation 
instruction had a beneficial effect on regulation of study. Moreover, the faster JOL reaction times for the low JOLs following sentence generation imply that retrieval of the meaning of idioms is not needed for accurate JOLs and restudy selections.

Previous research by De Bruin et al. (2011) showed that tasks which helped learners focus on the gist of novel information can improve monitoring and regulation for sixthgraders. However, monitoring of fourth-graders was inaccurate. Thus, even though De Bruin et al. (2011) found that a generation task affected regulation of fourth-graders, this regulation was based on inaccurate monitoring and therefore this regulation was not expected to have a beneficial effect on achievement. The present study is the first to show that after accurate monitoring, fourth-grade learners' regulation of study can be improved with the use of a sentence generation task. This is an important finding because more effective regulation following accurate monitoring leads to better academic achievement (Ertmer \& Newby, 1996; Thiede et al., 2003).

Even though the marginally significant effect of grade level on regulation has to be interpreted with some caution, the findings on metacognition when learning idioms are in line with previous research findings that developmental differences do not affect monitoring accuracy, but do affect regulation of study (Dufresne \& Kobasigawa, 1989; Krebs \& Roebers, 2010). Results by Krebs and Roebers (2012) suggested that effects of cognitive capacity are likely to be found with tasks requiring higher metacognitive demands. A possible explanation for the present findings is that older children have more cognitive capacity and are thus better at remembering how they judged their idiom learning. Therefore, for these learners it might be less difficult to decide which idioms need extra study before taking the test. Because sentence generation affected learners' restudy decisions, but did not substantially affect the accuracy of monitoring, the assumption arises that tasks which direct learners' attention to gist cues have more influence on regulation than on monitoring. Future research should further investigate the effect of developmental differences on metacognitive skills when learning idioms.

Based on established theories (e.g., Thiede et al., 2003), we presume that learners focus on gist when judging their learning following generation tasks. We did not directly measure the cues used when learners made metacognitive judgments following Sentence Generation. Another possible explanation for the effect of the sentence generation task could be that it leads learners to attempt visualizing their semantic knowledge (Bransford, 1979). Maybe this could have affected their metacognitive judgments and JOL reaction times. Research by Begg, Duft, Lalonde, Melnick, and Sanvito (1989) indicated that metacognitive judgments are based on the ease of processing. Possibly, the ease of sentence processing, that is, the ease of generating a correct and complete sentence, informed learners about the quality of their gist representation, Because we did not directly test cue utilization, future research should further investigate what causes the exclusive influence of sentence generation on regulation of study. 
Since this is the first study to examine the effect of delayed-JOLs and sentence generation on monitoring and regulation of idiom learning, we should be careful with interpretations. First of all, it is important to note that the measures of JOL RTs are indirect measures of cue use. It could be that the faster RTs for the low JOLs following sentence generation do not result from a focus on cues related to gist, but instead result from a retrieval attempt that learners made when generating the sentences prior to providing JOLs. In that case, the low reaction times may have been due to the retrieval attempt which was already made at the time of the sentence generation task, instead of the cues that the learners derived about their understanding of the gist of the idiom. However, if learners provide faster JOLs because they focus on the earlier retrieval attempt, we would also expect faster JOL RTs for intermediate and high JOLs following the sentence generation task. We did not find an overall difference in JOL RTs between the Delayed-JOL and the Sentence Generation conditions. This makes the plausibility of the explanation that the fast low JOL RTs are a result of a previous retrieval attempt during sentence generation unlikely.

Possibly, the beneficial effect of the sentence generation condition could also be due to the extra time the participants spent with the materials. Even though this explanation seems unlikely, because in that case sentence generation would also be expected to improve monitoring, it cannot be completely ruled out. Additionally, the less effective regulation in the delayed-JOL group could possibly be explained by the distraction of the filler task, rather than by the benefit of the sentence generation task. However, this explanation also seems improbable, because if the learners were distracted prior to providing metacognitive judgments we would also expect higher overall RTs for the delayed JOL group, whereas we found that only the RTs for the low judgments were higher. However, future research could benefit from a design in which learners who do not participate in a generation task are still presented with the target materials before providing JOLs, instead of with a completely different filler task.

We did not include a condition in which JOLs were provided immediately after the sentence generation task, because Thiede et al. (2005) showed that the delay between study and generation is the only critical lag when investigating monitoring accuracy, and that the lag between generation tasks and judgments is not that important. However, it might be interesting to include an immediate sentence generation condition in future research.

Moreover, in the present study, participants selected items for restudy relatively short after learning the idioms, whereas in educational contexts there is often more time between study sessions. Therefore, in future research it would be interesting to investigate whether the lag between study and restudy decisions influences the effect of the sentence generation instruction. 
Importantly, the current work contributes to insights into the validity of cues on which metacognitive judgments are based. Moreover, the findings add to the knowledge about potentially effective techniques to improve regulation when young learners study educationally relevant materials. As to implications for education, our findings suggest that sentence generation is preferable over delaying JOLs, as sentence generation improved regulation of study more, and we know that regulation of study influences learning and performance (Ertmer \& Newby, 1996). Thus, sentence generation instructions seem promising to improve self-regulated learning of educationally relevant materials such as idioms. 


\section{References}

Anderson, M. C. M., \& Thiede, K. W. (2008). Why do delayed summaries improve metacomprehension accuracy? Acta Psychologica, 128, 110-118.

Ariel, R., Al-Harthy, I. S., Was, C. A., \& Dunlosky, J. (2011). Habitual reading biases in the allocation of study time. Psychonomic Bulletin \& Review, 18, 1015-1021.

Benjamin, A. S., Bjork, R. A., \& Schwartz, B. L. (1998). The mismeasure of memory: When retrieval fluency is misleading as a metamnemonic index. Journal of Experimental Psychology: General, 127, 55-68.

Begg, I., Duft, S., Lalonde, P., Melnick, R., \& Sanvito, J. (1989). Memory predictions are based on ease of processing. Journal of Memory \& Language, 28, 610-632.

Bobrow, A., \& Bell, M. (1973). On catching on to idiomatic expressions. Memory \& Cognition, 1, 343-346.

Bransford, J. D. (1979). Human cognition: Learning, understanding, and remembering. Belmont, CA: Wadsworth.

Brinton, B., Fujiki, M., \& Mackey, T. A. (1985). Elementary school age children's comprehension of specific idiomatic expressions. Journal of Communication Disorders, 18, 245-257.

Brown, A. L., Bransford, J. D., Ferrara, R. A., \& Campione, J. C. (1983). Learning, remembering, and understanding. In J. H. Flavell \& E. M. Markham (Eds.), Handbook of child psychology: Cognitive development, vol. 3 (pp 77-166). New York: Wiley.

Cain, K., \& Towse, A. S. (2008). To get hold of the wrong end of the stick: Reasons for poor idiom understanding in children with reading comprehension difficulties. Journal of Speech, Language, and Hearing Research, 51, 1538-1549.

Cain, K., Towse, A. S., \& Knight, R. S. (2009). The development of idiom comprehension: An investigation of semantic and contextual processing skills. Journal of Experimental Child Psychology, 102, $280-298$.

Conway, A. R. A., \& Engle, R. W. (1994). Working memory and retrieval: A resource-dependent inhibition model. Journal of Experimental Psychology: General, 123, 354-373.

Cowan, N. (1999). An embedded-processes model of working memory. In A. Miyake \& P. Shah(Eds.), Models of working memory: Mechanisms of active maintenance and executive control (pp. 62-101). Cambridge, U.K.: Cambridge University Press.

De Bruin, A. B. H., Thiede, K. W., Camp, G., \& Redford, J. (2011). Generating keywords improves metacomprehension and self-regulation in elementary and middle school children. Journal of Experimental Child Psychology, 109, 294-310.

Dufresne, A., \& Kobasigawa, A. (1989). Children's spontaneous allocation of study time: Differential and sufficient aspects. Journal of Experimental Child Psychology, 47, 274-296.

Dunlosky, J., \& Lipko, A. R. (2007). Metacomprehension: A brief history and how to improve its accuracy. Current Directions in Psychological Science, 16, 228-232.

Dunlosky, J., \& Metcalfe, J. (2009). Metacognition. Thousand Oaks, CA: Sage Publications.

Ertmer, P. A., \& Newby, T. J. (1996). The expert learner: Strategic, self-regulated, and reflective. Instructional Science, 24, 1-24.

Fisher, R. A. (1915). Frequency distribution of the values of the correlation coefficient in samples of an indefinitely large population. Biometrika, 10, 507-521.

Fletcher, C. R., \& Chrysler, S. T. (1990). Surface forms, textbases, and situation models: Recognition memory for three types of textual information. Discourse Processes, 13, 175-190.

Graesser, A. C., Singer, M., \& Trabasso, T. (1994). Constructing inferences during narrative text comprehension. Psychological Review, 101, 371-395.

Graf, P. (1982). The memorial consequences of generation and transformation. Journal of Verbal Learning and Verbal Behavior, 21, 539-548.

Griffin, T. D., Jee, B. D., \& Wiley, J. (2009). The effects of domain knowledge on metacomprehension accuracy. Memory \& Cognition, 37, 1001-1013. 
Huff, J. D., \& Nietfeld, J. L. (2009). Using strategy instruction and confidence judgments to improve metacognitive monitoring. Metacognition \& Learning, 4, 161-176.

Kintsch, W. (1998). Comprehension: A paradigm for cognition. Cambridge, University Press.

Kintsch, W., \& Van Dijk, T. A. (1978). Toward a model of text comprehension and production. Psychological Review, 85, 363-394.

Kintsch, W., Welsch, D. M., Schmalhofer, F., \& Zimny, S. (1990). Sentence memory: A theoretical analysis. Journal of Memory and Language, 29, 133-159.

Koriat, A. (1997). Monitoring one's own knowledge during study: A cue-utilization approach to judgments of learning. Journal of Experimental Psychology: General, 126, 349-370.

Koriat, A., Ackerman, R., Lockl, K., \& Schneider, W. (2009). The easily learned, easily remembered heuristic in children. Cognitive Development, 24, 169-182.

Koriat, A., \& Ma'ayan, H. (2005). The effects of encoding fluency and retrieval fluency on judgments of learning. Journal of Memory and Language, 52, 478-492.

Koriat, A., \& Shitzer-Reichert, R. (2002). Metacognitive judgments and their accuracy. In P. Chambres, M. Izaute, \& P. J. Marescaux (Eds.), Metacognition: Process, function and use (pp. 1-17). Boston: Kluwer Academic Publishers.

Krebs, S. S., \& Roebers, C. M. (2010). Children's strategic regulation, metacognitive monitoring, and control processes during test taking. British Journal of Educational Psychology, 80, 325-340.

Krebs, S. S., \& Roebers, C. M. (2012). The impact of retrieval processes, age, general achievement level, and test scoring scheme for children's metacognitive monitoring and controlling. Metacognition and Learning, 7, 75-90.

Langlotz, A. (2006). Idiomatic creativity: A cognitive-linguistic model of idiom-representation and idiom variation. Amsterdam/Philadelphia: John Benjamins.

Levorato, M. C., \& Cacciari, C. (1992). Children's comprehension and production of idioms: The role of context and familiarity. Journal of Child Language, 19, 415-433.

Levorato, M. C., \& Cacciari, C. (1999). Idiom comprehension in children: Are the effects of semantic analysability and context separable? European Journal of Cognitive Psychology, 11, 51-66.

Levorato, M. C., Nesi, B., \& Cacciari, C. (2004). Reading comprehension and understanding idiomatic expressions: A developmental study. Brain and Language, 91, 303-314.

Lipko, A. R., Dunlosky, J., \& Merriman, W. E. (2009). Persistent overconfidence despite practice: The role of task experience in preschoolers' recall predictions. Journal of Experimental Child Psychology, 103, 152-166.

Maki, R. H. (1998). Predicting performance on text: Delayed versus immediate predictions and tests. Memory \& Cognition, 26, 959-964.

Metcalfe, J., \& Finn, B. (2008a). Evidence that judgments of learning are causally related to study choice. Psychonomic Bulletin \& Review, 15, 174-179.

Metcalfe, J., \& Finn, B. (2008b). Familiarity and retrieval processes in delayed judgments of learning. Journal of Experimental Psychology: Learning, Memory, \& Cognition, 34, 1084-1097.

Nelson, T. O. (1984). A comparison of current measures of the accuracy of feeling-of-knowing predictions. Psychological Bulletin, 95, 109-133.

Nelson, T. O., \& Dunlosky, J. (1991). When people's judgments of learning (JOLs) are extremely accurate at predicting subsequent recall: The "Delayed-JOL effect". Psychological Science, 2, 267-270.

Nelson, T. O., \& Narens, L. (1990). Metamemory: A theoretical framework and new findings. In G. H. Bower (Ed.), The psychology of learning and motivation (Vol. 26, pp. 125-171). New York : Academic Press.

Nippold, M. A., \& Taylor, C. L. (2002). Judgments of idiom familiarity and transparency: A comparison of children and adolescents. Journal of Speech, Language, and Hearing Research, 45, 384-391.

Rhodes, M. G., \& Tauber, S. K. (2011). The influence of delaying judgments of learning on metacognitive accuracy: A meta-analytic review. Psychological Bulletin, 137, 131-148.

Schneider, W., Eschman, A., \& Zuccolotto, A. (2002). E-Prime reference guide. Pittsburgh: Psychology Software Tools Inc. 
Schneider, W., Visé, M., Lockl, K., \& Nelson, T. O. (2000). Developmental trends in children's memory monitoring: Evidence from a judgment-of-learning task. Cognitive Development, 15, 115-134.

Son, L. K., \& Metcalfe, J. (2005). Judgments of learning: Evidence for a two-stage process. Memory \& Cognition, 33, 1116-1129.

Sprenger, S. A., Levelt, W. J. M., \& Kempen, G. (2006). Lexical access during the production of idiomatic phrases. Journal of Memory and Language, 54, 161-184.

Sternberg, S. (1969). Memory-scanning: Mental processes revealed by reaction-time experiments. American Scientist, 57, 421-457.

Swinney, D. A., \& Cutler, (1979). The access and processing of idiomatic expressions. Journal of Verbal Learning and Verbal Behavior, 18, 523-534.

Tabossi, P., Fanari, R., \& Wolf, K. (2009). Why are idioms recognized fast? Memory \& Cognition, 37, 529-540.

Thiede, K. W., \& Anderson, M. C. M. (2003). Summarizing can improve metacomprehension accuracy. Contemporary Educational Psychology, 28, 129-160.

Thiede, K. W., Anderson, M. C. M., \& Therriault, D. (2003). Accuracy of metacognitive monitoring affects learning of text. Journal of Educational Psychology, 95, 66-73.

Thiede, K. W. and Dunlosky, J. (1999). Toward a general model of self-regulated study: An analysis of selection of items for study and self-paced study time. Journal of Experimental Psychology: Learning, Memory and Cognition, 25, 1024-1037.

Thiede, K. W., Dunlosky, J., Griffin, T. D., \& Wiley, J. (2005). Understanding the delayed keyword effect on metacomprehension accuracy. Journal of Experimental Psychology: Learning, Memory, and Cognition, 31, 1267-1280.

Van Loon, M. H., De Bruin, A. B. H., Van Gog, T., \& Van Merriënboer, J. J. G. (2013). Activation of inaccurate prior knowledge affects primary-school students' metacognitive judgments and calibration. Learning and Instruction, 24, 15-25.

Von der Linden, N., Schneider, W., \& Roebers, C. (2011). The effects of summary production and encoding condition on children's metacognitive monitoring. Metacognition \& Learning, 6, 3-23.

Zimmerman, B. J., \& Martinez-Pons, M. (1990). Student differences in self-regulated learning: Relating grade, sex, and giftedness to self-efficacy and strategy use. Journal of Educational Psychology, 82, 51-59. 


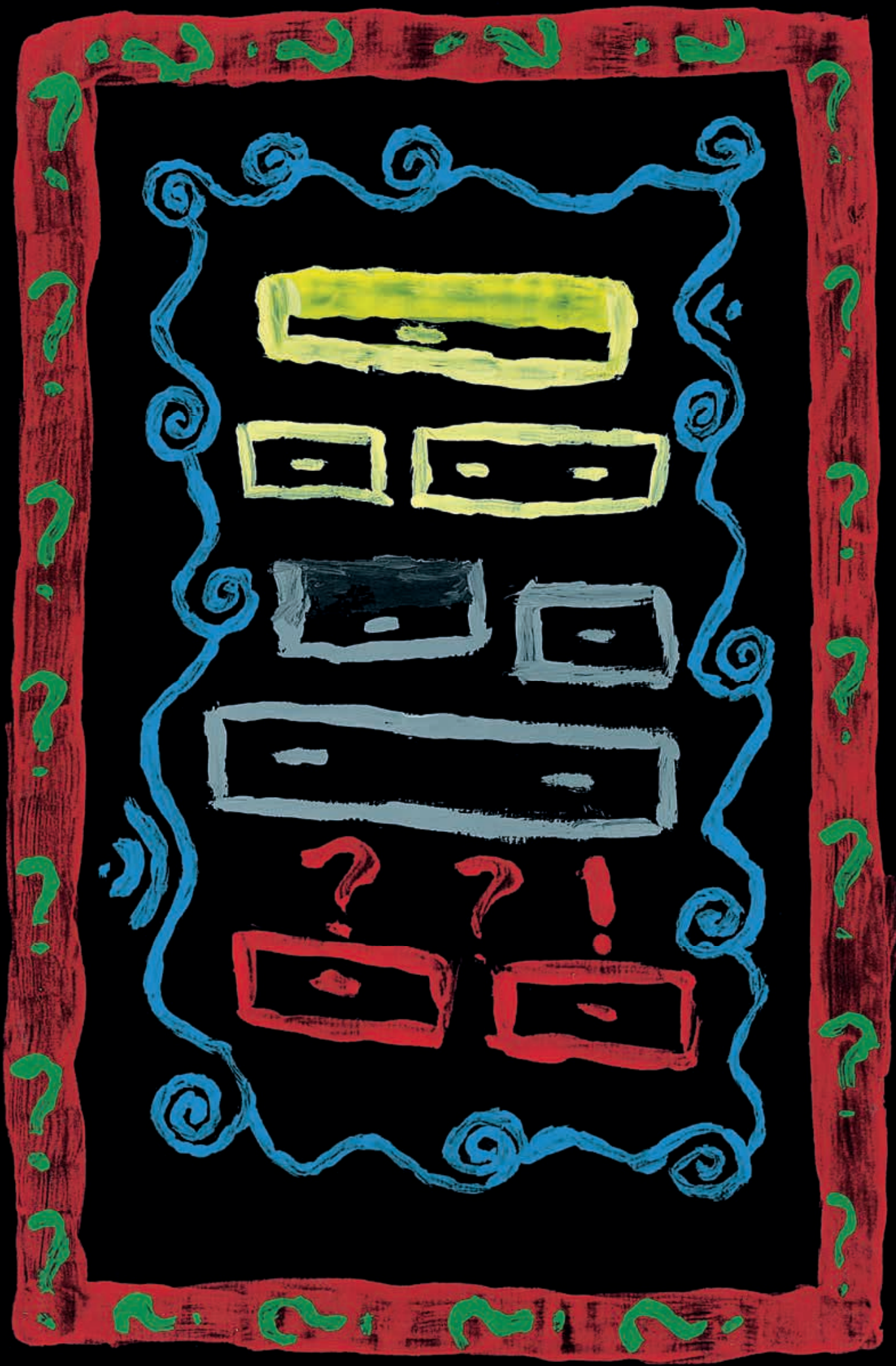




\title{
C HAPTER 3
}

\section{Effects of Reflection and Sentence Generation on Adolescents' Restudy Selections and Monitoring when Leaming Idioms}

\begin{abstract}
Study decisions are often maladaptive; learners drop materials from study that are not yet well learned. Maladaptive study selections can be caused by overconfidence when monitoring learning, which occurs when learners expect to receive credit for responses that are entirely incorrect. We aimed to investigate effects of reflection and sentence generation instructions on restudy selections and monitoring. Seventy-one adolescents ( $M$ age $=14.77$ years) studied idioms under one of three conditions: Reflection prompts after study; sentence generation after study; letter counting (control). Restudy selections were most adaptive following sentence generation. Restudy selections were least adaptive following reflection, when compared to sentence generation and control instructions. Further, reflection instructions led to overconfidence. Following reflection, it might be more difficult to focus on understanding of the gist of studied idioms than following sentence generation. Sentence generation seems more suitable than prompting for reflection to improve self-regulated learning.
\end{abstract}

This chapter is submitted as Van Loon, M. H., De Bruin, A. B. H., Van Gog, T., \& Van Merriënboer, J. J. G. Effects of reflection and sentence generation on adolescents' restudy selections and monitoring when learning idioms. Manuscript submitted for publication. 


\section{Effects of Reflection and Sentence Generation on Adolescents' Restudy Selections and Monitoring when Leaming Idioms}

Adolescents in secondary education are encountering the complex demands of becoming self-regulated learners (Alvermann, 2002). Self-regulated learning involves making decisions about when to continue and when to stop (re)studying (Kornell \& Bjork, 2009). A self-regulated learner takes control of learning by monitoring his current state of learning, and constantly making decisions about what materials to study further (Nelson \& Narens, 1990). In order to make adaptive study selections (i.e., leading to the best possible learning outcomes), they should decide to study materials that are not yet wellknown and drop study materials that they already know well (Thiede \& Dunlosky, 1999).

Unfortunately, study selections of both adults and young learners are often not adaptive (Ariel, Al-Harty, Was, \& Dunlosky, 2011; Kornell \& Bjork, 2008): They tend to drop materials from study that are not yet well learned (Dunlosky \& Thiede, 2004; Kornell \& Bjork, 2008). Therefore, it is important to support learners in making more adaptive selections. However, thus far, little is known about effects of instructions on adolescents' study selections. Therefore, we aimed to examine whether different types of instructions can improve decisions about what to study and what to drop from further study. We compared two instructions, reflection and sentence generation, with each other and with an additional control instruction. Prompting students to reflect on their learning and understanding of studied materials is an instructional strategy that has been widely applied. However, research shows varying results regarding effects of prompting for reflection on self-regulated learning (Dignath, Buettner, \& Langfeldt, 2008). Possibly, sentence generation instructions are more suitable than reflection instructions to support learners to make adaptive study selections. A recent study showed that sentence generation improved study selections in comparison to a group that did not generate sentences (Van Loon, De Bruin, Van Gog, \& Van Merriënboer, 2013a). Before describing possible effects of instructions on study selections, we will first focus on a factor which can limit the optimality of study decisions: Inaccurate monitoring of learning.

\section{Monitoring}

Models of self-regulated learning agree that in order to adaptively decide which materials to study and which ones to discard, learners should accurately monitor their learning progress (e.g., Dunlosky \& Ariel, 2011). Judgments of learning (JOLs) are widely used to measure monitoring accuracy (Nelson \& Dunlosky, 1991). When making JOLs, learners predict how well they will do on a test about the studied materials. When learners selfregulate their learning, they select materials for restudy on the basis of their subjective 
evaluations of how well the studied materials have been mastered (Son \& Metcalfe, 2000). Thus, the accuracy of JOLs can play a large role in whether self-regulated study ends up being adaptive or maladaptive (Bjork, Dunlosky, \& Kornell, 2013).

Learners' JOLs are well-calibrated when the absolute difference between their JOLs and their actual test performance is small. However, calibration of JOLs is often poor. Learners tend to be overconfident: Even when test responses are incorrect and not awarded any objective credit, learners often predict that these responses will be correct (e.g., Rawson \& Dunlosky, 2007; Van Loon, De Bruin, Van Gog, \& Van Merriënboer, 2013b). Overconfidence can cause learners to prematurely drop materials from study: Learners think they already know them, while they actually do not (Van Loon et al., 2013b).

Responses on a test that are scored as incorrect can either be omission errors (i.e., learners are not able to provide a response at all) or commission errors (i.e., learners provide a completely incorrect response). Learners tend to be overconfident when making JOLs for studied items that show up as omission errors on a later test, however, they are even more overconfident for studied items that show up as commission errors on a later test (Van Loon et al., 2013b). When studying content-rich materials -such as expository texts, or figurative language-, in order to correctly understand and apply studied content, learners need to comprehend the gist of studied information (e.g., Langlotz, 2006; McCrudden, Schraw, Lehman, \& Paliquin, 2007). This means that learners need to connect the studied information to their prior knowledge and to contextual information (Graesser, Singer, \& Trabasso, 2004; Kintsch, 1988). Presumably, learners are overconfident because, when judging their level of learning, they base JOLs on whether or not they have information accessible in memory, but they often do not have insight into how well they understand the gist of studied information (Baker \& Dunlosky, 2006; Kendeou \& Van den Broek, 2007; Koriat, 1993; Van Loon et al., 2013b). Therefore, overconfidence for incorrect responses, and especially overconfidence for commission errors, contributes to maladaptive restudy decisions and inefficient self-regulated learning (Dunlosky, Hartwig, Rawson, \& Lipko, 2011; Dunlosky \& Rawson, 2012; Van Loon et al., 2013b). For adaptive selection of materials for further study, learners need to be able to accurately monitor their memory for the gist of the materials, rather than using their memory for literal details, or accessibility of inaccurate or incomplete prior knowledge as a cue for monitoring judgments (Anderson \& Thiede, 2008; Thiede \& Anderson, 2003; Van Loon et al., 2013b).

Because learners are often poor at accurately monitoring actual understanding of the gist of studied information, they need instructional support (Dunlosky et al., 2011; Thiede, Griffin, Wiley, \& Anderson, 2010). It has been suggested that reflection instructions might foster accurate monitoring and effective self-regulation. 


\section{Reflection on Memory}

It is commonly advocated that, in order to improve restudy decisions and monitoring, students should reflect on their knowledge (e.g., Bannert \& Reimann, 2012; Ertmer \& Newby, 1996; Michalsky, Mevarech, \& Haibi, 2009). Because they are unlikely to selfreflect spontaneously, instructions are needed, such as prompting students to reflect (e.g., Berthold, Nückles, \& Renkl, 2007; Davis, 2003; Van Den Boom, Paas, \& Van Merriënboer, 2007). Reflection prompts give directions and guidelines about what to reflect on, and how to reflect on this (e.g., Berthold et al., 2007). These are often intended to help learners to monitor whether learning materials are understood, and to decide which information needs further study (Berthold et al., 2007; Davis, 2003). For example, Berthold et al. (2007) presented learners with reflection prompts such as "How can I overcome my comprehension problems?" Even though reflection might be useful to improve metacognitive skills and learning outcomes (Davis, 2003; Michalsky et al., 2009; Wilson, Perry, Anderson, \& Grosshandler, 2012), there are indications that reflection prompts may not always have beneficial effects on self-regulated learning. Bannert and Mengelkamp (2008) found that students who received reflection prompts reported less adaptive self-regulation of study than a control group. Furthermore, a meta-analysis indicated that, when learners are not provided with additional knowledge and examples of learning strategies, reflection often has no beneficial effects on primary school students' self-regulated learning and their learning outcomes (Dignath et al., 2008).

Possibly, when learners are instructed to reflect, it is difficult for them to focus on their actual understanding of the gist of studied content, and instead, reflection can lead to thoughts that are not related to actual understanding (Thiede et al., 2010). When learners have difficulties monitoring their current state of learning and have an inaccurate sense of understanding, these learners are also expected to be misguided in their subsequent study selections (Ackerman, Leiser, \& Shpigelman, 2012). Thus, prompting for reflection might not always be effective to improve self-regulated study.

\section{Sentence Generation}

Recent research demonstrated that sentence generation can be a promising generation task for primary-school learners to improve their restudy selections (Van Loon et al., 2013a). A sentence generation task prompts learners to self-test their understanding by incorporating previously studied information in a novel sentence. When learners perform a generation task after studying information, this may help them focus on the gist representation of the studied information in their long-term memory (Thiede, Anderson, \& Therriault, 2003; Thiede, Dunlosky, Griffin, \& Wiley, 2005). When learners generate 
sentences with studied information, they need to actively connect new knowledge with existing knowledge. Therefore, the ease of generating a novel sentence can provide learners with indications about their understanding of the gist of the studied content. However, when a learner's memory representation is not related to actual understanding of the gist, he should experience more difficulties when trying to construct a meaningful sentence (Van Loon et al., 2013a). Sentence generation prompts can thus help learners to monitor learning, and if they use this as a base for making restudy selections, these selections are expected to be more adaptive.

However, research on effects of sentence generation only investigated improvements in relative monitoring accuracy, that is, the correlation between JOLs and test performance (Van Loon et al., 2013a). While informative about whether learners can distinguish between items they do or do not know, this measure does not provide a good indication of learners' calibration, because relative accuracy can be perfect even when learners are overconfident. As especially overconfidence can lead to maladaptive restudy selections, we investigated effects of reflection and sentence generation on restudy selections and calibration.

\section{Present Study}

This study was designed to test our assumption that sentence generation will be more suitable than reflection to improve restudy selections when learners study idiomatic phrases. Idioms are figurative expressions which frequently occur in language, usually in the form of short sentences. When studying the meaning of idiomatic phrases, learners are not only required to memorize literal information, but they also have to understand the gist, in order to be able to use this idiom in connection with their prior knowledge (Cain \& Towse, 2008; Langlotz, 2006; Levorato \& Cacciari, 1995; Sprenger, Levelt, \& Kempen, 2006). When learners have insight into their understanding of the gist of idioms, this presumably also improves their restudy selections (Van Loon et al., 2013a).

Learners studied idioms, after which they either responded to reflection prompts, generated sentences, or followed control instructions. Then they provided JOLs, decided which idioms they liked to restudy and which ones they liked to drop from further study, and finally took a test of idiom knowledge.

When making adaptive restudy selections, participants should choose to restudy the idioms for which their test responses will be incorrect (commission and omission errors) and drop the items for which their responses will be correct. We hypothesized that restudy selections would be less adaptive following reflection and control instructions than following sentence generation (Hypothesis 1). Participants were expected to more often decide to restudy idioms for which they would provide commission and omission 
errors following sentence generation than following reflection and control instructions, and less often select idioms for which their responses would be correct.

Furthermore, we aimed to investigate how restudy selections are affected by learners' calibration accuracy. If sentence generation helps learners to accurately monitor their level of understanding of the gist of studied information, the sentence generation task would be hypothesized to reduce overconfidence for omission errors and, especially, commission errors in comparison to reflection and control instructions (Hypothesis 2).

\section{Method}

\section{Partic ipants}

Participants were 72 Dutch $9^{\text {th }}$ grade students ( 44 boys and 28 girls, age $M=14.77, S D=$ 0.59). One participant had to leave the session early; the remaining 71 participants completed the idiom learning task. All participants were in their third year of preuniversity education (the highest level of secondary education in the Netherlands with six year duration). Each participant was assigned randomly to one of three experimental groups. Because not all computers were occupied in each session, this resulted in a slightly different number of participants in each group: Reflection, $n=22$; Sentence generation, $n=26$, Control, $n=23$.

\section{Materials and Design}

The idiom learning task consisted of 5 consecutive subtasks: Study phase; Experimental instructions (reflection, sentence generation, or control); JOL task; Selection for restudy task, and Test. Figure 1 depicts an overview of the materials and the procedure. E-prime software (Schneider, Eschman, \& Zuccolotto, 2002) was used for presentation of stimuli and recording of responses. The order of items in all subtasks was randomized. 


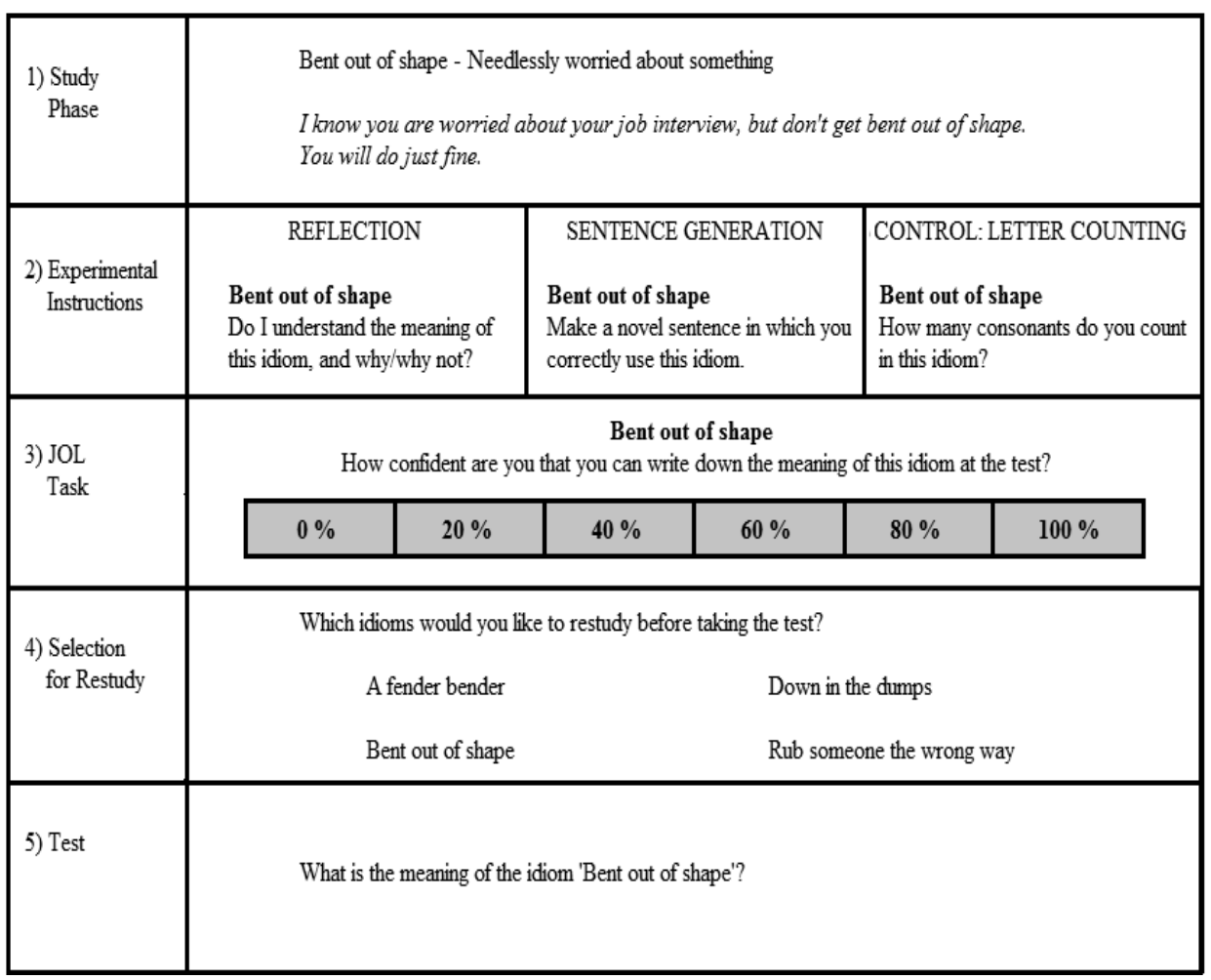

Figure 1. Materials and procedure.

Study phase. Selection of twenty English idioms was based on a small pilot study involving 3 adolescents who did not participate in the experiment. The pilot study indicated that the idioms were unfamiliar to the learners prior to study, and that after study they had on average 10 out of 20 idioms correct at the test $(S D=6.24)$. In the study phase, the 20 idioms, meanings, and example sentences were presented in English. An example of an idiom in the learning task is 'Step on it (idiom) - Hurry up (meaning) - Step on it, the taxi will be here any moment and you're not even dressed (example sentence)'. During idiom study, each of the 20 idioms was presented with its meaning and example sentence. Study was self-paced, the idiom remained on the screen until the participant pressed the F1 key.

Reflection group. Six reflection prompts were used, adapted from research by Berthold et al. (2007) and Chi, De Leeuw, Chiu, and La Vancher, (2004). All prompts were intended to focus participants' attention on their understanding of the studied idioms. The six reflection prompts were: (1) Do I understand this idiom sufficiently to write down its meaning in Dutch, and why? (2) What can I do to better understand the meaning of this idiom? (3) How hard or easy was it to understand this idiom, and why? (4) What 
comes up in my mind when I see this idiom? (5) Do I understand the meaning of this idiom, and why? (6) How much effort did it take to understand this idiom, and why? All prompts were presented in Dutch. In a second pilot study, three adolescents who were not involved in the first pilot study were presented with the reflection prompts; participants were able to provide a response to each prompt.

Participants received an introduction to the prompts before they started with the actual reflection task. It was explained that they would be asked to respond to a reflection prompt when presented with a studied idiom. Each of the six prompts was provided to them with an example response of learners who participated in the pilot study (refer to Appendix A for the example responses that were provided to the learners during the introduction to the prompts).

After this introduction, the task started. Participants were presented with the idioms plus prompts, one by one. Each of the reflection prompts came up three or four times with different idioms; the order of the reflection prompts was randomized. The participants typed their response in a text box below the idiom. When pressing the F1 key, the next idiom and prompt appeared.

Sentence generation group. Participants were instructed that they would be asked to generate novel sentences in which the studied idioms occurred. They were shown the example idiom and a novel sentence in which the idiom was used. After this introduction, the task started. Participants received the idioms one by one, and typed their sentence generation response in the text box below the idiom. When pressing the F1 key, the next idiom appeared with the prompt to generate a novel sentence.

Control group. In the control group, participants were also shown all idioms one by one, but were instructed to count the amount of vowels and consonants in each idiom. This task required learners only to focus on surface features of the idiom. This control condition was used in order to expose participants the same number of times to the idioms as the participants who received reflection and sentence generation instructions. The idiom was presented on the screen, and the participants typed their responses in the text box below the idiom. When pressing the F1 key, the next idiom with the counting prompt appeared.

JOLs. JOLs were provided with a mouse-click on a scale ranging from $0 \%$ ("I am sure I don't know the meaning of the idiom at the test") - 100\% ("I will definitely know the meaning of the idiom at the test"). The scale had 6 points, with increases of $20 \%$ (see Figure 1).

Restudy selections. Participants indicated which idioms they would want to restudy by making mouse-clicks on a grid with a $2 \times 10$ array in which each cell was filled by a previously studied idiom (in line with the design by Thiede \& Dunlosky, 1999). After participants selected the idioms for restudy, they were informed that they could not actually restudy those before taking a test. Their restudy decisions were not honored 
because this would affect recall on the test, which would make it impossible to determine the adaptivity of participants' restudy selections and calibration accuracy of their JOLs.

Test. The test phase showed the previously studied English idioms, with a text box below the idiom in which the participant could type a response. Participants were asked to provide the responses in Dutch. This was presumed to prevent students from superficial processing of the English meaning by copying this. When providing the response in Dutch, students needed to focus on a deeper level of processing than mere literal retrieval of the English meaning of the idiom (Elshout-Mohr \& Van DaalenKapteijns, 2002).

\section{Procedure}

All participants completed the tasks in the computer room at their school; the time needed to complete the tasks was about 50 minutes. There were 3 sessions, with 21 - 27 learners per session, and in each session learners were randomly assigned to one of the three groups.

Participants were informed they had to study English idioms with their meaning and an example sentence, so they would be able to show that they could provide its meaning in Dutch when cued with the idiom at the later test. Before the idiom study phase started, participants were presented with an example of a study trial and an example of a test trial.

When all participants were finished with the experimental task (reflection, sentence generation, or control instructions), the experimenter instructed them about the remainder of the procedure. They were told that they would be asked to provide JOLs, restudy selections, and make a final test. Following these instructions, all participants proceeded with the JOL task, in which they clicked with the mouse on the scale presented below each of the 20 studied idioms.

After providing $20 \mathrm{JOLS}$, participants were required to make restudy selections by clicking with the mouse on idioms they would like to restudy again, 0 to 20 could be selected. After making restudy selections, participants were informed that the test would start.

The test was self-paced and assessed knowledge of the 20 idioms, by asking participants to type the correct meaning in Dutch when provided with the English idiom. After pressing the F1 key, the next idiom appeared. Participants did not receive feedback in any phase of the experiment. 


\section{Scoring}

Test responses. In line with the scoring procedure used by Dunlosky et al. (2005) and Rawson and Dunlosky (2007), test responses on were scored as omission error (0 credit), commission error (0 credit), partially correct ( 0.5 credit), or completely correct ( 1 credit). Understanding of the idiom was emphasized, so if the participant responded with a paraphrase of the original meaning, for example 'make haste' instead of 'hurry up' when cued with 'step on it', this was scored as correct. Partial credit was given if a response expressed one or two but not all of the idea units. Two independent raters scored $20.6 \%$ of all test responses, and inter-rater agreement was high, Kappa $=.83$. Therefore the scores of the first rater were used for the analyses. As the frequency of partially correct responses was low (only 3.8\% of the total amount of responses), we excluded this category from further analyses.

Responses to reflection and sentence generation prompts. Reflection and sentence generation responses were coded to investigate whether specific responses affected restudy selections.

To code the 415 reflection responses, six codes were established: (1) Reflection response unrelated to the idiom; (2) Response related to the meaning of the idiom; (3) Response indicated that the idiom is easy and the learner is confident that he or she will provide a correct test response; (4) Response indicated that the idiom is difficult and that the learner is not confident that he or she will provide a correct test response; (5) Response indicated that extra practice with idiom is needed; (6) No response provided.

To code the 456 sentence generation responses, the following six codes were established: (1) Idiom correctly used in the generated sentence; (2) Idiom not correctly used in the generated sentence; (3) Not clear from the sentence whether the idiom is used correctly; (4) Example sentence from restudy phase used; (5) No generated sentence, instead the meaning of the idiom is reproduced; (6) No response provided.

\section{Analyses}

Analyses present the effects of experimental instructions on restudy selections and calibration accuracy. Because of the hierarchical structure of the data (responses to the idioms were nested under participants), our hypotheses about restudy selections and calibration accuracy were tested with multilevel regression analyses conducted in SPSS 20. In this restudy, the 20 studied idioms (repeated measures) were all measured at the participant level. The predictor Instruction (reflection, sentence generation, control) was used as a fixed factor. To account for differences at the level of the participant, for every participant a random intercept was included. 
Because restudy selections were measured on a binary scale ( 0 = idiom not selected; 1 = idiom selected), a generalized linear model for binary data was used to investigate effects of instructions on restudy selections for incorrect responses (commission and omission errors), and for correct responses. A Wald test with a Chi-square distribution was used for binary multilevel regression analyses, which tests the significance of a Z- statistic of each coefficient $(\beta)$ in the model.

The measure of calibration of the JOLs indicates the level of overconfidence or underconfidence of the participants. For incorrect responses (commission and omission errors), calibration is accurate when the $\mathrm{JOL}$ is $0 \%$, and values higher than $0 \%$ indicate overconfidence. For the correct responses, JOLs of 100\% indicate accurate calibration and lower JOLs indicate that learners were underconfident.

When investigating differences between the effects of instructions, the $B$ coefficients for the reflection and control groups are reported in comparison to $b$ for the sentence generation group. For significant effects, confidence intervals $(\mathrm{Cl})$ are reported as an indication of effect size, and to further investigate differences between the effects of the reflection and the control instructions, we use pairwise comparisons.

\section{Results}

\section{Restudy Selections}

When making adaptive restudy selections, participants should choose to restudy idioms for which their test responses will not receive credit (commission errors and omission errors), and not select idioms for which their responses are correct. The upper part of Table 1 shows the percentages of restudy selections for commission errors, omission errors, and correct responses at the later test. We hypothesized that restudy selections for incorrect test responses (i.e., commission and omission errors) would be less adaptive following reflection and control instructions than following sentence generation (Hypothesis 1). Figure 2 shows the restudy selections for the incorrect responses, the percentage of idioms selected for restudy is presented for omission and commission errors separately. Findings confirm Hypothesis 1, instructions affected selections for incorrect test responses, Wald Chi Square $(2)=32.78, p<.001$. Restudy selections were less adaptive following reflection instructions $(64.94 \%$ selected, $S D=47.81)$ than following sentence generation $(83.40 \%$ selected, $S D=37.28)$, Wald Chi Square $(1)=$ 26.82; $p<.001$ ( $B=1.09 ; S E=.21 ; \mathrm{Wald} \mathrm{Cl}=-1.50$ to -.67$)$. Following control instructions participants selected $80.18 \%(S D=39.95)$ of their incorrect responses for restudy, and this was significantly higher than following reflection, $p<.001(b=-.17$; $S E=.04$; Wald $\mathrm{Cl}$ 
$=-.25$ to -.10). The difference in selected incorrect responses between sentence generation and control instructions was not significant, $p=.370$.

There were no significant differences among experimental instructions on the overall percentage of selected idioms, $F(2,68)=.007, p=.993$. Overall selection of idioms for restudy was $52.50 \%(S D=49.99)$ following reflection, $52.88 \%(S D=49.96)$ following sentence generation, and $53.26 \%(S D=49.95)$ following control instructions, indicating that effects of instructions on restudy selections are not due to overall differences in the number of selected idioms.

Table 1. Restudy Selections, JOL Magnitude, and Test Performance

\begin{tabular}{llll}
\hline & Reflection & Sentence Generation & Control Group \\
\hline Restudy Selections & $61.76(48.79)$ & $80.87(39.51)$ & $64.47(48.18)$ \\
Commission Errors & $68.70(46.58)$ & $85.42(35.42)$ & $88.08(32.15)$ \\
Omission Errors & $34.29(47.60)$ & $19.57(39.75)$ & $26.27(44.11)$ \\
Correct Responses & & & \\
JOL Magnitude & $34.07(30.72)$ & $28.70(30.45)$ & $40.53(31.32)$ \\
Commission Errors & $29.82(28.91)$ & $15.86(20.12)$ & $24.76(24.81)$ \\
Omissions Errors & $82.53(24.58)$ & $81.40(26.25)$ & $83.33(23.20)$ \\
Correct Responses & $31.05(25.87)$ & & $16.56(20.12)$ \\
Test Responses & $26.18(26.35)$ & $22.19(18.74)$ & $32.83(17.44)$ \\
Commission Errors & $39.81(23.70)$ & $28.08(27.32)$ & $47.52(20.94)$ \\
Omissions Errors & $44.54(25.29)$ & \\
Correct Responses & & & \\
\hline
\end{tabular}

Note. Percentage of Idioms Selected for Restudy for Commission Errors, Omission Errors, and Correct Responses, JOL Magnitude and Test Performance. (SD of the Mean in parentheses.) 


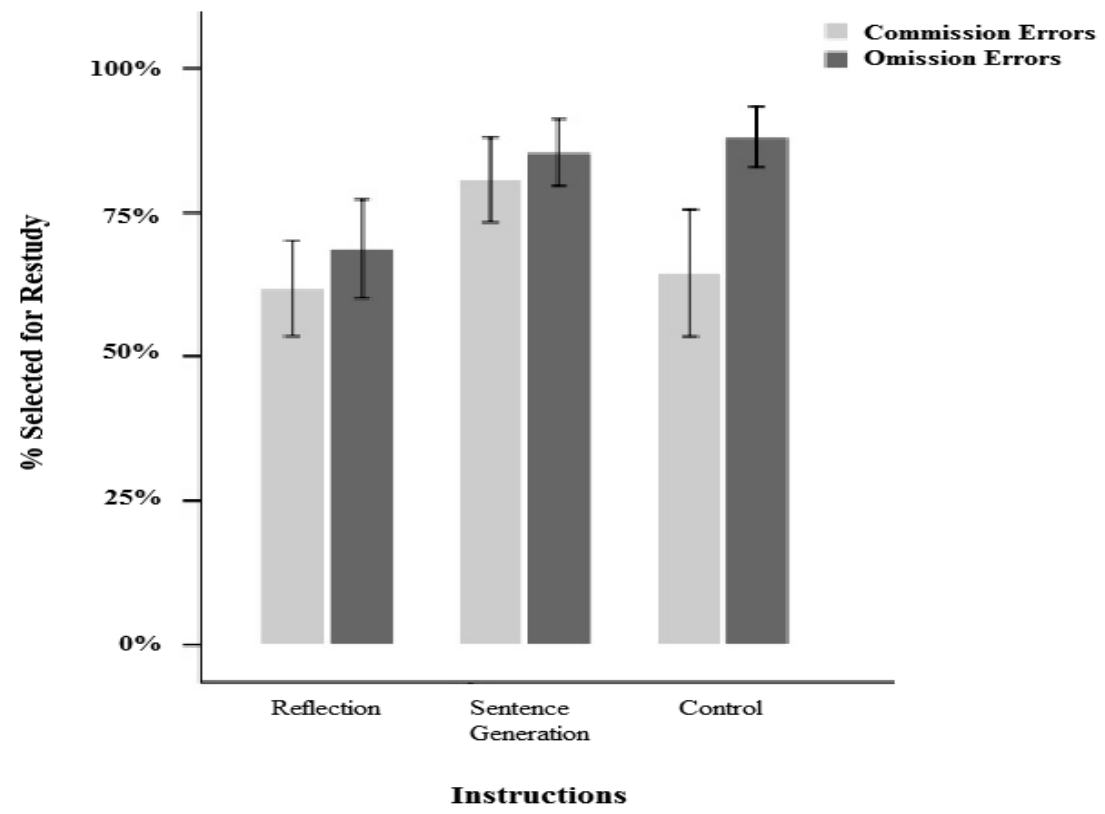

Figure 2. Restudy selections for incorrect responses (commission errors and omission errors) following reflection, sentence generation, and control instructions. Error bars indicate the $95 \%$ confidence interval.

Restudy selections for commission errors. Instructions affected restudy selections for commission errors, Wald Chi Square $(2)=12.10, p=.002$. Figure 2 shows that restudy selections for commission errors were less adaptive following reflection than following sentence generation. The difference between reflection and sentence generation was significant, Wald Chi Square $(1)=11.01 ; p=.001$ ( $B=1.02 ; \mathrm{SE}=.31 ; \mathrm{Wald} \mathrm{Cl}=.41$ to 1.63). Only $61.76 \%(S D=48.77)$ of the commission errors were selected following reflection, whereas $80.87 \%$ (SD $=39.51$ ) of the commission errors were selected following sentence generation. Moreover, Figure 2 shows that following sentence generation, restudy for commission errors was significantly more adaptive than following control instructions (only $64.47 \%$ selected for restudy, $S D=48.18), p=.006(B=.22 ; S E=.08$; Wald $\mathrm{Cl}=.06$ to .38). The difference between reflection and control instructions was not significant ( $p=$ .789).

Restudy selections for omission errors. Instructions affected restudy selections for omission errors, Wald Chi Square $(2)=12.10, p=.001$. Figure 2 shows that learners selected less omission errors for restudy following reflection $(M=68.70 \%, S D=46.58)$ than following sentence generation $(M=85.42 \%, S D=35.42), p=.003(b=8.86$; $S E=.32$; Wald $\mathrm{Cl}=.33$ to 1.58$)$ and control instructions $(M=88.08, S D=32.15), p=.002(B=9.26$; $S E=.33 ; \mathrm{Wald} \mathrm{Cl}=.36$ to 1.68). There was no significant difference between sentence generation and control instructions for restudy of omission errors $(p=.856)$. 
Restudy selections for correct responses. Furthermore, restudy selections for correct responses were affected by instructions, Wald Chi Square $(2)=11.36, p=.003$. Fewer already correct responses were selected for restudy following sentence generation $(M=$ $19.57 \%, S D=39.75)$ than reflection $(M=34.29 \%, S D=47.60), p=.001(B=.-.95 ; S E=.28$; Wald $\mathrm{Cl}=-1.50$ to -.40$)$ and control instructions $(M=26.27 \%, S D=44.11), p=.023$ ( $B=-$ .13; $S E=.06$; Wald $\mathrm{Cl}=-.24$ to -.02$)$. The difference between reflection and control instructions was not significant $(p=.408)$.

\section{Calibration of J OLS}

When judging learning for idioms for which the later test response will be incorrect, JOLs indicate overconfidence when they are higher than 0 . The middle part of Table 1 shows the JOL magnitudes (provided on a scale from 0\%-100\%) for the commission errors, omission errors, and correct responses. Participants were overconfident when providing JOLs for their incorrect responses (i.e., commission errors and omission errors); JOL magnitudes for incorrect responses were highest following reflection instructions $(M=$ $32.15 \%, S D=29.93)$, and lowest following sentence generation $(M=21.53 \%, S D=25.96)$; for the control group, the Mean JOL magnitude for incorrect responses was $30.13 \%$ (SD $=28.15)$. Multilevel analyses showed a near-significant effect of instructions on JOL magnitude, $F(2,64.7)=2.74, p=.072$. Following reflection, overconfidence for incorrect responses was significantly higher than following sentence generation, $p=.023$ ( $B=$ 11.99, $S E=5.13, \mathrm{Cl}=1.74$ to 22.25), confirming Hypothesis 2 . The difference in overconfidence for incorrect responses between sentence generation and control instructions was not significant $(p=.228)$.

Overall Mean JOL magnitudes were $53.47 \%$ ( $S D=37.10)$ for the reflection group, $50.41 \%(S D=39.80)$ for the sentence generation group, and $56.44 \%$ ( $S D=36.98)$ for the control group. There were no significant differences among experimental instructions on Mean JOL magnitudes, $F(2,68)=.59, p=.557$, therefore it seems unlikely that effects of instructions on calibration are caused by effects of the instructions on overall differences in JOL magnitudes.

Calibration for commission errors. Learners were especially overconfident when providing JOLs for the later commission errors. Even though learners would not receive any credit for these incorrect responses, Mean JOLs were 34.07\% (SD = 30.72) following reflection, $28.70 \%(S D=30.45)$ following sentence generation, and $40.53 \%$ (SD $=31.32$ ) following control instructions. Contrary to expectations, the effect of instructions on overconfidence for commission errors was not significant, $F(2,54.05)=.89, p=.415$.

Calibration for omission errors. Instructions significantly affected calibration accuracy for omission errors, $F(2,56.84)=3.72, p=.030$. Learners were more overconfident when judging their learning for the omission errors following reflection 
instructions $(M=29.82 \%, S D=28.91)$ than following Sentence Generation $(M=15.86 \%$, $S D=20.12 ; b=15.0, S E=5.57, C l=3.63$ to 25.96). The difference between the reflection and control instructions $(M=24.76 \%, S D=24.81$ ) was not significant, $p=.338$. Further, sentence generation seems to lead to more accurate calibration for omission errors than control group instructions, this difference was nearly significant, $p=.068, b=9.59$, SE $=$ 5.15, $\mathrm{Cl}=-.72$ to 19.90 .

Calibration for correct responses. When judging learning for idioms for which the later test response will be correct, JOLs indicate underconfidence when they are lower than $100 \%$. There was no significant effect of experimental instructions on calibration for fully correct responses, $F(2,41.76)=.57, p=.571$.

Test performance. The lower part of Table 1 shows the percentages of commission errors, omission errors, and correct responses for the experimental groups. Instructions did not significantly affect the percentage of commission errors, $F(2,68.06)=2.55 ; p=$ .086 , the percentage of omission errors, $F(2,67.96)=.45 ; p=.638$, or the percentage of fully correct responses, $F(2,67.97)=.61, p=.548)$.

Note that, to test the hypotheses, analyses of absolute accuracy are reported. For completeness, analyses of relative accuracy, indicated by the intra-individual gamma correlation between JOLs and test performance (cf. Nelson, 1984), are reported in Appendix B.

\section{Responses to Reflection and Sentence Generation Prompts}

Responses to reflection prompts. Learners who received reflection instructions responded to six different reflection prompts. There was no effect of reflection prompts on restudy selections for incorrect test responses, $F(5,227.12)=.61, p=.659$, thus, the selections for restudy are not likely to be due to the effect of specific reflection prompts.

Learners provided the following responses types when prompted for reflection: (1) Reflection response unrelated to the idiom (12.5\% of the reflection responses); (2) Response related to the meaning of the idiom (5.8\%); (3) Response indicated that the idiom is easy and the learner is confident to provide a correct test response (38.8\%); (4) Response indicated that the idiom is difficult and that the learner is not confident to provide a correct test response (27.2\%); (5) Response indicated that extra practice with idiom is needed (12.8\%); (6) No response provided (2.9\%). There was no significant effect of response type on restudy selections for incorrect test responses following reflection instructions, $F(5,231.09)=.93, p=.462$.

Responses to sentence generation prompts. Learners provided the following response types when prompted to generate a sentence: (1) Idiom correctly used in the generated sentence (34.2\% of the sentence generation responses); (2) Idiom not correctly used in the generated sentence (18.2\%); (3) Not clear from the sentence 
whether the idiom is used correctly (7.5\%); (4) Example sentence from study phase used $(0.7 \%)$; (5) No generated sentence, instead the meaning of the idiom is reproduced (1.5\%); (6) No sentence response provided (37.9\%).

For the idioms for which test responses were incorrect, learners did not provide a sentence for $61.2 \%$ of the idioms, generated an incorrect sentence for $25.1 \%$ of the idioms, generated a good sentence for $6.8 \%$ of the idioms, and for $6.8 \%$ of the sentences it did not become clear whether the idiom was used correctly.

Response type had a significant effect on restudy selections for the incorrect responses, $F(3,215.14)=4.68, p=.003$. Learners selected significantly more incorrect responses for restudy when they did not provide a sentence response ( $M$ restudy selections $=86.6 \%, S D=34.2$ ) than when they generated good sentences ( $M$ restudy selection $=53.3 \%, S D=51.6, p<.001)$. Further, learners selected more incorrect responses for restudy when they generated sentences in which the idiom was not used correctly ( $M$ restudy selection $=81.8 \%, S D=38.9$ ), than when they generated good sentences $(p=.004)$. These findings indicate that learners could distinguish between sentences in which the idiom was and in which the idiom was not used correctly.

\section{Disc ussion}

Restudy selections are maladaptive when learners do not select materials for restudy for which their test responses are incorrect. This study aimed to investigate how selfregulated learning can be improved, by comparing effects of reflection and sentence generation instructions on adolescents' restudy selections when learning idioms. Effects of these instructions were compared to a control group, in which learners were not asked to focus on understanding of studied idioms.

First of all, we expected restudy selections for inaccurate responses to be less adaptive following reflection and control instructions than following sentence generation (Hypothesis 1). Findings partially confirm this hypothesis: Learners more often prematurely dropped idioms that were not yet learned after responding to reflection prompts than after generating sentences. Surprisingly, following reflection, study selections were also less adaptive in comparison to control instructions. This suggests that responding to reflection prompts had negative effects on restudy selections.

When specifically investigating restudy selections for commission errors, these errors were most often selected for restudy following sentence generation instructions; both the reflection and the control group made less adaptive study selections. Generating sentences is presumed to support learners to evaluate whether they understood the gist of studied idioms. Possibly, when learners had incorrect or incomplete information in memory, after generating sentences they could most effectively decide that they did not 
understand the gist, and that this idiom needed further study in order to be understood. Analyses of generated sentences show that learners less often selected idioms for restudy for which generated sentences were correct, this indicates that they could discriminate between incorrect sentences and sentences in which they indicated understanding of the gist of studied information.

Learners who responded to reflection prompts did not only make maladaptive selections for commission errors; restudy selections for omission errors were also least adaptive. The finding that reflection led to more dropping of omission errors than the control group provides a second indication that responding to reflection prompts can be harmful to learning.

Instead of selecting incorrect responses for restudy, following reflection, learners more often decided to restudy idioms for which their test performance was already correct -more so than following sentence generation and control instructions. Even though restudy of items that have already been memorized can be beneficial for longterm memory (Pyc \& Dunlosky, 2010), it is not likely that learning outcomes can become optimal if learners prematurely drop study materials that have not yet been understood. For adaptive self-regulated learning, restudy of omission and commission errors should have been prioritized.

Hypothesis 2 -predicting that learners would be least overconfident for incorrect responses following sentence generation- was only partially confirmed by our data. Learners were overconfident for commission errors, and in contrast to our hypothesis, instructions did not reduce overconfidence for these errors. For omission errors, however, in line with our expectation, overconfidence was lowest following sentence generation, in comparison to both reflection and control instructions. This might imply that sentence generation makes learners aware of their omission errors; difficulties when trying to generate a sentence might have indicated to them that they did not understand the gist of studied information, and that they would not be able to provide a correct test response. The finding that sentence generation improved restudy selections and calibration for omissions, but not calibration for commission errors, implies that study selections are not only driven by monitoring. It is more complex to explain the nature of self-regulated learning, because besides monitoring, several other factors such as planning, motivation, use of learning strategies, and habitual responses affect learners' study selections (Dunlosky \& Ariel, 2011)

Restudy selections were most adaptive following sentence generation, and therefore, incorrect responses and specifically commission errors following sentence generation would seem less harmful for learning, as these are likely to be corrected for restudy. Especially commission errors contribute to maladaptive self-regulated learning (e.g. Dunlosky et al., 2011), our findings show that sentence generation is the most promising instruction to improve study selections for these errors. From our findings, it 
seems likely that learners who reflected would not have restudied idioms that were not yet understood, and instead would have allocated their study time to fully learned materials. Not only did reflection impair restudy selections, reflection also led to overconfidence. It thus seems unlikely that prompting for reflection during idiom learning will improve self-regulated learning and learning outcomes.

Even though the present study shows that reflection had disadvantageous effects on study selections and calibration, we do not aim to state that all types of reflection are detrimental to learning. In the present study, the used reflection prompts gave learners indications about what to reflect on, but might not have supported them with information about how to reflect. Possibly, reflection prompts need to be complemented with external tutor feedback, in order to foster self-regulated learning and improve performance (Butler \& Winne, 1995; Van den Boom, Paas, Van Merriënboer \& Van Gog, 2004; Van den Boom et al., 2007). Findings by Dignath et al. (2008) indicate the need to use additional instructions in combination with reflection prompts. It might be important that learners are explicitly prompted to focus on connections between studied information, contextual information, and prior knowledge, in order to provide them with insight into their actual understanding of the gist of studied information (Michalsky et al., 2009). Berthold et al. (2007) asked students to respond to what they called 'cognitive reflection prompts', which asked them to elaborate on connections. An example of such a prompt is "Which are the main points in your opinion?". They found that, even though cognitive prompts did not improve monitoring, these prompts improved performance. Future research should address effects of the nature of provided reflection prompts.

The present study is the first to demonstrate that sentence generation can improve restudy selections and monitoring accuracy (calibration) for incorrect responses. This extends previous research that demonstrated a beneficial effect of generation tasks in general (e.g., Anderson \& Thiede, 2008; De Bruin et al., 2011; Thiede et al., 2003; 2005) and sentence generation in particular (Van Loon et al., 2013a) on relative monitoring accuracy (i.e. the correlation between JOLs and performance). Because sentence generation is easy to implement, it seems a promising instruction for improving selfregulated learning in educational practice; more so than the commonly used reflection methods. 


\section{References}

Alvermann, D. E. (2002). Effective literacy instruction for adolescents. Journal of Literary Research, 34, 2, 189208.

Anderson, M. C. M., \& Thiede, K. W. (2008). Why do delayed summaries improve metacomprehension accuracy? Acta Psychologica, 128, 110-118.

Baker, J. M. C., \& Dunlosky, J. (2006). Does momentary accessibility influence metacomprehension judgments? The influence of study-judgment lags on accessibility effects. Psychonomic Bulletin \& Review, 13(1), 60-65.

Bannert, M. \& Mengelkamp, C. (2008). Assessment of metacognitive skills by means of instruction to think aloud and reflect when prompted. Does the verbalisation method affect learning? Metacognition \& Learning, 2008, 39-58.

Bannert, M., \& Reimann, P. (2012). Supporting self-regulated hypermedia learning through prompts. Instructional Science, 40, 193-211.

Berthold, K., Nuckles, M., \& Renkl, A. (2007). Do learning protocols support learning strategies and outcomes? The role of cognitive and metacognitive prompts. Learning and Instruction, 17, 564-577.

Bjork, R. A., Dunlosky, J., \& Kornell, N. (2013). Self-regulated learning: Beliefs, techniques, and illusions. Annual review of psychology, 64, 417-444.

Butler, D. L., \& Winne, P. H. (1995). Feedback and self-regulated learning: A theoretical synthesis. Review of Educational Research, 65, 245-281.

Cain, K., \& Towse, A. S. (2008). To Get Hold of the Wrong End of the Stick: Reasons for Poor Idiom Understanding in Children With Reading Comprehension Difficulties. Journal of Speech Language and Hearing Research, 51, 1538-1549.

Chi, M. T. H., De Leeuw, N., Chiu, M. H., \& La Vancher, C. (1994). Eliciting self-explanations improves understanding. Cognitive Science, 18, 439-477.

Davis, E. A. (2003). Prompting middle school science students for productive reflection: Generic and directed prompts. Journal of the Learning Sciences, 12, 91-142.

De Bruin, A. B. H., Thiede, K. W., Camp, G., \& Redford, J. (2011). Generating keywords improves metacomprehension and self-regulation in elementary and middle school children. Journal of Experimental Child Psychology, 109, 294-310.

Dignath, C., Buettner, G., \& Langfeldt, H. P. (2008). How can primary school students learn self-regulated learning strategies most effectively? A meta-analysis on self-regulation training programmes. [Review]. Educational Research Review, 3, 101-129.

Dunlosky, J., Hartwig, M. K., Rawson, K. A., \& Lipko, A. R. (2011). Improving college students' evaluation of text learning using idea-unit standards. Quarterly Journal of Experimental Psychology, 64, 467-484.

Dunlosky, J., \& Rawson, K. A. (2012). Overconfidence produces underachievement: Inaccurate self evaluations undermine students' learning and retention. Learning and Instruction, 22, 271-280.

Dunlosky, J., Rawson, K. A., \& Middleton, E. L. (2005). What constrains the accuracy of metacomprehension judgments? Testing the transfer-appropriate-monitoring and accessibility hypotheses. Journal of Memory and Language, 52, 551-565.

Ertmer, P. A., \& Newby, T. J. (1996). The expert learner: Strategic, self-regulated, and reflective. Instructional Science, 24, 1-24.

Graesser, A. C., Singer, M., \& Trabasso, T. (1994). Constructing inferences during narrative text comprehension. Psychological Review, 101, 371-395.

Grimaldi P. J., \& Karpicke, J. D. (2012). When and why do retrieval attempts enhance subsequent encoding? Memory \& Cognition,40, 505-513.

Hacker, D. J., Bol, L., \& Keener, M. C. (2008). Metacognition in education: A focus on calibration. In J. Dunlosky, \& R. Bjork (Eds.), Handbook of metamemory and memory. Mahwah, NJ: Lawrence Erlbaum Associates.

Kintsch, W. (1998). Comprehension: A paradigm for cognition: Cambridge: University Press. 
Kintsch, W., Welsch, D. M., Schmalhofer, F., \& Zimny, S. (1990). Sentence memory: A theoretical analysis. Journal of Memory and Language, 29, 133-159.

Koriat, A. (1993). How do we know that we know - The accessibility model of the feeling of knowing. Psychological Review, 100, 609-639.

Koriat, A. (1997). Monitoring one's own knowledge during study: A cue-utilization approach to judgments of learning. Journal of Experimental Psychology-General, 126, 349-370.

Langlotz, A. (2006). Idiomatic creativity: A cognitive-linguistic model of idiom-representation and idiom variation. Amsterdam/Philadelphia: John Benjamins.

Levorato, M. C., \& Cacciari, C. (1995). The effects of different tasks on the comprehension and production of idioms in children. Journal of Experimental Child Psychology, 60, 261-283.

Lipko, A. R., Dunlosky, J., Hartwig, M. K., Rawson, K. A., Swan, K., \& Cook, D. (2009). Using standards to improve middle school students' accuracy at evaluating the quality of their recall. Journal of Experimental Psychology: Applied, 15, 307-318.

Lipko, A. R., Dunlosky, J., \& Merriman, W. E. (2009). Persistent overconfidence despite practice: The role of task experience in preschoolers' recall predictions. Journal of Experimental Child Psychology, 103, 152-166.

McCrudden, M. T., Schraw, G., Lehman, S., \& Poliquin, A. (2007). The effect of causal diagrams on text learning. Contemporary Educational Psychology, 32, 367-388.

Metcalfe, J., \& Finn, B. (2008). Evidence that judgments of learning are causally related to study choice. Psychonomic Bulletin \& Review, 15, 174-179.

Michalsky, T., Mevarech, Z. R., \& Haibi, L. (2009). Elementary School Children Reading Scientific Texts: Effects of Metacognitive Instruction. Journal of Educational Research, 102, 363-374.

Nelson, T. O., \& Dunlosky, J. (1991). When people's judgments of learning (JOLs) are extremely accurate at predicting subsequent recall: The "Delayed-JOL effect". Psychological Science, 2, 267-270.

Rawson, K. A., \& Dunlosky, J. (2007). Improving students' self-evaluation of learning for key concepts in textbook materials. European Journal of Cognitive Psychology, 19, 559-579.

Schneider, W., Eschman, A., \& Zuccolotto, A. (2002). E-Prime Reference Guide. Pittsburgh: Psychology Software Tools Inc.

Schooler, J. W. (1998). The distinctions of false and fuzzy memories. Journal of Experimental Child Psychology, 71, 130-143.

Sprenger, S. A., Levelt, W. J. M., \& Kempen, G. (2006). Lexical access during the production of idiomatic phrases. Journal of Memory and Language, 54, 161-184.

Thiede, K. W., \& Anderson, M. C. M. (2003). Summarizing can improve metacomprehension accuracy. Contemporary Educational Psychology, 28, 129-160.

Thiede, K. W., Anderson, M. C. M., \& Therriault, D. (2003). Accuracy of metacognitive monitoring affects learning of texts. Journal of Educational Psychology, 95, 66-73.

Thiede, K. W., \& Dunlosky, J. (1999). Toward a general model of self-regulated study: An analysis of selection of items for study and self-paced study time. Journal of Experimental Psychology: Learning, Memory and Cognition, 25, 1024-1037.

Thiede, K. W., Dunlosky, J., Griffin, T. D., \& Wiley, J. (2005). Understanding the delayed keyword effect on metacomprehension accuracy. Journal of Experimental Psychology: Learning, Memory, and Cognition, 31, 1267-1280.

Thiede, K. W., Griffin, T. D., Wiley, J., \& Anderson, M. C. M. (2010). Poor metacomprehension accuracy as a result of inappropiate cue use. Discourse Processes, 47, 331-362.

Van den Boom, G., Paas, F., \& Van Merriënboer, J. J. G. (2007). Effects of elicited reflections combined with tutor or peer feedback on self-regulated learning and learning outcomes. Learning \& Instruction, 17, 532 $-548$.

Van den Boom, G., Paas, F., Van Merriënboer, J. J. G., \& Van Gog, T. (2004). Reflection prompts and tutor feedback in a web-based learning environment: Effects on students' self-regulated learning competence. Computers in Human Behavior, 20, 551-567. 
Van Loon, M. H., De Bruin, A. B. H., Van Gog, T., \& Van Merriënboer, J. J. G. (2013a). The effect of delayed-JOLs and sentence generation on children's monitoring accuracy and regulation of idiom study. Metacognition and Learning, 8, 173-191.

Van Loon, M. H., De Bruin, A. B. H., Van Gog, T., \& Van Merriënboer, J. J. G. (2013b). Activation of inaccurate prior knowledge affects primary-school students' metacognitive judgments and calibration. Learning and Instruction, 24, 15-25.

Von der Linden, N., Schneider, W., \& Roebers, C. (2011). The effects of summary production and encoding condition on children's metacognitive monitoring. Metacognition \& Learning, 6, 3-23.

Wilson, T., Perry, M., Anderson, C. J., \& Grosshandler, D. (2012). Engaging young students in scientific investigations: prompting for meaningful reflection. Instructional Science, 40(1), 19-46. 


\section{Appendix A. Reflection Prompts and Example Responses}

Prompt 1: Do I understand this idiom sufficiently to write down its meaning in Dutch, and why?

Example response: Yes, I do understand this meaning very well, because I have seen this idiom in a game that I play.

Prompt 2: What can I do to better understand the meaning of this idiom?

Example response: I could use a dictionary when studying the example sentence, in order to better understand the idiom.

Prompt 3: How hard or easy was it to understand this idiom, and why?

Example response: It was not very hard to understand the idiom, I didn't know what the word 'beat' means, but I understood it when reading the example sentence.

Prompt 4: What comes to my mind when I see the idiom?

Example response: The meaning of the idiom comes to mind because it followed logically from the idiom.

Prompt 5: Do I understand the meaning of this idiom, and why?

Example response: No, I did not understand the meaning because the meaning was not similar to the Dutch language.

Prompt 6: How much effort did it take to understand this idiom, and why?

Example response: It took more effort than most of the other idioms, I did not really understand the idiom so I studied the example sentence for a long time. 


\section{Appendix B. Analyses of Relative Accuracy}

The described analyses in this study investigated how instructions affected participants' restudy selections and overconfidence for incorrect responses. These were measures of absolute accuracy. For completeness, below data on relative accuracy of the JOLs, and the relation between JOLs and restudy selections are presented. Conform Nelson (1984), relative accuracy is measured with intra-individual gamma correlations between JOLs and test performance. A gamma correlation close to +1 demonstrates high JOL accuracy. Given the delayed-JOL procedure, it would be expected that relative accuracy would be high (Nelson \& Dunlosky, 1991; Van Loon et al., 2013a). An ANOVA with instructions as fixed factor (sentence generation, reflection, control group), and relative JOL accuracy as dependent variable, shows that that instructions did not affect JOL accuracy, $F(2,63)=$ $.008, p=.679$. Mean gamma correlations were $.86(S D=.16)$ for the sentence generation group; 83 (SD = .15) for the reflection group; and .87 (SD = .14) for the control group.

Furthermore, there was a strong relation between the JOLs and the restudy selections, the gamma correlation between JOLs and selections was -.93 (SD = .11) for the sentence generation group, -.92 (SD = .13) for the reflection group, and -.93 (.10) for the control group. An ANOVA did not show a significant effect of instructions on the relation between JOLs and restudy selections, $F(2,56)=.070, p=.933$. 


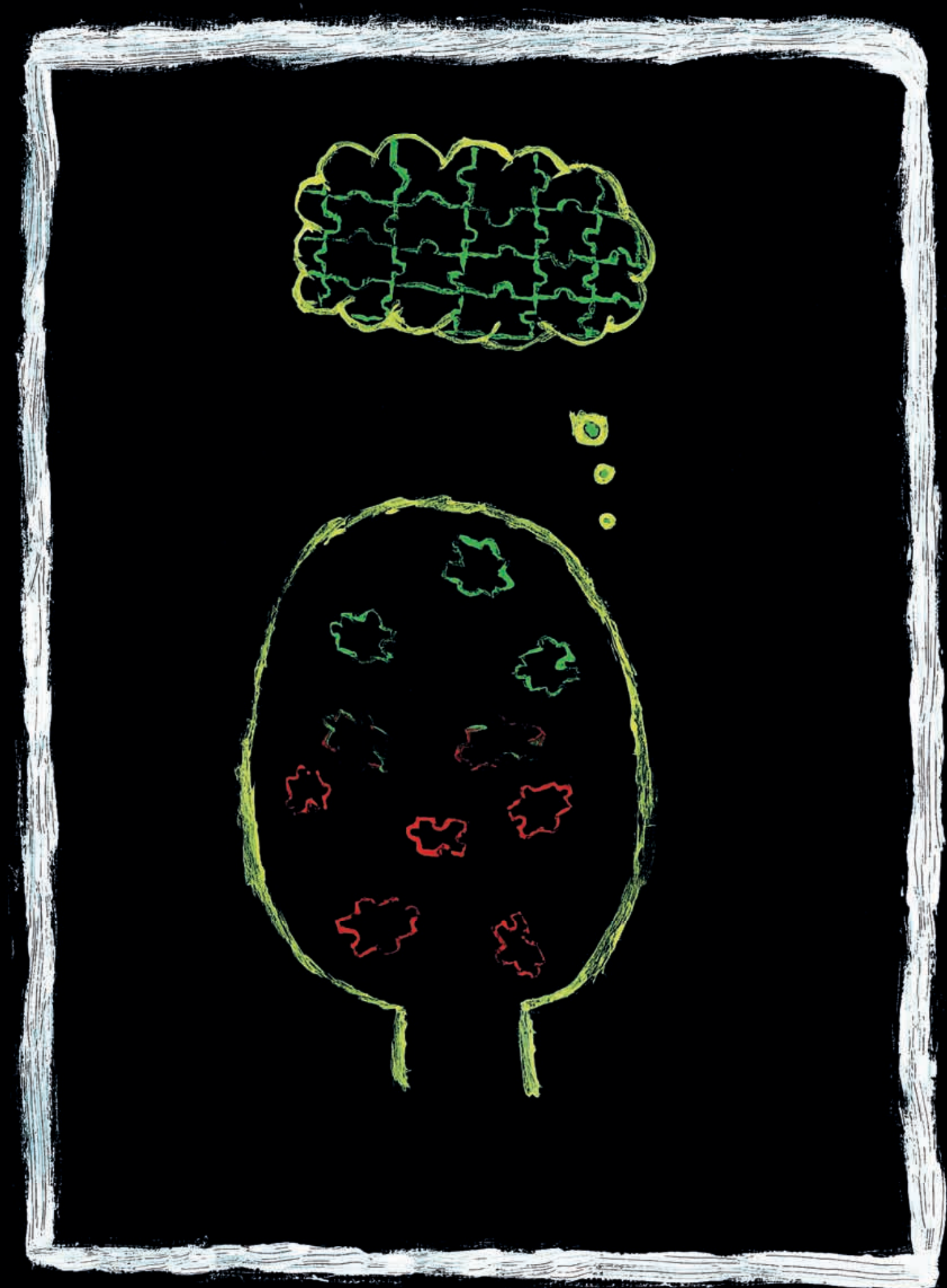




\title{
CHAPTER 4
}

\section{Can Students Accurately Evaluate Their Understanding of Cause-and- Effect Relations? The Effects of Diagram Completion on Monitoring Accuracy}

\begin{abstract}
For effective study of science texts, it is crucial that learners can accurately monitor their understanding of cause-and-effect relations. Because monitoring accuracy tends to be inaccurate, this study aimed to improve monitoring accuracy using a diagram completion task. Participants read six texts, judged their learning, selected texts for restudy, and were tested for comprehension. Three groups were compared, in which learners either completed causal diagrams immediately after reading, completed them after a delay, or received no-diagram control instructions. Judgment accuracy was higher for learning of causal relations following diagram completion than no-diagram completion. Judgment accuracy was also higher following delayed rather than immediate diagram completion. Moreover, completing diagrams focused learners specifically on their learning of causal relations, given that diagram completion did not improve monitoring accuracy for learning of factual information. Fine-grained analyses also showed that, when completing delayed diagrams, learners based judgments on diagnostic cues that indicated actual understanding of connections between events in the text. Most important, completing causal diagrams sometime after reading can improve students ability to judge their learning of cause-and-effect relations.
\end{abstract}

This chapter is submitted as: Van Loon, M. H., De Bruin, A. B. H., Van Gog, T., Van Merriënboer, J. J. G., \& Dunlosky, J. Can students accurately evaluate their understanding of cause-and-effect relations? The effect of diagram completion on monitoring accuracy. Manuscript submitted for publication. 


\section{Can Students Accurately Eva lua te Their Understanding of Cause-and-Effect Relations? The Effects of Diagram Completion on Monitoring Accuracy}

The ability to read and comprehend expository texts is crucial for adolescents' school progress and future careers (Otero, Leon, \& Graesser, 2002). Integral to the process of text comprehension is one's ability to evaluate whether the information that is read has been understood and can be recalled later on. When learners evaluate their level of text understanding, this process is referred to as monitoring (Nelson \& Narens, 1990). Based on the output from monitoring, students decide how well they have achieved their learning goals, and then regulate their learning by further reading passages or dropping them from study (De Bruin \& Van Gog, 2012; Koriat, 2012). Readers who can accurately monitor their current level of understanding are able to learn more from textual information (Dunlosky \& Rawson, 2012; Thiede, Anderson, \& Therriault, 2003), presumably because they can strategically decide which passages are not well learned and need further study (Son \& Metcalfe, 2000; Thiede et al., 2003). Some interventions have been identified that can improve monitoring accuracy when learning from texts, such as generating keywords (Thiede, Anderson, \& Therriault, 2003), summaries (Thiede \& Anderson, 2003), or sentences (Van Loon, De Bruin, Van Gog, \& Van Merriënboer, 2013). However, very little is known about how to improve monitoring accuracy when reading texts containing causal relations, such as science texts.

The main goal of the current study is to improve the accuracy of adolescents' monitoring judgments when reading expository science texts. More specifically, we investigated the effects of a diagram completion task on improving students' ability to evaluate their comprehension of cause-and-effect relations. To motivate our study, we first briefly discuss students' difficulties in evaluating their comprehension of text and how it can be improved. Based on theory of text comprehension, we then argue that supplementing science texts with to-be-completed diagrams will help students more accurately evaluate their comprehension. Finally, we discuss the importance of having students make delayed evaluations, and we then summarize our theoretical predictions.

\section{Monitoring Accuracy}

Readers' monitoring of their text comprehension is often inaccurate, as demonstrated, for instance, by De Bruin, Thiede, Camp, and Redford (2011). They asked participants to read a set of texts. After reading, participants made judgments of learning (JOLs), namely, for each of the texts, participants predicted how well they would do on the future comprehension test. Monitoring accuracy, which was operationalized as the correlation 
between JOLs and test performance (Nelson, 1984), was not significantly higher than zero. This outcome indicates that readers were unable to monitor their text comprehension. Unfortunately, this low level of monitoring accuracy is commonly reported throughout the literature. In their review of research over the past two decades, Thiede, Griffin, Wiley, and Redford (2009) reported that the average correlation across 57 studies was only 27 (see also Dunlosky \& Lipko, 2007; Maki, 1998).

Despite this poor monitoring accuracy, research on text comprehension suggests that it can be improved if readers are encouraged to evaluate the gist of what they are reading (Anderson \& Thiede, 2008; De Bruin et al., 2011). Knowledge about text can be represented at different levels (Graesser, Singer, \& Trabasso, 1994; Kintsch, 1998; Van den Broek, Rapp, \& Kendeou, 2005). When students have to study factual information, such as the year an event took place when studying a history text, they need to focus on memorizing textbase information. For complete comprehension, learners must go beyond textbase processing and establish a coherent representation of the gist of the text, which is called a situation model (Kintsch, 1998). To achieve this level of gist comprehension, learners need to generate inferences by connecting relations between elements presented in the text. Thus, to improve accuracy, learners need to base their JOLs on cues that arise from processing information about the gist of a text (for a detailed discussion, see Rawson, Dunlosky, \& Thiede, 2000), such as processing the steps in a causal chain that is laid out across the text. Doing so should provide them with cues that are more diagnostic of their subsequent comprehension test performance; hence, using these diagnostic cues to predict future performance should lead to higher levels of monitoring accuracy (e.g., Brunswik, 1956; Koriat, 1997).

\section{Improving Monitoring Accuracy when Leaming Causal Relations}

With respect to science texts, gist comprehension depends to a large extent on a reader's ability to connect and understand the cause-and-effect relations in the text (Graesser et al., 1994). Some science textbooks support comprehension by depicting cause-and-effect relations with causal diagrams, wherein events presented in the text are connected with arrows (Cromley, Bergey, Fitzhugh, Newcombe, Wills, Shipley, \& Tanaka, 2013; Cromley, Snyder-Hogan, \& Luciw-Dubas, 2010; McCrudden, Magliano, \& Schraw, 2011; McCrudden, Schraw, Lehman, \& Poliquin, 2007). When learners actively generated causal diagrams, their understanding improved for inferences and causal relations in the science texts, in comparison to when they were asked to re-read or summarize the text (Gobert \& Clement, 1999). 
In the present study, we presume that the use of causal diagrams might also be a promising instructional strategy to improve monitoring accuracy for learning of causal relations in text. To help learners focus on their comprehension of these relations, we developed a diagram completion task in which readers attempt to depict the steps in a causal chain presented in the text (see Figure 1). To support learners with this task, the structure of the causal diagram was presented to them, and they were instructed to complete the diagram by filling out the empty text boxes. When completing the diagram about a studied text, the learner must identify the steps presented in the text and infer the relations between these steps. The diagram completion task encourages learners to focus on their understanding of the gist by identifying whether they can make connections between events presented in the text. More generally, this theoretical claim is based on cue-utilization framework (e.g., Koriat, 1997) which states that to monitor their learning, people use cues that are accessed prior to making a judgment, so that the accuracy of the judgments will be determined by how well those cues predict criterion test performance (called cue diagnosticity, which is described further below). In the present context, completing the diagrams is expected to provide diagnostic cues about whether readers have understood the cause-and-effect relations within the text and hence should boost the accuracy of their monitoring judgments. Put differently, diagram completion can focus learners' attention on cues that are diagnostic of future test performance by indicating whether or not they are able to connect the events that were presented in the text.

Prior research suggests, however, that any benefits of using diagrams to improve monitoring accuracy might be most beneficial when learners complete the diagrams some time after studying a text than immediately after studying it. For instance, Thiede and Anderson (2003) showed that JOL accuracy could be improved with the use of generative self-tests, such as summary or keyword generation. These tasks presumably focus readers' attention on diagnostic cues related to their comprehension of the gist of texts. When diagnostic cues are used to inform learners' JOLs, they can support more accurate monitoring judgments (Thiede \& Anderson, 2003; Redford, Thiede, Wiley, \& Griffin, 2012). Despite the improvements in monitoring accuracy, these generation tasks only had beneficial effects on monitoring when both tasks and JOLs were made after a delay, indicating the importance of the timing of the generation tasks. When performing a generative self-test immediately after study, learners can still access the textbase level, including the factual information they just read in the text. However, memory for these literal details decays more rapidly than memory for gist (Kintsch, Welsch, Schmalhofer, \& Zimny, 1990; Anderson \& Thiede, 2008). Because learners still have the textbase level available when performing a generative self-test immediately after study, this task does not inform them about their long-term memory for the gist of the text. By contrast, when learners perform a generation task after a short delay, typically only a few minutes after 
reading, they may be better able to access the gist representation of the text from their long-term memory (Thiede, Dunlosky, Griffin, \& Wiley, 2005). Therefore, delaying the generation and the judgment tasks provides learners with better diagnostic cues about their understanding of the text, and using these cues improves monitoring accuracy (Thiede et al., 2009). Based on this evidence, we presume that the timing of the diagram completion task is an important factor when aiming to improve monitoring accuracy, so that accuracy will be better when learners complete the diagrams some time after reading a text than immediately after reading it.

\section{Present Study}

Even though readers often have difficulties understanding relations between events presented in science texts (Graesser et al., 2003), metacognition research has not yet specifically focused on interventions that can improve monitoring accuracy when readers study cause-and-effect relations. Thus, we aimed to investigate the effects of asking learners to complete causal diagrams. Three groups were compared; one group completed diagrams immediately after reading texts; one group completed these after a short delay, and a no-diagram group that did not complete diagrams (but just made delayed judgments) was also included. All participants made two judgments for each text: One in which they predicted how well they would perform on a test about causal relations, and one in which they predicted how well they would perform on a test about factual information. Note that for all groups, the JOLs were made at a delay after reading the texts. We hypothesize that (a) monitoring accuracy for learning of causal relations will be greater when participants complete diagrams than when they do not (Hypothesis 1); (b) monitoring accuracy for learning of causal relations will be greater when diagrams are completed after a delay than immediately after reading (Hypothesis 2 ), and (c) there will be no differences across groups in monitoring accuracy for learning of factual information, because the diagram completion task is expected to focus learners explicitly on their learning of causal relations rather than factual information (Hypothesis 3). Given that these are a priori hypotheses based on theory and prior findings, we evaluated these predictions using planned comparisons.

Learners may use a variety of cues when monitoring their learning; for instance, they may judge that they understand one text better than another because they could generate more relations for one text than another. To assess a person's cue utilization, the cue is correlated with his or her judgments across the texts. As introduced above, learners' judgments will be accurate to the degree that the cues they use to make the judgments are indicative of actual learning, which is referred to as cue diagnosticity (Brunswik, 1956). Analogous to assessing cue diagnosticity, cue utilization is measured 
using a within-participant correlation between the cue and test performance. In this example, the cue of generating relations (where more are generated for some texts than other texts) would be diagnostic if it positively correlated with test performance across texts. Based on this framework, the current experimental design allows us to explore why diagrams improve monitoring accuracy, because the quality of learners' diagrams can be scored and used to estimate the diagnosticity of available cues (Question 1a). For instance, if the number of correctly completed causal relations for each diagram (a cue) correlates highly with future test performance, this cue would be considered highly diagnostic (Brunswik, 1956). We can also evaluate utilization of these cues by investigating the degree to which learners' monitoring judgments are related to this diagnostic cue and hence can benefit from it (Question 1b). In summary, to isolate the causes of judgment accuracy, we also estimated the diagnosticity and utilization of a variety of cues that arise from diagram completion.

Finally, although our primary goal was to evaluate whether delayed diagrams would improve monitoring accuracy, accurate JOLs can improve comprehension only if a learner is given the opportunity to use monitoring (Thiede, 1999). When readers identify which information they have not yet correctly understood, doing so can guide them to select materials that need further study. JOLs are related to restudy selections (for reviews, see Dunlosky \& Ariel, 2011; Son \& Metcalfe, 2000), and hence inaccurate monitoring is a serious problem for learning, because if learners cannot accurately judge their level of comprehension, they cannot effectively decide which texts need further study. Therefore, a secondary goal of this study was to explore how readers used their judgments to make decisions about restudying. In particular, we expected a strong relation between JOLs and restudy selections for all three groups, indicating that regardless of judgment accuracy, regulation of study is based on people's judgments of how well they have learned the texts (Hypothesis 4).

\section{Method}

\section{Partic ipants}

Participants were 123 adolescents (Mean age $=14.78, S D=.67$, range $14-16$ years) from the ninth grade of a secondary school in the south of The Netherlands. All participants followed secondary education in one of the two programs that lead to higher education: Seventy-three were in the third year of pre-university secondary education level (VWO; 6 year duration, highest level of secondary education), and 50 were in the third year of higher general secondary education level (HAVO; 5 year duration, middle level of secondary education). All participants were native Dutch speakers. Each participant was 
assigned randomly to one of three groups in a computer classroom. Because not all computers were occupied in each session, this resulted in a slightly different number of participants in each group: Immediate diagram completion, $n=40$; delayed diagram completion, $n=44$; no-diagram group, $n=39$.

\section{Materia ls and Design}

The experiment included five phases: text study, experimental task, JOLs, restudy selections, and test. The only difference between the three groups was the experimental task.

Pre-reading instructions. Before the experimental task started, the experimenter provided all participants with pre-reading instructions, to get accustomed to the types of texts, the distinction between causal relations and factual information, the JOLs, and the test format. Participants were asked to read two example texts: "The Heart" and " Suburbs". To explain the difference between causal relations and factual information, after reading the example texts, they were provided with two examples of test questions about causal relations and two examples of test questions about factual information. Then, they were shown that the causal relations between the events in the text could be visualized by drawing a diagram. They were explained that causal events could occur in a serial manner, meaning that these follow each other in time, or that events can occur simultaneously (refer to Figure 1 for examples of serial and simultaneous relations).

Then participants were presented with two blank diagrams on a flip-over, one example diagram for the text "The heart" (containing only serial relations), and one diagram text: "Suburbs" (containing both serial and simultaneous relations). The experimenter and the participants jointly completed the two diagrams, the experimenter ensured that everyone understood how to complete diagrams about cause-and-effect relations.

Text study. To select texts, a pilot study with 20 texts was conducted. Forty-one ninth-grade students read five texts, completed diagrams, provided JOLs and took a test. Based on this pilot study, six science texts were selected for the experimental task. The pilot study established that the texts had a sufficient level of difficulty, because none of the participants exhibited ceiling or floor effects. Causal relations can occur both in a serial and a simultaneous format (see Appendix 1 and Figure 1 for an example of a text and a diagram containing serial relations and a text and a diagram containing both serial and simultaneous relations). To have some variety in the type of causal events in the texts, the texts were selected so that three of those contained only serial causal relations, and three texts contained both serial and simultaneous relations. These two text types had a comparable level of difficulty; the pilot study showed that there were no differences between the two text types in the number of completed diagram boxes $(M=$ 
$3.47, S D=.16$ for texts with serial relations vs. $M=3.13, S D=.18$ for texts with serial and simultaneous relations, $p=.182$ ) and the number of correct causal relations described at the test $(M=1.73, S D=.20$ for texts with serial relations vs. $M=1.53, S D=.16$ for texts with serial and simultaneous relations). Topics of the selected texts were: "Botox", "Sinking of metro cars", "Concrete constructions", "Money does not bring happiness", "The Suez Canal", and "Music makes smart" (See Appendix A for examples of the texts). Texts were written so that they comprised five clauses to convey causal relations. All texts were presented in a single-paragraph format.
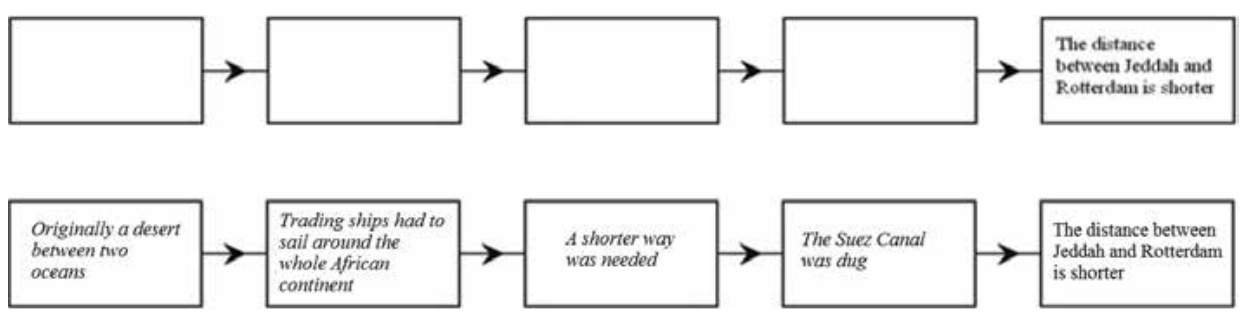

Figure 1a. An empty and a correctly completed diagram for the text 'Suez Canal'.
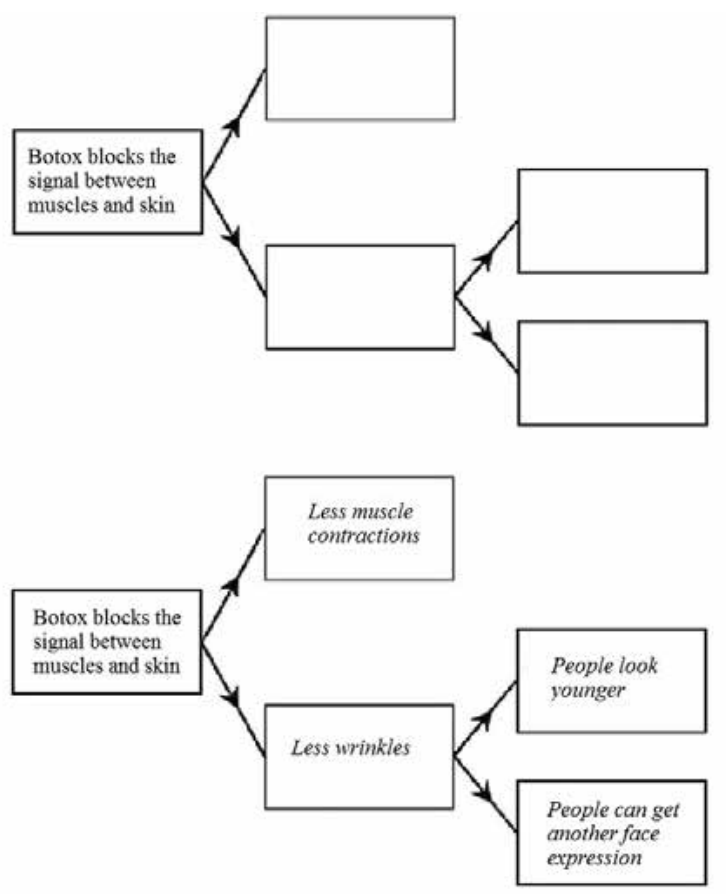

Figure 1b. An empty and a correctly completed diagram for the text 'Botox'. 
Experimental task. When logging-in, participants were randomly assigned, by using the log-in number, to one of three experimental groups: 1) Immediate diagram; 2) Delayed diagram; 3) No-diagram group. In the two diagram completion groups, participants were provided with a diagram on the screen. Each diagram contained five text boxes which were connected with arrows. One of the text boxes was already filled; participants were instructed to complete the diagram by typing a response in the other four text boxes. Participants could only continue to the next screen if they had typed a response in all four of the text boxes.

In the immediate diagram group, participants completed a diagram immediately after reading each text. When they pressed the 'continue' button after reading the text, the following screen was a diagram for that text. In the delayed diagram group, participants first read all six texts and then completed the six diagrams for these texts (see Thiede et al., 2003, for the same procedure used with the keyword generation strategy).

In the no-diagram group, participants read all six texts and were then presented with a picture-matching task for which they had to match two pictures related to the topics of the read texts. Participants had to provide a response about the four differences between the pictures, by typing their response in the four text boxes below the pictures. To present participants in the no-diagram group with the same information as the participants in the two diagram completion groups, above the pictures, they were provided with the same statement that was presented in the filled-out text box in the diagram completion groups.

JOLs. For each text, participants provided two JOLs: One for their learning of causal relations, and one for their learning of factual information. When making JOLs, participants saw the title of the text on the screen, accompanied by two questions. The first JOL question was: How many questions do you expect to complete correctly when tested for understanding of causal relations in this text? The second JOL question was: How many questions do you expect to complete correctly when tested for factual information about this text? The JOLs were provided with a mouse-click on a 6-point scale ranging from $0 \%-100 \%$ (points on the scale matched $0 \%, 20 \%, 40 \%, 60 \%, 80 \%$, and $100 \%$ ). Note that these JOLs are delayed after study and diagram completion, we decided to not include immediate judgments because they typically show poor accuracy (Nelson \& Dunlosky, 1991; Van Loon et al., 2013).

Restudy selections. Participants indicated which texts they would want to restudy by clicking on a grid with a $3 \times 2$ array in which each cell was filled by a title of a previously studied text (in line with the design by Thiede \& Dunlosky, 1999). Note, however, that learners did not actually restudy any of the texts, because restudying the texts after judgments were made could inadvertently influence monitoring accuracy (Kimball \& Metcalfe, 2003), which is the focus of the present research. 
Test. The test consisted of six questions about causal relations (one for each text), and 30 questions about factual information (five per text). One causal relation question was always followed by five factual information questions on a text. The questions about facts required short answers. Examples of questions about causal relations and factual information are provided in Appendix B.

All tasks were presented in Dutch, and the order of the six text topics was randomized anew in each phase. Note that in the immediate-diagram phase, the order of the text study was randomized, but the experimental diagram completion task had the same topic as the text that was previously read. Presentation of all materials was selfpaced.

\section{Procedure}

Participants were tested in a computer room in their school. The number of participants per session ranged from 22 to 28 . They completed the task in one session lasting for approximately one hour. Before the study task started, participants received the prereading instructions. They were told that they would study six texts for a later test with questions on factual information and causal relations. Before study, they were presented with the two example texts, example test questions (about causal relations and factual information), and example diagrams. Then participants were told that they would be asked to judge their learning by predicting future test performance, and they were provided with an example of the JOL scale for causal relations and the JOL scale for questions about factual information.

Following these classroom instructions, participants used the log-on information presented on a sheet of paper next to their computer to start the text study task. They were not provided with feedback on their responses in any of the phases of the experiment. After studying each text, they pressed a key, and the page was removed and replaced by the next page. In the immediate diagram group, participants completed a diagram about each text immediately after reading. In the delayed diagram group, participants read all six texts and then completed all six diagrams. The no-diagram group read all six texts and then completed the picture-matching task. In all groups, participants typed in their answers before being presented with the next page. They were instructed to type a "?" in a text box when they were not able to come up with a response.

For all participants, all JOLs occurred after a delay, i.e., JOLs were made after reading the texts and performing the experimental task. When providing JOLs, separate judgments were provided for each text. After selecting texts for restudy, participants received the instruction on the screen that they would not actually get to restudy those texts. When taking the test, participants were shown the title of the texts, accompanied 
by the questions. All test questions were answered by typing in the answers on the computer.

\section{Scoring of Responses}

Test performance. Responses on the questions about causal relations were scored as per McCrudden, Magliano, and Schraw (2011). Scores on these questions ranged from 0 - 4; the score refers to the amount of correctly stated causal relations. Comprehension was emphasized; therefore, responses were also scored as correct when participants did not respond with what was literally stated in the text but instead responded with a response indicating that they understood what was implied or meant with the original text, i.e., a response indicating gist understanding. For example, the following test response about the text on Botox was scored as containing two correct relations: "The muscles in the skin relax (correct relation) because something is injected, that's why some facial expressions are not visible anymore (correct relation)". Two independent raters scored $25.1 \%$ (a total of 185) of all test responses on questions about causal relations (responses were scored using an ordinal scale, inter-rater agreement was high, Gamma $=.89$ ).

Responses on the questions about factual information were scored as omission, commission error, partially correct, or completely correct. For example, when a question asked a participant to provide the complete name of Botox (which is botulinium toxin), and the answer contained one of the words botulinium or toxin (but not both), the answer was scored as partially correct; when a participant would provide the response botoxicum, this answer was scored as a commission error. Two raters scored 17.5 \% (a total of 654) responses on questions about factual information and agreement was high (responses were scored using a nominal scale, Kappa $=.96$ ).

Diagram completion task. The responses in the 4 filled-out text boxes in the completed diagrams were scored as correct (a step in the causal chain is provided); commission error (the provided response did not come from the text); factual information (the response refers to a detail from the text, but not to a step in the causal chain); or omission (no response provided).

For instance, when a person only typed "Indian Ocean" in a text box of the diagram about the Suez Canal, this response was scored as factual information, because the response contains a detail from the text but not the correct step in the causal chain. Two raters independently coded $13.6 \%$ of the diagrams (a total of 400 text box responses) and inter-rater agreement was high (Kappa $=.80)$. 


\section{Analyses}

As in prior research on metacomprehension (Thiede et al., 2009), our focus was on relative accuracy. Relative accuracy is the degree to which the judgments discriminate between the different level of performance on the criterion test for one text relative to another. ${ }^{1}$ We used the gamma correlation to measure relative accuracy (Nelson, 1984), because this non-parametric statistic has been considered one of the most appropriate measures of relative accuracy (Nelson, 1984), and it has been reported in prior research on the effects of generation tasks on judgment accuracy (e.g., Thiede et al., 2003; Thiede et al., 2005). The value of gamma indicates the strength of the association between JOLs and test performance; the values range from -1 (indicating a perfect negative association) to +1 (indicating a perfect positive association). A value of zero indicates that there is no association between JOLs and performance.

To assess monitoring accuracy for causal relations, intra-individual gamma correlations were calculated between participants' JOLs and their actual test scores for causal relations. Due to invariance in monitoring judgments or test performance, we could not calculate gamma correlations for 12 participants. To assess monitoring accuracy for factual information, intra-individual gamma correlations were calculated between JOLs for learning of factual information and test scores for questions about factual information. Due to invariance in JOLs or test scores, we could not calculate monitoring accuracy gammas for learning of factual information for 14 participants.

For regulation of study, the intra-individual gamma correlation between JOLs for causal relations and whether a text was selected for restudy (yes $=1$, no $=0$ ) was calculated, as operationalized by Thiede et al. (2003). A correlation below 0 (i.e., negative) between JOLs and restudy indicates that previous JOLs are translated into the selection of less-well-known texts for restudy.

To obtain insight into cue diagnosticity, we investigated whether learners' responses in the diagram text boxes were related to later test performance on questions about causal relations. As previously mentioned, responses in the diagram text boxes were scored as correct response, omission, commission error, or response containing only factual information but no causal relations from the text. Intra-individual gamma correlations were calculated between the number of such responses (individually for different types of responses) per diagram and the number of correct relations that were provided at the later test. A correlation involving a given response type (i.e., cue) that is

\footnotetext{
${ }^{1}$ In contrast to relative accuracy, absolute accuracy refers to the degree to which the absolute level of the judgments match the level of test performance. The hypotheses evaluated here make predictions about relative accuracy. For completeness, analyses of absolute accuracy are reported in Appendix C.
} 
greater than 0 would indicate that the cue is diagnostic, with increasingly higher values (closer to +1.0) indicating greater diagnosticity.

Cue utilization was estimated by computing the relation between learners' JOLs and the number of the response types provided during diagram completion. We calculated intra-individual gamma correlations between the number of the response types in the diagrams about each text and JOLs about learning of causal relations for each text. A correlation involving a particular response type (i.e., cue) that is greater than 0 indicates would suggest the cue is used for making JOLs, with increasingly higher correlations (closer to +1.0 ) indicating greater utilization.

\section{Results}

\section{Monitoring Accuracy}

Figure 2 depicts the effect of diagram-completion task on monitoring accuracy for learning of causal relations and factual information. The figure shows that for causal relations, monitoring accuracy is higher for the immediate diagram condition and, especially, for the delayed diagram condition than for the no-diagram condition. For factual information, this pattern is not evident.

Because we had a priori predictions about how diagrams would influence monitoring accuracy for learning of causal relations, planned comparisons were conducted to evaluate these effects, which is the preferred method for focusing inferential statistics on hypotheses of interest while maximizing statistical power (for a rationale, see Judd \& McLelland, 1989; Rosnow, Rosenthal, \& Rubin, 2000). For significant effects, Cohen's $d$ is presented as a measure of effect size.

To evaluate Hypothesis 1 that diagram completion would lead to more accurate monitoring, the accuracy of causal JOLs for the two diagram groups $(M=.43, S D=.61)$ was compared against the no-diagram group $(M=.07, S D=.73)$. The planned comparison indicated that monitoring accuracy was higher when learners completed diagrams than when they did not, $t(109)=2.67, p=.005$, Cohen's $d=.55$. Concerning Hypothesis 2 , monitoring accuracy was also greater when diagrams were completed after a delay $(M=$ $.56, S D=.57)$ than immediately after study $(M=.28, S D=.62), t(75)=2.04, p=.023$, Cohen's $d=.60$.

ANOVAs were used to analyze whether diagram completion affected monitoring accuracy for learning of factual information. In this case, the particular task did not affect monitoring accuracy for learning of factual information, $F(2,106)=.37$, MSE $=.381, p=$ .692, which confirms Hypothesis 3 that diagram-completion tasks would only affect 
monitoring for learning of causal relations. Moreover, monitoring for learning of factual information was inaccurate (gammas not different from 0 ) for all groups.

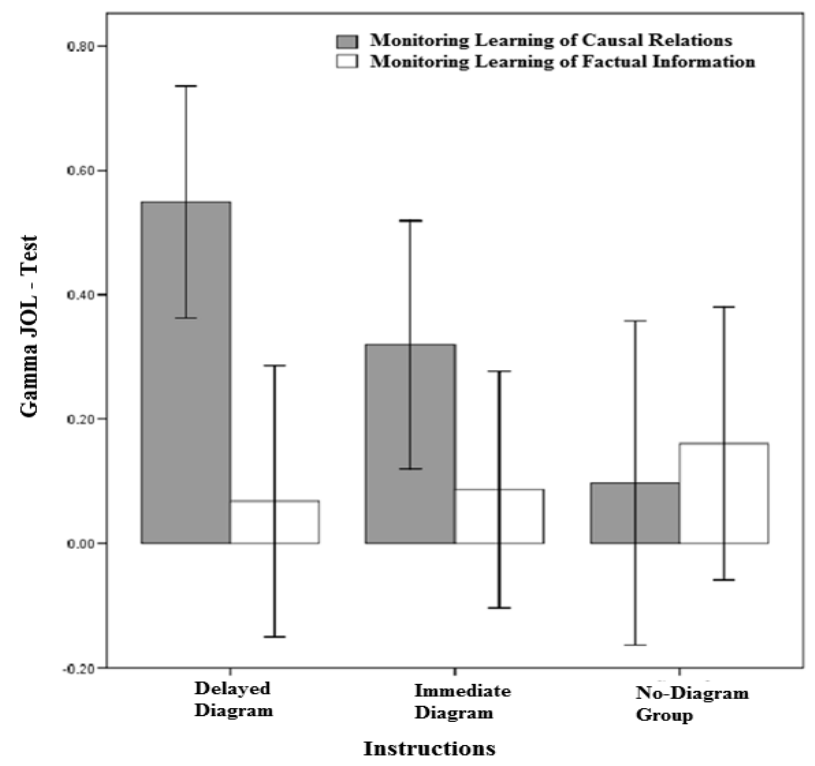

Figure 2. Effects of Instructions on Monitoring Accuracy for Learning of Causal Relations and Factual Information (error bars indicate the 95\% confidence intervals).

\section{Diagram Responses and their Contribution to Monitoring Accuracy}

Diagram responses. We explored whether learners' responses in the diagrams were diagnostic of test performance (cue diagnosticity, Question 1a) and whether learners actually based their judgments on these cues (cue utilization, Question 1b). Table 1 shows the number of responses (correct relations, omissions, responses containing factual information, and commission errors) provided in the text boxes for the delayed and the immediate diagram groups. Participants who completed diagrams immediately after reading included more correct relations in the diagrams than those who completed diagrams at a delay, $t(81)=1.99, p=.050$, Cohen's $d=.44$. Following the delayed-diagram task, participants made more omissions as compared to those in the immediate diagram group, $t(81)=2.16, p=.034$, Cohen's $d=.47$. Differences between the immediate and delayed diagram group were not significant for the number of commission errors in diagrams $(p=.470)$ or for the number of responses containing factual information ( $p=$ $.366)$. 
Table 1. Responses in Diagrams

\begin{tabular}{lllll}
\hline & Correct Relations & Omission & Factual Information & Commission Error \\
\hline Immediate Diagrams & $2.34(.61)$ & $.41(.43)$ & $.47(.24)$ & $.67(.44)$ \\
Delayed Diagrams & $2.06(.67)$ & $.67(.63)$ & $.42(.27)$ & $.73(.43)$ \\
\hline
\end{tabular}

Note. Mean number of correct relations, omissions, responses containing factual information, and commission errors in the four text boxes for the Immediate Diagram and Delayed Diagram groups. Standard deviations of the mean in parentheses.

Cue diagnosticity. Table 2 includes the gamma correlations between the number of response types in the diagram text boxes and the number of correct relations at the test, indicating cue diagnosticity of the diagram responses. The correlations involving correct responses were highly positive (.53 and .57 for delayed and immediate diagrams, respectively), indicating that providing a correct response in the diagram was strongly related to providing correct relations at the later test. Moreover, the gamma correlation involving omissions was highly negative for both the delayed (-.62) and the immediate (.42) diagram groups, indicating that when learners did not provide responses in the diagram about a text, they did not produce correct causal relations at the later test. No significant differences occurred in cue diagnosticity between immediate and delayed diagram groups for omissions in the diagram $(p=.124)$ and for correct relations in the diagram $(p=.721)$. Thus, completing delayed diagrams did not provide learners with more diagnostic cues than immediate diagram completion, and hence differences in diagnosticity cannot explain the finding that the delayed diagram group showed more accurate monitoring.

In the analysis of cue diagnosticity described above, the cues did not necessarily need to correspond to the actual outcomes of the test; for instance, overall correct diagram completion was predictive of test performance, so it is considered a diagnostic cue. Even so, a participant may have correctly generated one relationship during diagram completion for a particular text, but when tested later, the participant may have been incorrect about that relationship but correctly responded about another one instead. In this case, the cue (recalling one relationship) was not diagnostic of eventually responding correctly about that relationship again. Accordingly, we also evaluated how well correct responses during diagram completion corresponded to responding correctly about the same information on the test. In particular, we computed the percentage of correct responses during diagram completion that were also correct on the final test; a higher value indicates higher correspondence. The percentage of correct responses that were both correct during diagram completion and on the final test was $87.60 \%$ (SD $=18.28$ ) for the delayed diagram group and $87.17 \%(S D=18.18)$ for the immediate diagram group. The groups did not differ, $p=.807$, and most important, the correspondence between correct diagram responses and test responses was high. 
Table 2. Cue Diagnosticity and Cue Utilization

\begin{tabular}{lll}
\hline & Cue Diagnosticity & Cue Utilization \\
\hline Correct Relations & $.53^{*}(.44)$ & $.59(.42)^{*}$ \\
Delayed Diagrams & $.57^{*}(.47)$ & $.23(.60)^{*}$ \\
Immediate Diagrams & $-.62^{*}(.43)$ & $-.64(.58)^{*}$ \\
Omissions & $-.42^{*}(.59)$ & $-.50(.64)^{*}$ \\
Delayed Diagrams & & \\
Immediate Diagrams & $-.25^{*}(.59)$ & $-.16(.66)$ \\
Commission Errors & $-.37^{*}(.58)$ & $.00(.64)$ \\
Delayed Diagrams & & \\
Immediate Diagrams & $.17(.68)$ & $.20(.79)$ \\
Factual Information & $-.29 *(.64)$ & $-.11(.65)$ \\
Delayed Diagrams & Immediate Diagrams &
\end{tabular}

Note. Cue diagnosticity is calculated by the gamma correlation between diagram responses and test scores on questions about causal relations. Cue utilization is calculated between diagram responses and JOLs about learning of causal relations. The Table presents the means of the intra-individual gamma correlations. Standard deviations of the mean in parentheses.

* Gamma correlation significantly differs from zero, $p<.01$.

Cue utilization. Results in Table 2 suggest that following both delayed and immediate diagram completion, learners used the number of omissions and correct relations in their completed diagrams as a cue for JOLs. They did not use their commission errors and the responses containing factual information in the diagrams as a cue when providing their JOLs (i.e., gamma correlations were not different from zero for these response types). The gamma correlation between the number of correct relations and JOLs was .59 for delayed diagrams and .23 for immediate diagrams; this difference represents a significant and large effect, $t(76)=3.07, p=.003$, Cohen's $d=.70$. Omissions in diagrams were also used as cue for the JOLs, the correlation between the number of omissions and JOLs was highly negative for both groups (-.64 and -.50 for delayed and immediate diagrams, respectively). This small difference was not significant $(p=.359)$. Thus, delayed diagram completion helped learners to more accurately distinguish among diagrams for which they knew more versus less correct relations. Given that this cue was highly diagnostic (Table 2), then differences in its use is implicated as a cause for the increase in monitoring accuracy for delayed versus immediate diagram completion. 


\section{Regulation}

Participants selected $48.75 \%$ (SD $=27.04)$ of texts for restudy following delayed diagram completion, whereas they only selected $33.3 \%(S D=26.11)$ following immediate diagrams and $36.69 \%(S D=25.41)$ following the no-diagram instructions. The percentage of texts selected for restudy was significantly affected by the diagram task, $F(2,120)=$ $3.52, p=.033, \eta_{p}{ }^{2}=.055$. Following delayed diagrams, participants selected significantly more texts for restudy than following immediate diagrams $(p=.039)$. There were no significant differences between the delayed diagram and the no-diagram group ( $p=.073$ ) and between the immediate diagram and the no-diagram group ( $p>$.999).

The means across individual gamma correlations between JOLs for causal relations and selection for restudy were highly negative for all groups, - $.74(S D=.54)$ for delayed diagrams, $-.53(S D=.71)$ for immediate diagrams, and -.69 $(S D=.53)$ for the no-diagram group. These gamma correlations indicate a strong relation between monitoring judgments and restudy selections. There was no significant effect of diagram completion group on the correlations between JOLs for causal relations and restudy selections: $F(2$, $92)=1.03, p=.362$. Thus, even though monitoring was less accurate in the immediate diagram group and the no-diagram group, restudy selections were still highly related to their JOLs, which is consistent with Hypothesis 4.

\section{Supplementary Analyses}

In this section, we briefly discuss analyses relevant to whether the diagram-completion tasks influence JOL magnitude and test performance. Bonferroni corrections were used for the post-hoc tests. Although these measures were not critical for evaluating our key predictions, we report them here for completeness.

JOL magnitude. Mean JOLs for causal relations and factual information are presented in Table 3. The diagram-completion group significantly affected the JOL level for learning of causal relations, $F(2,120)=3.97, p=.021, \eta_{p}{ }^{2}=.062$. Following the immediate diagram task, JOLs for causal relations (57.35) were significantly higher than JOLs following the no-diagram comparison task (46.76), $p=.022$. For the delayed diagram group, causal relation JOLs (54.32) did not significantly differ from the immediatediagram group $(p>.999)$ and the no-diagram group $(p=.144)$.

The diagram-completion group also had an effect on the level of JOLs for factual information, $F(2,120)=3.64, p=.029, \eta_{p}{ }^{2}=.057$. The mean level of JOLs was higher for the delayed diagram group $(M=57.35)$ than for the no-diagram group ( $M=47.70, p=$ .033). The immediate-diagram group $(M=55.34)$ did not significantly differ from the delayed-diagram ( $p>$.999) and the no-diagram group $(p=.144)$. 
Test performance and study time. Table 3 includes the mean performance for questions about causal relations (test performance for questions about causal relations could range from $0-4$ ) and the mean percentage of correct responses to questions about factual information. Diagram-completion group significantly affected performance for questions about causal relations, $F(2,119)=9.28, p<.001, \eta_{p}{ }^{2}=.14$. Performance was highest for the immediate diagram group $(M=2.40)$ as compared to the delayed diagram $(M=1.97$, $p=.004)$ and the no-diagram group $(M=1.77, p<.001)$. Mean study time per text (refer to Table 3 ) was also significantly affected by group, $F(2,120)=5.65, p=.004, \eta_{p}{ }^{2}=.086$. Study time per text was longer for the immediate diagram group ( $M=97.71$ seconds) when compared to the delayed diagram group ( $M=81.47$ seconds, $p=.014)$ and the nodiagram group ( $M=80.51$ seconds, $p=.011)$. There was no significant difference in test performance between the delayed diagrams and no-diagram group $(p=.175)$, and there was no significant difference in study time for these two groups, $p>$.999. In addition, group did not affect test performance on questions about factual information, $F(2,120)$ $=.44, p=.647$.

Table 3. JOLs, Study Time, and Test Performance

\begin{tabular}{llllll}
\hline Instruction & $\begin{array}{l}\text { JOL Causal } \\
\text { Relations }\end{array}$ & JOL Facts & $\begin{array}{l}\text { Study Time } \\
\text { per Text }\end{array}$ & $\begin{array}{l}\text { Correct Causal } \\
\text { Relations }\end{array}$ & $\begin{array}{l}\text { Percentage } \\
\text { Correct Facts }\end{array}$ \\
\hline Delayed Diagrams & $54.32(17.24)$ & $57.35(16.66)$ & $81.47(26.57)$ & $1.97(.68)$ & $32.57(14.06)$ \\
Immediate Diagrams & $57.35(18.83)$ & $55.34(18.32)$ & $97.71(29.29)$ & $2.40(.64)$ & $30.14(11.77)$ \\
Control & $46.76(15.27)$ & $47.70(15.87)$ & $80.51(20.43)$ & $1.77(.67)$ & $30.72(12.71)$ \\
\hline
\end{tabular}

Note. Statistics are presented for the instructions Delayed Diagram Completion; Immediate Diagram Completion; and Control Group. The Table presents Mean JOLs for causal relations (ranging from $0-100 \%$ ); Mean JOLs for factual information (ranging from 0 - 100\%); study time per text (in seconds); Mean amount of correct causal relations at the test (ranging from $0-4$ ); and the percentage of correct responses to questions about factual information. Standard Deviations of the Mean in parentheses.

\section{Disc ussion}

This study demonstrates that adolescents' monitoring accuracy for learning causal relations from texts improved when they completed diagrams prior to providing JOLs, in comparison to learners who did not use causal diagrams (confirming Hypothesis 1). Moreover, the timing of the diagram completion task was an important factor when aiming to improve monitoring accuracy for learning of causal relations. Participants who completed the diagrams after a delay showed more accurate monitoring than did participants who completed diagrams immediately after study of each text (which was a large effect, $d=.60$, which confirmed Hypothesis 2). Furthermore, the findings imply that the diagram completion task focused learners on understanding of cause-and-effect 
relations presented in the studied text and not on learning of textbase factual information (confirming Hypothesis 3).

These findings are consistent with research demonstrating beneficial effects of delayed generation tasks, such as summary generation (Thiede \& Anderson, 2003), keyword generation (De Bruin et al., 2011; Thiede et al., 2003) and sentence generation (Van Loon et al., 2013) on monitoring accuracy. The present results extend previous findings by demonstrating that a diagram completion task can focus learners on gist understanding when they have to study expository science texts containing cause-andeffect relations.

With analyses of cue diagnosticity and cue utilization, we isolated causes of the delayed diagram effect; that is, the experimental design allowed us to investigate why delayed diagram completion improved monitoring in comparison to immediate diagrams. Analyses showed that both the immediate diagram and the delayed diagram completion tasks established cues that were diagnostic of learners' future test performance. Namely, for both diagram groups, within-participant variability in completing diagram boxes (i.e. correct responses) and in not completing boxes (i.e., omission errors) predicted final test performance (Question 1a). Importantly, monitoring judgments can only be accurate when learners utilize cues that are diagnostic of their actual learning (Brunswik, 1956; Koriat, 1997). Findings also indicated that following delayed diagram completion, participants' were more successful at utilizing diagnostic cues; their JOLs were more strongly related to the diagnostic cues (the number of correct relations generated) that were established during diagram completion and the effect size was large, $d=.70$ (Question 1b).

From these findings, the question arises as to why delayed diagram completion leads to more successful utilization of diagnostic cues. We did not include a condition in which JOLs were provided immediately after the diagram completion task. Thus, the lag between completing diagrams and providing JOLs might have been longer for the immediate than the delayed diagram group, so perhaps participants in the immediate group were more likely to forget the cues that arose from diagram generation. This possibility, however, is not well supported. First, regardless of whether diagram completion was immediate or delayed, participants equally utilized omissions in their judgments, suggesting the differential forgetting played a minimal role. Second, Thiede et al. (2005) investigated which task lags could explain the effects of delayed generative tasks on JOLs and found that the delay between reading and generation task is the only lag which is critical to improvement of monitoring accuracy. The lag between the generation task and the judgment was not related to improvement of monitoring accuracy (Thiede et al., 2005). Thus, it seems unlikely that the difference between the lag between the generative self-test and the monitoring judgments explains the observation that monitoring is more accurate following delayed diagram completion. 
Another explanation for our finding that delayed diagram completion supported higher judgment accuracy and led to the most effective cue utilization is that there was more variability in correct responses in the diagrams following delayed diagram completion than following immediate diagram completion. If there was more variability in this diagnostic cue, learners might have found it easier to use it, perhaps because it was more salient to them. If so, the intra-individual standard deviations for the correct responses in the diagrams should then be higher for the delayed diagrams than the immediate diagrams. We evaluated this possibility and found that the intra-individual standard deviations for the mean number of correct causal relations in the generated diagrams did not differ between the immediate and the delayed diagram groups (mean SD $=.30$ for immediate diagrams; mean $S D=.28$ for delayed diagrams, $t(81)=.38, p=.705$ ).

Given that differences in lag or cue variability do not seem to explain why learners more effectively used diagnostic cues when completing diagrams after a delay rather than immediately, it is an open issue why this effect occurred. Future research should investigate this issue. One possibility is to ask learners to think aloud during diagram completion and when providing JOLs, which could provide insight into the effects of delaying diagram completion on cue utilization.

Note that completing diagrams immediately during learning led to higher scores when learners were tested for learning of causal relations. This finding is not surprising, as research has demonstrated that interaction with diagrams immediately during learning can improve learning gains (Cromley et al., 2013). In our study, reading times were longer for the group who completed immediate diagrams than for the delayed diagram group and the no-diagram group. These outcomes are consistent with findings by Ainsworth, Prain, and Tytler (2011), who showed that interaction with diagrams immediately during reading led to more engagement with the learning task. This outcome implies that even though an immediate diagram completion is not likely to be highly beneficial when aiming to improve learners' monitoring of their learning, this immediate diagram completion task can be promising to improve student learning. However, our evidence suggests that in a self-regulated learning context, delayed diagram completion may emerge as the more effective task to improve self-regulated learning of cause-andeffect relations in science texts. In particular, regardless of group and the level of monitoring accuracy, regulation of study was based on participants' subjective judgments of how well they had learned the texts (Hypothesis 4). ${ }^{2}$ Thus, even though the JOLs of the immediate diagram and the no diagram group were not that accurate, they still used

\footnotetext{
${ }^{2}$ Note that it is possible that the task of making JOLs would influence which texts would be chosen for restudy. Given that our current focus was on relative accuracy of the JOLs, however, we did not include extra groups to assess the reactive effects of JOLs on restudy decisions. Instead, our question focused on whether the JOLs were related to restudy choices themselves.
} 
their JOLs for their study selections; by contrast, using the more accurate judgments to make restudy decisions after delayed diagram completion would be expected to support more effective self-regulated learning (Thiede, 1999).

The finding that delayed diagram completion is a promising task to improve monitoring accuracy when studying science texts containing causal relations provides a novel contribution for educational practice. For optimal comprehension of causal relations, learners should study the texts, interact with diagrams after a delay, and then use their judgments to focus further restudy on those causal relations that have been least well learned. The present study also highlights a novel application of tasks asking learners to interact with diagrams (e.g., Cromley et al., 2013). Namely, delayed diagram completion is the first task that has been demonstrated to improve monitoring accuracy specifically for learning of causal relations in science text. 


\section{References}

Ainsworth, S., Prain, V., \& Tytler, R. (2011). Drawing to learn in science. Science, 333, 1096-1097. doi: 10.1126/science. 1204153

Anderson, M. C. M., \& Thiede, K. W. (2008). Why do delayed summaries improve metacomprehension accuracy? Acta Psychologica, 128, 110-118. doi: 10.1016/j.actpsy.2007.10.006

Brunswik, E. (1956). Perception and the Representative Design of Psychological Experiments.Berkeley: University of California Press.

Cromley, J. G., Bergey, B. W., Fitzhugh, S., Newcombe, N., Wills, T. W., Shipley, T. F., \& Tanaka, J. C. (2013). Effects of three diagram instruction methods on transfer of diagram comprehension skills: The critical role of inference while learning. Learning and Instruction, 26, 45-58. doi: 10.1016/j.learninstruc.2013.01.003

Cromley, J. G., Snyder-Hogan, L. E., Luciw-Dubas, U. A. (2010). Reading comprehension of scientific text: A domain-specific test of the direct and inferential mediation model of reading comprehension. Journal of Educational Psychology, 102, 687-700. doi: 10.1037/A0019452

Koriat, A. (2012). The relationships between monitoring, regulation and performance. Learning and Instruction, 22(4), 296-298. doi: 10.1016/j.learninstruc.2012.01.002

De Bruin, A. B. H., Thiede, K. W., Camp, G., \& Redford, J. (2011). Generating keywords improves metacomprehension and self-regulation in elementary and middle school children. Journal of Experimental Child Psychology, 109, 294-310. doi: 10.1016/j.jecp.2011.02.005

De Bruin, A. B. H., \& Van Gog, T. (2012). Improving self-monitoring and self- regulation: From cognitive psychology to the classroom. Learning and Instruction, 22(4), 245-252. doi: 10.1016/j.learninstruc.2012.01.003

Dunlosky, J \& Ariel, R. (2011). Self-regulated learning and the allocation of study time. In B. Ross (Ed), Psychology of Learning and Motivation, 54, 103-140. doi: 10.1016/B978-0-12-385527-5.00004-8

Dunlosky, J., \& Lipko, A. R. (2007). Metacomprehension: A brief history and how to improve it's accuracy. Current Directions in Psychological Science, 16, 228-232. doi: 10.1111/j.1467-8721.2007.00509.x

Dunlosky, J., \& Rawson, K. A. (2012). Overconfidence produces underachievement: Inaccurate self-evaluations undermine students' learning and retention. Learning and Instruction, 22(4), 271-280. doi: 10.1016/j.learninstruc.2011.08.003

Gobert, J. D., \& Clement, J. J. (1999). Effects of student-generated diagrams versus student-generated summaries on conceptual understanding of causal and dynamic knowledge in plate tectonics. Journal of Research in Science Teaching, 36(1), 39-53. doi: 10.1002/(sici)1098-2736(199901)36:1<39::aidtea4>3.0.co; 2 -i

Graesser, A. C., Singer, M., \& Trabasso, T. (1994). Constructing inferences during narrative text comprehension. Psychological Review, 101, 371-395. doi: 10.1037/0033-295x.101.3.371

Judd, C. M., \& McClelland, G. H. (1989). Data Analysis: A Model Comparison Approach. New York: Harcourt Brace Jovanovich.

Kimball, D. R., \& Metcalfe, J. (2003). Delaying judgments of learning affects memory, not metamemory. Memory \& Cognition, 31, 6, 918-929. doi: 10.3758/Bf03196445

Kintsch, W. (1998). Comprehension: A Paradigm for Cognition. Cambridge, University Press.

Kintsch, W., Welsch, D. M., Schmalhofer, F., \& Zimny, S. (1990). Sentence memory: A theoretical analysis. Journal of Memory and Language, 29, 133-159. doi: 10.1016/0749-596x(90)90069-C

Koriat, A. (1997). Monitoring one's own knowledge during study: A cue-utilization approach to judgments of learning. Journal of Experimental Psychology: General, 126, 349-370. doi: 10.1037/0096-3445.126.4.349

Maki, R. H. (1998). Predicting performance on text: Delayed versus immediate predictions and tests. Memory \& Cognition, 26, 959-964. doi: 10.3758/bf03201176

McCrudden, M. T., Magliano, J. P., \& Schraw, G. (2011). The effect of diagrams on online reading processes and memory. Discourse Processes, 49, 69-92. doi: 10.1080/01638531003694561 
McCrudden, M. T., Schraw, G., Lehman, S., \& Poliquin, A., (2007). The effects of causal diagrams on text learning. Contemporary Educational Psychology, 32, 367-388. doi: 10.1016/j.cedpsych.2005.11.002

Nelson, T. O. (1984). A comparison of current measures of the accuracy of feeling-of-knowing predictions. Psychological Bulletin, 95, 109-133. doi: 10.1037/0033-2909.95.1.109

Nelson, T. O., \& Narens, L. (1990). Metamemory: A theoretical framework and new findings. Psychology of Learning and Motivation, 26, 125-141. doi: 10.1016/S0079-7421(08)60053-5

Otero, J., Leon, J.A., \& Graesser, A.C. (2002) (Eds). The Psychology of Science Text Comprehension. Mahwah, NJ: Erlbaum.

Rawson, K. A., Dunlosky, J., Thiede, K. W. (2000). The rereading effect: Metacomprehension accuracy improves across reading trials. Memory \& Cognition, 28, 1004-1010. doi: 10.3758/BF03209348

Rosnow, R. L., Rosenthal, R., \& Rubin, D. B. (2000). Contrasts and correlations in effect size estimation. Psychological Science, 11, 446-453. doi : 10.1111/1467-9280.00287

Son, L.K., \& Metcalfe, J. (2000). Metacognitive and control strategies in study-time allocation. Journal of Experimental Psychology: Learning, Memory, and Cognition, 26, 204-221. doi: 10.1037/02787393.26.1.204

Thiede, K.W. (1999). The importance of accurate monitoring and effective self-regulation during multitrial learning. Psychonomic Bulletin \& Review, 6, 662-667. doi: 10.3758/BF03212976

Thiede, K. W., \& Anderson, M. C. M. (2003). Summarizing can improve metacomprehension accuracy. Contemporary Educational Psychology, 28, 129-160. doi: 10.1016/S0361-476x(02)00011-5

Thiede, K. W., Anderson, M. C. M., \& Therriault, D. (2003). Accuracy of metacognitive monitoring affects learning of text. Journal of Educational Psychology, 95, 66-73. doi: 10.1037/0022-0663.95.1.66

Thiede, K. W. \& Dunlosky, J. (1999). Toward a general model of self-regulated study: An analysis of selection of items for study and self-paced study time. Journal of Experimental Psychology: Learning, Memory and Cognition, 25, 1024-1037. doi: 10.1037/0278-7393.25.4.1024

Thiede, K. W., Dunlosky, J., Griffin, T. D., \& Wiley, J. (2005). Understanding the delayed keyword effect on metacomprehension accuracy. Journal of Experimental Psychology: Learning, Memory, and Cognition, 31, 1267-1280. doi: 10.1037/0278-7393.31.6.1267

Thiede, K. W., Griffin, T. D., Wiley, J., \& Redford, J. (2009). Metacognitive monitoring during and after reading. In D. J. Hacker, J. Dunlosky \& A. C. Graesser (Eds). Handbook of Metacognition in Education, pp. 85-106. Routledge.

Van den Broek, P., Rapp, D. N., \& Kendeou, P. (2005). Integrating memory-based and constructionist processes in accounts of reading comprehension. Discourse Processes, 39, 299-316. doi: 10.1080/0163853X.2005.9651685

Van Loon, M. H., De Bruin, A. B. H., Van Gog, T., \& Van Merriënboer, J. J. G. (2013). The effect of delayed-JOLs and sentence generation on childrens's monitoring accuracy and regulation of idiom study. Metacognition and Learning, 8, 173-191. doi: 10.1007/s11409-013-9100-0 


\section{Appendix A. Example Texts}

\section{Text "The Suez Canal"}

"The Suez Canal, which connects the Indian Ocean and the Mediterranean Sea with each other, is of great importance to the world. Originally, there was no natural water connection between the Atlantic and the Indian Ocean. Between these two seas is a desert. This meant that trading ships that traveled from the harbor city Jeddah in Saudi Arabia to Europe had to make a long journey around the whole African continent. It was therefore decided that a shorter waterway was needed that would connect the two oceans with each other. For this reason, the Suez Canal, which was designed by the Austrian engineer Alois Negrelli, was dug. For years, workers were digging; the canal was finally opened in 1869 for shipping. By the digging of the Suez Canal, the distance from the harbor city of Jeddah to the harbor city of Rotterdam has been reduced by $40 \%$. Through the Suez Canal, the distance between these cities is 6,337 nautical miles, when ships sail around the African continent this distance is 10,743 nautical miles."

\section{Text “Botox"}

Botox is the abbreviation of Botulinium Toxin, this is a poison that is produced by the bacterium Clostridium Botulinum. This substance blocks the signal between the nerves and the muscles in the skin. Since 1989, use of Botox is permitted, although this is strictly controlled in The Netherlands. In 2004, 28 people died in America, they had an accident with an incorrect dosage of Botox. Due to the blocking of the signal between the nerves and skin, originally, Botox was particularly used against muscle contractions, for example with patients who could not control muscle contractions and continuously blinked their eyes. By injecting Botox around the eyes, the muscles are paralyzed and the muscle contractions disappear. Because Botox blocks the signal between the nerves and the muscles in the skin, this is also used in plastic surgery to smoothen the skin: It can reduce the wrinkles around the eyes and the forehead. Because wrinkles are reduced, this treatment makes people look younger. The effect of such a treatment usually lasts between 1 and 6 months. However, this treatment against wrinkles between the eyes and on the forehead can also undesirably change peoples' face expressions. 


\section{Appendix B. Test Questions}

Example Questions:

Questions about causal relations:

- The distance for trading ships that sail between Jeddah and Rotterdam has been reduced a lot. For what reasons has the distance between Jeddah and Rotterdam been reduced?

- Botox blocks the signal between the nerves and the skin. What are the effects of this? Questions about factual information:

- In what year was the Suez Canal opened for ships?

- From which country was the engineer who designed the Suez Canal?

- What is the full name of Botox?

- Since when has use of Botox been officially permitted? 


\section{Appendix C. Analyses of Absolute Accuracy}

Even though the main focus was on effects of diagram completion instructions on relative monitoring accuracy, indicated by of the gamma correlations between JOLs and performance, for completeness we also report a measure of absolute accuracy, which is the absolute difference between the JOLs (ranging from 0-100\%) and the percentage correct test scores. Values that are higher than zero indicate overconfidence, scores lower than zero indicate underconfidence, and a difference score of zero indicates perfect correspondence between JOLs and performance.

Difference scores for causal relations were not affected by instructions, $F(2,120)=$ $1.837, p=.164$. Mean scores were $5.40(S D=17.92)$ for delayed diagrams, -2.47 (SD = 19.80) for immediate diagrams, and $1.06(S D=18.96)$ for the no-diagram group. Note that the absolute accuracy for all three groups was close to zero, which indicates that the diagram instructions mainly had an effect on learners' relative accuracy.

The absolute difference between JOLs and the percentage of correct test responses for factual information was affected by instructions, $F(2,119)=3.780, p=.026, \eta_{p}{ }^{2}=.06$. The mean difference is $24.67(S D=14.33)$ for delayed diagrams; 25.24 ( $S D=22.12)$ for immediate diagrams; and $15.73(S D=13.85)$ for the no-diagram group. The no-diagram group significantly differed from the immediate diagram group ( $p=.048$ ), and the difference between the delayed diagram group and the no-diagram group was near significance $(p=.061)$. There was no difference in overconfidence for fact learning between the immediate and the delayed diagram group $(p>$.999). These findings show that the no-diagram group that showed a lower level of overconfidence for learning of factual information, which implies that, after completing diagrams, learners became somewhat more overconfident when asked to predict the percentage of correct responses when tested about factual information. 
Effects of Diagram Completion on Monitoring and Regulation 


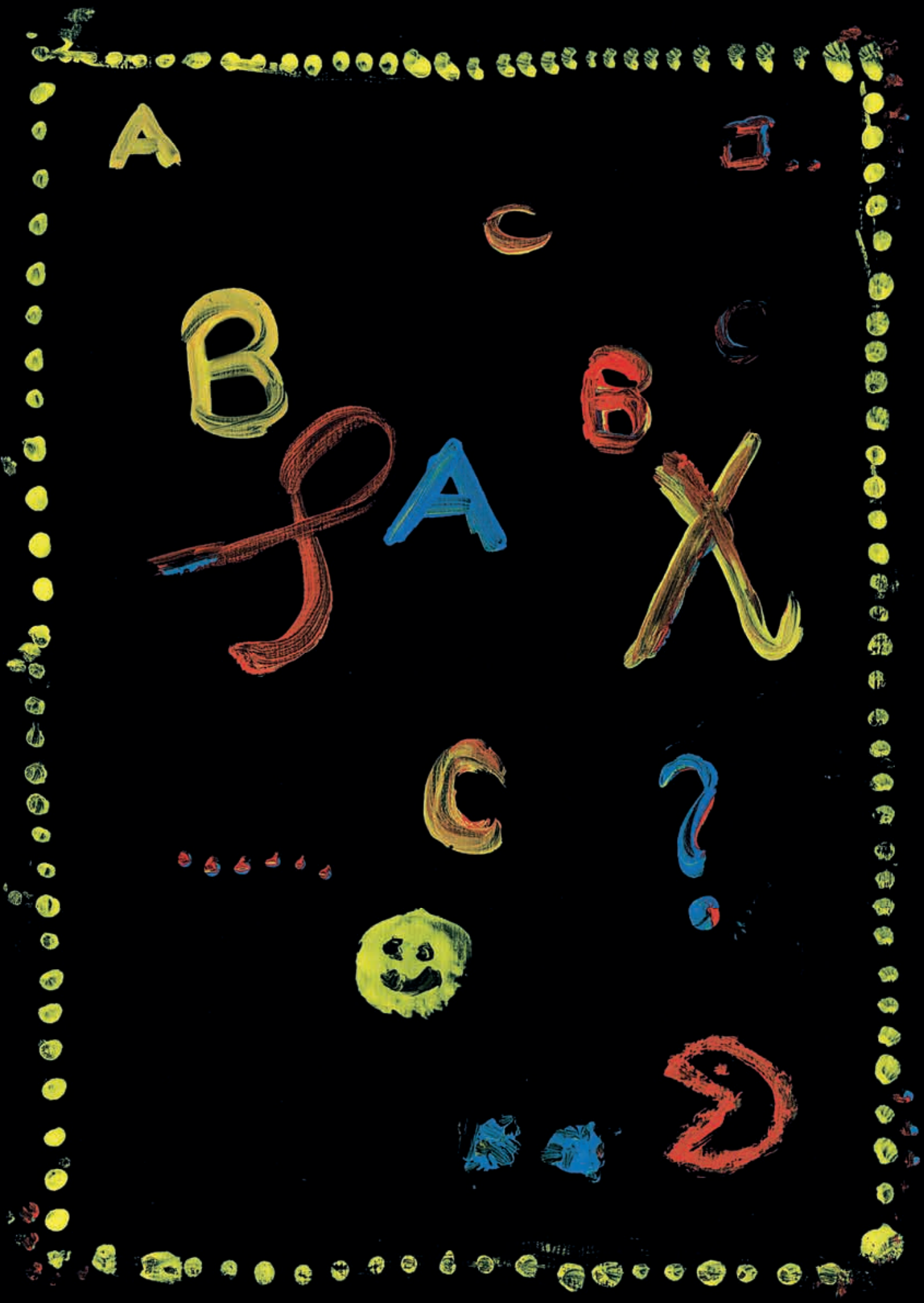




\title{
C HAPTER 5
}

\section{Activation of Ina c curate Prior Knowledge Affects Primary-School Students' Metacognitive J udgments and Calibration}

\begin{abstract}
The study investigated whether activation of inaccurate prior knowledge before study contributes to primaryschool children's commission errors and overconfidence in these errors when learning new concepts. Findings indicate that inaccurate prior knowledge affects children's learning and calibration. The level of children's judgments of learning for recall responses for which they would not receive credit was inappropriately high after activation of inaccurate prior knowledge. Moreover, results showed that activation of inaccurate prior knowledge was not only detrimental for monitoring judgments during learning, but also for calibration accuracy after test taking. When judging the quality of their recall responses on the posttest, children were more overconfident when they had activated inaccurate prior knowledge. Also, the children often discarded concepts from further study after activation of inaccurate prior knowledge. These results suggest that in order to improve self-regulated learning, it may be important to detect inaccuracies in children's prior knowledge.
\end{abstract}

This chapter has been published as Van Loon, De Bruin, Van Gog, \& Van Merriënboer (2013). Activation of inaccurate prior knowledge affects primary-school students' metacognitive judgments and calibration. Learning and Instruction, 24, 15-25. 


\section{Activation of Ina c curate Prior Knowledge Affects Prima ry- School Students' Metacognitive Judgments and Calibration}

Learning and understanding new concepts presented in a text is an activity that young learners have to perform frequently (Lipko, Dunlosky, Hartwig, Rawson, Swan, \& Cook, 2009). In order to study efficiently, students have to accurately monitor the quality of their learning while studying, that is, by correctly judging the extent to which the studied information has been understood (e.g. Hadwin \& Webster, 2013; Nelson \& Narens, 1990; Thiede, Anderson, \& Therriault, 2003). This affects the efficiency of their learning, because without accurate monitoring, learners might not spend enough time studying concepts they think they know, but actually have not yet learned. However, monitoring the quality of learning is not only relevant during the study phase. It is also important for learners to accurately evaluate the quality of their test performance, so that when taking in-between self-tests, they can use this information to regulate further study.

Unfortunately, research on monitoring judgments made during learning (i.e., Judgments of Learning -JOLs) and on monitoring test performance (i.e., Self-Score Judgments -SSJS) has shown that both tend to be inaccurate (Dunlosky, Rawson, \& Middleton, 2005; Nelson \& Dunlosky, 1991). The present study aimed to investigate whether poor monitoring accuracy might in part be caused by the accessibility of inaccurate prior knowledge. We will first give an overview of research on the accuracy of JOLs and SSJs, before examining why activating inaccurate knowledge prior to study might contribute to inaccurate monitoring.

The research on JOL accuracy has mainly focused on relative accuracy, which is usually measured by means of intra-individual correlations between JOLs and performance on test items (Maki, Shields, Wheeler, \& Zacchilli, 2005; Nelson, 1984; Rhodes \& Tauber, 2011; Schraw, Kuch, \& Gutierrez, 2013). When providing JOLs about studied concepts, the higher the JOLs are, the more confident the learner is to retrieve the correct meaning of the concept on the test. The correlation between JOLs and performance, with values ranging between -1 to +1 , indicates whether a person can discriminate between items that are more or less likely to be recalled on a test. A highly positive correlation between JOLs and performance shows accurate monitoring, whereas a value of zero indicates that there is no association between predictions and performance. Research has shown that when JOLs are made immediately after studying an item, correlations often do not exceed .25, indicating that students have problems discriminating between items which they have or have not understood (Dunlosky \& Lipko, 2007). When regulating further study, learners typically select items for restudy for which they gave low JOLs (Metcalfe \& Finn, 2008; Nelson, Dunlosky, Graf, \& Narens, 1994). Thus, when JOLs are inaccurate, students cannot accurately decide which items should receive the highest priority for additional study. 
Accuracy of Self-Score Judgments (SSIs) is usually measured in terms of calibration, or absolute accuracy, by comparing the correspondence between an SSJ for an item and performance on that item. SSJs require learners to provide an estimate regarding the quality of their response (i.e., their recall, Dunlosky et al., 2005). When providing SSJs for the recall of concepts, learners usually indicate on a scale whether they expect to receive no, partial, or full credit for their response (e.g., Dunlosky et al., 2005; Rawson \& Dunlosky, 2007).

By calculating the difference between the SSJs and performance, the measure of SSJ calibration accuracy provides insight into the match between a learner's perception of performance and the actual level of performance. When comparing SSJs with actual test scores, researchers acquire insight into the level of over- or underconfidence of a learner. The smaller the difference between SSJs and actual scores, the better the calibration of the learner is (Hacker, Bol, \& Keener, 2008). A person is overconfident if the calculated discrepancy between SSJS and test scores is a positive value, and underconfident if this value is negative. For example, if a learner judges the quality of a recall response as fully correct ( 1 credit) and the actual test score for that item is partially correct $(0.5$ credit), this shows that the student was overconfident. On the other hand, if the learner would have provided a SSJ of 0 credit and the actual test response would receive 0.5 credit, this person would be underconfident.

Unfortunately, research has shown that learners are often inaccurate when making SSIs. Both adults and younger learners tend to be overconfident (Flavell, 1970; Koriat, 2011) when monitoring the quality of recall responses that are entirely incorrect, referred to as commission errors. Even though these responses are not awarded credit, learners often expect to receive partial or full credit for their commission errors (Dunlosky et al., 2005; Lipko, Dunlosky, \& Merriman, 2009; Rawson \& Dunlosky, 2007). Findings with eighth-grade learners showed that as much as $43 \%$ of their recall responses consisted of commission errors (Lipko, Dunlosky, Hartwig, et al., 2009). When regulating further study, this tends to be inefficient as learners usually discard items for which they believe their recall response was correct. Commission errors thus contribute to inefficient study regulation to a large extent (Dunlosky, Hartwig, Rawson, \& Lipko, 2011; Dunlosky \& Rawson, 2012).

The cue utilization framework (Koriat, 1997) provides an explanation for learners' poor accuracy, and overconfidence when monitoring learning and performance. Presumably, poor accuracy results when learners base their judgments on cues that are not valid indicators of test performance. According to the accessibility theory (Koriat, 1993), learners often derive their monitoring judgments from the amount of accessible information that comes to mind. Koriat (1995) found that adult learners' confidence increased when the accessibility of information increased (i.e. the presence of information in memory), and this increase in confidence was independent of the actual 
correctness of their test response (i.e. the quality). Accessibility might not be a valid cue when monitoring learning, because learners would focus on the quantity of information in memory, instead of the quality, which is what is being judged by teachers when students take a test (Dunlosky et al. 2005; Koriat, 1993; Koriat, 1995; Koriat \& Levy-Sadot, 2001; Rawson \& Dunlosky, 2007).

Studies have shown that monitoring accuracy can improve when learners' attention is focused on valid cues. Improvements in the relative accuracy of JOLs have been found when they are provided at a short delay after learning, rather than immediately during learning (Koriat \& Shitzer-Reichert, 2002; Nelson \& Dunlosky, 1991; Rhodes \& Tauber, 2011; Schneider, Visé, Lockl, \& Nelson, 2000). However, the measure of relative JOL accuracy shows only whether participants can discriminate between items they studied, it does not provide insight into the level of learners' overconfidence in their commission errors (Schraw, 2009). A measure of calibration, or absolute accuracy, would be needed to determine to what extent learners are able to accurately monitor the quality of their recall response on each item.

The few studies that have investigated calibration accuracy of young learners' SSJs have shown that children show a high level of overconfidence (Barnett \& Hixon, 1997; Huff \& Nietfeld, 2009; Lipko, Dunlosky, Hartwig, et al. 2009). An important factor that might affect the calibration accuracy of commission errors, but which has, to our knowledge, not yet received any attention, is accessibility of prior knowledge. We know that learners' prior knowledge has a large influence on what they understand and remember when learning from text (Alexander \& Jetton, 2000). Several studies have shown that activating prior knowledge before studying has positive effects on learning (e.g. Ozuru, Dempsey, \& McNamara, 2009; Wetzels, Kester, Van Merriënboer, \& Broers, 2011). However, inaccurate prior knowledge may have a detrimental effect not only on learning but also on monitoring, for instance, when learners have inaccurate ideas about the meaning of certain concepts to be studied.

Research has found that when the inaccuracy of prior knowledge is not directly identified and addressed, it can be resistant to change and hinder the learning of new information (Dochy, Segers, \& Buehl, 1999; Lipson, 1982; Van den Broek, \& Kendeou, 2008). For instance, Lipson (1982) showed that when children activated inaccurate prior knowledge before studying a text that contradicted their prior knowledge, they still used their inaccurate prior knowledge when answering questions after study. It has been suggested that learning outcomes might actually be better when learners are not able to activate prior knowledge than when they activate inaccurate prior knowledge (Lipson, 1982).

In a study examining the effect of prior knowledge on calibration, it has been found that learners reported using their prior knowledge when monitoring learning (Dinsmore \& Parkinson, 2013). However, learners' prior knowledge may either be absent, 
completely inaccurate, partially accurate, or fully accurate. Inaccuracy of prior knowledge may be especially problematic when learners use their prior knowledge in monitoring. Activation of inaccurate prior knowledge might lead to accessibility of incorrect information both during study and during test taking. If learners are unaware of the inaccuracy of their prior knowledge, they might judge these responses as partially or fully correct, leading to overconfidence. In sum, this study intends to investigate whether inaccurately activated prior knowledge might lead to overconfidence in commission errors, more than when learners do not have any prior knowledge accessible. Note that, of course, it is also possible that a learners' prior knowledge is partially correct or fully correct. However, in the present study we focus on unsuccessful prior knowledge activation, because to improve learning, insight into monitoring and regulation processes for incorrect responses is far more important than insight into metacognitive processes for correct responses (Krebs \& Roebers, 2010).

In the present study, primary school learners studied a list of concepts with their meanings. Prior to this, they were required to activate any prior knowledge they had about these concepts. After studying the meaning of the concepts, the students were asked to monitor their learning of these concepts (by providing JOLs and SSJs), and to regulate further study (by selecting concepts for restudy).

In line with the findings of Lipson (1982), first of all we expected that activation of inaccurate prior knowledge before study would persist on the recall test, thus leading to more commission errors at the recall test compared to items for which no prior knowledge was available (Hypothesis 1).

Second, activation of inaccurate prior knowledge before study was expected to affect monitoring accuracy. JOLs were expected to indicate more overconfidence after activation of inaccurate prior knowledge compared to no activation of prior knowledge (Hypothesis 2a). Moreover, consistent with the findings of Lipko and colleagues (2009), we expected that SSJs would show overconfidence. More specifically, if activation of inaccurate prior knowledge is detrimental for calibration, we would expect that SSJs would show a higher level of overconfidence after activation of inaccurate prior knowledge at the pretest than when children were not able to activate any prior knowledge (Hypothesis 2b).

Third, if accessibility of inaccurate prior knowledge has a negative effect on monitoring accuracy, then it is also likely that regulation of study is negatively affected. When investigating regulation regarding concepts for which learners would not show correct understanding at the test, we would expect less efficient regulation after activation of inaccurate prior knowledge. That is, learners are expected to prematurely discard these concepts from further study more often after activation of inaccurate prior knowledge than after not being able to activate any prior knowledge (Hypothesis 3 ). 
There is evidence that monitoring accuracy and overconfidence might be affected by developmental factors (Schneider \& Pressley, 1997). Therefore, we conducted two studies to investigate developmental differences, by using similar procedures in the two studies but involving children of different age cohorts. In Study 1, participants were in third- and fourth-grade (8/9-year-old), whereas Study 2 involved fifth- and sixth-grade (10/11-year-old) children. At a young age, relative accuracy of JOLs can already be high, because children seem to be able to accurately discriminate between items (e.g. Dufresne \& Kobasigawa, 1989; Koriat \& Shitzer-Reichert, 2002, Schneider et al., 2000). However, research on calibration has shown that 8/9-year-old children tend to be more overconfident and often overestimate their memory performance than 10/11-year-old children (e.g. Flavell, 1970; Krebs \& Roebers, 2010, 2011; Schneider \& Pressley, 1997). Krebs and Roebers (2010) showed that 10/11-year-old children can monitor more accurately, and show better calibration for questions on which they cannot provide a correct answer than 8/9-year-old children. Moreover, research indicates that older primary school learners show better regulation abilities than younger learners (e.g. De Bruin, Thiede, Camp, \& Redford, 2011; Krebs \& Roebers, 2010). So we addressed our hypotheses, keeping the nature of the learning task similar across the two studies, but the concepts differed to ensure that the materials were age-appropriate.

\section{Study 1}

\section{Method}

Participants. One-hundred-and-three primary school children from two third-grade $(n=$ $51)$ and two fourth-grade classrooms in The Netherlands $(n=52)$ participated in this study (51.5\% male, $48.5 \%$ female; $M=8.6$ years, $S D=0.8$ ). Most of the children came from middle-class families and all participants exhibited sufficient Dutch language abilities to follow school lessons and to understand our instructions.

Materials. The concept study task was a pen-and-paper task. Based on a study on lexical richness of young learners in the Dutch language (Vermeer, 2000), and a pilot study with four learners in the same age group as the participants, Dutch concepts were selected. These concepts were assumed to be unknown for learners in the age cohort under investigation, thus learners were assumed to have very little accurate prior knowledge about the items. Figure 1 shows a representation of the materials and the procedure of the study.

The pretest consisted of a list of the to-be studied concepts on one page, containing a space to write down their response about the meaning next to each concept. 
The concept study task consisted of 20 concepts, which were presented with their meaning and an example sentence in which the concept was used. The meanings and example sentences were taken from a dictionary for young learners (Verburg, 2008). JOLs were provided by marking a square on an 11-point thermometer adapted from Koriat and Shitzer-Reichert, (2002), ranging from "certain I will not recall the meaning" (0) to "certain I will recall the meaning" (10).

When the participants regulated their study, they selected items for re-study on a page that displayed the concepts in a $10 \times 2$ array. The JOLs were not visible when participants selected concepts for restudy.

The posttest (recall test) was the same as the pretest. Self-score judgments (SSJs) were provided by marking on a square that was depicted next to the tested concept whether the participants expected their recall response to be incorrect, partially correct or fully correct (in line with e.g., Lipko, Dunlosky, Hartwig, et al. 2009).

All subtasks were presented in a booklet, with blank pages in between the subtasks. The order of the concepts was randomized across children and across subtasks (i.e., pretest, study task, JOL task, restudy selection, recall test, and SSJ task). The obtained results were not likely to be influenced by order of item presentation because children received different versions of the concept tasks, and the order of concepts was different for every subtask. 


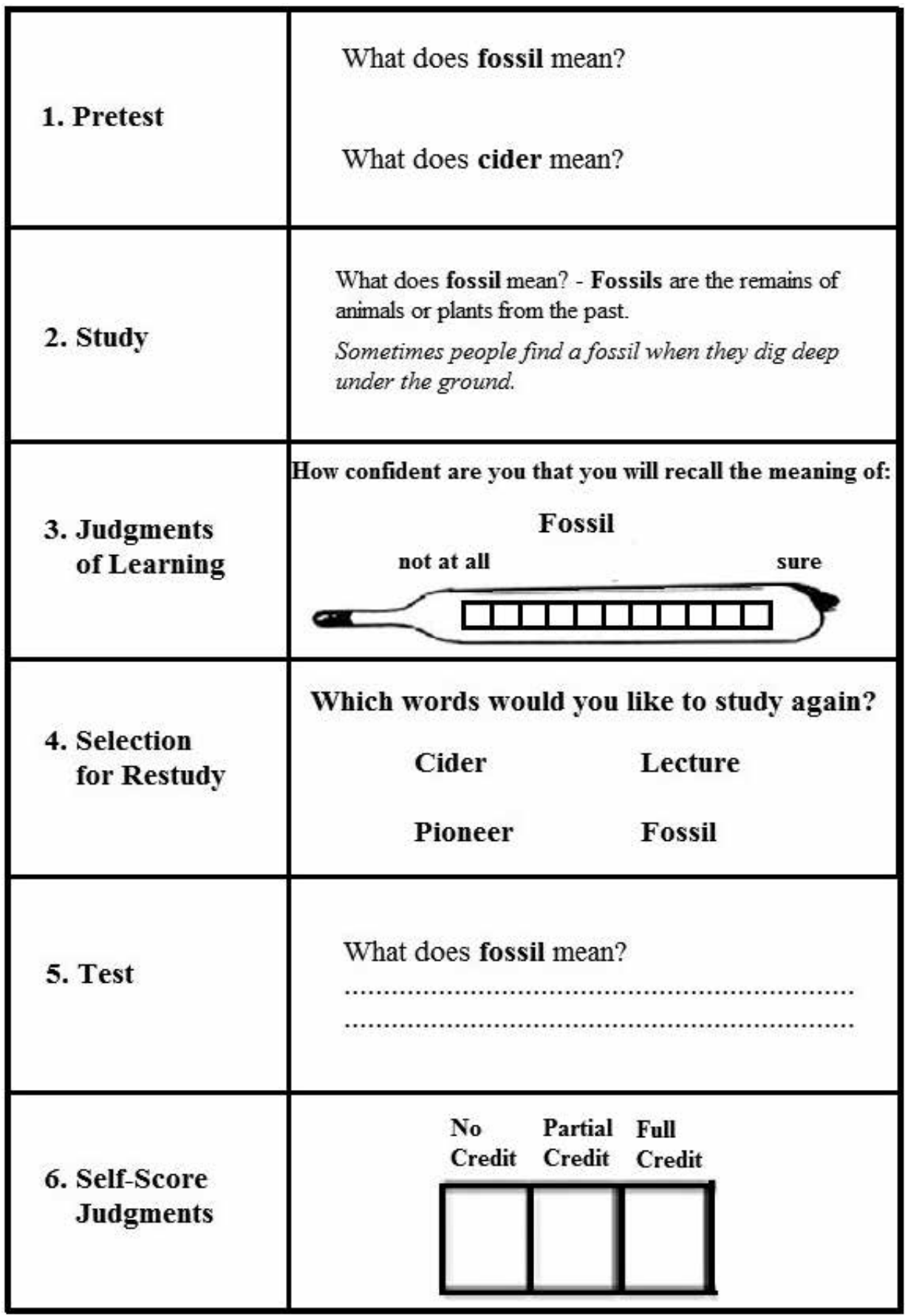

Figure 1. Materials and procedure. 
Procedure. Children were tested in the classroom, the duration of the session was approximately 1 hour. The task began with the experimenter informing the participants that they would receive a booklet with subtasks, and that blank pages indicated the end of subtasks. Children were asked to wait when they came to a blank page until the experimenter announced they could turn that page. The experimenter then explained that they would study concepts, and provided them with an example of a concept and an example of the recall test. Participants were informed that the aim of studying was to show their understanding of the concepts during testing. After this explanation, children received the booklet and were asked to provide their names on the first page.

The concept task consisted of six consecutive phases which are depicted in Figure 1. The first phase was a pretest of prior knowledge. Participants saw the 20 concepts listed, and were asked to write down the meaning of the concept if they knew it, and to leave the space blank if they did not know its meaning.

After 10 minutes they came to the second phase and were asked to study the materials. At the start of this study phase, the experimenter showed that the task consisted of 20 concepts, and told learners they would have 10 minutes to study these concepts. After the study phase, children performed an unrelated filler task (i.e., finding the differences between two pictures that were almost identical but differed on 6 small details) to insert a delay between study and providing JOLs.

In phase 3, children were asked to provide JOLs. First, they were shown the example concept again, and received instructions about the JOL scale. Use of the thermometer was explained and practiced. The experimenter discussed with the children what the various points on the thermometer meant in terms of likelihood to recall the meaning of a concept on the test. Then, participants were asked to provide JOLs for each studied concept in their booklet by marking the corresponding square of choice on the 11-point thermometer.

The fourth phase began after the children provided the JOLs. The children were reminded that they would be asked to take a test, on which they had to show that they had learned the meaning of the concepts. They were instructed to indicate with a mark those concepts they wished to restudy. However, participants were not given the opportunity to restudy the concepts they had selected because the aim of the study was to examine the effect of prior knowledge and JOLs on item selection.

After selecting items for restudy participants received the recall test (the fifth phase), they were asked to write down the correct meaning of the previously studied concepts.

The sixth phase followed this test, the participants were asked to review their test responses in order to provide SSJs about the correctness of their answer. Participants were not able to compare their answers to a standard when self-scoring their test 
responses. SSJs were provided by marking the squares ranging from incorrect to fully correct that were depicted next to the tested concepts.

Data analysis. Types of responses measured in the study include: (a) pretest responses, which were scored on an interval level ranging from 0 (incorrect) to 1 (fully correct), (b) JOLs, which were measured on an 11-point interval scale ranging from 0 to 10 (JOLs were then transformed to a 0-1 scale in order to make them comparable to the other outcome measures), (c) restudy selections, which were measured on a binary scale ( 0 = concept was not selected for restudy; 1 = concept was selected), and (d) SSJs, which were scored on an interval scale ranging from 0 (incorrect) to 1 (fully correct).

Each studied concept consisted of 2-4 idea units $(M=3.0, S D=.64)$, which was comparable to the concepts used by Dunlosky et al. (2005). Credit was given to the responses in line with the scoring procedure used by Dunlosky et al. (2005) and Rawson and Dunlosky (2007). Responses were scored using a gist criterion that is, the idea was scored if it was either provided verbatim or as a paraphrase of the idea unit.

Pretest (prior knowledge) responses were rated as omissions (no response), inaccurate (a completely incorrect response, containing no idea units of the meaning of the concept), partially correct (a response contained at least one idea unit), or fully correct (a response containing all the main idea units). Two independent raters scored $43 \%$ of the pretest responses, and showed high inter-rater reliability (Cohen's Kappa = .90). Agreement was reached about the idea units where scoring diverged. As a result of the high inter-rater reliability, one rater scored the remaining pretest responses.

Posttest (recall) responses were scored as omission errors (no response was given, no credit), commission errors (a completely incorrect response was given, no credit), partially correct responses (a response contained at least one idea unit, partial credit) and fully correct responses (containing all the idea units, full credit). For example, participants studied the concept Cider (concept) - an alcoholic drink made of apples (meaning). Then the participants were asked to provide the meaning of the concept cider at the posttest. When the response was: A drink with alcohol, this was scored as partially correct because it contains two of the three idea units. When participants responded with: A drink made of apples that contains alcohol, this response was scored as being fully correct. A response containing none of the idea units was scored as a commission error, such as answering for cider: somebody who is working in prison. Two raters scored $18 \%$ of the posttest responses, Kappa $=.82$. Agreement was reached about the idea units where scoring diverged and one rater subsequently scored the remaining pretest responses.

Consistent with previous studies (Nelson, 1984; Nelson \& Dunlosky, 1991), JOL accuracy was measured by intra-individual gamma correlations between JOLs and test performance on the items (the closer to +1 , the more accurate). The gamma correlation measures whether learners can judge their understanding of each concept relative to 
other concepts. Concordance occurs when the meaning of a concept with a JOL that is higher than that of another item is recalled, while the meaning of that second concept is not recalled. Discordance occurs when the meaning of a concept with a JOL that is higher of that of another concept is not recalled, while the meaning of that second concept is recalled. The gamma correlation is computed as follows: (ConcordancesDiscordances)/(Concordances + Discordances). Refer to Nelson (1984) for a discussion why a gamma correlation is the best measure of relative accuracy, and more preferable than a Spearman or Pearson correlation.

Restudy accuracy was measured by the intra-individual gamma correlations between JOLs and restudy choice (as a person should select items for restudy for which he provided low JOLs, a correlation closer to -1 indicates more accurate restudy selections, Thiede \& Dunlosky, 1999). For seven participants, JOL accuracy could not be calculated because of invariance in either the JOLs or the test score. Restudy accuracy could not be calculated for 11 children due to invariance in selection of items for restudy or invariance in their test score.

Calibration accuracy of SSIs was measured per item as the difference between the SSJ and the objective score for the recall response. Calibration accuracy increases as the absolute difference between SSJs and performance decreases. With the calibration score, the directionality between judgments and actual performance is taken into account, so this measure indicates the extent to which one is overconfident or underconfident. As SSIs and test scores were both rated as $0,0.5$, or 1 , calibration scores range from -1 to +1 . A calibration score of 0 indicates perfect calibration, scores below 0 indicate underconfidence and scores above 0 indicate overconfidence.

Because of the hierarchical structure of the data (items were nested in participants, and participants were nested in classrooms and grade levels), the effect of inaccurate prior knowledge on commission errors, metacognitive judgments, and on calibration was investigated with multilevel regression analyses conducted in SPSS 19.

\section{Results}

Descriptive statistics. Participants activated prior knowledge on $27 \%$ of the items at the pretest, these responses were scored as inaccurate, partially correct, or fully correct. The remaining items (73\%) were left blank by the participants and these were scored as omissions. Table 1 shows descriptive statistics regarding the percentage and the total amount prior knowledge activation (omissions, inaccurate, partially correct, or fully correct). At the recall test, participants provided responses on $44 \%$ of the items; the remaining 56\% were scored as omission errors. Table 2 shows the percentage and total amount of omission errors, commission errors, partially correct, and fully correct responses. 
Table 3 presents descriptive statistics about Mean JOLs, the percentage of concepts selected for restudy, credit for recall test responses, and Mean SSJs following the four categories of prior knowledge activation (omissions, inaccurate, partially correct, and fully correct). Table 4 presents descriptive statistics about credit for prior knowledge, Mean JOLs, the percentage of concepts selected for restudy, and Mean SSJs in relation to the four categories of recall test responses (omission errors, commission errors, partially correct responses, and fully correct responses).

As would be expected given the delayed JOL procedure, JOL accuracy was quite high, $M$ gamma correlation $=.78(S D=.39)$. The strength of the gamma correlation for restudy accuracy, $M$ gamma correlation $=-.80(S D=.39)$ shows that children selected concepts for restudy that they gave low JOLs and were less likely to select concepts for which they provided high JOLs.

Figure 2 shows the calibration scores for the four different categories of the recall responses (omission errors, commission errors, partially correct, fully correct) for both age cohorts. For the third- and fourth-grade students, mean posttest self-score judgments for commission errors were $.72(S D=.24)$, indicating high overconfidence in these errors. Children often expected to receive credit for responses that were entirely incorrect. The children expected to receive no credit for only $5.3 \%$ of their commission errors, whereas they expected to receive partial credit for $42.3 \%$ and full credit for $52.4 \%$ of the commission errors.

Table 1. Pretest Responses. Percentage and Total Amount of Omissions, Inaccurate, Partially Correct, and Fully Correct) for the Two Grade Cohorts.

\begin{tabular}{lllll}
\hline Grade Level & $\begin{array}{l}\text { Prior Knowledge: } \\
\text { Omission }\end{array}$ & $\begin{array}{l}\text { Prior Knowledge: } \\
\text { Inaccurate }\end{array}$ & $\begin{array}{l}\text { Prior Knowledge: } \\
\text { Partially Correct }\end{array}$ & $\begin{array}{l}\text { Prior Knowledge: } \\
\text { Fully Correct }\end{array}$ \\
\hline Grade 3 and 4 & $74 \%(1452)$ & $14.8 \%(290)$ & $10.2 \%(201)$ & $0.9 \%(18)$ \\
Grade 5 and 6 & $72.2 \%(1382)$ & $14.7 \%(279)$ & $9.6 \%(183)$ & $2.9 \%(56)$ \\
\hline
\end{tabular}

Table 2. Recall Test Responses (Percentage and Total Amount of Omission Errors, Commission Errors, Partially Correct, and Fully Correct) for the Two Grade Cohorts.

\begin{tabular}{lllll}
\hline Grade Level & $\begin{array}{l}\text { Recall Test: } \\
\text { Omission Error }\end{array}$ & $\begin{array}{l}\text { Recall Test: } \\
\text { Commission Error }\end{array}$ & $\begin{array}{l}\text { Recall Test: } \\
\text { Partially Correct }\end{array}$ & $\begin{array}{l}\text { Recall Test: } \\
\text { Fully Correct }\end{array}$ \\
\hline Grade 3 and 4 & $56.3 \%(1108)$ & $12.6 \%(248)$ & $19.6 \%(386)$ & $11.5 \%(226)$ \\
Grade 5 and 6 & $39.9 \%(739)$ & $9.1 \%(168)$ & $21.4 \%(396)$ & $29.6 \%(549)$ \\
\hline
\end{tabular}


Table 3. Mean JOLs, Percentage of Concepts Selected for Restudy, Mean Recall Response Credit, and Mean SSJs of $3^{\text {rd }} / 4^{\text {th }}$ and $5^{\text {th }} / 6^{\text {th }}$ Grade Cohorts following Omitted, Inaccurate, Partially Correct and Fully Correct Prior Knowledge Activation (SD of the Mean in Parentheses).

\begin{tabular}{lclll}
\hline Grade Level & $\begin{array}{l}\text { Prior Knowledge: } \\
\text { Omission }\end{array}$ & $\begin{array}{l}\text { Prior Knowledge: } \\
\text { Inaccurate }\end{array}$ & $\begin{array}{l}\text { Prior Knowledge: } \\
\text { Partially Correct }\end{array}$ & $\begin{array}{l}\text { Prior Knowledge: } \\
\text { Fully Correct }\end{array}$ \\
\hline JOLs (range 0 -1) & & & $.94(.18)$ & $.99(.03)$ \\
Grade 3 and 4 & $.42(.41)$ & $.78(.32)$ & $.91(.18)$ & $.96(.1)$ \\
Grade 5 and 6 & $.47(.41)$ & $.8(.31)$ & $12 \%(33)$ & $6 \%(23)$ \\
Restudy Selections (\%) & & & $10 \%(29)$ & $11 \%(31)$ \\
Grade 3 and 4 & $60 \%(49)$ & $28 \%(45)$ & $.56(.31)$ & $.72(.35)$ \\
Grade 5 and 6 & $51 \%(41)$ & $24 \%(43)$ & $.68(.27)$ & $.82(.32)$ \\
Recall Response Credit (range 0-1) & & $.26(.36)$ & $.81(.31)$ & $.92(.19)$ \\
Grade 3 and 4 & $.15(.31)$ & $.50(.41)$ & $.88(.22)$ & $.50(.46)$ \\
Grade 5 and 6 & $.33(.43)$ & & &
\end{tabular}

Table 4. Mean Pretest Response Credit, Mean JOLs, Percentage of Concepts Selected for Restudy, and Mean SSJs of $3^{\text {rd }} / 4^{\text {th }}$ and $5^{\text {th }} / 6^{\text {th }}$ Grade Cohorts for Omission Errors, Commission Errors, Partially Correct Responses and Fully Correct Responses at the Recall Test (SD of the Mean in Parentheses).

\begin{tabular}{lllll}
\hline Grade Level & $\begin{array}{l}\text { Recall Test: } \\
\text { Omission Error }\end{array}$ & $\begin{array}{l}\text { Recall Test: } \\
\text { Commission Error }\end{array}$ & $\begin{array}{l}\text { Recall Test: Partially } \\
\text { Correct Response }\end{array}$ & $\begin{array}{l}\text { Recall Test: Fully } \\
\text { Correct Response }\end{array}$ \\
\hline $\begin{array}{l}\text { Pretest Response Credit (range 0 -1) } \\
\text { Grade } 3 \text { and } 4\end{array}$ & $.01(.05)$ & $.03(.14)$ & $.17(.25)$ & $.16(.28)$ \\
Grade 5 and 6 & $0(.04)$ & $.03(.17)$ & $.16(.26)$ & $.14(.3)$ \\
JOLs (range 0 - $)$ & & & & \\
Grade 3 and 4 & $.26(.33)$ & $.84(.28)$ & $.89(.23)$ & $.89(.23)$ \\
Grade 5 and 6 & $.19(.27)$ & $.69(.35)$ & $.85(.26)$ & $.85(.26)$ \\
Restudy Selections (\%) & & & & $12 \%(33)$ \\
Grade 3 and 4 & $76 \%(43)$ & $19 \%(39)$ & $15 \%(36)$ & $22 \%(41)$ \\
Grade 5 and 6 & $71 \%(46)$ & $35 \%(48)$ & $19 \%(40)$ & $.91(.23)$ \\
SSJs (range 0 -1$)$ & & & $.81(.29)$ & $.89(.22)$ \\
Grade 3 and 4 & $.01(.1)$ & $.74(.3)$ & $.84(.25)$ & \\
Grade 5 and 6 & $.01(.11)$ & $.62(.36)$ &
\end{tabular}


Relation between inaccurate prior knowledge activation and recall responses. Table 5 shows the effect of the four categories of pretest prior knowledge activation (omission, inaccurate, partially correct, fully correct) on the percentage of recall test responses (omission error, commission error, partially correct, fully correct). These results show that when participants activated inaccurate prior knowledge on the pretest, this resulted in an omission on the recall test for $25.1 \%$ of the responses, in a commission error for $36.6 \%$ of the responses, in partially correct for $25.4 \%$, and in a fully correct for $12.9 \%$ of the responses. A binary logistic multilevel regression analysis, $(0=$ no ability to activate any prior knowledge, 1 = inaccurate prior knowledge) was used to investigate the effect of prior knowledge activation at the pretest on commission errors at the recall test. When inaccurate prior knowledge was activated, this led to more commission errors at the recall test than when learners were not able to activate any prior knowledge (Hypothesis 1), Wald Chi-Square $=1,109.47, p=.0001$ ( $b=1.83, \mathrm{SE}=.17$, Wald $\mathrm{Cl}=1.49$ to 2.17). When inaccurate prior knowledge was activated at the pretest, $36.6 \%$ of this inaccurate prior knowledge became a commission error at the recall test. When learners were not able to activate any prior knowledge, only $8.5 \%$ of these omissions became a commission error at the recall test.

Table 5 shows that inaccurate prior knowledge not only led to more commission errors, but also to more partially correct responses than when learners were not able to activate any prior knowledge, Wald Chi-Square $=1,30.62, p=<.0001(b=0.86, S E=.16$, Wald $\mathrm{Cl}=.56$ to 1.17). In addition, Table 5 shows that when participants were not able to activate any prior knowledge at the pretest, these concepts remained omission errors at the recall test significantly more often than when inaccurate prior knowledge was activated, Wald Chi-Square $=1,39.38, p<.0001$ ( $b=1.09, \mathrm{SE}=.17$, Wald $\mathrm{Cl}=.75$ to 1.44). 
Table 5. Percentage of Students' Recall Test Omission and Commission Errors, and Partially and Fully Correct Responses Following Omitted, Inaccurate, Partially Correct and Fully Correct Prior Knowledge Activation. Findings are Tabled for Both Grade Cohorts.

\begin{tabular}{|c|c|c|c|c|}
\hline & \multicolumn{4}{|c|}{ Recall Test Responses } \\
\hline & $\begin{array}{l}\text { Test: Omission } \\
\text { Error }\end{array}$ & $\begin{array}{l}\text { Test: Commission } \\
\text { Error }\end{array}$ & $\begin{array}{l}\text { Test: Partially } \\
\text { Correct Response }\end{array}$ & $\begin{array}{l}\text { Test: Fully Correct } \\
\text { Response }\end{array}$ \\
\hline \multicolumn{5}{|l|}{ Grade 3 and 4} \\
\hline $\begin{array}{l}\text { Prior Knowledge: } \\
\text { Omission }\end{array}$ & $70.1 \%$ & $8.5 \%$ & $12.6 \%$ & $8.8 \%$ \\
\hline $\begin{array}{l}\text { Prior Knowledge: } \\
\text { Inaccurate }\end{array}$ & $25.1 \%$ & $36.6 \%$ & $25.4 \%$ & $12.9 \%$ \\
\hline $\begin{array}{l}\text { Prior Knowledge: } \\
\text { Partially Correct }\end{array}$ & $7.5 \%$ & $6.0 \%$ & $60.8 \%$ & $25.6 \%$ \\
\hline $\begin{array}{l}\text { Prior Knowledge: } \\
\text { Fully Correct }\end{array}$ & $0 \%$ & $11.1 \%$ & $33.3 \%$ & $55.6 \%$ \\
\hline \multicolumn{5}{|l|}{ Grade 5 and 6} \\
\hline $\begin{array}{l}\text { Prior Knowledge: } \\
\text { Omission }\end{array}$ & $52.1 \%$ & $7.7 \%$ & $14.5 \%$ & $25.8 \%$ \\
\hline $\begin{array}{l}\text { Prior Knowledge: } \\
\text { Inaccurate }\end{array}$ & $13.2 \%$ & $20.9 \%$ & $31.9 \%$ & $34.1 \%$ \\
\hline $\begin{array}{l}\text { Prior Knowledge: } \\
\text { Partially Correct }\end{array}$ & $.6 \%$ & $2.3 \%$ & $58.8 \%$ & $38.4 \%$ \\
\hline $\begin{array}{l}\text { Prior Knowledge: } \\
\text { Fully Correct }\end{array}$ & $1.8 \%$ & $7.1 \%$ & $17.9 \%$ & $73.2 \%$ \\
\hline
\end{tabular}

Effect of inaccurate prior knowledge activation on monitoring and regulation. A mixed model regression analysis was conducted to investigate whether JOLs were inappropriately high after activation of inaccurate prior knowledge, when compared to no activation of prior knowledge at all (Hypothesis 2a). Items were included as repeated measures, and a random intercept was included for every participant. Only the JOLs provided for concepts for which the recall responses would not receive credit (omissions and commission errors) were used in this analysis. For these incorrect responses, accurate JOLs should be low. Regression coefficients, standard errors, and 95\% confidence intervals are reported for inaccurate prior knowledge activation.

Results show that JOLs for concepts for which participants did not receive credit at the test were significantly higher after activation of inaccurate prior knowledge than after no activation of prior knowledge, $t(1274.5)=15.91, p<.0001,(b=4.47, S E=.28, \mathrm{Cl}=3.92$ to 5.02). JOLs (measured on a scale ranging from 0-10) for incorrect recall test responses were on average $7.3(S D=3.6)$ after activation of inaccurate knowledge, and 2.9 (SD = 3.6) after no activation of prior knowledge. 
Figure 3 depicts calibration accuracy of SSJs for recall test responses following omissions, inaccurate, partially, and fully correct prior knowledge activation at the pretest. A mixed model regression analysis was used to investigate whether inaccurate prior knowledge activation led to more overconfidence compared to not being able to activate any prior knowledge (Hypothesis 2b). Items were included as repeated measurement and a random intercept was included for the participants. Calibration accuracy for the SSJS showed that children were more overconfident when judging the quality of their recall after inaccurate prior knowledge activation at the pretest $(M=.32, S D=.42)$ than when they were unable to activate prior knowledge $(M=.09, S D=.28), t(1657)=11.41, p<$ $.0001(b=.23, S E=.02, \mathrm{Cl}=.19$ to .27$)$.

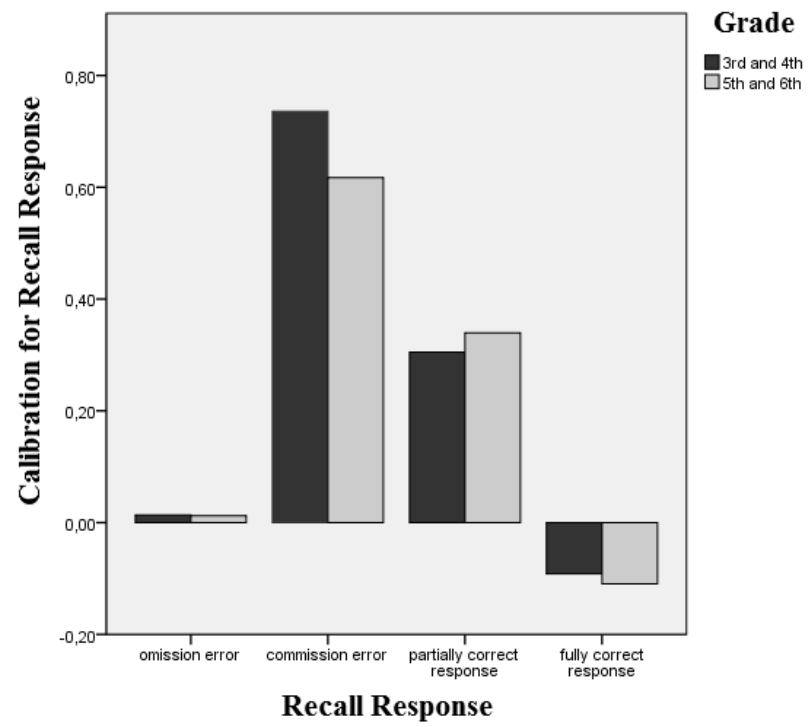

Figure 2. Calibration of self-score judgments for recall responses (omission errors, commission errors, partially correct, and fully correct) for the two grade cohorts. Calibration is measured as the difference between selfscore judgments and objective credit for recall responses. Positive values indicate overconfidence, negative values underconfidence. 


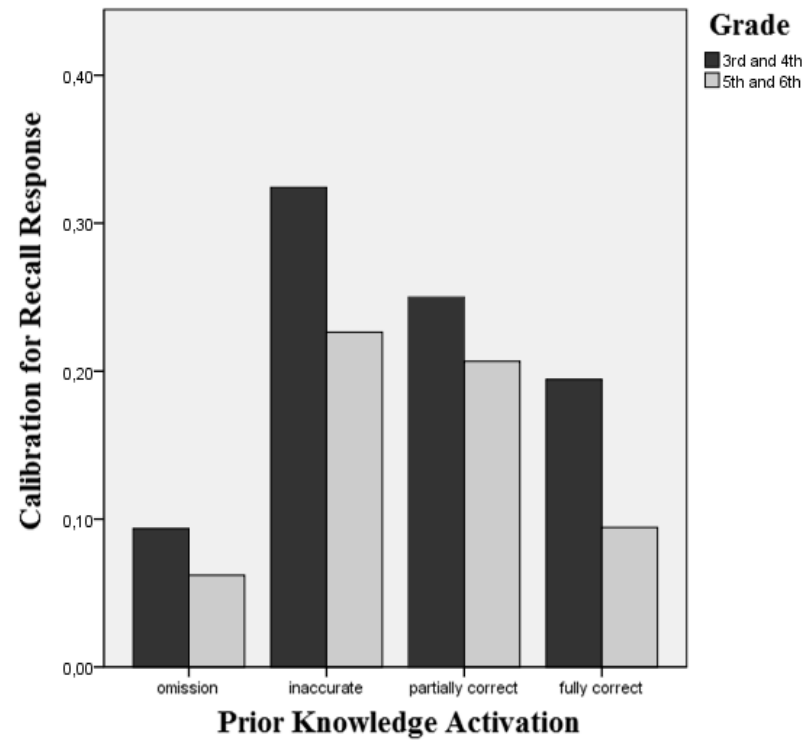

Figure 3. Calibration of self-score judgments for recall responses following prior knowledge activation (omissions, inaccurate, partially correct, and fully correct) for the two grade cohorts. Calibration is measured as the difference between self-score judgments and objective credit for recall responses.

Because the selection of items for restudy was measured on a binary scale $(0=$ item not selected, 1 = item selected), a generalized linear model for binary data was used to investigate the effect of prior knowledge activation on item selection. When accurately selecting items for restudy, participants would choose concepts of which they do not recall the meaning. Therefore, this analysis was again conducted on the concepts for which the participants would receive no credit at the recall test. We investigated whether activation of inaccurate prior knowledge at the pretest would lead children to more often discard these concepts from further study when compared to no activation of prior knowledge (Hypothesis 3). After activation of inaccurate prior knowledge at the pretest, concepts for which they would not receive credit at the recall test were less often selected for restudy, than after no activation of prior knowledge. After activation of inaccurate prior knowledge, $34 \%$ of the concepts was selected (SD $=.48$ ) versus $75 \%$ of the concepts $(S D=.45)$ when no prior knowledge could be activated. This difference was significant, Wald Chi-Square $=1,55.23, p<.0001(b=-1.53, \mathrm{SE}=.20, \mathrm{Wald} \mathrm{Cl}=-1.93$ to 1.12).

\section{Disc ussion}

The results of Study 1 showed that third- and fourth-grade children were highly overconfident when they evaluated the quality of their commission errors. This finding is 
consistent with the results of Lipko, Dunlosky, Hartwig, et al. (2009). The results showed that commission errors on the recall test occurred more often after activation of inaccurate prior knowledge at the pretest, than after no activation of prior knowledge, or after (partially) correct activation (Hypothesis 1). A substantial part of the commission errors emanated from inaccurate prior knowledge at the pretest.

When providing JOLs for concepts that were not yet understood, children's JOLs were higher after activation of inaccurate prior knowledge than after not being able to activate any prior knowledge (Hypothesis 2a). Moreover, the results showed that activation of inaccurate prior knowledge was detrimental to calibration accuracy of the SSIs (Hypothesis 2b). That is, children were more overconfident after commission errors than after omissions or (partially) correct prior knowledge activation.

With regard to regulation, children more often prematurely discarded concepts for which they activated inaccurate prior knowledge, whereas they more often decided to restudy the concepts for which they were not able to activate any prior knowledge (Hypothesis 3).

In sum, our findings indicate that commission errors, and overconfidence in these errors, in part results from the activation of inaccurate prior knowledge. Possibly, inaccurate prior knowledge activation leads to inaccurate JOLs and SSJs because learners base these judgments on accessibility of information, instead of the quality of the accessible information (Koriat, 1993). However, the present findings were obtained for third- and fourth-grade students. At this young age, metacognitive skills are still developing. There is evidence that between the ages of 9 and 12, metacognitive skills become more accurate and learners become less overconfident (e.g. Flavell, 1970; Krebs \& Roebers, 2010, 2011; Schneider \& Pressley, 1997). Therefore, it might be that inaccurate activation of prior knowledge has smaller effects on performance, metacognitive judgments, and calibration for older primary-school children. To test this possibility, we conducted a second study with fifth- and sixth-grade students. The same hypotheses were tested as in the first study, and the same procedure was used; only the concepts in the study task differed to make them age appropriate.

\section{Study 2}

\section{Method}

Participants. Participants were 95 primary-school children ( $48.4 \%$ male, 51.6\% female, $M$ $=10.6$ years, $\mathrm{SD}=0.8)$ from two fifth- $(n=48)$ and two sixth-grade $(n=47)$ classrooms from the same Dutch primary-school as participants in Study 1 . Study 2 did not include any of the Study 1 participants because both studies occurred in the same school year. 
All participants were fluent enough in Dutch to follow school lessons and to understand our instructions.

Materials and procedure. The procedure of Study 2 was exactly the same as that of the first study, except for the concepts. Based on the measure of lexical richness (Vermeer, 2000) and a pilot study with four participants, Dutch concepts were selected in the same manner as in the first study.

Data analysis. Studied concepts consisted of two to four idea units $(M=3.0, S D=$ .71). The prior knowledge responses and recall responses were scored according to the same criteria as used in Study 1 . Two independent raters scored $42 \%$ of the pretest and $13 \%$ of the recall test responses and showed a high level of agreement (Kappa $=.90$ and .79 respectively). Scoring of the first rater was used and this rater scored the remaining pretest and recall test responses.

Relative accuracy of JOLs could not be calculated for two participants due to invariance in JOL or test score. Gamma correlations indicating the efficiency of regulation of study could not be calculated for three participants due to invariance in selection or test score.

\section{Results}

Descriptive statistics. Participants provided a prior knowledge response at the pretest for $27 \%$ of the items. Table 1 shows the percentage and total amount of omissions, inaccurate, partially, and fully correct prior knowledge for the provided pretest responses. At the recall test, participants provided responses for $60 \%$ of the items. Table 2 shows the percentage and total amount of omission errors, commission errors, partially correct, and fully correct responses at the recall test. Descriptive statistics in relation to the four categories of prior knowledge activation (omissions, inaccurate, partially correct, fully correct) and the four categories of recall responses (omission errors, commission errors, partially correct responses, fully correct responses) are presented in Table 3 and 4 , respectively. Because different materials were used for the two age groups we could not test whether there were significant differences between the younger and the older cohort.

As in Study 1, relative JOL accuracy was high, $M$ gamma correlation = .76 (SD =.27), and the gamma correlation for regulation of study, gamma $=-.81(S D=.40)$, indicated that participants used their JOLs to select concepts for restudy.

Calibration accuracy for the four categories of recall responses (omission errors, commission errors, partially correct responses, and fully correct responses) is depicted in Figure 2. The mean of the SSJs for commission errors at the test was .62 (SD =.26), indicating that participants were overconfident when judging the quality of these recall responses. For $16 \%$ of these commission errors they expected to receive no credit, for 
$44.4 \%$ they expected to receive partial credit, and for $39.5 \%$ they expected to receive full credit.

Relation between inaccurate prior knowledge activation and recall responses. Table 5 displays the relation between pretest prior knowledge activation and responses at the recall test. As the table shows, when participants activated inaccurate prior knowledge on the pretest, there was an omission on the recall test for $13.2 \%$ of the responses, a commission error for $20.9 \%$, a partially correct response on the recall test for $31.9 \%$ of the responses, and a fully correct response on the recall test for $34.1 \%$ of the responses. When participants activated inaccurate prior knowledge, they were more likely to make commission errors at the test than when they were unable to activate prior knowledge, 20.9\% compared with 7.7\%, (Hypothesis 1), Wald Chi Square $=1,37.87, p<.0001$ ( $b=$ $1.16, S E=.19$, Wald $\mathrm{Cl}=.79$ to 1.53 ). In addition, activation of inaccurate prior knowledge led more often to partially correct responses at the recall test than when participants were unable to activate prior knowledge, Wald Chi Square $=1,45.63, p<.0001(b=1.02$, $S E=.15$, Wald $\mathrm{Cl}=.72$ to 1.31 ). When participants were unable to activate prior knowledge, this significantly more often remained an omission error at the recall test than when inaccurate prior knowledge was activated, Wald Chi Square $=1,151.34, p<$ .0001 ( $b=1.86, S E=.15$, Wald $\mathrm{Cl}=1.58$ to 2.19 ).

Effect of inaccurate prior knowledge activation on monitoring and regulation. $A$ mixed model regression analysis showed that JOLs for the incorrect recall responses were significantly higher after pretest activation of inaccurate prior knowledge than after no activation of prior knowledge, $t(818,79)=10.38, p<.0001,(b=3.37, S E=.32, \mathrm{Cl}=2.73$ to 4.00). JOLs for incorrect recall responses were on average $6.1(S D=2.4)$ after activation of inaccurate prior knowledge, and $2.4(S D=3.1)$ when learners were unable to activate prior knowledge (Hypothesis 2a).

Figure 3 depicts calibration accuracy following prior knowledge activation. The influence of inaccurate prior knowledge activation on posttest calibration accuracy of SSIs was investigated with a mixed model regression analysis (Hypothesis 2b). Calibration scores indicated more overconfidence after inaccurate prior knowledge activation $(M=$ .23, $S D=.39)$ than after no activation $(M=.06, S D=.28), t(1578)=8.14, p<.0001(b=$ $.16, S E=.02, \mathrm{Cl}=.12$ to .20$)$.

To investigate the effect of inaccurate prior knowledge on selection of items for restudy for which incorrect recall would follow, a generalized linear model for binary data was used (Hypothesis 3). Findings showed that after activation of inaccurate prior knowledge items were more often prematurely discarded from study (only $38 \%$ of the concepts were selected for restudy, $S D=4.8$ ) than when participants were unable to activate prior knowledge (67\% of the concepts were selected, $S D=4.9$ ), Wald Chi Square $=1,28.62, p<.0001(b=-1.23, S E=.23$, Wald $\mathrm{Cl}=-1.68$ to -.78$)$. 


\section{Disc ussion}

The results of Study 2 show the same pattern as those of Study 1. Even though the older children had a lower frequency of commission errors, and their absolute level of overconfidence was lower than those of the younger children, overconfidence in commission errors was high. Again, activation of inaccurate prior knowledge before study led to inappropriately high JOLs, less accurate calibration, and less efficient selection for restudy than when children were not able to activate any prior knowledge.

\section{General Disc ussion}

The aim of the present study was to investigate the effect of inaccurate prior knowledge activation on young learners' commission errors and their overconfidence in these errors when learning concepts. To the best of our knowledge, this study is the first to investigate the effect of inaccurate prior knowledge activation on children's calibration accuracy.

The study shows that inaccurate prior knowledge negatively affects children's metacognitive judgments in several ways when learning novel concepts. First of all, children did not accurately monitor the quality of information that was accessible in their memory. The findings showed that JOLs prior to recall responses for which they would not receive any credit were inappropriately high after activation of inaccurate prior knowledge (Hypothesis 2a). Moreover, results showed that activation of inaccurate prior knowledge was not only detrimental for monitoring judgments during learning, but also for calibration after test taking. That is, children were overconfident when self-scoring the quality of their recalled ideas after activation of inaccurate prior knowledge (Hypothesis 2b). Finally, this also applied when selecting concepts for further study. Children often prematurely discarded concepts for which they did not accurately recall the meaning after activation of inaccurate prior knowledge (Hypothesis 3).

Our findings show that when inaccurate prior knowledge was activated at the pretest, this more often resulted in a commission error at the recall test when compared with concepts for which no prior knowledge could be activated (Hypothesis 1). This implies that when activated prior knowledge is inaccurate, children are often not aware of this. Presumably, learners focus on the mere accessibility of information in memory instead of on the quality (Koriat, 1993), and therefore their inaccurate prior knowledge is often not corrected through further learning.

Note that when children did activate inaccurate prior knowledge at the pretest, recall test responses were more often partially correct than when children were not able to activate any prior knowledge (in that case pretest responses mainly remained omissions). At first sight, this seems to make the interpretation that inaccurate prior 
knowledge deteriorates self-regulated learning somewhat paradoxical. However, the problematic finding is that when learners activated inaccurate prior knowledge for concepts, later test responses not only became more often partially correct, but also more often turned into commission errors (on average $29 \%$ versus $8 \%$ when learners could not activate any prior knowledge). Calibration was most inaccurate for these commission errors: When children judged the quality of these errors they expected to receive credit for these completely incorrect responses. Moreover, findings show that it is unlikely that children will decide to allocate their study time to their commission errors: On average participants selected only $37 \%$ of the commission errors for restudy (whereas they decided to restudy $74 \%$ of the concepts for which they made omission errors). Our findings imply that when children engage in self-regulated learning in a naturalistic setting, they mainly allocate their study time to omissions, and often decide not to further study commission errors. It thus seems likely that recall performance will improve for omissions, but it is less likely that recall performance will improve for commission errors. In sum, our findings show that inaccurate prior knowledge activation can lead to commission errors, and inaccurate prior knowledge seems therefore more problematic for calibration and self-regulated learning than when learners do not have any prior knowledge accessible prior to studying.

It should be noted that the percentage of items that were responded to on the pretest, and as a consequence, the percentage of inaccurately activated prior knowledge, was relatively low in both studies. At the pretest as well as the recall test participants were allowed omissions (i.e., not providing any response), because we would have artificially inflated the frequency of inaccurate responses on the pretest if we would have forced the children to provide a response. The low percentage of responses in general confirms that the concepts we selected were largely unknown to the participants (a necessity because otherwise there would not be much left to learn).

In the present study, learners were asked to attempt to activate prior knowledge at a pretest prior to study. This may have been a limitation of the study because in real-life learners are usually not confronted with a pretest. However, it is likely that inaccurate prior knowledge also hinders self-regulated learning when learners are not explicitly asked to activate prior knowledge at a pretest, as other research has shown that learners base their monitoring judgments on their assessment of prior knowledge (Dinsmore \& Parkinson, 2013).

Relative accuracy of the JOLs was high, in line with prior findings on delayed JOLs (Nelson \& Dunlosky, 1991; Rhodes \& Tauber, 2011). In addition, consistent with previous research (De Bruin et al., 2011; Metcalfe \& Finn, 2008), the children decided to restudy the concepts for which they provided low JOLs. This indicates that children can accurately discriminate between concepts on the basis of accessibility of these concepts in memory as a cue, such as is measured by the correlations between JOLs and performance. 
However, our findings reveal that JOLs and restudy selections were not always accurate. When children are asked to judge the quality of these ideas, which is required when making absolute judgments, their monitoring was very poor. The monitoring judgments were inappropriately high when children had inaccurate information accessible, and children often prematurely discarded these items from restudy.

Even though we were unable to statistically compare the age cohorts, the equal pretest scores indicate that these materials were of similar difficulty. The results on activation of inaccurate prior knowledge between cohorts also largely parallel each other. It seems that learners in the older age cohort were able to overwrite their inaccurate prior knowledge more often. They made less commission errors at the recall test, and showed less overconfidence in these errors than the younger age cohort. Consistent with Krebs and Roebers (2010; 2011), the older age group was better calibrated than the younger one. However, overconfidence occurred for commission errors for the older age group too, and inaccurate prior knowledge led to inflated JOLs, less efficient regulation of study, and less accurate calibration.

The focus of the present study was on calibration for omissions and commission errors, because to improve learning it is most important to investigate monitoring and control for incorrect responses (Krebs \& Roebers, 2010). Therefore, we did not explicitly focus on evaluations of the partially correct responses that contained some correct ideas but were incomplete. However, even though we did not specifically focus on partially correct responses, it has to be noted that the children also overestimated the quality of their recall when evaluating these responses. Previous studies have also shown that overconfidence is not only a problem with commission errors. When judging the quality of recall of partially correct responses, learners often expect to receive full credit (Dunlosky et al., 2005; Dunlosky \& Lipko, 2007). The present results indicate that the absolute level of calibration accuracy was not only poor after inaccurate prior knowledge activation, but also after activation of partially correct prior knowledge. Therefore, it appears that partially correct prior knowledge can also be hard to correct through instruction. Future research should further investigate the effect of activation of partially correct prior knowledge on calibration and self-regulated learning.

The present study shows that inaccurate prior knowledge can contribute to commission errors at the recall test, and to poor calibration for these errors. These findings reinforce the need for future research to investigate interventions that improve children's self-regulated learning, by focusing not only on accessibility but also on the quality of information in memory. Even though learners did overwrite some of their inaccurate prior knowledge in our studies, the findings demonstrate that this does not necessarily happen, especially not for the 8/9-year-old children.

Unfortunately, learners often have problems overwriting their inaccurate knowledge (e.g., Chi, Slotta, \& De Leeuw, 1994). Research has shown that to overwrite 
accessible inaccurate prior knowledge, it is necessary that learners co-activate this together with the correct information, and that they become aware that the two conflict with each other (Van den Broek \& Kendeou, 2008). It is possible that an explicit feedback intervention after prior knowledge activation might be promising to improve calibration accuracy. The definitions of the concepts were provided in the learning phase, and could have implicitly served as feedback, but apparently this was not sufficient. Explicit feedback could make learners aware of the fact that their prior knowledge conflicts with the information presented in the learning phase. Metcalfe and Finn (2012) found that although children's errors were not self-corrected without feedback, when feedback was given about errors performance improved drastically.

To conclude, as Ausubel, Novak, and Hanesian (1978) stated: "The most important factor influencing learning is what the learner already knows. Ascertain this and teach him accordingly" (pp. 163). Our findings add to this statement that what the learner believes to know also influences his learning, not only directly, but also indirectly by affecting monitoring and regulation of learning. Therefore, the identification of what children already know, and the detection of inaccuracies in their prior knowledge, might be important to improve their self-regulated learning. 


\section{References}

Alexander, P. A., \& Jetton, T. L. (2000). Learning from text: A multidimensional and developmental perspective. In M. L. Kamil, P. B. Mosenthal, P. D. Pearson, \& R. Barr (Eds.), Handbook of reading research: Vol. III (pp. 285-310). Mahwah, NJ: Lawrence Erlbaum Associates.

Ausubel, D., Novak, J., \& Hanesian, H. (1978). Educational psychology: A cognitive view (2nd Ed.). New York: Holt, Rinehart \& Winston.

Barnett, J. \& Hixon, J. (1997). A developmental study of self-assessment in elementary school children. Journal of Educational Research, 90, 170-174.

Chi, M. T. H., Slotta, J. D., \& De Leeuw, N. (1994). From things to processes: A theory of conceptual change for learning science concepts. Learning and Instruction, 4, 27-43. doi:10.1016/0959-4752(94)90017-5

De Bruin, A. B. H., Thiede, K. W., Camp, G., \& Redford, J. (2011). Generating keywords improves metacomprehension and self-regulation in elementary and middle school children. Journal of Experimental Child Psychology, 109, 294-310. doi: 10.1016/j.jecp.2011.02.005

Dinsmore, D. L., \& Parkinson, M. M. (2013). What are confidence judgments made of? Students' explanations for their confidence ratings and what that means for calibration. Learning and Instruction, 24, 4-14. doi: 10.1016/j.learninstruc.2012.06.001

Dochy, F., Segers, M., \& Buehl, M. (1999). The relation between assessment practices and outcomes of studies: The case of research on prior knowledge. Review of Educational Research, 69, 147-188. doi: $10.2307 / 1170673$

Dufresne, A., \& Kobasigawa, A. (1989). Children's spontaneous allocation of study time: Differential and sufficient aspects. Journal of Experimental Child Psychology, 47, 274-296. doi: 10.1016/00220965(89)90033-7

Dunlosky, J., Hartwig, M. K., Rawson, K. A., \& Lipko, A. R. (2011). Improving college students' evaluation of text learning using idea-unit standards. Quarterly Journal of Experimental Psychology, 64, 467-484. doi: 10.1080/17470218.2010.502239

Dunlosky, J., \& Lipko, A. R. (2007). Metacomprehension: A brief history and how to improve its accuracy. Current Directions in Psychological Science, 16, 228-232. doi: 10.1111/j.1467-8721.2007.00509.x.

Dunlosky, J., \& Rawson, K. A. (2012). Overconfidence produces underachievement: Inaccurate self evaluations undermine students' learning and retention. Learning and Instruction. doi: 10.1016/j.learninstruc.2011.08.003

Dunlosky, J., Rawson, K. A., \& Middleton, E. L. (2005). What constrains the accuracy of metacomprehension judgments? Testing the transfer-appropriate-monitoring and accessibility hypotheses. Journal of Memory and Language, 52, 551-565. doi: 10.1016/j.jml.2005.01.011

Flavell, J. H. (1970). The development of mediated memory. In H. W. Reese \& L. P. Lipsitt (Eds.), Advances in child development and behavior (Vol. 5). New York: Academic Press.

Hadwin, A. F., \& Webster, E. A. (2013). Calibration in Goal Setting: Examining the nature of judgments of confidence. Learning and Instruction, 24, 37-47. doi: 10.1016/j.learninstruc.2012.10.001

Huff, J. D., \& Nietfeld, J. L. (2009). Using strategy instruction and confidence judgments to improve metacognitive monitoring. Metacognition \& Learning, 4, 161-176. doi: 10.1007/s11409-009-9042-8

Hacker, D. J., Bol, L., \& Keener, M. C. (2008). Metacognition in education: A focus on calibration. In J. Dunlosky, \& R. Bjork (Eds.), Handbook of memory and metacognition. Mahwah, NJ: Lawrence Erlbaum Associates.

Koriat, A. (1993). How do we know what we know: The accessibility model of the feeling of knowing. Psychological Review, 100, 609-639. doi: 10.1037/0033-295X.100.4.609

Koriat, A. (1995). Dissociating knowing and the feeling of knowing: Further evidence for the accessibility model. Journal of Experimental Psychology, General, 124, 311-333. doi: 10.1037/0096-3445.124.3.311

Koriat, A. (1997). Monitoring one's own knowledge during study: A cue-utilization approach to judgments of learning. Journal of Experimental Psychology: General, 126, 349-370. doi: 10.1037/0096-3445.126.4.349 
Koriat, A. (2011). Subjective confidence in perceptual judgments: A test of the self-consistency model. Journal of Experimental Psychology: General, 140, 117-139. doi 10.1037/a0022171

Koriat, A. \& Levy-Sadot, R. (2001). The combined contributions of the cue-familiarity and the accessibility heuristics to feelings of knowing. Journal of Experimental Psychology: Learning, Memory, and Cognition, 27, 34-53. doi: 10.1037/0278-7393.27.1.34

Koriat, A., \& Shitzer-Reichert, R. (2002). Metacognitive judgments and their accuracy. In P. Chambres, M. Izaute, \& P. J. Marescaux (Eds.), Metacognition: Process, function and use (pp. 1-17). Boston: Kluwer Academic Publishers.

Krebs, S. S., \& Roebers, C. M. (2010). Children's strategic regulation, metacognitive monitoring, and control processes during test taking. British Journal of Educational Psychology, 80, 325-340. doi: 10.1348/000709910X485719

Krebs, S. S., \& Roebers, C. M. (2011). The impact of retrieval processes, age, general achievement level, and test scoring scheme for children's metacognitive monitoring and controlling. Metacognition and Learning. doi: 10.1007/s11409-011-9079-3.

Lipko, A. R., Dunlosky, J., Hartwig, M. K., Rawson, K. A., Swan, D., \& Cook, D. (2009). Using standards to improve middle school students' accuracy at evaluating the quality of their recall. Journal of Experimental Psychology: Applied, 15, 307-318. doi: 10.1037/a0017599

Lipko, A.R., Dunlosky, J., \& Merriman, W. E. (2009). Persistent overconfidence despite practice: The role of task experience in preschoolers' recall predictions. Journal of Experimental Child Psychology, 103, 152-166. doi: 10.1016/j.jecp.2008.10.002

Lipson, M. Y. (1982). Learning new information from text: The role of prior knowledge and reading ability. Journal of Reading Behavior, 14, 243-261.

Maki, R.H., Shields, M., Wheeler, A., \& Zacchilli, T. (2005). Individual differences in absolute and relative metacomprehension accuracy. Journal of Educational Psychology, 97, 723-731. doi: 10.1037/00220663.97.4.723

Metcalfe, J., \& Finn, B. (2008). Evidence that judgments of learning are causally related to study choice. Psychonomic Bulletin \& Review, 15, 174-179. doi:10.3758/pbr.15.1.174

Metcalfe, J., \& Finn, B. (2012). Hypercorrection of high confidence errors in children. Learning \& Instruction, 22, 253-261. doi: 10.1016/j.learninstruc.2011.10.004

Nelson, T. O. (1984). A comparison of current measures of the accuracy of feeling-of-knowing predictions. Psychological Bulletin, 95, 109-133. doi: 10.1037/0033-2909.95.1.109

Nelson, T. O., \& Dunlosky, J. (1991). When people's judgments of learning (JOLs) are extremely accurate at predicting subsequent recall: The "Delayed-JOL effect". Psychological Science, 2, 267-270. doi: 10.1111/j.1467-9280.1991.tb00147.x

Nelson, T. O., Dunlosky, J., Graf, A., \& Narens, L. (1994). Utilization of metacognitive judgments in the allocation of study during multitrial learning. Psychological Science, 5, 207-213. doi: 10.1111/j.14679280.1994.tb00502.x

Nelson, T. O., \& Narens, L. (1990). Metamemory: A theoretical framework and new findings. In G. H. Bower (Ed.), The psychology of learning and motivation (Vol. 26, 125-171). New York: Academic Press.

Ozuru, Y., Dempsey, K., \& McNamara, D. S. (2009). Prior knowledge, reading skill, and text cohesion in the comprehension of science texts. Learning and Instruction, 19, 228-242. doi: 10.1016/j.learninstruc.2008.04.003

Pieschl, S. (2009). Metacognitive calibration: An extended conceptualization and potential applications. Metacognition \& Learning, 4, 3-31. doi: 10.1007/s11409-008-9030-4

Rawson, K. A., \& Dunlosky, J. (2007). Improving students' self-evaluation of learning for key concepts in textbook materials. European Journal of Cognitive Psychology, 19, 559-579. doi: 10.1080/09541440701326022

Rhodes, M. G. \& Tauber, S. K. (2011). The influence of delaying judgments of learning on metacognitive accuracy: A meta-analytic review. Psychological Bulletin, 137, 131-148. doi: 10.1037/a0021705

Schneider, W., \& Pressley, M. (1997). Memory development between two and twenty. Mahwah, NJ: Erlbaum. 
Schneider, W., Visé, M., Lockl, K., \& Nelson, T. O. (2000). Developmental trends in children's memory monitoring: Evidence from a judgment-of-learning task. Cognitive Development, 15, 115-134. doi: 10.1016/s0885-2014(00)00024-1

Schraw, G. (2009). Measuring metacognitive judgments. In D. J. Hacker, J. Dunlosky, \& A. C. Graesser (Eds.), Handbook of Metacognition in Education (pp 415-429). New York: Routledge.

Schraw, G., Kuch, F., \& Gutierrez, A. P. (2013). Measure for measure: Calibrating ten commonly used calibration scores. Learning and Instruction, 24, 48-57. doi: 10.1016/j.learninstruc.2012.08.007

Thiede, K. W., Anderson, M. C. M., \& Therriault, D. (2003). Accuracy of metacognitive monitoring affects learning of text. Journal of Educational Psychology, 95, 66-73. doi: 10.1037/0022-0663.95.1.66

Thiede, K. W. and Dunlosky, J. (1999). Toward a general model of self-regulated study: An analysis of selection of items for study and self-paced study time. Journal of Experimental Psychology: Learning, Memory and Cognition, 25, 1024-1037. doi: 10.1037/0278-7393.25.4.1024

Van den Broek, P. \& Kendeou, P. (2008). Cognitive processes in comprehension of science text: The role of coactivation in confronting misconceptions. Applied Cognitive Psychology, 22, 335-351. doi 10.1002/acp.1418

Verburg, M. (2008). Van Dale woordenboek Nederlands voor VMBO \& MBO: Het woordenboek in begrijpelijke taal. Utrecht: Van Dale Lexicografie.

Vermeer, A. (2000). Lexicale rijkdom, tekstmoeilijkheid en woordenschatgrootte. Beschrijving van de MLR, een woordenschat-analyse programma. Toegepaste Taalwetenschap in Artikelen, 64, 95-105.

Wetzels, S. A. J., Kester, L., \& Van Merriënboer, J. (2011). The influence of prior knowledge on the retrievaldirected function of note taking in prior knowledge activation. British Journal of Educational Psychology, 81, 274-291. doi: 10.1348/000709910X517425 


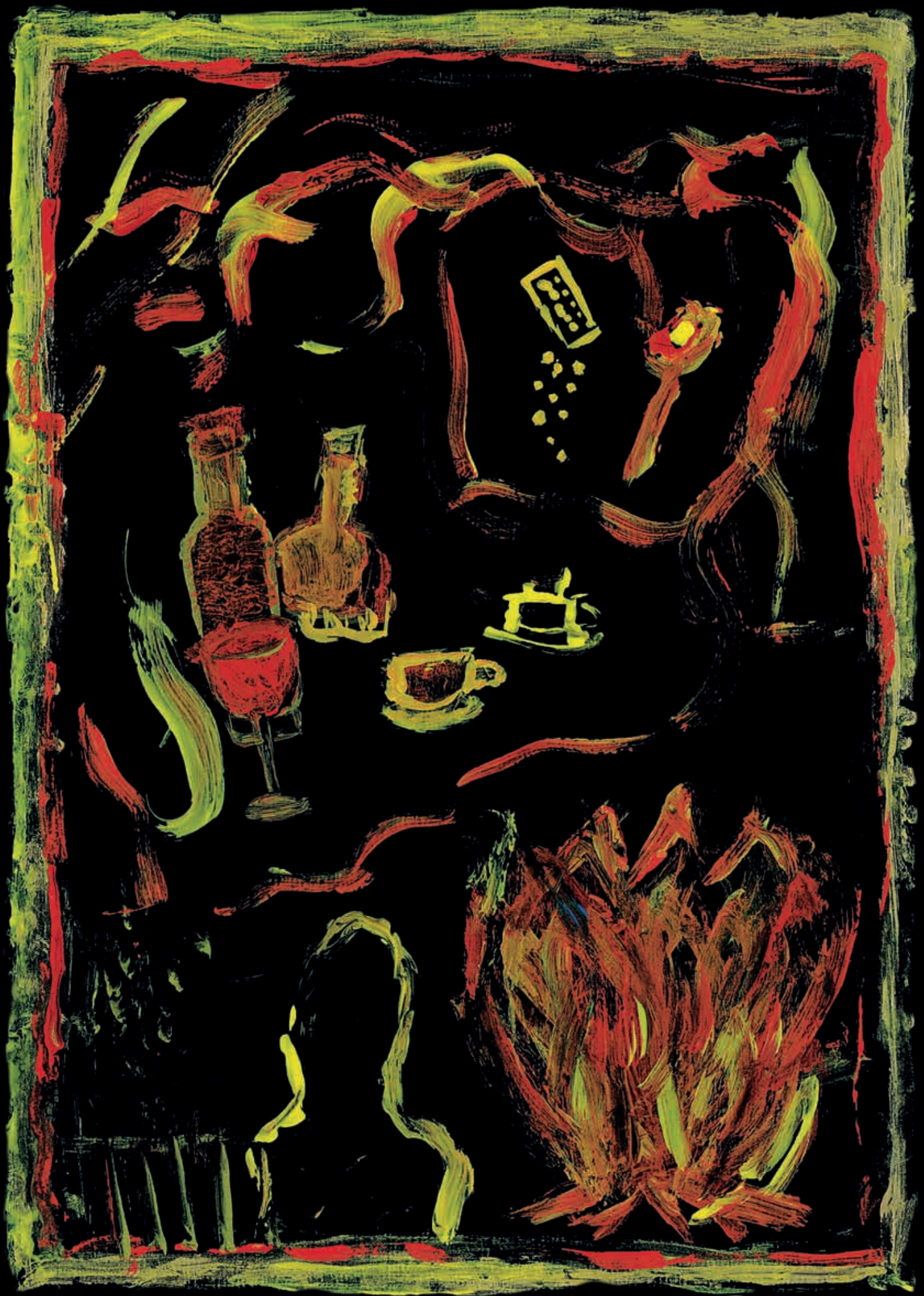




\title{
CHAPTER 6 \\ Refutations in Science Texts Lead to Hyperc orrection of High-Confidence Misconceptions
}

\begin{abstract}
Misconceptions about science are often not corrected during study when these misconceptions are held with high-confidence. However, when corrective feedback co-activates a misconception together with the correct conception this may surprise the learner and draw attention, especially when the misconceptions are held with high confidence. Therefore, high-confidence misconceptions might be more likely to be corrected than lowconfidence misconceptions. The present study investigates whether this hypercorrection effect occurs when students read science texts. Effects of two text formats were compared: Standard texts that presented factual information, and refutation texts that explicitly addressed misconceptions and proceeded to refute these before presenting factual information. Eight-grade adolescents $(n=114$ ) took a pre-reading test about 16 common misconceptions about science concepts; rated their confidence in correctness of their response to the pre-reading questions; read 16 texts about the science concepts; and finally took a post-test. Analyses of posttest responses show that reading refutation texts indeed causes hypercorrection: Learners more often corrected high-confidence misconceptions after reading refutation texts than after reading standard texts. Reading refutation texts did not have beneficial effects on correction of low-confidence misconceptions. Presumably, reading refutation texts surprised learners and drew attention to high-confidence misconceptions and their corrections.
\end{abstract}

This chapter is submitted as Van Loon, M.H., Dunlosky, J., Van Merriënboer, J. J. G., Van Gog, T., \& De Bruin, A. B. H. Refutations in science texts lead to hypercorrection of high-confidence misconceptions. Manuscript submitted for publication. 


\section{Refutations in Science Texts Lead to Hypercorrection of High- Confidence Misconceptions}

Adolescents in secondary education are increasingly expected to engage in self-regulated learning in many subjects, and science is no exception (Alvermann, 2002). To achieve good learning outcomes, students must understand the concepts presented in the texts, so effective self-regulated learning requires them to determine how well they have understood these concepts, and to continue studying if they do not yet understand them. However, comprehending science texts can be challenging. In many situations, learners fail to correctly understand the concepts presented in the text (Otero, Leon, \& Graesser, 2002; Sinatra \& Broughton, 2011). For instance, learners have difficulty understanding concepts such as airflow (Braasch, Goldman, \& Wiley, 2013), motion (McCloskey, 1983), or the nature of light (Mason, Gava, \& Boldrin, 2008). Furthermore, learners often cannot accurately monitor whether they correctly understand the information presented in studied texts (Thiede, Griffin, Wiley, \& Redford, 2009). When monitoring of text learning is inaccurate, learning is not likely to be well adapted to the current level of understanding, because learners cannot strategically decide which passages are not yet well learned and thus they may stop studying prematurely (Dunlosky \& Rawson, 2013; Son \& Metcalfe, 2000; Thiede, Anderson, \& Therriault, 2003).

One major obstacle to learning from science texts are learners' misconceptions, which are often based on naive ideas about concepts that differ from the accepted scientific conceptions, are quite resistant to change, and can therefore hinder learning (Alvermann \& Hynd, 1989; Braasch, Goldman, \& Wiley, 2013; Kendeou \& van den Broek, 2005). For instance, Schneps (1989) reported that many university students hold the misconception that seasonal changes are caused by fluctuations in the distance between the Earth and the Sun. Instead, seasonal changes are caused by the tilted position of the Earth. Such misconceptions about scientific concepts are prevalent and persistent (Hammer, 1996) and hinder acquisition of accurate knowledge. Interestingly, Schneps (1989) also found that the students were very confident in their misconceptions, suggesting that these are firmly established. Indeed, misconceptions that learners state with high confidence are resistant to change (Dole \& Sinatra, 1998; Ecker, Lewandowsky, \& Tang, 2010). Presumably, high-confidence misconceptions are harder to correct than the ones which are held with lower confidence, because high-confidence misconceptions are more accessible in memory (Ecker, Lewandowsky, Swire, \& Chang, 2011).

However, there are indications from studies with other kinds of learning materials that, when learners receive explicit feedback that their response is incorrect, misconceptions that are committed with high confidence are more likely to be corrected than misconceptions that are held with less confidence, a finding called the hypercorrection effect (Butterfield \& Metcalfe, 2001). This effect has been shown with 
tasks such as: What is the name of the river that runs through Rome? When learners answered questions incorrectly, they received feedback immediately in the form of the correct answer (Butterfield \& Metcalfe, 2001; Metcalfe \& Finn, 2012). The hypercorrection effect in part occurs because after people confidently make an incorrect response, the correcting feedback surprises them and draws attention to the feedback (e.g., Butler, Fazio, \& Marsh, 2011; Metcalfe, Butterfield, Habeck, \& Stern, 2012). Many studies have concluded that surprising events are better remembered than unsurprising events (Butterfield \& Metcalfe, 2006; Metcalfe et al., 2012). Put differently, because people are more surprised when feedback contradicts their high-confidence misconceptions, they might pay extra attention to the correct information, and therefore, one would expect that the high-confidence misconceptions will be corrected more often than the low-confidence ones (Butterfield \& Metcalfe, 2006).

Whether the hypercorrection effect will also occur for science concepts is not yet known. As we will explain below, simply giving feedback that an answer is not correct is usually insufficient for conceptual change to occur, but there are certain instructional formats that are effective for promoting conceptual change, such as refutation texts. Would such instructions also lead to hypercorrection? Furthermore, it is important to investigate whether hypercorrection (if it occurs) would remain after some delay. Almost all research on hypercorrection has used a delay of only a few minutes between the presentation of feedback and the final test, although two studies suggested that the hypercorrection effect persists after one week (Butler, et al., 2011; Butterfield \& Mangels, 2003). In educational settings, learners are typically not tested immediately after studying texts, and hence they need to retain the studied information in long-term memory because they are tested after a delay. Therefore, we investigated whether reading refutation texts, containing explicit feedback about incorrectness of a misconception, has beneficial effects on adolescents' correction of high-confidence misconceptions of science concepts at a delayed test.

\section{Correcting Misc onceptions: Refutations when Studying Science Text}

In most text books, standard text formats are used which emphasize and explain currently accepted scientific explanations of concepts (Tippett, 2010). However, when reading standard texts, learners might have difficulties noticing the discrepancy between their misconceptions and the provided explanation for the correct conception. The standard text format might not be suitable to support learners to deeply process the discrepancies between their naive ideas and the explanatory frameworks in the science text (Diakidoy, Kendeou, \& Ioannides, 2003). Therefore, standard text formats may not be effective for 
correcting misconceptions, because explanations in the studied text do not undermine the perceived truth of learners' science misconceptions (Braasch et al., 2013; Diakidoy et al., 2003).

When studying science texts, providing explicit refutations of misconceptions seems to increase the likelihood of correction (Guzzetti, Snyder, Glass, \& Gamas, 1993). To correct misconceptions, learners need to co-activate these together with the correct concepts to become aware that the two conflict with each other (Van den Broek \& Kendeou, 2008). A special text format, called a refutation text, has been designed to support such co-activation. Refutation texts always contain two components in addition to a standard text: The statement of the misconception and explicit refutation of this misconception (Braasch et al., 2013; Tippett, 2010).

One reason why a hypercorrection effect might occur with co-activation caused by refutation texts, is that when high-confidence misconceptions are activated and then refuted in the texts, learners might be surprised and hence might more fully attend to the correct conception than when this is presented to learners through standard texts. Accordingly, the main purpose of this study was to test the refutation-causeshypercorrection $(\mathrm{RCH})$ hypothesis, which is that reading refutation texts will lead to hypercorrection of high-confidence misconceptions in comparison to reading standard texts (Hypothesis 1), and that, for correction of low-confidence misconceptions, reading refutation texts will not have an additional benefit over reading standard texts (Hypothesis 2)).

Finally, the question is whether refutation texts can support the self-regulated learning process, in other words, whether they also improve learners' ability to accurately monitor their understanding of studied texts (Dunlosky, Rawson, Hartwig, \& Lipko, 2011; Dunlosky \& Thiede, 2013), and to make adaptive study selections. In making study selections, learners should use the output of their monitoring to select the texts for which they yet hold misconceptions for further study, and discard the texts for which they have corrected the misconception (e.g., Thiede et al., 2003). Monitoring of text learning would likely be inaccurate when learners hold misconceptions, because they often perceive this knowledge as correct and complete when, in fact, their knowledge is entirely inaccurate (Van Loon, de Bruin, Van Gog, \& Van Merriënboer, 2013). When learners do not accurately monitor their understanding of studied texts, their confidence in the accuracy of their misconception can lead to premature termination of study (Van Loon et al., 2013). Even though refutation texts have been demonstrated to improve learning when students hold misconceptions, it is unknown whether reading refutation texts can improve monitoring accuracy and regulation when reading texts about misconceptions. Therefore, our second aim was to investigate effects of refutation texts on monitoring accuracy and study selections. We address as an open question whether reading 
refutation texts fosters accurate monitoring (Question 1a) and adaptive study selections (Question $1 \mathrm{~b}$ ) in comparison to reading standard texts.

\section{Present Study}

We investigated eighth graders' misconceptions by asking them to answer pre-reading test questions, which were true/false statements about common misconceptions (see Table 1 for an overview of the method and refer to Appendix A for examples of misconceptions). After responding to each statement they rated their confidence in the accuracy of their response. Next, participants studied texts with information that contradicted common misconceptions: Half of the learners studied refutation texts and the other half studied standard texts. Following reading, participants provided a judgment of learning $(\mathrm{JOL})$ about their understanding of each text. Specifically, for each of the texts, learners were asked to predict how well they would perform on a future test. Following JOLs, they made restudy selections by indicating which texts they wanted to restudy before taking the test.

Learners completed two post-tests one week after studying: A test with open-ended questions and a statement test with the same true/false statement questions as used in the pre-reading test. These post-tests assessed whether learners corrected their misconceptions and were able to replace misconceptions with the correct information. Furthermore, detail questions were asked about information in the texts that was not directly related to correction of the misconceptions. Conform Sanchez \& Garcia-Rodicio (2013), we expected that reading refutation texts would specifically focus learners on correction of misconceptions, and that text format would not affect learning of details.

\section{Method}

\section{Partic ipants and Design}

Participants were 114 eighth-grade pupils ( $M$ age $=13.75$ years, $S D=.51,72$ females, 46 males) of a secondary school in The Netherlands (all participants followed education in the highest level of secondary education, with a duration of 6 years). Each participant was assigned randomly to one text format (standard, refutation). The experiment consisted of two separate sessions. During the first session, participants were tested in the computer room of their school. During the second session, which was one week after the first session, they were tested with a paper-and-pencil task. In the first session, 118 pupils participated, however, four participants did not attend the second session, the remaining 
participants completing both sessions; 57 participants read refutation texts and 57 read standard texts.

\section{Materials}

Pre-reading test and confidence ratings. Pre-reading test questions were true/false statements about common misconceptions. An example of a statement is: "The brightest stars are the largest stars." The statements were addressing common misconceptions that were identified in a pilot study beforehand. In this pilot study, 51 participants in the same age group as our sample answered true/false statements and then rated confidence on a scale from $0 \%$ to $100 \%$ (ranging from 'not sure whether my response is correct' to 'entirely sure that my response is correct'), with increasing steps of $20 \%$. Participants were divided in two subgroups, two versions of the pilot study were used, and participants in each subgroup answered 20 of the 40 selected pilot statements. From these pilot data, 16 statements were selected. Mean accuracy for the selected statements on the pilot was 56\%; mean confidence was $69 \%$ for correct responses and $77 \%$ for incorrect responses. The statements were selected to ensure that these were common misconceptions that were often answered incorrectly, and to ensure that the responses to the statements would show sufficient variability in accuracy and confidence ratings. For eight of the pre-reading test questions the correct response was 'true', for the other eight the correct response was 'false'.

In the pre-reading test, participants filled out a response for each statement (i.e., true or false) and then rated their confidence for this statement on the confidence scale, ranging from $0 \%$ to $100 \%$ (i.e., points on the scale matched $0 \%, 20 \%, 40 \%, 60 \%, 80 \%$, and $100 \%)$.

Study phase. The study materials consisted of 16 passages that had the same topics as the pre-reading test statements. The topics of these passages, the misconceptions, and the correct information for all topics are listed in Appendix A. The difference between the two experimental groups was the format of the text. The standard texts consisted of a passage that explained a contradiction of the common misconception and details that were related to the topic of the text. The refutation texts contained, in addition to the contradiction of the misconception and the passage about details, a sentence that presented the common misconception and then explicitly refuted it. In the refutation text, an additional paragraph introduced the misconception (e.g., "many people believe that a camel's hump is filled with water"); then refuted it (e.g., "this is not true"), and then provided the correct information (e.g., "a camel's hump consists of fat"). See Appendix $\mathrm{B}$ for an example of a standard text and a refutation text. The mean number of words per text was 108.88; $S D=9.31$; range $=93$ - 125 for standard texts; for refutation texts mean words per texts was 126.00; $S D=10.27$; range $=111$ to 143 . 
JOLs and restudy selections. When making JOLs, participants saw the title of the text on the screen, accompanied by the question: How many test questions do you expect to complete correctly about the text [Title]? The JOLs were provided with a mouse-click on a 6 -point scale ranging from $0 \%-100 \%$ (points on the scale matched $0 \%, 20 \%, 40 \%, 60 \%$, $80 \%$, and $100 \%)$.

When making restudy decisions, participants indicated which texts they would want to restudy by clicking on a grid with an $8 \times 2$ array in which each cell was filled by a title of a previously studied text. The order of the texts in this grid was randomized for every participant, 0 to 16 texts could be selected. Note, however, that learners did not actually restudy any of the texts, because restudying the texts after judgments were made could inadvertently influence test performance and therefore have an artifactual influence on monitoring accuracy.

Post-tests. The open-ended test contained 16 questions that addressed key aspects of the common misconceptions that were contradicted by the study passages.

The statement test consisted of the same 16 true/false statements that were used for the pre-reading test. As in the pre-reading test, after filling out the true/false statements, participants were asked to rate their confidence in their response.

The details test consisted of 16 questions about details from the studied texts. Appendix C presents examples of open-ended test question about misconceptions, the statement test, and detail questions.

Table 1. Procedure of the Study

\begin{tabular}{ll}
\hline & Materials \\
\hline $\begin{array}{ll}\text { 1. Pre-reading test and } \\
\text { confidence rating }\end{array}$ & $\begin{array}{l}\text { - True/false statements, } 16 \text { statements about } \\
\text { common misconceptions }\end{array}$ \\
& - Confidence scale, rating of confidence in pre-reading \\
& test response from $0 \%-100 \%$
\end{tabular}




\section{Procedure}

The two sessions took about 80 minutes of instructional time; the second session occurred one week after the first session. All participants were tested in groups of 27 to 32 in their own classroom, with different conditions being present in each session to which the students were randomly assigned. In both sessions, all tasks were self-paced, and participants were encouraged to guess when they were not sure about their answer. Apart from the refutations in the texts for the refutation group, participants did not receive feedback in any phase of the experiment. Table 1 shows the procedure of the study.

The first session took place in the computer room of the school. Before starting the task, the experimenter explained to the participants that they would take a test and then study texts, and they were shown an example of the confidence scale. Further, they were instructed that they would need to take a test about the studied texts the following week, and that the test would contain both open-ended and multiple-choice questions. Participants were instructed to use their personal log-in number to start the task.

Once all pre-reading test statements had been answered, there was a short filler task in which participants completed some questions about their experience with scientific research. These filler questions were added to ensure that the study phase did not follow immediately after completing the pre-reading test. When reading the texts, participants could proceed to the next text with a mouse-click. After reading the texts, participants again completed short filler questions, which were four riddles. This filler task was given to ensure that judgments and study decisions did not follow immediately after text study. Both the JOLs and the restudy selections were provided with a mouse-click on the scale.

In session 2, which took place one week after the first session, participants were tested with pencil-and-paper tests about their memory for texts they studied in session 1 with the open-ended questions as well as the statement test with true/false questions.

\section{Scoring}

All responses to the open-ended questions were scored by hand. Scores on the questions about the misconception topic were scored as omission (0 credit), misconception (0 credit), other error (0 credit), partially correct (.5 credit), or fully correct (1 credit). For example, for the question concerning why some stars are brighter than others (which is related to how close they are to the earth), if the answer stated that the brighter stars are largest, it was scored as a misconception. When the participants did not provide any response, it was scored as an omission. If a participant stated, for example, that star brightness depends on the material with which a star is made, this response was scored 
as 'other error'. When the participant would respond that it had something to do with the distance, but did not explain that the brighter stars are closer to the earth, this response was scored as partially correct. Comprehension was emphasized; therefore, a response was also scored as correct when the participant responded with a paraphrase of the original text and spelling errors did not affect scoring. Two raters scored $19.4 \%$ (a total of 367) responses on questions about statements and inter-rater agreement was high (Kappa = .88); the scores of the first rater were used for the analyses.

The detail questions were scored as omission ( 0 credit), error ( 0 credit), partially correct (.5 credit), or fully correct (1 credit). Two raters scored 19.3\% (a total of 365) of all test responses on detail questions, and agreement was high (Kappa $=.93)$.

\section{Results}

First, data about pre-reading test and post-test responses and the effect of text format on test performance are presented. Next, data relevant to evaluating the $\mathrm{RCH}$-hypothesis are presented, and then the effects of text format on JOL accuracy and restudy selections are analyzed.

\section{Mean Performance on Pre-Reading Test and Post-Tests}

Pre-reading test responses and confidence. Of the responses to the pre-reading test statements, 53.9\% consisted of misconceptions, $46.1 \%$ was correct. Mean confidence was $68.57 \%$ ( $S D=13.72$ ) for the misconceptions and $64.65 \%$ (SD = 16.03) for the correct responses; learners were more confident in their misconceptions than in their correct answers, $t(113)=3.343, p=.001$, Cohen's $d=.63$. This outcome indicates inaccurate monitoring of the correctness of the provided response at the pre-reading test.

Table 2. Test Responses at the Open-Ended and the Statement Test for the Group Reading Standard Texts and the Group Reading Refutation Texts.

\begin{tabular}{llll}
\hline Text Format & $\begin{array}{l}\text { Misconceptions } \\
\text { Open-Ended Test }\end{array}$ & $\begin{array}{l}\text { Correct Responses } \\
\text { Open-Ended Test }\end{array}$ & $\begin{array}{l}\text { Correct Responses } \\
\text { Statement Test }\end{array}$ \\
\hline Refutation & $13.04(9.17)$ & $61.40(15.45)$ & $88.49(12.49)$ \\
Standard & $19.85(13.72)$ & $55.37(15.37)$ & $78.94(13.96)$ \\
\hline
\end{tabular}

Effect of text format on post-test performance. Table 2 shows the effect of text format on participants' percentage of misconceptions and correct responses at the open-ended test; this Table also shows the percentage of correct performance at the true/false statement test. 
Analyses of the effect of text format on participants' test performance showed that, after reading refutation texts, participants provided less misconceptions at the open-ended test than after reading standard texts, $t(112)=3.109, p=.002$, Cohen's $d=.58$. Moreover, after reading refutation texts, the percentage of correct responses at the open-ended test was higher than after reading standard texts, $t(112)=2.089, p=.039$, Cohen's $d=$ .39. Further, after reading refutation texts, the percentage of correct responses at the statement test was higher than after reading standard texts, $t(112)=3.846, p<.001$, Cohen's $d=.72$. Note that, for both text reading groups, the number of correct responses was significantly higher on the statement test $(M=83.7 \%)$ than on the open-ended test $(M=59.8 \%), t(114)=22.50, p<.001$. Thus, even though learners often provided correct responses at the statement test, the lower number of correct responses at the openended test indicates that they did not always replace the misconception with correct information.

As expected, reading refutation texts specifically focused learners on misconceptions, there was no effect of text format on the accuracy of responses to the details test, $F(1,114)=.059, p=.810$. After reading standard texts, participants answered $21.33 \%$ of details test questions correctly $(S D=39.79)$, after reading refutation texts participants provided correct answers to $20.78 \%$ of the questions ( $S D=39.46$ ). This finding indicates that the reading refutation texts supported learners to specifically correct their misconceptions, and that reading those texts did not lead to extra processing of details from the texts. Furthermore, there was no significant effect of text format on reading times, $F(1,114)=1.343, p=.249$. Mean reading times per text were $36.11(S D=19.45)$ seconds for standard texts, and $38.75(S D=18.97)$ seconds for refutation texts.

\section{Effects of Text Format on Hyperc orrection}

Correction of high-confidence misconceptions at the open-ended test. The confidence judgments to answers on the pre-reading test (ranging from 0\% to 100\% with increasing steps of $20 \%$ ) were split into low confidence (0\% and $20 \%$ ); medium confidence $(40 \%$ and $60 \%)$; and high confidence (80\% and 100\%) categories. Figure 1 shows the effects of confidence and text format on correction of misconceptions at the open-ended test. To test Hypothesis 1, that high-confidence misconceptions are more often corrected after reading refutation texts than after reading standard texts, a mixed model regression analysis was used to take the level of the texts into account (all readers read 16 texts). Text format was entered as a fixed factor, participants were included as a random factor, the value of $b$ indicates the proportion of the difference between the standard and the refutation texts, and the $95 \%$ confidence interval provides an indication of the effect size. This analysis showed a trend, although not significant, that high-confidence 
misconceptions were more often corrected after reading refutation texts than after reading standard texts, $F(1,517)=2.932, p=.087, b=.075, \mathrm{SE}=.04, \mathrm{Cl}=-.011$ to .160 . Table 3 shows that $58.28 \%(S D=29)$ of high-confidence misconceptions were corrected at the open-ended test after reading refutation texts, whereas only $48.34 \%(S D=29)$ were corrected after reading standard texts.

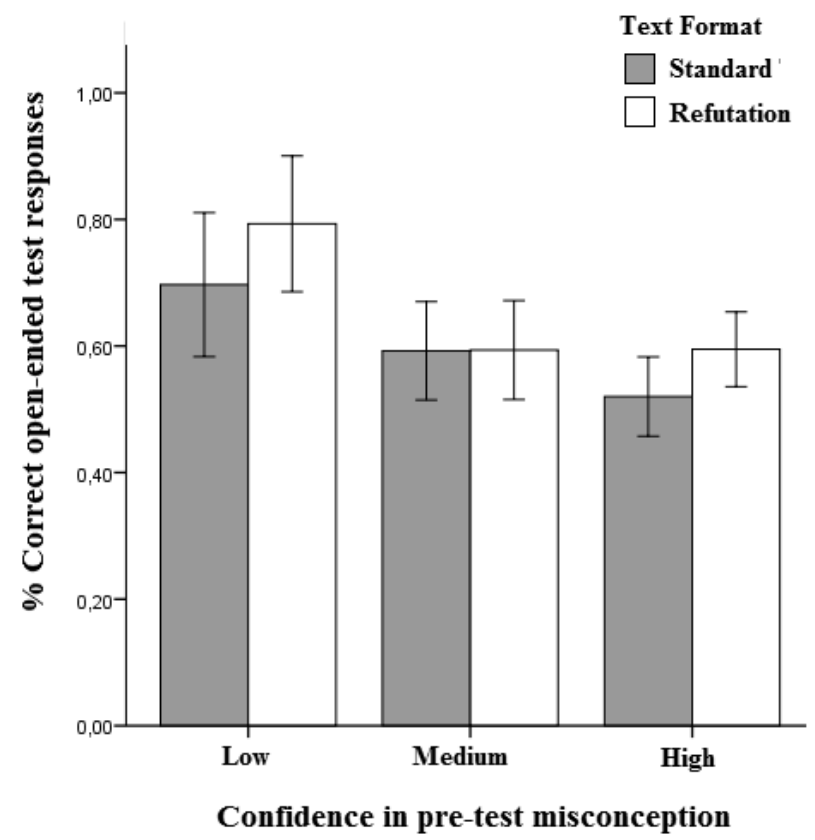

Figure 1. Percentage of correct responses at the open-ended test for the standard text and the refutation text group, as a function of confidence in the misconception at the pre-reading test. The error bars indicate the $95 \%$ confidence interval. Although there was a trend that high-confidence errors were more often corrected after reading refutation text, no significant differences were found between the standard text group and the refutation text group for correction of high-confidence misconceptions and low-confidence misconceptions.

Correction of low-confidence misconceptions at the open-ended test. The RCH hypothesis predicts that the effects of refutation texts will lead to correction of high-confidence misconceptions in comparison to reading standard texts (Hypothesis 1), and that there will be no difference between text formats on correction low-confidence misconceptions (Hypothesis 2). Table 3 shows that $76.88 \%(S D=37$ ) of low-confidence misconceptions were corrected after reading refutation texts, and $72.75 \%(S D=39)$ were corrected after reading standard texts. We did not find a significant effect of reading refutation texts on correction of low-confidence misconceptions, $F(1,124)=1.508, p=.222$. The finding that reading refutation texts did not have an additional benefit in comparison to reading standard texts for correction of low-confidence misconceptions supports Hypothesis 2. 
Correlations between confidence and correction at the open-ended test. To further investigate the $\mathrm{RCH}$-hypothesis, intra-individual gamma correlations were calculated between confidence in misconceptions and performance on the open-ended questions. This non parametric correlation coefficient, ranging from -1 to 1 , relates rankings on the confidence scale to response correctness at the post-test with open-ended questions for each text (cf. Nelson, 1984). A negative gamma correlation indicates an inverse relation between confidence and correction, which means that the misconceptions committed with lower confidence at the pre-reading test were more often corrected than the misconceptions committed with higher confidence. Instead, a positive value for gamma shows that high-confidence misconceptions are more often corrected than lowconfidence misconceptions. The mean gamma correlation between confidence in the misconception and open-ended test performance is $-.067(S D=.61)$ after reading refutation texts, and $-.338(S D=.51)$ after reading standard texts. Both gamma correlations are negative, indicating that low-confidence misconceptions were more often corrected than high-confidence misconceptions. However, the difference between the gamma correlations for the refutation text group and the standard text group is significant, $t(105)=2.226, p=.014$, Cohen's $d=.43$. This difference between the gamma correlations between confidence in misconceptions and test performance indicates that, after reading refutation texts, misconceptions committed with higher confidence were more often corrected than after reading standard texts. The negative gamma correlation for the group reading standard texts was significantly lower than $0, t(53)=-4.827, p<$ .001 , which shows that after reading standard texts, misconceptions committed with lower confidence were more often corrected than misconceptions committed with higher confidence. This mean gamma correlation was not significantly lower than 0 for the group reading refutation texts, $t(52)=-.790, p=.433$, indicating that after reading refutation texts, confidence in the misconception did not have a significant effect on correction. Overall, the findings confirm the $\mathrm{RCH}$-hypothesis: Reading refutation texts supports correction of misconceptions that are committed with a higher level of confidence whereas reading standard texts does not. The higher gamma correlation for the refutation text group indicates that the high-confidence misconceptions are more often corrected at the open-ended test after reading refutation texts than after reading standard texts (Hypothesis 1). 
Table 3. Percentage of High-Confidence and Low-Confidence Misconceptions Corrected at the Open-Ended and the Statement Test

\begin{tabular}{lllll}
\hline & \multicolumn{2}{l}{ Correct at Open-Ended Test } & \multicolumn{2}{l}{ Correct at Statement Test } \\
\hline Text Format & High-Confidence & Low-Confidence & High-Confidence & Low-Confidence \\
& Misconception & Misconception & Misconception & Misconception \\
Refutation & $58.28(32)$ & $76.88(37)$ & $87.84(22)$ & $91.93(22)$ \\
Standard & $48.34(29)$ & $72.75(39)$ & $63.60(31)$ & $91.89(24)$ \\
\hline
\end{tabular}

Correction of high-confidence misconceptions at the statement test. Figure 2 shows the effect of learners' confidence in the misconceptions and text format on correction of misconceptions at the statement test. For correction of high-confidence misconceptions, Figure 2 shows that after reading refutation texts, learners more often corrected their high-confidence misconceptions than after reading standard texts. Indeed, mixed model analyses show that this difference was significant, $F(1,532)=27.91, p<.001, b=.183, \mathrm{Cl}$ $=.115$ to .251 (confirming Hypothesis 1).

Table 3 shows that $87.84 \%(S D=22)$ of the high-confidence misconceptions were corrected after reading refutation text, whereas only $63.60 \%(S D=31)$ were corrected after reading standard texts.

Correction of low-confidence misconceptions at the statement test. Table 3 shows that at the statement test, $91.93 \%(S D=22)$ of low-confidence misconceptions were corrected after reading refutation texts, and $91.98 \%(S D=24)$ after reading standard texts. There was no difference between refutation texts and standard texts on correction of low-confidence misconceptions, $F(1,127)=.166, p=.685$, confirming Hypothesis 2 , which stated that the reading refutation texts would not lead to more correction of lowconfidence misconceptions than reading standard texts. 


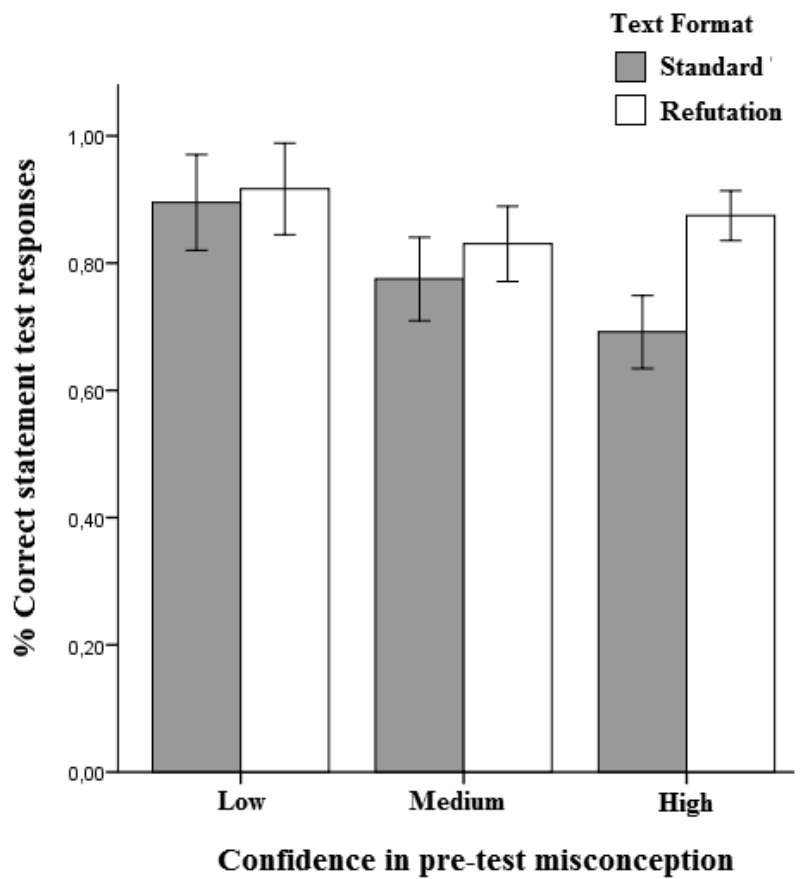

Figure 2. Percentage of correct responses provided at the true/false statement test for the standard text and the refutation text group, as a function of confidence in the misconception at the pre-reading test. The error bars indicate the $95 \%$ confidence interval. A significant difference was found between the standard text group and the refutation text group for high-confidence misconceptions; learners provided more correct test responses after reading refutation texts.

Correlations between confidence and correction at the statement test. The gamma correlation between confidence in pre-reading misconceptions and statement test score is $.129(S D=.64)$ for the group reading refutation texts, and $-.439(S D=.52)$ for the group reading the standard texts, the difference between groups is significant, $t(77)=4.34, p<$ .001 , Cohen's $d=.99$. The gamma correlation for the group reading refutation texts was not significantly different from $0, t(32)=1.154, p=.257$, whereas the gamma correlation for the group reading standard texts was significantly below $0, t(45)=-5.74, p<.001$. This shows a reverse relation between confidence in misconceptions and correction for the group reading standard texts, low confidence misconceptions were more often corrected than high-confidence misconceptions for the group reading standard texts, whereas there was no relation between confidence in misconceptions and correction for the group reading refutation texts.

In sum, the findings on correction of misconceptions at the statement test support the RCH-hypothesis: Reading refutation texts supports learners to correct their highconfidence misconceptions more so than reading standard texts (Hypothesis 1); for 
correction of low-confidence misconceptions, reading refutation texts does not have an additional benefit over reading standard texts (Hypothesis 2).

Table 4. JOLs and Restudy Selections

\begin{tabular}{lll}
\hline & JOLs & \% Selected for Restudy \\
\hline Refutation Text Group, Open-Ended Test & & $21.47 \%(41.13)$ \\
Misconception corrected & $56.11 \%(29.05)$ & $31.32 \%(46.66)$ \\
Misconception not corrected & $51.81 \%(26.14)$ & \\
Refutation Text Group, Statement Test & & $22.73 \%(41.96)$ \\
Misconception corrected & $54.34 \%(28.83)$ & $31.34 \%(46.74)$ \\
Misconception not corrected & $53.73 \%(25.40)$ & $23.13 \%(42.24)$ \\
Standard Text Group, Open-Ended Test & & $26.72 \%(44.44)$ \\
Misconception corrected & $57.84 \%(27.27)$ & \\
Misconception not corrected & $54.83 \%(27.17)$ & $24.23 \%(42.91)$ \\
Standard Text Group, Statement Test & & $30.57 \%(46.26)$ \\
Misconception corrected & $56.71 \%(27.47)$ & $55.04 \%(27.48)$ \\
Misconception not corrected & & \\
\hline
\end{tabular}

Note. Mean JOLs (provided on a scale from 0\% - 100\%) and Mean percentage restudy selections for the Corrected and the Not-Corrected Misconceptions at the Open-Ended and the Statement Test for the Two Text Formats. Standard deviations of the Mean in parentheses.

\section{JOLsand Restudy Selections}

JOLs. Participants' JOLs ranged from 0\% (indicating the learners are sure they will not be able to provide a correct test response) to $100 \%$ (confident to provide the correct test response). Table 4 shows the mean JOLs for the not-corrected and the corrected misconceptions for the refutation text group and the standard text group.

If reading refutation texts reduces overconfidence for the misconceptions that are not yet corrected through reading science texts, then learners will (a) make lower JOLs for these not-corrected misconceptions than for those that are corrected through reading, and (b) this effect of reading the science texts on JOLs will be larger after reading refutation texts than standard texts. (Note that, when making accurate JOLs for notcorrected misconceptions, the test response will be incorrect and these JOLs should be $0 \%$.) Mixed model analyses show that the JOLs for the misconceptions that were not corrected at the open-ended test were not affected by text format, $F(1,83.60)=.657, p$ $=.420$. As visible in the left column in Table 4, mean JOLs for not-corrected misconceptions were $51.81 \%(S D=26.14)$ after reading refutation text and $54.83 \%(S D=$ 
26.14) after reading standard text, indicating that learners in both groups were overconfident for these errors. JOL magnitudes for the misconceptions that were not corrected at the statement test confirm this finding, and also indicate overconfidence $(M$ $\mathrm{JOL}=53.73 \%, S D=25.40$ for refutation text group; $M J O L=55.04 \%, S D=27.48$ for standard text group). The difference between the two groups is not significant, $F(1$, $71.74)=.403, p=.527$. Thus, even though reading refutation texts supported correction of misconceptions, this text format did not improve monitoring accuracy.

Note that analyses of JOL accuracy investigated absolute accuracy, that is, the difference score between JOLs and actual performance. These analyses are considered more relevant in this case, because they provide the opportunity to analyze the degree of overconfidence for not-corrected misconceptions. For completeness, measures of relative accuracy, indicated by the correlation between JOLs and overall test performance (Nelson, 1984; Weaver, 1990) are reported in Appendix D.

Restudy selections. Study selections are adaptive if the studied texts for which the misconceptions are not yet corrected are selected for further study, whereas studied texts for which the misconception is corrected are discarded from further study. The right column in Table 2 shows the restudy selections for the not-corrected and the corrected misconceptions for the refutation and the standard text format. When investigating restudy selections for the texts for which the misconceptions were not corrected at the open-ended test, findings show that the text format did not lead to more adaptive restudy selections for the misconceptions that were not corrected at the open-ended test. Even though, if restudy selections were adaptive, $100 \%$ of these texts should have been selected for further study, only $28.80 \%$ (SD $=45.41$ ) of these texts were selected after reading refutation text and $28.57 \%(S D=45.29)$ after reading standard text, $F(1$, $86.58)=1.01, p=.318$. Thus, reading refutation texts did not improve the restudy selections for the not-corrected misconceptions at the open-ended test.

Moreover, text format did not affect restudy selections for the misconceptions that were not yet corrected at the statement test. Even though learners should have selected $100 \%$ of these misconceptions for further study, only $31.34 \%$ (SD $=46.74$ ) of the texts were selected after reading refutation texts and 30.58\% (SD $=46.27)$ after reading standard texts, $F(1,42.37)=2.252, p=.141$.

Thus, even though refutation texts improved correction of high-confidence misconceptions, reading refutation texts did not improve learners' restudy selections.

\section{Disc ussion}

The main aim of this experiment was to compare the effects of two text formats, refutation and standard texts, on adolescents' correction of high-confidence 
misconceptions. Second, we investigated effects of text format on monitoring accuracy and regulation of study. We discuss the findings regarding each of these aims in turn.

Errors which are committed with high confidence tend to be more difficult to correct than those committed with a lower level of confidence (Butterfield \& Metcalfe, 2001; Ecker et al., 2010). We evaluated the Refutation-Causes Hypercorrection (RCH) hypothesis, and in line with prior hypercorrection research (Butterfield \& Metcalfe, 2001, 2006; Metcalfe \& Finn, 2011; Metcalfe et al., 2012), we expected that the explicit feedback in the refutation texts would surprise learners and capture their attention, especially when these refutations contradict high-confidence misconceptions (given that such refutations would presumably be the most surprising). The findings provided convergent support for the RCH-hypothesis: Reading refutation texts led to more correction of high-confidence errors than reading standard texts (confirming Hypothesis 1). In contrast, for the low-confidence misconceptions, reading refutation texts did not support correction more than reading standard texts (confirming Hypothesis 2).

We also compared the effect of text format on responses on the open-ended test and responses to true/false statements. When responding to the statements, learners were merely asked to indicate whether a stated fact was true or false, whereas when responding to the open-ended questions, learners were required to reason. As would be expected (cf. Braasch et al., 2013; Guzzetti et al., 1993; Mason et al., 2008), reading refutation texts supported correction of misconceptions both at the open-ended and statement test more than did reading standard texts. Interestingly, the effect of reading refutation texts had a stronger effect on correction of misconceptions at the statement test than on correction of misconceptions at the open-ended test. Correcting a misconception involves both outdating of the misconception (which happens when a misconception becomes less accessible in memory because it has lost activation in the memory representation, Kendeou, Smith, \& O'Brien, 2013; Zwaan \& Radvansky, 1998) and updating of the memory representation by the incorporation of correct information (encoding, assimilating and accommodating novel information in memory, Kendeou et al., 2013; Rapp \& Kendeou, 2007). Effect sizes were larger for the effect of refutation texts on responses to statement tests than on the open-ended test. This outcome implies that outdating the misconception was more successful than updating the memory representation. In particular, although the learners often provided correct statement test responses for initially incorrect misconceptions, they often failed to show that they incorporated the novel information into their prior knowledge when responding to openended questions. Possibly, reading refutations in text explicitly focused learners' attention on processing of the misconception, and not on deeper processing, and the results might indicate that learners processed the refutations in the text at a shallow fashion (Kendeou \& van den Broek, 2005) and focused more on outdating than on updating. 
In classical hypercorrection studies (Butterfield \& Metcalfe, 2001; 2006; Fazio \& Marsh, 2009; Metcalfe \& Finn, 2011; Metcalfe et al., 2012), high-confidence errors are corrected more often than low confidence errors. Even though the present study shows that reading refutation texts supported correction of high-confidence misconceptions, we did not replicate the classical hypercorrection research, because the high-confidence errors were not more often corrected than low-confidence errors. After reading standard texts, low-confidence misconceptions were more often corrected than high-confidence misconceptions; after reading refutation texts, there was no significant relation between confidence in misconceptions and later correction. This effect could possibly be explained by differences in the pre-reading test and the feedback format. In the present experiment, learners responded to true/false questions about science concepts, whereas in traditional hypercorrection studies, learners respond to open-ended general information questions (developed by Nelson \& Narens, 1980), which they can typically answer with a one-word response. In our study, the learners were already presented with the option that their responses could be incorrect. Possibly, study of texts that provide feedback that a pre-reading test response was incorrect did not draw as much attention as the feedback that was provided in the classical hypercorrection research.

Furthermore, in the present study, learners received delayed feedback about the correctness of pre-reading test responses by reading expository science texts. In classical hypercorrection studies, learners received direct feedback in the form of short sentences containing the correct information, and only received detailed feedback about the correct response when they made an error. Therefore, learners' attention might not have been as captured as much by the feedback as it was in the hypercorrection studies. Future research should shed more light on effects of pre-test and feedback on hypercorrection of high-confidence errors.

We addressed whether reading refutation texts would improve monitoring accuracy (Question 1) and regulation of study (Question 2). The majority of research on refutation texts focused on improvement of performance and it was not known whether or how reading refutation texts affects metacognitive accuracy. Our findings show that reading refutation texts did not have any beneficial effect on monitoring accuracy: Participants were highly overconfident when predicting performance for not-corrected misconceptions. Furthermore, regulation was maladaptive; when selecting texts for restudy, they prematurely discarded most of the texts about which they still held misconceptions.

When monitoring, learners base predictions of performance on retrieval of information from the long-term memory representation (Rhodes \& Tauber, 2011a). Presumably, because learners could retrieve misconceptions from memory, the accessibility of information was not predictive of correct test performance (Koriat, 1998). Through reading refutation texts, learners were provided with a warning that 
misconceptions were incorrect. However, as demonstrated by Rhodes and Tauber (2011b), these warnings did not improve monitoring, possibly because processing the refutation did not alter participants' ability to monitor the accuracy of information in memory after reading the text. Future research should address improvement of monitoring when reading refutation texts.

Even though we presume that learners focused more attention when highconfidence misconceptions were co-activated with the refutations, a limitation of the present research is that we did not directly measure learners' attention. Future research could possibly use a tone detection task (cf. Butterfield \& Metcalfe, 2006) and think-aloud protocols to further investigate the assumption that hypercorrection of high-confidence misconceptions through reading science texts is caused by surprise and attention.

In conclusion, our findings add to the growing literature on the hypercorrection effect and the effect of refutations on correcting misconceptions (e.g., Braasch et al., 2013; Mason et al., 2008; Metcalfe et al., 2012) by showing that misconceptions about science are often not corrected when learners hold these with high confidence, and that reading refutation text supports learners more than reading standard texts to correct these high-confidence misconceptions. 


\section{References}

Alvermann, D. E. (2002). Effective literacy instruction for adolescents. Journal of Literacy Research, 34(2), 189208. doi: 10.1207/s15548430jlr3402_4

Alvermann, D. E., \& Hynd, C. R. (1989). Effects of Prior Knowledge Activation Modes and Text Structure on Nonscience Majors' Comprehension of Physics. Journal of Educational Research, 83(2), 97-102.

Braasch, J. L. G., Goldman, S. R., \& Wiley, J. (2013). The Influences of Text and Reader Characteristics on Learning From Refutations in Science Texts. Journal of Educational Psychology, 105(3), 561-578. doi: 10.1037/a0032627

Butler, A. C., Fazio, L. K., \& Marsh, E. J. (2011). The hypercorrection effect persists over a week, but highconfidence errors return. Psychonomic Bulletin \& Review, 18(6), 1238-1244. doi: 10.3758/s13423-0110173-y

Butterfield, B., \& Mangels, J. A. (2003). Neural correlates of error detection and correction in a semantic retrieval task. Cognitive Brain Research, 17(3), 793-817. doi: 10.1016/s0926-6410(03)00203-9

Butterfield, B., \& Metcalfe, J. (2001). Errors committed with high confidence are hypercorrected. Journal of Experimental Psychology-Learning Memory and Cognition, 27(6), 1491-1494. doi: 10.1037//02787393.27.6.1491

Butterfield, B., \& Metcalfe, J. (2006). The correction of errors committed with high confidence. Metacognition and Learning, 1(1), 69-84. doi: 10.1007/s11409-006-6894-z

Diakidoy, I. A. N., Kendeou, P., \& loannides, C. (2003). Reading about energy: The effects of text structure in science learning and conceptual change. Contemporary Educational Psychology, 28(3), 335-356. doi: 10.1016/s0361-476x(02)00039-5

Dole, J. A., \& Sinatra, G. M. (1998). Reconceptualizing change in the cognitive construction of knowledge. Educational Psychologist, 33(2-3), 109-128. doi: 10.1207/s15326985ep3302\&3_5

Dunlosky, J., Hartwig, M. K., Rawson, K. A., \& Lipko, A. R. (2011). Improving college students' evaluation of text learning using idea-unit standards. Quarterly Journal of Experimental Psychology, 64(3), 467-484. doi: 10.1080/17470218.2010.502239

Dunlosky, J., \& Thiede, K. W. (2013). Four cornerstones of calibration research: Why understanding students' judgments can improve their achievement. Learning and Instruction, 24, 58-61. doi: 10.1016/j.learninstruc.2012.05.002

Ecker, U. K. H., Lewandowsky, S., Swire, B., \& Chang, D. (2011). Correcting false information in memory: Manipulating the strength of misinformation encoding and its retraction. Psychonomic Bulletin \& Review, 18(3), 570-578. doi: 10.3758/s13423-011-0065-1

Ecker, U. K. H., Lewandowsky, S., \& Tang, D. T. W. (2010). Explicit warnings reduce but do not eliminate the continued influence of misinformation. Memory \& Cognition, 38(8), 1087-1100. doi: 10.3758/mc.38.8.1087

Fazio, L. K., \& Marsh, E. J. (2009). Surprising feedback improves later memory. Psychonomic Bulletin \& Review, 16(1), 88-92. doi: 10.3758/pbr.16.1.88

Guzzetti, B. J., Snyder, T. E., Glass, G. V., \& Gamas, W. S. (1993). Promoting conceptual change in science - a comparative metaanalysis of instructional interventions from reading education and science-education. Reading Research Quarterly, 28(2), 117-155. doi: 10.1002/acp.1418

Hammer, D. (1996). More than misconceptions: Multiple perspectives on student knowledge and reasoning, and an appropriate role for education research. American Journal of Physics, 64(10), 1316-1325. doi: 10.1119/1.18376

Kendeou, P., Smith, E. R., \& O'Brien, E. J. (2013). Updating During Reading Comprehension: Why Causality Matters. Journal of Experimental Psychology-Learning Memory and Cognition, 39(3), 854-865. doi: 10.1037/a0029468 
Kendeou, P., \& van den Broek, P. (2005). The effects of readers' misconceptions on comprehension of scientific text. Journal of Educational Psychology, 97(2), 235-245. doi: 10.1037/0022-0663.97.2.235

Koriat, A. (1998). Illusions of knowing: The link between knowledge and metaknowledge Metacognition: Cognitive and social dimensions (pp. 16-34). Thousand Oaks, CA: SAGE

Mason, L., Gava, M., \& Boldrin, A. (2008). On warm conceptual change: The interplay of text, epistemological beliefs, and topic interest. Journal of Educational Psychology, 100(2), 291-309. doi: 10.1037/00220663.100.2.291

McCloskey, M. (1983). Naive theories of motion. In D. G. A. L. Stevens (Ed.), Mental Models. Hillsdale, N.J: Erlbaum

Metcalfe, J., Butterfield, B., Habeck, C., \& Stern, Y. (2012). Neural Correlates of People's Hypercorrection of Their False Beliefs. Journal of Cognitive Neuroscience, 24(7), 1571-158

Metcalfe, J., \& Finn, B. (2011). People's hypercorrection of high-confidence errors: Did they know it all along? Journal of Experimental Psychology: Learning, Memory and Cognition, 37(2), 437-448. doi: 10.1037/a0021962

Metcalfe, J., \& Finn, B. (2012). Hypercorrection of high confidence errors in children. Learning and Instruction, 22(4), 253-261. doi: 10.1016/j.learninstruc.2011.10.004

Nelson, T. O. (1984). A comparison of current measures of the accuracy of feeling-of-knowing predictions. Psychological Bulletin, 95(1), 109-133. doi: 10.1037/0033-2909.95.1.109

Nelson, T. O., \& Narens, L. (1980). Norms of 300 General-Information Questions: Accuracy of Recall, Latency of Recall, and Feeling-of-Knowing Ratings. Journal of Verbal Learning and Verbal Behavior, 19, 338-368.

Otero, J., Leon, J. A., \& Graesser, A. C. (2002). Introduction to the psychology of science text comprehension. In J. Otero, J. A. Leon \& A. C. Graesser (Eds.), The Psychology of Science Text Comprehension (pp. 1-15). Mahwah, NJ: Erlbaum

Rapp, D. N., \& Kendeou, P. (2007). Revising what readers know: Updating text representations during narrative comprehension. Memory \& Cognition, 35(8), 2019-2032. doi: 10.3758/bf03192934

Rhodes, M. G., \& Tauber, S. K. (2011a). The Influence of Delaying Judgments of Learning on Metacognitive Accuracy: A Meta-Analytic Review. Psychological Bulletin, 137(1), 131-148. doi: 10.1037/a0021705

Rhodes, M. G., \& Tauber, S. K. (2011b). Monitoring memory errors: The influence of the veracity of retrieved information on the accuracy of judgements of learning. Memory, 19(8), 853-870. doi: 10.1080/09658211.2011 .613841

Sanchez, E., \& Garcia-Rodicio, H. (2013). Using online measures to determine how learners process instructional explanations. Learning and Instruction, 26, 1-11. doi: 10.1016/j.learninstruc.2012.12.003

Schneps, M. (1989). A Private Universe. San Francisco: Astronomical Society of the Pacific.

Retrieved from http://www.youtube.com/watch?v=TrXaQu_qGeo

Sinatra, G. M., \& Broughton, S. H. (2011). Bridging Reading Comprehension and Conceptual Change in Science Education: The Promise of Refutation Text. Reading Research Quarterly, 46(4), 374-393. doi: $10.1002 /$ rrq.005

Son, L. K., \& Metcalfe, J. (2000). Metacognitive and Control Strategies in Study-Time allocation. Journal of Experimental Psychology: Learning, Memory and Cognition, 26, 204-221.

Thiede, K. W., Anderson, M. C. M., \& Therriault, D. (2003). Accuracy of metacognitive monitoring affects learning of texts. Journal of Educational Psychology, 95(1), 66-73. doi: 10.1037/0022-0663.95.1.66

Thiede, K. W., Griffin, T. D., Wiley, J., \& Redford, J. (2009). Metacognitive monitoring during and after reading. Handbook of metacognition in education, 85-106.

Tippett, C. D. (2010). Refutation text in science education: A review of two decades of research. International Journal of Science and Mathematics Education, 8(6), 951-970. doi: 10.1007/s10763-010-9203-x

Van Den Broek, P., \& Kendeou, P. (2008). Cognitive processes in comprehension of science texts: The role of coactivation in confronting misconceptions. Applied Cognitive Psychology, 22(3), 335-351. doi: 10.1002/acp.1418 
Chapter 6

Van Loon, M. H., de Bruin, A. B. H., van Gog, T., \& van Merrienboer, J. J. G. (2013). Activation of inaccurate prior knowledge affects primary-school students' metacognitive judgments and calibration. Learning and Instruction, 24, 15-25. doi: 10.1016/j.learninstruc.2012.08.005

Weaver, C. A. (1990). Constraining Factors in Calibration of Comprehension. Journal of Experimental PsychologyLearning Memory and Cognition, 16(2), 214-222. doi: 10.1037/0278-7393.16.2.214

Zwaan, R. A., \& Radvansky, G. A. (1998). Situation models in language comprehension and memory. Psychological Bulletin, 123(2), 162-185. doi: 10.1037/0278-7393.24.5.1224 


\section{Appendix A. Misconceptions Add ressed in this Study}

\section{Misconception}

1) The largest part of the Sahara consists out of sand

2) Most male animals are stronger than the females

3) Columbus discovered North America

4) Bees always die after stinging

5) Bats are blind

6) Seasons are caused by the earth being closer to the sun in summer than in winter

7) Dragonflies can sting

8) Spanish peppers originally come from Spain

9) A camel stores water in its humps

10) Objects float in water because they are lighter than water

11) You get a cold from exposure to cold temperatures

12) Eskimos have 20 different words for snow

13) A falling star is a star

14) The brightest stars are the largest stars

15) It takes years to digest swallowed chewing gum

16) When in a heavy thunderstorm, it is safest to lay down flat on the ground

\section{Correct Information}

The largest part of the Sahara consists out of rocks

Most female animals are stronger than the males

The Vikings made settlements long before

Columbus discovered America

Bees can stay alive after stinging

Bats can see (and catch prey by using vision)

Seasons are caused by the tilted position of the earth (and the sun is even further away from the earth in summer)

Dragonflies can't sting

Spanish peppers originally come from Mexico

A camel stores fat in its humps

Objects float in water because they have buoyancy, can move water

You get a cold from a virus

Eskimos don't have more words for snow than we do

A falling star is not a star

The brightest stars are closer to the earth

Chewing gum does not remain in the body and there is no need for digestion

When in a heavy thunderstorm, it is safest to obtain a squatted position 


\section{Appendix B. Examples of Standard Texts and Refutation Texts}

\section{Refutation Text Star Brightness}

In ancient times, the scientist Hipparchus defined the brightness of stars with numbers. Nowadays, scientists use the term 'Magnitude' to define the brightness of stars.

Not all stars are at the same distance to the Earth, some stars are closer to us, and some are further away. A lot of people think that the brightest stars are the largest stars, but this is not necessarily true. The brightest stars are closer to Earth than stars that are less bright.

The star that's most near the Earth is the Sun. The Sun is an average size star. It is 190 times bigger than Earth, and the distance from Earth to the Sun is approximately 150 million kilometers.

\section{Standard Text Star Brightness}

In ancient times, the scientist Hipparchus defined the brightness of stars with numbers. Nowadays, scientists use the term 'Magnitude' to define the brightness of stars.

Not all stars are at the same distance to the Earth, some stars are closer to us, and some are further away. The brightest stars are closer to Earth than stars that are less bright.

The star that's most near the Earth is the Sun. The Sun is an average size star. It is 190 times bigger than Earth, and the distance from Earth to the Sun is approximately 150 million kilometers.

\section{Refutation Text Stinging Bees}

Bees have stingers that are strongly barbed. When they sting, the venom is secreted from the venom gland into the skin. Only female bees have stingers.

A lot of people think that bees always die after stinging. In most cases, this is not true. When bees sting, they most often sting insects or other animals that, just like insects, have an external skeleton made out of chitin. It protects these animals and gives them stability. Despite the barbs, bees can retract their stingers from these animals.

Only when stinging animals with a thick, flexible skin, bees most of the time get stuck and lose their stinger after stinging. This causes them to lose part of their rear body, leaving a big wound, which most of the time causes their death. 


\section{Standard Text Stinging Bees}

Bees have stingers that are strongly barbed. When they sting, the venom is secreted from the venom gland into the skin. Only female bees have stingers.

When bees sting, they most often sting insects or other animals that, just like insects, have an external skeleton made out of chitin. It protects these animals and gives them stability. Despite the barbs, bees can retract their stingers from these animals.

Only when stinging animals with a thick, flexible skin, bees most of the time get stuck and lose their stinger after stinging. This causes them to lose part of their rear body, leaving a big wound, which most of the time causes their death. 


\section{Appendix C. Examples of Post-Test Questions}

\section{Open-Ended Questions a bout Misc onceptions}

a) Why are some stars brighter than other stars? (Correct response: The brighter stars are closer to the Earth.)

b) What happens when a bee stings another insect? (Correct response: The bee can retract its stinger and will survive.)

\section{True/False Statement Questions}

a) The brighter stars are closer to the Earth than stars that are less bright (true)

b) A bee always dies after stinging (false)

\section{Deta ils Test Questions}

a) Which term is used by scientists to define the brightness of stars? (Correct response: Magnitude.)

b) Which bees have stingers? (Correct response: Female bees.) 


\section{Appendix D. Analyses of Relative Accuracy}

The main interest in this study was investigation of the effect of the text format (refutation, standard) on JOLs for not-corrected misconceptions. However, for completeness we also report the measure of relative accuracy in this appendix. Relative accuracy was operationalized as the within-participant gamma correlation between JOLS and overall test performance for the open-ended questions and the statement test responses combined. These two measures were combined because Weaver (1990) states, that for reliability of gamma, it is preferable to use multiple measures of text comprehension. The intra-individual gamma correlation between JOLs and performance on the two tests indicates a learners' ability to discriminate between correct and incorrect test performance. A gamma correlation close to +1 demonstrates high JOL accuracy (Nelson, 1984). The mean gamma correlation between JOLs and performance was 19 $(S D=.41)$ for the group reading refutation texts, and the mean gamma correlation was $.09(S D=.32)$ for the group reading standard texts. These low gamma correlations imply that monitoring was inaccurate for both groups, and there was no significant difference between the groups, $t(112)=1.345, p=.181$.

Furthermore, the relation between JOLs and restudy selections was investigated. The mean gamma correlation between JOLs and restudy selections was -.57 (SD = .51) for the group reading refutation texts and -.52 for the group reading standard texts. This shows that the relationship between JOLs and restudy selections was strong, even though the JOLs were inaccurate. The difference between groups was not significant, $t(103)=$ $.461, p=.646$. 


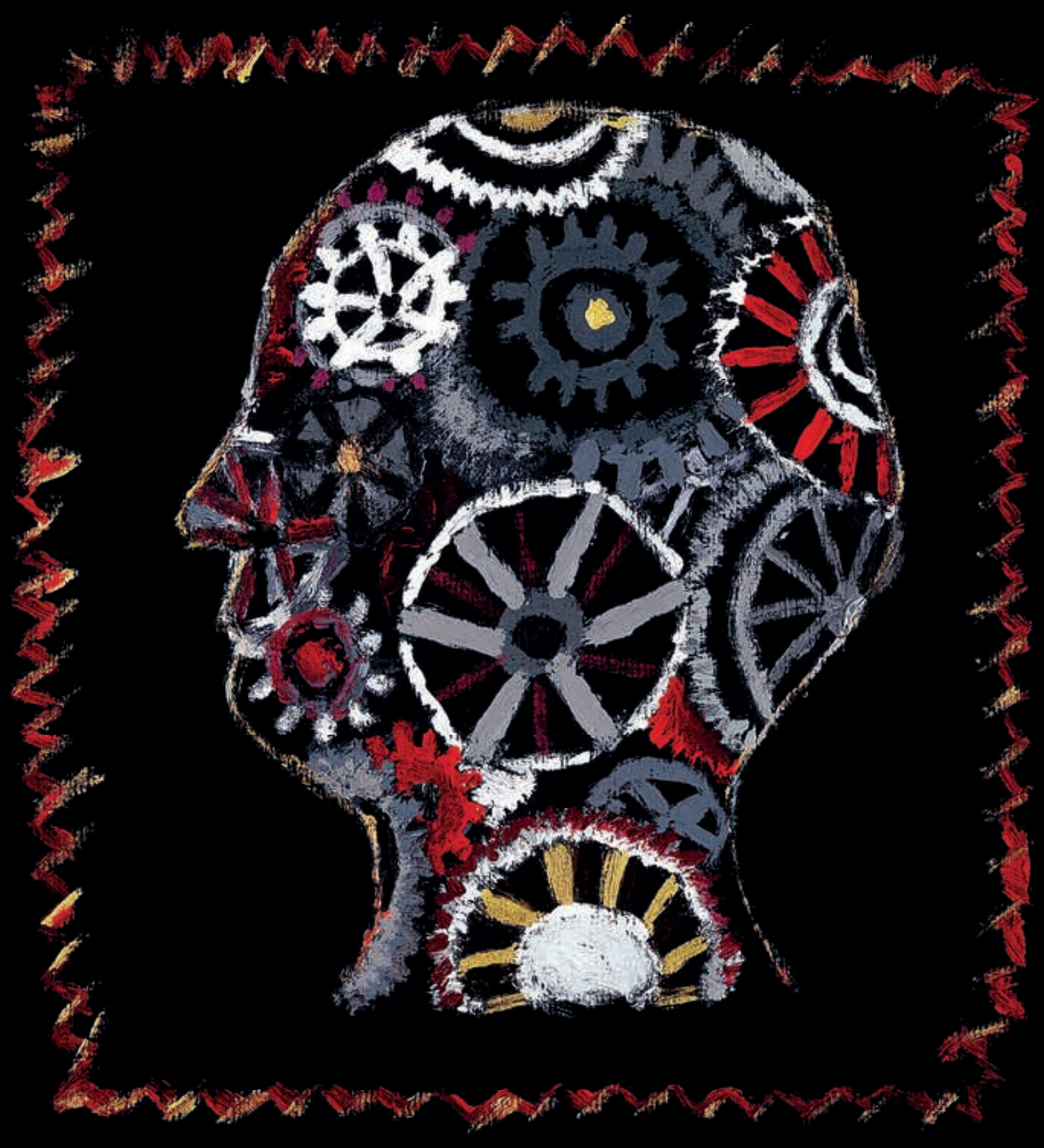




\section{HAPTER 7 \\ General Disc ussion}

In this Chapter, the main findings from the studies reported in this dissertation are discussed in relation to the literature and in terms of theoretical implications. Then, the implications for educational practice, limitations of the studies and recommendations for future research are discussed.

\section{Background and Research Questions}

Monitoring and regulation play an important role during self-regulated learning (Thiede, Anderson, \& Therriault, 2003). When learners evaluate their level of text understanding, this process is referred to as monitoring (Nelson \& Narens, 1990). The output from monitoring is then used to regulate further study, by deciding whether to terminate or continue learning (Nelson \& Narens, 1990). Effective regulation contributes to academic achievement (Ertmer \& Newby, 1996). Unfortunately, learners often cannot distinguish between text materials that are and that are not yet understood; a review across 57 studies showed a weak relation (a mean correlation of .27) between subjective monitoring judgments and objective performance (Thiede, Griffin, Wiley, \& Redford, 2009). Because inaccurate monitoring often leads to suboptimal regulation and performance (Dunlosky \& Rawson, 2012), the first aim of the studies presented in this dissertation was to improve monitoring and regulation for young learners during study of text materials. In order to do so, effects of generation tasks (sentence generation and diagram completion) on monitoring and regulation were investigated. Because generation was presumed to support learners to evaluate their understanding of studied information, sentence generation and diagram completion tasks were expected to improve monitoring accuracy and regulation of study. 
Because it was not yet clear how individual differences in age and prior knowledge affect young learners' metacognitive skills, the second aim was to evaluate how age and prior knowledge affect monitoring and regulation.

In five empirical studies it was investigated how instructions, developmental differences and prior knowledge affect primary and secondary education students' monitoring and regulation of learning. School level of the participants ranged from fourth grade to ninth grade (9-15 years of age).

Thus far, research on the accuracy of monitoring judgments mainly focused on relative accuracy, measured by intra-individual correlations between judgments of learning (JOLs) and performance (cf. Nelson \& Dunlosky, 1991). However, measures of relative accuracy do not provide an indication of absolute accuracy, which is the deviation between confidence judgments and test scores. To measure monitoring accuracy, in the analyses in this dissertation both relative and absolute accuracy were used.

\section{Ma in Findings}

Table 1 in Chapter 1 provides an overview of the research questions addressed in this dissertation. The first three studies (Chapter 2-4) investigated effects of two novel types of generation tasks on monitoring and regulation: Sentence generation and diagram completion.

The study reported in Chapter 2 addressed the research question "How do the timing of JOLs and sentence generation instructions affect monitoring accuracy and regulation of study?" Results showed that JOLs that were made after a delay were more accurate than JOLs that were made immediately during learning. Moreover, sentence generation improved regulation. Older children made more adaptive study selections. That is, they were better able to select the idioms for restudy that they had judged as more difficult than the younger children. Even though generation tasks (such as summary generation or keyword generation) have been demonstrated to be promising to improve monitoring (De Bruin et al., 2011; Thiede et al., 2003; Thiede \& Anderson, 2003), this is the first study that shows that sentence generation can improve monitoring and regulation of learning for young learners.

In Chapter 3, the research question "Can sentence generation and reflection instructions improve study selections and reduce overconfidence?" was addressed. Findings showed that restudy selections were more adaptive after sentence generation than when learners were instructed to reflect on their learning. Moreover, sentence generation reduced overconfidence. The study reported in Chapter 3 is the first to demonstrate that generation tasks are not only promising to improve relative accuracy, but can also improve absolute accuracy. 
The study presented in Chapter 4 aimed to extend the research on generation to a more complex text comprehension task. The purpose of the study was to answer the research question "How do diagram instructions and the timing of these instructions affect monitoring and regulation when studying cause-and-effect relations?" Diagram completion improved monitoring for learning of cause-and-effect relations when adolescents ( $9^{\text {th }}$ grade) were studying complex science texts. The timing of diagram completion affected monitoring accuracy; monitoring was most accurate when diagrams were completed after a delay, rather than after immediate diagram completion.

In the last two studies (Chapters 5 and 6), potential effects of learners' inaccurate prior knowledge on learning, monitoring, and regulation were addressed. The study in Chapter 5 addressed the question "How does inaccurate prior knowledge affect overconfidence and regulation of study?" Findings showed that inaccurate prior knowledge was harmful for learning; it was often not corrected through study and became a commission error (a completely inaccurate response) at the test. Learners were especially overconfident for commission errors, and regulation of study was not adaptive. The level of overconfidence was affected by developmental differences: The older age group (grade 5 and 6, 11-12 years of age) showed less overconfidence than the younger age group (grade 3 and 4, 9-10 years of age).

Chapter 6 investigated how refutations in texts affect learning, monitoring and regulation, by addressing the research question: "How do inaccurate prior knowledge, confidence in prior knowledge, and text format affect learning, overconfidence, and regulation of study?" Refutations supported correction when inaccurate prior knowledge was held with high confidence. However, reading refutation texts did not improve monitoring and regulation, learners' JOLs showed overconfidence for the misconceptions that were not yet corrected through study.

\section{Theoretic al Implic ations and Future Research}

Figure 3 in Chapter 1 depicts the factors that are expected to affect monitoring, regulation, and learning. In this section, the findings are discussed in relation to these factors. First of all, assumptions about effects of generation tasks and the timing are discussed. Second, individual differences in age and prior knowledge and effects of text format are described. Finally, differences between analyses of relative and absolute accuracy are discussed. 


\section{Generation Tasks and Timing}

Findings from Chapters 2, 3, and 4 showed that generation tasks improved monitoring and regulation. Four specific assumptions about the effects of generation tasks on monitoring and regulation were evaluated, namely: 1 . Generation tasks were assumed to focus learners' attention on valid cues related to the quality of their long-term memory representation for studied information, and these cues were assumed to be more predictive of test performance than not asking learners to generate anything. 2. Timing was supposed to be an important factor: To focus learners' attention on valid cues, the generation task and the JOLs need to be performed at a delay after study, rather than immediately after study. 3. A generation task was presumed to be more effective to attend learners to valid cues than asking them to directly assess their memory representation through reflection. 4. It was assumed that learners do not need to deliberately retrieve studied information when providing a JOL after performing a generation task. Because generation provides learners with valid cues about their longterm memory representation, they can base their JOLs on these cues that are established through generation, instead of on deliberate retrieval of studied information from longterm memory when making the JOL.

Multiple indications supported the first assumption that generation supported learners' access to valid cues. By generating sentences, learners became aware whether or not they could apply the studied information in a novel sentence. If they were not able to make a novel sentence with studied content, this indicated to them that this information was not yet learned and needed restudy. Indeed, learners less often selected content for restudy when their generated sentences were correct (Chapter 3), implying that they were able to discriminate between incorrect and correct sentences. The diagram study in Chapter 4 provided the opportunity to analyze diagram completion responses, and to assess cue validity by comparing these diagram responses to the accuracy of test responses. Findings confirmed the assumption that generation tasks focus learners on valid cues; the responses that were provided in the filled-out diagram textboxes were highly predictive of learners' test performance.

The second assumption was that, to improve monitoring and regulation, both the generation tasks and the JOLs need to be performed after a delay. This assumption about the importance of the timing of the tasks was confirmed by the studies reported in chapter 2 and 4 . Immediate JOLs were only moderately accurate, whereas delayed JOLs were highly predictive of performance (Chapter 2). Moreover, delayed generation improved monitoring accuracy in comparison to immediate generation. Completing the diagrams after a delay was more beneficial for monitoring than completing diagrams immediately after study, because learners were more successful at using the valid cues indicating test performance when making the JOLs (Chapter 4). 
Assumption three, that generation tasks are more effective to improve monitoring and regulation than asking learners to directly access their memory through reflection was supported with findings reported in Chapter 3. In line with theoretical assumptions on the nature of memory (Koriat, 1998), reported findings indicate that students did not have direct access to the quality of their memory representation. Therefore, reflection instructions did not support learners to access valid cues indicating test performance, and instructing learners to explicitly reflect on their learning was even harmful, instead of adaptive for monitoring and regulation.

The fourth assumption that, after performing a generation task learners do not need to deliberately retrieve studied information when monitoring learning, was supported by learners' reaction times that were measured when they provided JOLs. In Chapter 2 , the low JOLs, which indicate that learners were not confident that they had learned the studied information, were provided much faster by the group who performed the sentence generation task than by the group that was not asked to generate sentences. Low JOLs were provided as fast as high JOLs following sentence generation, whereas low JOLs were provided much slower than the high JOLs for the group who made uninstructed delayed JOLs. This indicates that, through sentence generation, participants already knew that they could not provide a correct test response, whereas, when making uninstructed delayed JOLs, they attempted retrieval. Because they could use this insight that was established to them through sentence generation, they did not need to attempt retrieval of studied information from long-term memory when providing the JOL.

\section{Age Differences}

Thus far, not many successful interventions have been identified to improve monitoring and regulation for young learners, implying that monitoring and regulation processes are complex activities that are hard to influence (Von der Linden, Schneider, \& Roebers, 2011). The research findings on developmental differences reported in Chapter 2 and Chapter 5 show that there were no age differences in relative accuracy. However, regulation of study was affected by developmental differences; study selections were more adaptive for the older learners than for younger learners. These findings add to research demonstrating age differences in monitoring and regulation of study (Dufresne \& Kobasigawa, 1989; Koriat \& Shitzer-Reichert, 2002; Schneider \& Lockl, 2009), by showing that relative monitoring accuracy of children can be fairly accurate during study of figurative language and difficult concepts. Importantly, the findings show that the important developmental process is young learners' self-regulation.

In contrast to measures of relative judgment accuracy, absolute accuracy was affected by developmental differences. (Note that measures of relative and absolute accuracy are discussed in more detail below.) The older age group (grades 5 and 6, 11-12 
years of age) was better calibrated than the younger age group (grades 3 and 4, $9-10$ years of age). Younger and older learners could distinguish quite well between correct responses and omissions (when they were not able to provide a test response at all); however, when they were asked to judge the quality of their test responses, younger learners expected to receive more credit for their commission errors. It has been suggested that effects of developmental factors are likely to be found with tasks requiring higher metacognitive demands (Krebs \& Roebers, 2010; 2011). Besides use of cues that are not predictive of test performance, the demands of the monitoring process itself may constrain accurate monitoring and effective regulation. The commission errors seem most troubling for accurate monitoring, especially when learners have incorrect information accessible in the memory representation, it might be a complex task to monitor the accuracy of this information. Research with college students showed that the learners with low verbal skills were more overconfident than learners with high verbal ability (Maki, Shields, Wheeler \& Zacchilli, 2005). Possibly, younger learners' lower level of verbal ability might explain their overconfidence for commission errors. Future research could further investigate why younger learners overestimate their performance, in order to help younger students develop accurate monitoring abilities and enhance their regulation.

\section{Prior Knowledge and Effects of Text Format}

Chapters 5 and 6 in this dissertation investigated how prior knowledge affected learning, monitoring and regulation. Learners' inaccurate prior knowledge was harmful for acquisition of knowledge, and led to overconfidence and maladaptive regulation of study. It is not easy to correct inaccurate prior knowledge, especially when inaccurate prior knowledge is held with high-confidence. Chapters 5 and 6 show that learners often did not correct this through reading, even though study materials provided them with feedback that their prior knowledge was inaccurate. The research reported in Chapter 6 investigated effects of text format by comparing refutation texts and standard texts, this study shows that instructions that improve correction of inaccurate prior knowledge do not automatically also improve monitoring and regulation. Monitoring of comprehension is an additional task above and beyond reading for comprehension (Griffin, Wiley, \& Thiede, 2008). When instructions help a reader to understand a text's meaning, these instructions do not necessarily also support learners to accurately monitor how complete their understanding of the text is. Learners need to focus on valid cues when monitoring, and the findings from Chapter 6 imply that only providing learners with feedback in text is not sufficient, because refutations in text did not focus learners' attention on valid cues related to their actual level of comprehension. A next step could be to develop learning environments that can support learners both at the cognitive level (e.g., providing an 
appropriate text format to support correction of inaccurate prior knowledge) and at the meta-level (e.g., providing delayed generation tasks).

Of course, monitoring and regulation are affected by other individual differences, for instance on the personal goals students set, and how much study time is available. Study situations may require learners to make a choice between studying and other activities, and motivation may play an important role when learners make study selections. Therefore, in addition to investigating effects of age and prior knowledge on monitoring and regulation, it would be useful to examine effects of individual differences in learning goals, study time, and motivational variables in future studies.

\section{Relative and Absolute accuracy}

For analyses of metacognitive accuracy, both relative and absolute accuracy are reported in this dissertation. Measures of relative accuracy (gamma correlation) take only the rank order of the underlying distribution of responses on the confidence scale into account. Measures of absolute accuracy only take the magnitude of the difference between JOL and performance in account. This implies that use of single measures might not provide optimal insights into effects of instructional interventions on monitoring and regulation (e.g. Schraw, Kuch, \& Gutierrez, 2013). In this dissertation, measures of relative accuracy were used to investigate whether learners could discriminate between studied information for which the test performance was correct and studied information for which learners could not provide a correct test response. Measures of absolute accuracy were used to investigate whether learners were overconfident for their incorrect test responses.

The findings show that the measures of relative accuracy and absolute accuracy do not necessarily match. Relative accuracy can be high even when learners are overconfident (Chapter 5); it is also possible that learners are well-calibrated but still cannot discriminate between correct and incorrect test responses (Chapter 4); and it is also possible that measures of both discrimination (relative accuracy) and calibration (absolute accuracy) are inaccurate (Chapter 6).

When learners performed a generation task, both the measures of relative accuracy (in Chapters 2 and 4), and absolute accuracy (Chapter 3) showed improvement of monitoring accuracy. These findings indicate that performing generation tasks made learners more sensitive to discriminate between correct and incorrect test performance, and also became more aware that their commission errors, which are entirely incorrect test responses, did not have any quality.

Learners seem to be able to accurately distinguish between omissions (no test response provided - no information accessible in memory) and correct responses (correct information accessible in memory). The accessibility hypothesis (Koriat, 1995) 
might provide an explanation for the observation that learners are overconfident for commission errors, even when relative accuracy is high. This hypothesis states that students' evaluations are influenced by response quantity. When learners have information accessible in memory, they have no privileged access to the accuracy of this memory representation. This means that, when people retrieve incorrect information, which will lead to a commission error at the test, their judgments are still high. Or, in other words, the learners thought that, because they were able to retrieve information, at least part of their answer must be correct (Lipko et al., 2009).

Moreover, even though effects of instructions on improvement of monitoring and regulation in this dissertation are large in comparison to effects reported in the literature (Thiede, et al, 2009), measures of both relative and absolute accuracy show that monitoring accuracy was far from perfect. Therefore, future research should continue with evaluating how instructions can improve metacognitive accuracy. Further investigation is needed of cognitive processes leading to differences in relative and absolute accuracy, and instructions supporting accurate metacognitive decisions. Furthermore, future research should not only take the effect of instructions on measures of metacognitive accuracy into account, but make a step forward by investigating effects of developmental and individual differences in relative and absolute accuracy on learning outcomes. A start was made in this dissertation, by addressing effects of age and prior knowledge differences.

\section{Implic ations for Practice}

The studies which are described in this dissertation provide insight into ways to improve monitoring, regulation, and learning; both in primary education and secondary education. Figure 1 presents a flowchart, which shows how the thesis findings can be used in an educational context.

First of all, in advance of learning, it is important to address whether learners already have prior knowledge of the study materials (Figure 1, Decision 1). If learners have inaccurate prior knowledge, this can be detrimental for learning, because learners are not aware that their prior knowledge is incorrect, and instead think that they already understand the information they need to study. Therefore, when learners' prior knowledge is inaccurate, it is important to provide learners with explicit feedback: Learners need to co-activate their incorrect prior knowledge and the correct information simultaneously (Van den Broek \& Kendeou, 2008). Presenting learners with explicit refutations in text can be useful to correct their inaccurate prior knowledge (Chapter 6).

Second, learning environments need to provide learners with the opportunity to monitor their own understanding. Monitoring is a complex task for learners, and they 
need support with this. When aiming to improve learners' monitoring accuracy, first of all it is important to take the complexity of the study materials into account (Figure 1, Decision 2). When learners have to study vocabulary, and have to literally remember the meaning of words, this does not require learners to have a deep level of comprehension. When learners study more complex materials, they need to gain a deeper level of comprehension, instead of literal retrieval of factual information. The required level of comprehension has consequences for the monitoring task.

When learners have to monitor learning of materials comparable to pairedassociate learning, for instance study of vocabulary, only providing them with an opportunity to monitor their learning after a short delay can be sufficient to lead to accurate monitoring. When judging learning after a delay, learners retrieve information and thus self-test their long-term memory, which leads to accurate monitoring (Nelson \& Dunlosky, 1991). When learners have to study more complex information such as idioms or difficult concepts, it is recommended to present learners with a sentence generation task to improve monitoring and regulation of learning. The sentence generation task proved suitable for young learners, even $4^{\text {th }}$ grade learners (approximately 10 years of age) were able to generate novel sentences with studied idioms. When generating sentences, learners have to test their understanding of studied materials by applying it in a new sentence, which connects studied information with contextual information and prior knowledge. After generating sentences, they should have the opportunity to judge their learning. Note that both the generation task and JOLs are delayed.

When studying complex expository text, learners have to show that they understand relations between sentences in the text, and understand cause-and-effect relations between events in the text. A delayed diagram completion task can support learners with monitoring of such complex science texts; when completing diagrams, learners test their comprehension of relations between the described events in the text. After completing the diagrams, learners should be provided with the opportunity to monitor their understanding of the studied texts.

After monitoring, learners should be instructed to regulate their further study (Figure 1, Decision 3). When they decide that a text has been understood, the learner can discard this text from further study. Instead, when learners decide that the text needs further study, they should have the opportunity to allocate more study time to learn these materials. 


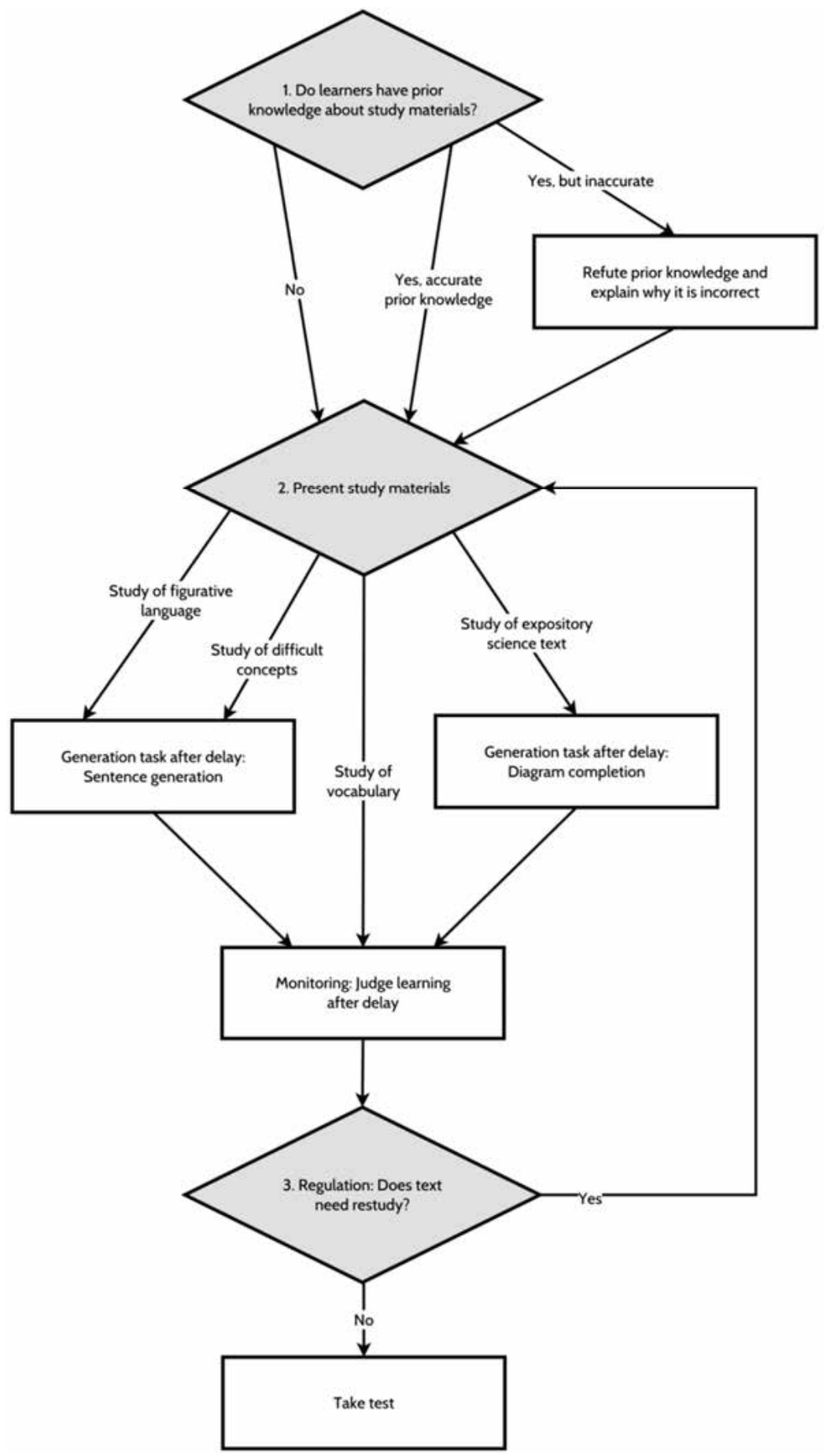

Figure 1. Fostering monitoring and regulation in the classroom. 


\section{Limitations}

The research presented in this dissertation adds new insights to the existing literature on metacognition and provides implications for practice. However, it is important to recognize that the research has some limitations that should be addressed by future research with regard to the format of the generation tasks, the timing of the tasks, eliciting restudy selections, and generalizability of the findings.

In the reported research on the effect of generation tasks, it was assumed that these tasks need to be performed actively by a learner. It was presumed that studying already generated information, for instance sentences or diagrams that are generated by a teacher, will not be sufficient to improve monitoring and regulation. However, this assumption was not tested in this dissertation. With adults, this assumption was already supported. That is, research by Thiede, Dunlosky, Griffin, and Wiley (2005) demonstrated that generation of keywords improved metacognitive accuracy in comparison to reading keywords that were generated by others. Through active generation, learners self-test their long-term memory representation, and this provides them with feedback about their understanding of studied information. Even though study of already-generated sentences might support learners in constructing a memory representation and creating a deep understanding of a text's content, learners are not provided with insights into the accuracy of their memory representation because they did not actively self-test their understanding. This active-generation hypothesis was not yet tested for young learners; therefore future research should test whether active generation is more suitable to improve monitoring and regulation for young learners than study of already-generated content.

Furthermore, in most studies reported in this dissertation, learners studied text materials, monitored learning, made restudy selections and were tested in one single session that lasted approximately one hour. Only in the last study, reported in Chapter 6, learners' memory for studied information was tested one week after the study session. In educational settings, learners are typically tested at a delay after studying texts, and they need to retain the studied information in memory for a longer period than in most studies in the present dissertation. It is yet unclear whether the beneficial effect of generation tasks is also apparent when learners judge their long-term retention of studied information, instead of their ability to remember the studied information at the post-test that occurs a few minutes after making judgments of learning. To gain insight into effects of generation tasks on monitoring accuracy for long-term retention, future research should investigate this with use of delayed post-tests.

Moreover, learners were asked to indicate which materials they liked to restudy; however, they did not actually restudy the selected materials. Thus, improvement in monitoring and regulation was not related to final learning outcomes. The current design 
was used because actual restudy would interfere with performance, and would not provide the opportunity to measure JOL accuracy. Even though previous research provided evidence that more accurate monitoring leads to higher test performance (Dunlosky \& Rawson, 2012), the evidence is still scarce. Therefore, future studies should not only investigate effects of instructions on monitoring and restudy selections, but also investigate how monitoring and regulation are related to achievement. Honor-choice paradigms, in which students actually restudy the selected materials, and measures of actual study time allocation, could be used to investigate the effect of metacognitive accuracy on learning outcomes.

Finally, even though the research was conducted in schools, our studies were carried out in experimental settings. Participants only performed a limited number of tasks, and these tasks typically did not last longer than one hour. Moreover, we selected the materials based on pilot studies, to adapt the materials to learners' level of prior knowledge. Therefore, materials were selected for which learners were not supposed to have accurate prior knowledge for the idiom comprehension research, and materials for which learners were likely to have inaccurate prior knowledge were selected for the last study. Because presentation of materials was controlled, instructions were not integrated in their curriculum. In addition, instructions were provided to the learners by the experimenter. In education, teachers provide the instructions. Thus, even though the findings show that monitoring and regulation of learning can be improved through instructions, future research should further investigate the generalizability of the current research findings to educational settings. Learning environments need to provide learners with the opportunity to monitor their own understanding, and metacognitive instructions need to be integrated in instruction (Bannert \& Mengelkamp, 2013). Future studies need to focus on the effects of integrating generation instructions in educational programs, and in other educational domains than study of text materials. Furthermore, research should focus not only on effects of generation instructions on metacognition and performance, but should also research how teachers can be trained to provide appropriate generation tasks to their pupils.

\section{Conclusion}

The empirical research reported in this dissertation highlights novel applications of generation tasks. Delayed sentence generation and diagram completion tasks are promising to foster monitoring and self-regulated learning when studying text materials. This dissertation contributes to a deeper understanding of effects of these novel generation tasks on young learners' use of valid cues when monitoring learning, by showing that, through sentence and diagram generation, learners acquire insight into 
whether they can apply studied information. Performing a generation task provides learners with feedback about the quality of their memory representation, and gives them insight into what they know and don't know.

Developmental differences affected monitoring and regulation, with findings indicating that it is more difficult for younger learners than for older learners to monitor and, especially, regulate their learning; future research should further investigate reasons why young learners' metacognitive skills are less accurate and adaptive. Further, inaccurate prior knowledge was detrimental for accurate monitoring and effective regulation, future research is recommended to address how this can be improved especially when learners study texts that are contradicting their prior knowledge.

Accurate monitoring improved study selections. Because the ultimate goal of research on monitoring and regulation is to improve learning performance, future investigations should address the relation between improved monitoring skills and improved learning outcomes.

Findings provide novel contributions for educational practice. To foster students' optimal text comprehension, teachers should advise students to perform generation task after a delay after study, in order to improve monitoring and self-regulated learning. 


\section{References}

Bannert, M., \& Mengelkamp, C. (2013). Scaffolding Hypermedia Learning Through Metacognitive Prompts. In R. Azevedo \& V. Aleven (Eds.), International Handbook of Metacognition and Learning Technologies (pp. 171-186). New York: Springer

De Bruin, A. B. H., Thiede, K. W., Camp, G., \& Redford, J. (2011). Generating keywords improves metacomprehension and self-regulation in elementary and middle school children. Journal of Experimental Child Psychology, 109(3), 294-310. doi: 10.1016/j.jecp.2011.02.005

Dufresne, A., \& Kobasigawa, A. (1989). Children's spontaneous allocation of study time: Differential and sufficient aspects. Journal of Experimental Child Psychology, 47, 274-296.

Dunlosky, J., \& Rawson, K. A. (2012). Overconfidence produces underachievement: Inaccurate self evaluations undermine students' learning and retention. Learning and Instruction, 22(4), 271-280. doi: 10.1016/j.learninstruc.2011.08.003

Ertmer, P. A., \& Newby, T. J. (1996). The expert learner: Strategic, self-regulated, and reflective. Instructional Science, 24, 1-24. doi: 10.1007/BF00156001

Griffin, T. D., Wiley, J., \& Thiede, K. W. (2008). Individual differences, rereading, and self-explanation: Concurrent processing and cue validity as constraints on metacomprehension accuracy. Memory \& Cognition, 36(1), 93-103. doi: 10.1758/MC.36.1.93

Koriat, A. (1995). Dissociating knowing and the feeling of knowing: Further evidence for the accessibility model. Journal of Experimental Psychology: General, 124(3), 311-333. doi: 10.1037/0096-3445.124.3.311

Koriat, A. (1998). Illusions of knowing: The link between knowledge and metaknowledge Metacognition: Cognitive and social dimensions (pp. 16-34). Thousand Oaks, CA: SAGE

Koriat, A., \& Shitzer-Reichert, R. (2002). Metacognitive judgments and their accuracy. In P. Chambres, M. Izaute \& P. Marescaux (Eds.), Metacognition: Process, function, and use (pp. 1-17). New York: Kluwer

Krebs, S. S., \& Roebers, C. M. (2010). Children's strategic regulation, metacognitive monitoring, and control processes during test taking. British Journal of Educational Psychology, 80(3), 325-340. doi: 10.1348/000709910x485719

Krebs, S. S., \& Roebers, C. M. (2011). The impact of retrieval processes, age, general achievement level, and test scoring scheme for children's metacognitive monitoring and controlling. Metacognition Learning. doi: 10.1007/s11409-011-9079-3

Lipko, A. R., Dunlosky, J., Hartwig, M. K., Rawson, K. A., Swan, K., \& Cook, D. (2009). Using standards to improve middle school students' accuracy at evaluating the quality of their recall. Journal of Experimental Psychology: Applied, 15(4), 307-318. doi: 10.1037/a0017599

Maki, R. H., Shields, M., Wheeler, A. E., \& Zacchilli, T. L. (2005). Individual differences in absolute and relative metacomprehension accuracy. Journal of Educational Psychology, 97(4), 723-731. doi: 10.1037/00220663.97.4.723

Nelson, T. O., \& Dunlosky, J. (1991). When peoples judgments of learning (JOLs) are extremely accurate at predicting subsequent recall: The "Delayed-JOL effect". Psychological Science, 2(4), 267-270. doi: 10.1111/j.1467-9280.1991.tb00147.x

Nelson, T. O., \& Narens, L. (1990). Metamemory: A theoretical framework and new findings. Psychology of Learning and Motivation, 26, 125-141. doi: 10.1016/S0079-7421(08)60053-5

Schneider, W., \& Lockl, K. (2008). Procedural metacognition in children: Evidence for developmental trends. In J. Dunlosky \& R. A. Bjork (Eds.), Handbook of metamemory and memory (Vol. 14, pp. 391-409). Mahwah, NJ: Lawrence Erlbaum

Schraw, G., Kuch, F., \& Gutierrez, A. P. (2013). Measure for measure: Calibrating ten commonly used calibration scores. Learning and Instruction, 24, 48-57. doi: 10.1016/j.learninstruc.2012.08.007

Thiede, K. W., \& Anderson, M. C. M. (2003). Summarizing can improve metacomprehension accuracy. Contemporary Educational Psychology, 28, 129-160. doi: 10.1016/S0361-476X(02)00011-5 
Thiede, K. W., Anderson, M. C. M., \& Therriault, D. (2003). Accuracy of metacognitive monitoring affects learning of texts. Journal of Educational Psychology, 95(1), 66-73. doi: 10.1037/0022-0663.95.1.66

Thiede, K. W., Dunlosky, J., Griffin, T. D., \& Wiley, J. (2005). Understanding the delayed-keyword effect on metacomprehension accuracy. Journal of Experimental Psychology: Learning, Memory and Cognition. doi: 10.1037/0278-7393.3.1.6.1267

Thiede, K. W., Griffin, T. D., Wiley, J., \& Redford, J. (2009). Metacognitive monitoring during and after reading. In D. J. Hacker, J. Dunlosky \& A. C. Graesser (Eds.), Handbook of metacognition in education (pp. 85-106). New York: Routledge

Van Den Broek, P., \& Kendeou, P. (2008). Cognitive processes in comprehension of science texts: The role of coactivation in confronting misconceptions. Applied Cognitive Psychology, 22(3), 335-351. doi: 10.1002/acp.1418

Von der Linden, N., Schneider, W., \& Roebers, C. (2011). The effects of summary production and encoding condition on children's metacognitive monitoring. Metacognition and Learning, 6(1), 3-23. doi: 10.1007/s11409-010-9063-3 


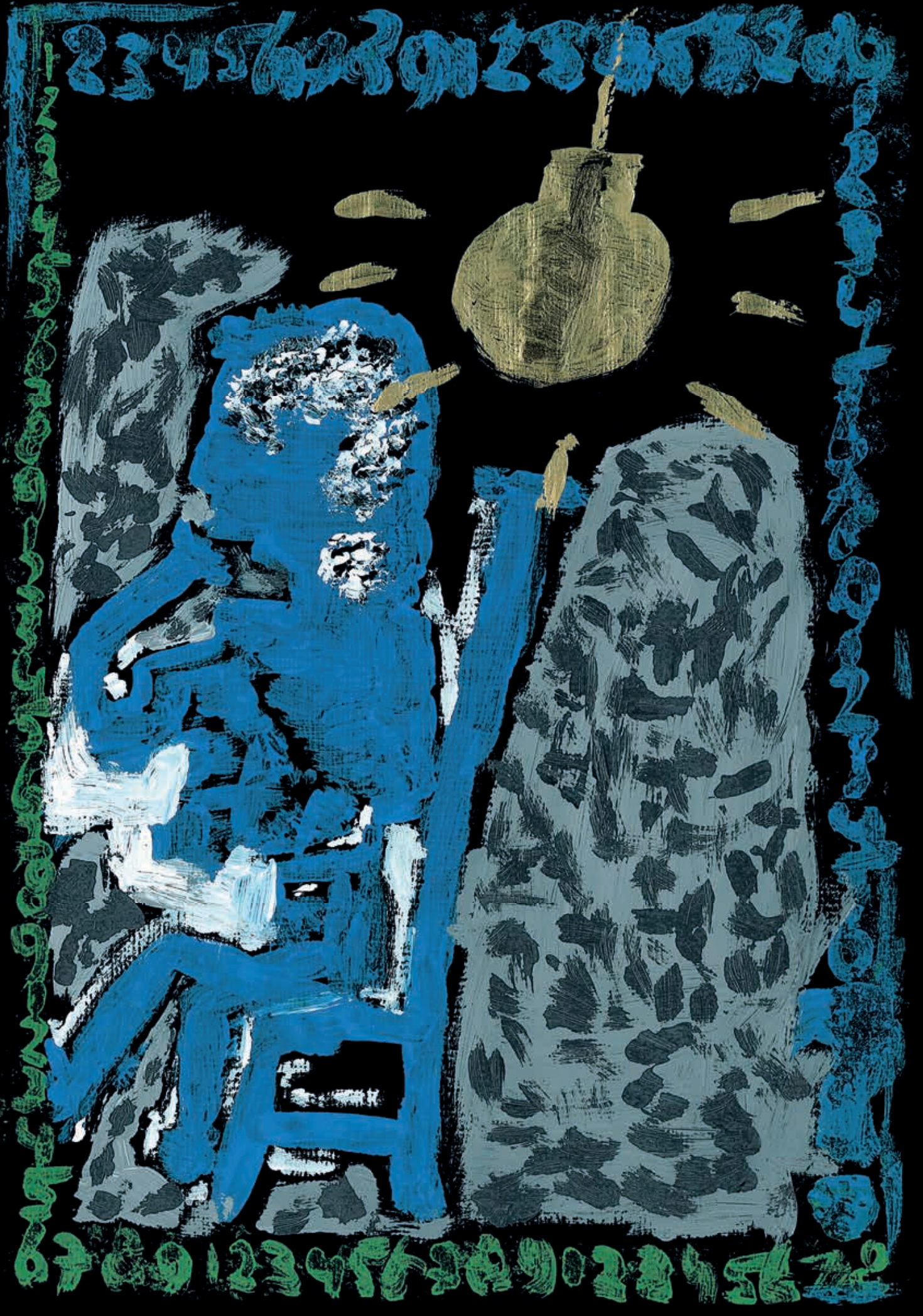




\section{Summary}

This dissertation starts with an introduction (Chapter 1 ) describing the relevance of monitoring and regulation in education. Monitoring is defined as learners' insight into their current state of learning; learners can be asked to monitor by providing subjective judgments about their current state of learning. Monitoring informs regulation; based on their monitoring learners decide to continue studying or to discard materials from further study. Accurate self-monitoring is important to improve self-regulated learning and text comprehension. However, adult students as well as young learners often cannot accurately monitor what they do and don't understand, and often overestimate their actual level of comprehension.

The first aim was to investigate how generation instructions can improve learners' monitoring and regulation when studying textual information. Generation instructions ask learners to self-test their understanding of studied materials by applying the studied information. The timing of instructions and judgments was considered an important factor for improving monitoring and regulation: Delayed judgments and delayed generation tasks were expected to improve monitoring more than immediate judgments and immediate generation tasks.

The second aim was to take individual differences in age level and prior knowledge into account. The effect of age differences on monitoring was addressed as an open question; regulation of study was expected to be more adaptive for the older learners than for younger learners. Furthermore, individual differences in prior knowledge were taken into account. Inaccurate prior knowledge was expected to be harmful to learning, monitoring, and regulation.

Five empirical studies were conducted; these are described in Chapter $2-6$. The research described in Chapter $2-4$ addresses the effects of generation tasks on monitoring and regulation. The research reported in Chapter 5 and 6 addresses on individual differences in prior knowledge. In addition, both in Chapter 2 and Chapter 5, effects of age differences were taken into account. The specific research questions were as follows:

1. How do the timing of judgments of learning (JOLs) and sentence generation instructions affect monitoring accuracy and regulation of study (Chapter 2)?

2. Can sentence generation and reflection instructions improve study selections and reduce overconfidence (Chapter 3$)$ ? 
3. How do diagram completion instructions and the timing of these instructions affect monitoring and regulation when studying cause-and-effect relations (Chapter 4)?

4. How does inaccurate prior knowledge affect overconfidence and regulation of study (Chapter 5)?

5. How do inaccurate prior knowledge, confidence in prior knowledge, and text format affect learning, overconfidence, and regulation of study (Chapter 6)?

In Chapter 2 and 3, learners' monitoring and regulation of idiom comprehension is evaluated. Chapter 2 describes an experimental study that examined primary school children's ( $4^{\text {th }}$ grade, approximately 10 years, and $6^{\text {th }}$ grade, approximately 12 years) monitoring and regulation when they studied idiomatic phrases. After studying, they judged their learning, and selected idioms for restudy before taking the test of idiom learning. A between-subjects design was used; participants judged their learning either (a) immediately; (b) after a delay of a few minutes; or (c) after generating novel sentences with the previously studied idioms. When judging learning immediately after study, people rely on their short-term memory; whereas after a delay, people rely on retrieval from long-term memory. It was assumed that, when judging learning after sentence generation, people focus on their understanding of the gist of studied information, instead of on literal retrieval of studied information from memory. The results showed that monitoring of idiom learning improved after a delay. Even though regulation of study was better for the $6^{\text {th }}$ graders than the $4^{\text {th }}$ graders, sentence generation led to the most effective selection of items for restudy for both age groups. Analyses of the JOL reaction times support the assumption that the group who made delayed JOLs attempted to retrieve information from memory, whereas the group who generated sentences already knew at the time of the judgment whether or not they understood the studied information.

Chapter 3 presents an experimental study that compared effects of a sentence generation and a reflection instruction on adolescents' $\left(9^{\text {th }}\right.$ grade, approximately 15 years) monitoring and regulation. Because it has been shown that learners do not have direct access to the quality of their memory traces, it was expected that sentence generation would be more promising to reduce overconfidence and improve restudy decisions than instructing learners to reflect on their memory. A between subjects-design was used to evaluate this expectation, with (a) one group generating sentences after idiom learning; (b) one group reflecting on memory after learning; and, (c) a control group who did neither generate nor reflect. Results confirmed that sentence generation led learners to more effectively select items for restudy than reflection. Furthermore, learners showed more overconfidence following reflection than following sentence generation. 
Chapter 4 describes an experimental study in which learners studied complex expository science texts, containing multiple cause-and-effect relations. For effective study of these materials, it is crucial that learners accurately monitor their understanding of cause-andeffect relations. We aimed to improve monitoring accuracy using diagram completion instructions. Adolescents (approximately 15 years) read six texts, monitored learning by making a JOL, and were tested for comprehension. A between-subjects design was used: Learners either completed causal diagrams (a) immediately after reading; (b) after a delay, or (c) received no diagram (control) instructions. Results showed that monitoring accuracy for learning of causal relations was higher following diagram completion than following control instructions. Importantly, monitoring was more accurate following delayed rather than immediate diagram completion. Completing diagrams focused learners' attention specifically on their learning of causal relations, given that instructions did not affect monitoring accuracy for detail learning. The findings provide insight into reasons why delayed generation tasks have more beneficial effects on monitoring than immediate generation tasks. Analyses of the completed diagrams show that both the immediate and the delayed diagrams were indicative of future test performance. However, learners in the delayed diagram group were more successful to use the cues indicating test performance when judging their learning.

For the research reported in Chapter 5 and 6, learners were asked to activate their prior knowledge before studying the text materials. Chapter 5 describes an empirical study that aimed to investigate whether activation of inaccurate prior knowledge before study contributes to primary school learners' commission errors and overconfidence for these errors when learning new concepts. Two age-cohorts of primary school learners participated $\left(3^{\text {rd }}\right.$ and $4^{\text {th }}$ grade, approximately 9-10 years, and $5^{\text {th }}$ and $6^{\text {th }}$ grade, approximately 11-12 years). First, they were asked on a pre-test whether they had prior knowledge about difficult concepts. Subsequently, they studied the meaning of these concepts. After study of all concepts they judged their learning, selected items for restudy, performed the recall test for the studied concepts, and judged the quality of their test responses. The findings show that inaccurate prior knowledge was harmful to monitoring, regulation, and learning. First of all, inaccurate prior knowledge activation led to more inaccurate test responses (commission errors) at the recall test than when learners were not able to activate any prior knowledge. Second, the level of children's predictions of test performance (i.e., their JOLs) and their self-score judgments (SSJs) of test responses after test-taking for commission errors were inappropriately high after activation of inaccurate prior knowledge. Moreover, children more often prematurely discarded concepts from further study after activation of inaccurate prior knowledge, than after no activation of prior knowledge. Overconfidence was higher for the younger age group than for the older learners. These findings indicate that when children study, 
detection of inaccuracies in their prior knowledge might be important to improve monitoring accuracy, self-regulated learning, and learning outcomes.

The research in Chapter 6 investigated whether a specific text format, namely a refutation text which provided learners with explicit feedback about their inaccurate prior knowledge, had beneficial effects on learners' correction of inaccurate prior knowledge. The findings show that inaccurate prior knowledge is often not corrected when learners hold this with high confidence, and that reading refutation text supports learners more than reading standard texts to correct inaccurate prior knowledge. Moreover, the findings show that reading refutation texts did not have any beneficial effect on monitoring accuracy: Participants were highly overconfident when predicting performance for not-corrected inaccurate prior knowledge. Furthermore, regulation was maladaptive; when selecting texts for restudy, they prematurely discarded most of the texts about which they still held inaccurate prior knowledge. This implies that providing learners with a warning that their prior knowledge is incorrect during reading is not sufficient to improve monitoring and regulation.

Chapter 7 describes theoretical and practical implications of the research in this dissertation, as well as recommendations for future research and concluding remarks. Theoretical implications focus on the effect of generation tasks. The reported research demonstrates that these tasks focus learners on valid cues predicting performance; that delayed generation improves monitoring more so than immediate generation; that generation is more effective than asking learners to directly access their memory traces through reflection; and, that through generation, learners do not need to deliberately attempt retrieval of studied information when monitoring learning. Furthermore, this dissertation shows that generation tasks were suitable to improve both measures of relative accuracy (correlations between monitoring judgments and test performance) and absolute accuracy (by reducing the discrepancy between the absolute level of judgments and test performance). Age differences did not have an effect on relative accuracy, but had an effect on overconfidence and regulation; the older learners were less overconfident and showed more adaptive restudy selections. This suggests that accurately estimating the level of performance is a complex task for younger learners. Because we did not manage to improve monitoring accuracy when learners hold inaccurate prior knowledge, improvement of metacognitive skills in this context remains an issue for future research.

Finally, findings provide contributions for educational practice. To foster students' optimal text comprehension, teachers should advise students to perform generation task delayed after study. After completing the generation task, learners should be provided with an opportunity to monitor their learning and to decide to which materials they would like to allocate further study time. 


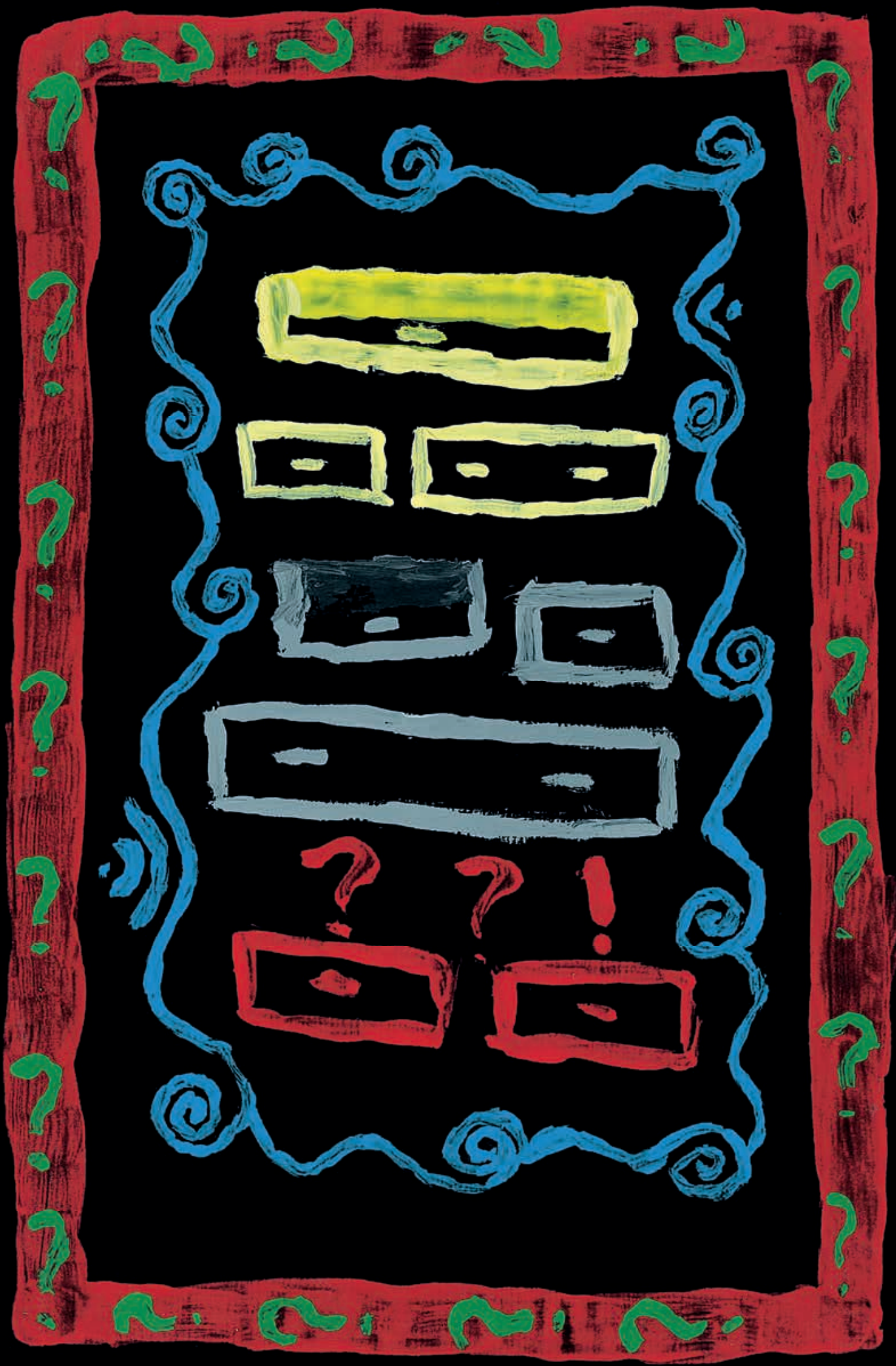




\section{G lossary}

Definitions of terms about monitoring judgments, control processes, instructional interventions and measures.

\begin{tabular}{|c|c|}
\hline Term & Definition \\
\hline \multicolumn{2}{|l|}{ Monitoring Judgments } \\
\hline $\begin{array}{l}\text { Confidence in prior } \\
\text { knowledge }\end{array}$ & $\begin{array}{l}\text { Judgments or how confident the learner is that activated prior knowledge is } \\
\text { complete and correct. }\end{array}$ \\
\hline Judgments of learning (JOL) & $\begin{array}{l}\text { Judgments of the likelihood of remembering studied information on an } \\
\text { upcoming test; often referred to as prospective confidence judgments or } \\
\text { predictions. }\end{array}$ \\
\hline Self-score judgments (SSJ) & $\begin{array}{l}\text { Judgments of the likelihood that a provided response on a test is correct; often } \\
\text { referred to as retrospective confidence judgments or postdictions. }\end{array}$ \\
\hline \multicolumn{2}{|l|}{ Control Processes } \\
\hline Selection for restudy & $\begin{array}{l}\text { Decision about whether to restudy materials before an upcoming test, or to } \\
\text { discard materials from further study. }\end{array}$ \\
\hline \multicolumn{2}{|l|}{ Instructional Interventions } \\
\hline Generation tasks & $\begin{array}{l}\text { Tasks that ask learners to apply the studied information by actively connecting } \\
\text { studied materials with contextual information and/or prior knowledge. }\end{array}$ \\
\hline Sentence generation & $\begin{array}{l}\text { A type of generation task: Learners are prompted to generate a novel sentence } \\
\text { about studied information. }\end{array}$ \\
\hline Diagram completion & $\begin{array}{l}\text { A type of generation task: Learners are asked to indicate cause-and-effect } \\
\text { relations between studied events by filling out a diagram. }\end{array}$ \\
\hline Refutation text & $\begin{array}{l}\text { A text format that provides the reader with explicit feedback about common } \\
\text { inaccuracies in prior knowledge, often referred to as misconceptions. }\end{array}$ \\
\hline \multicolumn{2}{|c|}{ Measures of Monitoring and Control } \\
\hline Relative monitoring accuracy & $\begin{array}{l}\text { The correlation between item-by-item monitoring judgments and test } \\
\text { performance; often referred to as resolution or discrimination. A correlation } \\
\text { close to } 1 \text { indicates that the learner can accurately discriminate between } \\
\text { materials which are well-learned and materials which are not yet well-learned. }\end{array}$ \\
\hline $\begin{array}{l}\text { Absolute monitoring } \\
\text { accuracy }\end{array}$ & $\begin{array}{l}\text { The absolute difference between item-by-item monitoring judgments and test } \\
\text { performance; often referred to as calibration. When the difference score is } \\
\text { higher than } 0 \text { this indicates that the learner is overconfident, a difference score } \\
\text { below } 0 \text { indicates underconfidence. }\end{array}$ \\
\hline Regulation of study & $\begin{array}{l}\text { The correlation between monitoring judgments and selection of materials for } \\
\text { restudy. A correlation close to - } 1 \text { indicates that the learner selected the } \\
\text { materials for which low monitoring judgments were provided for restudy. }\end{array}$ \\
\hline $\begin{array}{l}\text { Adaptivity of restudy } \\
\text { selections }\end{array}$ & $\begin{array}{l}\text { The match between restudy selections and test performance. For adaptive } \\
\text { restudy, a learner should select materials for restudy for which test responses } \\
\text { are not yet correct, and discard materials for which the test responses are } \\
\text { correct. }\end{array}$ \\
\hline
\end{tabular}




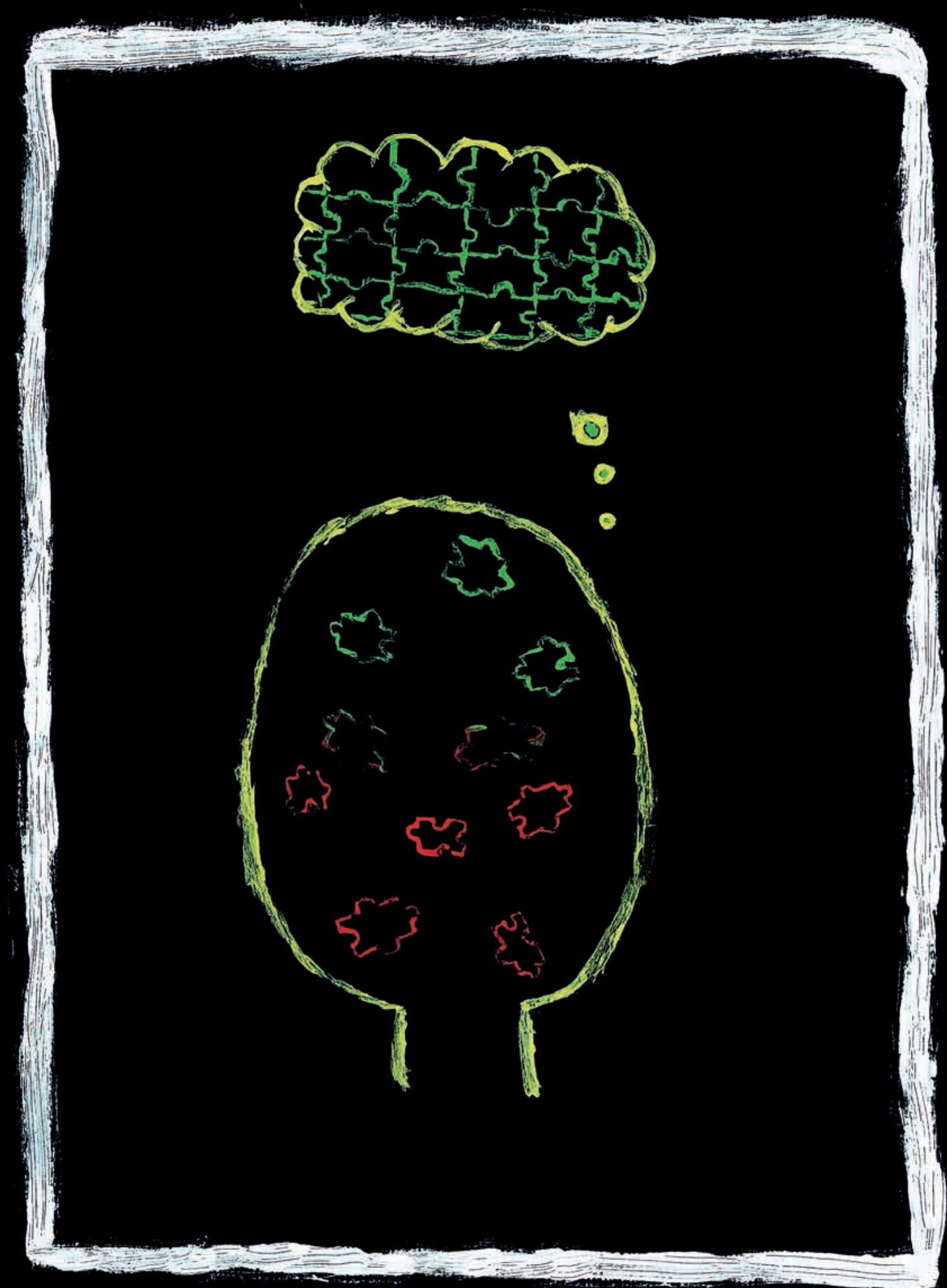




\section{Samenvatting (Summary in Dutch)}

Dit proefschrift beschrijft onderzoek naar metacognitieve vaardigheden van leerlingen in het basisonderwijs en voortgezet onderwijs tijdens het bestuderen van tekstuele informatie. Goede metacognitieve vaardigheden zijn essentieel; om effectief te leren is het belangrijk dat een leerling accuraat kan beoordelen welke gelezen informatie al wel begrepen is en welke informatie nog niet. Neem bijvoorbeeld Tom, die voor een toets voor aardrijkskunde, biologie en Engels leert. Het is belangrijk dat Tom goed kan beoordelen welke studiestof hij al kent en welke informatie nog niet voldoende begrepen is. Op basis van zijn zelfbeoordeling beslist Tom welke leerstof hij nog verder zal bestuderen.

Accurate zelfbeoordelingen zijn een noodzakelijke voorwaarde voor effectieve zelfregulatie. Uit onderzoek is gebleken dat leerlingen die accuraat kunnen beoordelen welke informatie ze wel en niet begrepen hebben effectiever zelfgestuurd kunnen leren en betere leeruitkomsten behalen. Helaas zijn metacognitieve vaardigheden vaak suboptimaal. Zelfbeoordelingen zijn vaak niet accuraat; zowel volwassenen als jongere leerlingen hebben vaak weinig inzicht of gelezen informatie ook daadwerkelijk begrepen is. De zelfbeoordelingen laten meestal zien dat er sprake is van overschatting; vaak verwachten leerlingen een hoog resultaat op een toets te halen, terwijl de gelezen informatie in werkelijkheid nog niet goed begrepen is. Wanneer de zelfbeoordelingen onnauwkeurig zijn is zelfregulatie (bijvoorbeeld opnieuw bestuderen van een tekst) vaak niet effectief, wat kan resulteren in suboptimale leeruitkomsten.

Het is dus belangrijk om leerlingen te ondersteunen bij het maken van accurate zelfbeoordelingen en bij effectieve zelfregulatie. Er is echter nog weinig bekend over de manier waarop leerlingen in het basis en voortgezet onderwijs hierbij geholpen kunnen worden. Onderzoek naar zelfbeoordelingen en zelfregulatie heeft zich tot nu toe namelijk vooral gericht op jongvolwassenen (studenten) die getest werden in laboratoria. Het onderzoek in dit proefschrift richt zich daarom op zelfbeoordelingen van leerlingen tijdens het bestuderen van onderwijskundig relevante informatie op school.

In het onderzoek in dit proefschrift bestudeerden leerlingen tekstuele informatie, daarna beoordeelden ze zelf hun begrip van bestudeerde informatie en beslisten zij welke informatie ze nog verder zouden moeten bestuderen om tot een goede toetsprestatie te komen.

In dit proefschrift worden vijf empirische studies beschreven. De twee doelen van dit onderzoek waren: a) inzicht krijgen in hoe instructies zelfbeoordelingen en 
zelfregulatie kunnen verbeteren tijdens het bestuderen van tekstuele informatie, en b) inzicht krijgen in het effect van individuele verschillen tussen leerlingen op de accuratesse van zelfbeoordelingen en de effectiviteit van zelfregulatie.

In de Introductie (hoofdstuk 1) wordt beschreven dat toepassingstaken (generation tasks) een positief effect kunnen hebben op de accuratesse van zelfbeoordelingen en de kwaliteit van zelfregulatie tijdens het bestuderen van tekstuele informatie. Wanneer leerlingen toepassingstaken maken, wordt van hen gevraagd om actief verbanden te leggen tussen de studiestof, contextuele informatie en voorkennis. Voorbeelden van toepassingstaken zijn het maken van samenvattingen of nieuwe zinnen over bestudeerde informatie. Op basis van voorgaand onderzoek werd verder verwacht dat de timing van zowel de zelfbeoordeling als de toepassingstaak belangrijk is. Zelfboordelingen zijn mogelijk accurater wanneer deze na het leren gemaakt worden dan tijdens het leren. Verder werd verwacht dat toepassingstaken die ná, in plaats van tijdens het leren gemaakt worden, een positiever effect hebben op accuratesse van zelfbeoordelingen. Wanneer de leerling tijdens het leren een toepassingstaak maakt, is geeft het uitvoeren van deze taak een leerling niet noodzakelijkerwijs een indicatie of bestudeerde informatie ook opgeslagen is in het langetermijngeheugen. Daarom geeft het maken van een toepassingstaak tijdens het leren de leerling vaak geen inzicht in zijn daadwerkelijke begrip van bestudeerde stof. Wanneer de toepassingstaak ná het leren gemaakt wordt, moet de leerling actief het langetermijngeheugen voor de bestudeerde informatie toetsen, zo krijgt de leerling inzicht in hoeverre deze leerstof begrepen is.

Ook wordt in de Introductie beschreven dat individuele verschillen tussen leerlingen de metacognitieve vaardigheden mogelijk beïnvloeden. Omdat zelfregulatie een moeilijke taak is, werd verwacht dat de oudere leerlingen effectiever konden selecteren welke informatie nog bestudeerd moest worden dan de jongere leerlingen. Omdat inaccurate voorkennis vaak niet gemakkelijk gecorrigeerd wordt, werd verwacht dat activatie van inaccurate voorkennis negatieve effecten zou hebben op de accuratesse van zelfbeoordelingen en de effectiviteit van zelfregulatie.

In hoofdstuk 2 tot 6 van het proefschrift worden de empirische studies beschreven. De studies in hoofdstuk 2 tot en met 4 beschrijven het effect van toepassingstaken op zelfbeoordelingen en zelfregulatie. Hoofdstuk 5 en 6 beschrijven studies naar het effect van individuele verschillen in voorkennis op de metacognitieve vaardigheden en de leeruitkomsten. Het effect van leeftijd wordt zowel in hoofdstuk 2 als hoofdstuk 5 onderzocht. 


\section{Effec ten va $n$ toepassingsta ken}

In de studies beschreven in hoofdstuk 2 en 3 bestudeerden leerlingen de betekenis van uitdrukkingen (bijvoorbeeld de uitdrukking een bok schieten met als betekenis iets doms doen). Hoofdstuk 2 beschrijft een experimentele studie, waarmee onderzocht werd hoe accuraat leerlingen op de basisschool (uit groep 6 en groep 8) hun begrip van uitdrukkingen kunnen beoordelen. De onderzoeksvraag in dit hoofdstuk is: wat is het effect van de timing van de zelfbeoordeling en de toepassingstaak 'zinnen maken' op zelfbeoordelingen en zelfregulatie? De accuratesse van zelfbeoordelingen en effectiviteit van zelfregulatie van drie verschillende groepen werd vergeleken: a) een groep die tijdens het leren zelfbeoordelingen maakte; b) een groep die zelfbeoordelingen maakte na het leren van alle uitdrukkingen; en c) een groep die de zelfbeoordelingen maakte nadat alle uitdrukkingen geleerd waren en zij nieuwe zinnen maakten waarin de uitdrukkingen toegepast werden. De resultaten laten zien dat zelfbeoordelingen accurater waren wanneer deze gemaakt werden na het leren van alle uitdrukkingen. Zelfregulatie was het meest effectief voor leerlingen die nieuwe zinnen maakten voordat zij de zelfbeoordelingen maakten. Verder was zelfregulatie effectiever voor de leerlingen uit groep 8 dan de leerlingen uit groep 6.

Voor het onderzoek beschreven in hoofdstuk 3 zijn middelbare scholieren (3 VWO leerlingen) getest. In dit onderzoek is de toepassingstaak 'zinnen maken' vergeleken met een instructie om te reflecteren op het begrip van bestudeerde uitdrukkingen. De leerlingen die reflecteerden hoefden geen toepassingstaak te maken, in plaats daarvan werd hen gevraagd of ze de uitdrukkingen moeilijk of gemakkelijk vonden, of ze de uitdrukkingen begrepen, en wat ze zouden kunnen doen om de geleerde uitdrukkingen beter te begrijpen. Alle leerlingen maakten zelfbeoordelingen en beslisten daarna welke uitdrukkingen zij opnieuw zouden willen bestuderen. De resultaten laten zien dat de leerlingen die nieuwe zinnen maakten betere zelfregulatie lieten zien dan leerlingen die reflecteerden. Ook laten resultaten zien dat de leerlingen die reflecteerden hun begrip van de uitdrukkingen meer overschatten dan leerlingen die zinnen maakten. Een verklaring hiervoor is dat wanneer leerlingen zinnen maken, ze actief hun begrip toetsen door het toepassen van de bestudeerde informatie. Het blijkt moeilijker te zijn voor leerlingen om door middel van reflectie inzicht te krijgen in hun begrip van de geleerde uitdrukkingen.

In hoofdstuk 4 is een studie beschreven waarin leerlingen (3 HAVO en 3 VWO) complexe teksten lazen waarin verschillende causale verbanden beschreven werden. Voor het effectief bestuderen van complexe teksten is het belangrijk dat leerlingen inzicht hebben in hun begrip van de causale verbanden. Het doel was om de accuratesse van zelfbeoordelingen te verbeteren met een diagrammen-invulinstructie. De onderzoeksvraag voor deze studie was: wat is het effect van de toepassingstaak 
'diagrammen invullen' en de timing van deze taak op zelfbeoordelingen en zelfregulatie? Drie groepen werden vergeleken: a) een groep vulde diagrammen in tijdens het leren, $b$ ) een groep vulde de diagrammen in na het bestuderen van de teksten, en c) een groep leerlingen vulde geen diagrammen in. Resultaten laten zien dat zelfbeoordelingen accurater waren na het invullen van diagrammen dan wanneer geen diagrammen ingevuld werden. Zelfbeoordelingen waren het meest accuraat wanneer de diagrammen na het leren ingevuld werden, in plaats van tijdens het leren. Analyses van de inhoud van de ingevulde diagrammen laten zien dat de leerlingen die de diagrammen na het leren invulden meer inzicht kregen in hun begrip. Daardoor konden zij hun toetsprestaties beter voorspellen dan leerlingen die de diagrammen direct na het lezen invulden.

\section{Effecten van individuele versc hillen in voorkennis}

Voor het onderzoek in hoofdstuk 5 en 6 werd aan leerlingen gevraagd om voorkennis te activeren vóór het bestuderen van de tekstuele informatie. Voorgaand onderzoek duidt aan dat correcte en complete voorkennis meestal positieve effecten heeft op leeruitkomsten, maar dat leerlingen vaak moeite hebben on inaccurate voorkennis te corrigeren. De onderzoeksvraag in hoofdstuk 5 is: wat is het effect van inaccurate voorkennis op de zelfoverschatting en de zelfregulatie van leerlingen? Om tevens inzicht te krijgen in de invloed van leeftijd werden twee cohorten basisschoolleerlingen met elkaar vergeleken, groep 5-6 en groep 7-8. Leerlingen activeerden hun voorkennis over moeilijke definities, na het activeren van voorkennis bestudeerden leerlingen de betekenis van deze definities. De bevindingen van deze studie laten zien dat activatie van inaccurate voorkennis een negatief effect had op metacognitieve vaardigheden en leerprestaties. Na activatie van inaccurate voorkennis gaven leerlingen meer incorrecte antwoorden op de toets dan wanneer zij geen voorkennis konden activeren. Ook lieten leerlingen meer zelfoverschatting zien na activatie van inaccurate voorkennis, en was zelfregulatie minder effectief. Leerlingen besloten vaker om de definities waarvoor zij inaccurate voorkennis hadden niet verder te bestuderen dan de definities waarvoor zij géén voorkennis konden activeren. Jongere leerlingen lieten meer zelfoverschatting zien dan oudere leerlingen. Deze resultaten laten zien dat het belangrijk is om inaccurate voorkennis te detecteren en te corrigeren.

Met de laatste studie in dit proefschrift, beschreven in hoofdstuk 6, werd onderzocht of het contrasteren van inaccurate voorkennis met de juiste kennis en het verwerpen van de inaccurate voorkennis gunstige effecten heeft op leerprestaties en metacognitieve vaardigheden. Vóór het bestuderen van teksten activeerden leerlingen (2 VWO) voorkennis over veelvoorkomende misvattingen en gaven zij een zelfbeoordeling over hoe zeker zij waren dat deze voorkennis accuraat was. De 
onderzoeksvraag was: hoe beïnvloeden zelfbeoordelingen over de correctheid van inaccurate voorkennis en het formaat van de bestudeerde tekst leeruitkomsten, zelfoverschattingen en zelfregulatie? Twee groepen werden vergeleken: a) één groep las teksten waarin inaccurate voorkennis expliciet verworpen werd (dit soort teksten worden 'refutation texts' genoemd) en b) één groep las teksten waarin alleen de juiste informatie beschreven werd, zonder expliciete verwerping van inaccurate voorkennis. Resultaten laten zien dat inaccurate voorkennis vaak niet gecorrigeerd werd wanneer leerlingen er zeker van waren dat deze voorkennis correct was. Het lezen van teksten waarin inaccurate voorkennis expliciet verworpen werd (de refutation texts) hielp leerlingen om inaccurate voorkennis te corrigeren. Echter, verwerping van inaccurate voorkennis had geen voordelige effecten op de accuratesse van zelfbeoordelingen die gemaakt werden na het lezen van de teksten. Wanneer inaccurate voorkennis tijdens het lezen niet gecorrigeerd was, lieten leerlingen beduidend meer zelfoverschatting zien en de zelfregulatie was niet effectief. Deze bevindingen laten zien dat expliciete verwerping van inaccurate voorkennis de leerprestatie verbetert, maar dat deze interventie niet voldoende is om de zelfbeoordelingen en de zelfregulatie voor niet-gecorrigeerde voorkennis te verbeteren.

\section{Implicaties}

Hoofdstuk 7, de Discussie, beschrijft theoretische implicaties van het uitgevoerde onderzoek. Verder worden in dit hoofdstuk de beperkingen van het onderzoek in dit proefschrift, aanbevelingen voor toekomstig onderzoek en praktische toepassingsmogelijkheden beschreven.

Het beschreven onderzoek levert nieuwe inzichten op in het effect van toepassingstaken. We wisten nog niet veel over effecten van toepassingstaken op de zelfbeoordelingen en zelfregulatie van leerlingen in het basis en voortgezet onderwijs, uit dit onderzoek blijkt dat deze taken een positief effect hebben op metacognitieve vaardigheden. Omdat leerlingen tijdens het maken van een toepassingstaak actief aan de slag gaan met het zelf testen van hun begrip van bestudeerde informatie, kunnen zij na het maken van die toepassingstaken accurater zelf beoordelen welke informatie zij wel en niet begrepen hebben. Door deze verbeterde zelfbeoordelingen kunnen ze effectiever kiezen welke informatie nog verdere studie nodig heeft.

$\mathrm{Na}$ het maken van een toepassingstaak konden leerlingen bovendien de zelfbeoordelingen snel en accuraat maken. Resultaten impliceren dat de leerlingen die géén toepassingstaak hadden gemaakt, tijdens het geven van een zelfbeoordeling de bestudeerde informatie letterlijk probeerden op te halen uit het geheugen. Wanneer het deze leerlingen niet lukte om de bestudeerde informatie weer op te halen, duurde het 
lang voordat ze een zelfbeoordeling konden geven. Echter, leerlingen die wel een toepassingstaak hadden gemaakt gaven de zelfbeoordelingen snel en accuraat, ook wanneer ze aangaven dat ze de bestudeerde stof nog niet begrepen. Dit impliceert dat deze leerlingen door het maken van een toepassingstaak al inzicht hadden gekregen in hun begrip.

Ook impliceert het onderzoek dat toepassingstaken effectiever zijn dan reflectietaken om de zelfbeoordelingen en zelfregulatie te verbeteren. Leeftijdsverschillen hadden effect op zelfoverschatting en regulatie: oudere leerlingen overschatten zichzelf in mindere mate en selecteerden effectiever welke informatie ze opnieuw wilden bestuderen. De timing van de toepassingstaak blijkt ook belangrijk te zijn; wanneer toepassingstaken ná het leren worden gemaakt krijgen leerlingen meer inzicht in hun begrip van informatie dan wanneer deze taken tijdens het leren worden gemaakt.

Verder was er nog niet veel bekend over de effecten van activatie van voorkennis op metacognitieve vaardigheden, dit onderzoek levert nieuwe inzichten op. De resultaten laten zien dat activatie van inaccurate voorkennis negatieve effecten heeft op de accuratesse van zelfbeoordelingen en de effectiviteit van zelfregulatie en dat het belangrijk is om inaccurate voorkennis expliciet te verwerpen.

Ook worden in de Discussie beperkingen van dit onderzoek en aanbevelingen voor vervolgonderzoek beschreven. Het beschreven onderzoek levert nog geen inzichten op in hoe de zelfbeoordelingen verbeterd kunnen worden wanneer leerlingen inaccurate voorkennis hebben. Dit blijft een belangrijke vraag voor vervolgonderzoek. Verder maakten leerlingen selecties welke stof zij nog verder wilden bestuderen, maar kregen zij niet de kans om de geselecteerde informatie opnieuw te bestuderen. Voor toekomstig onderzoek wordt aangeraden om deze geselecteerde stof daadwerkelijk te laten bestuderen. Dit kan meer inzicht opleveren in het effect van verbeterde zelfbeoordelingen en zelfregulatie op uiteindelijke leeruitkomsten.

De studies in dit proefschrift leveren toepassingsmogelijkheden op voor de onderwijspraktijk. Voordat leerlingen informatie gaan bestuderen is het allereerst belangrijk om te identificeren of de voorkennis van leerlingen correct is. Zo niet, dan is het belangrijk om de inaccurate voorkennis te verwerpen en te contrasteren met de correcte informatie. Om leerlingen te ondersteunen bij het maken van accurate zelfbeoordelingen over het begrip van bestudeerde informatie kan de docent hen adviseren om toepassingstaken ná het leren te maken, in plaats van tijdens het leren. Op deze manier krijgen leerlingen de kans om hun begrip van bestudeerde informatie te toetsen. Na het maken van de toepassingstaken is het belangrijk dat leerlingen de mogelijkheid krijgen om hun leren te beoordelen en daarna te selecteren welke informatie nog verder bestudeerd moet worden. Het gebruik van de onderzochte interventies in het basis en voortgezet onderwijs zal waarschijnlijk zeer positieve effecten 
Samenvatting (Summary in Dutch)

hebben op de accuratesse van zelfbeoordelingen, het zelfgestuurd leren en de leeruitkomsten. 


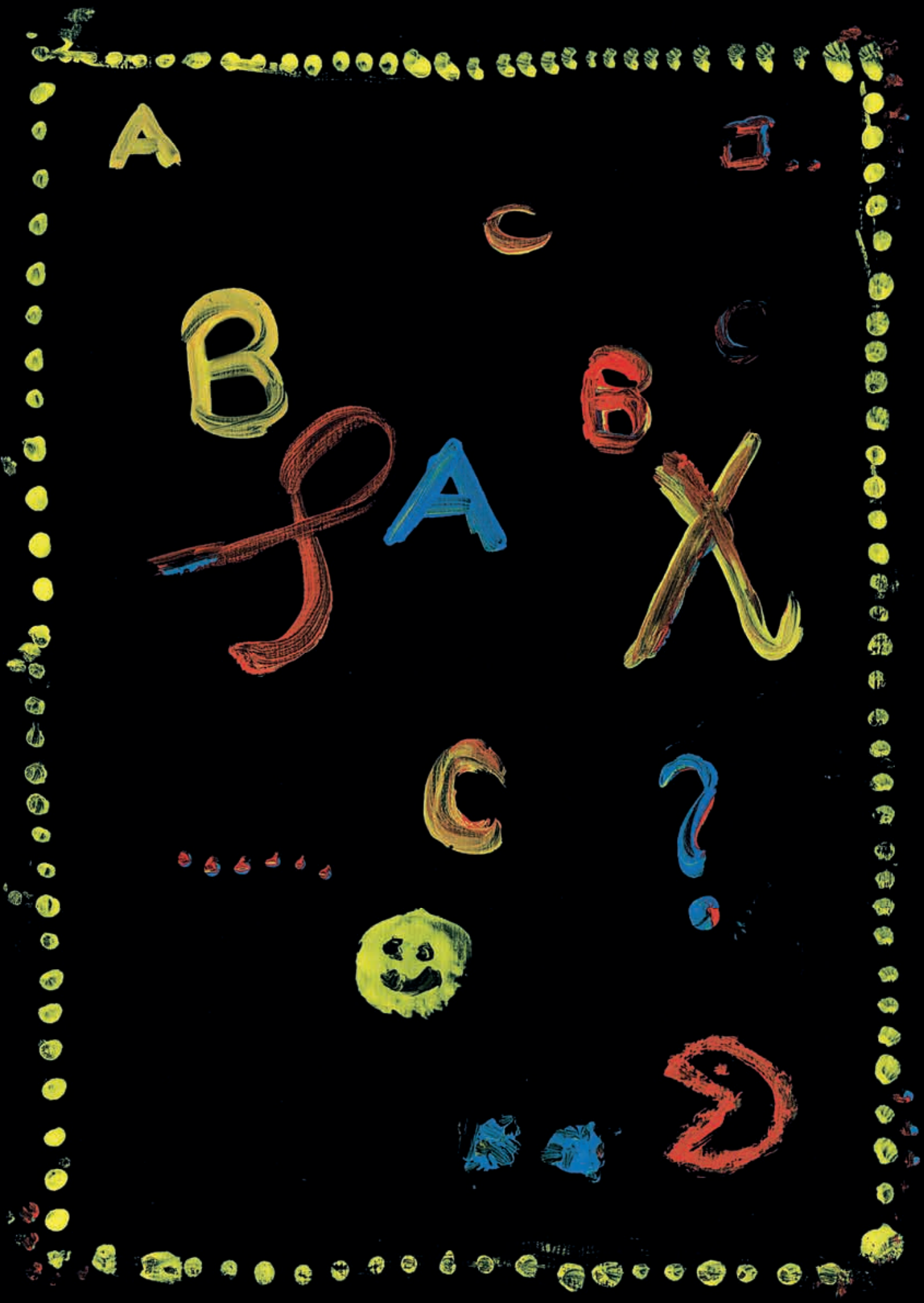




\section{Dankwoord (Acknowledgements)}

In november 2009 begon ik bij O\&O aan het promotietraject 'Fostering self-monitoring and self-regulation in language learning'. Vier jaar lang ben ik bezig geweest met napluizen en nadenken, materialen ontwikkelen, leerlingen testen, discussies voeren, schrijven en presenteren. De tijd is snel gegaan, er is een einde gekomen aan mijn promotieonderzoek en het resultaat daarvan is dit proefschrift. Zonder de hulp van een heel aantal mensen was dit proefschrift er nu niet geweest. Daarom wil ik een aantal belangrijke personen heel hartelijk bedanken!

Allereerst veel dank voor mijn topteam, bestaande uit copromotor Anique en de promotores Jeroen en Tamara. Ik had geen beter team kunnen hebben (het bewijs daarvoor is jullie prijs voor het beste begeleidingsteam). Met jullie heb ik hardop nagedacht en dat was altijd weer inspirerend. Jullie hadden veel geduld en hebben heel veel tijd gestoken in het samen nadenken en in het lezen en bekritiseren van mijn stukken. In het begin schrok ik van die hoeveelheid feedback, maar ik ben het enorm gaan waarderen! Nadat ik met jullie om de tafel (of op Skype) gezeten had was er altijd weer veel om mee aan de slag te gaan. En gelukkig was het niet alleen maar werk wat we deden, we hebben ook veel gezellige tijden gehad met lekker eten en een biertje erbij, we zijn zelfs een keer in een Duitse karaokebar beland!

Anique, als hoofdaanvrager van het onderzoeksbudget bij NWO was je de eerste persoon die ik over dit project sprak. Heel veel dank voor je gedrevenheid, je analytische blik en al je tijd! Jij pepte me op als ik even niet meer wist waar ik moest beginnen en remde me af als ik iets te enthousiast was. Dankzij jouw passie voor metacognitie ben ik nu 'voor altijd' geïnteresseerd in zelfbeoordelingen en zelfregulatie. Je bent echt een voorbeeld voor me en ik hoop dat we in de toekomst nog veel zullen samenwerken.

Jeroen, wat een geluk dat ik jou als promotor heb getroffen. Je bekeek mijn onderzoek vanuit een helicopterview en je hield vooral van overzichtelijke figuren, maar had tegelijkertijd oog voor de kleinste details (jij ontdekte bijvoorbeeld de bijna onzichtbare spel- en redeneerfoutjes). Je verwachtte van mij dat ik de agenda opstelde met eigen prioriteiten en je liet me veel zelf uitzoeken, maar op momenten dat ik je inzicht en wijsheid nodig had was je er om mee te denken en advies te geven. Dat is heel waardevol geweest!

Tamara, je was fysiek wat verder weg (in Rotterdam) maar daar was niet veel van te merken. Ook al ben je tijdens het promotietraject prof geworden en was je agenda overvol, je bleef heel erg betrokken en gefocust. Van jou kwamen e-mails vaak om 1 uur 
's nachts of om 6 uur in de ochtend binnen, zelfs als je out-of-office aanstond. Je hebt heel veel bijzondere en zeer bruikbare input geleverd voor dit proefschrift. En je bracht ook veel gezelligheid met je mee. Bedankt voor alles!

Martine en Luciana, jullie waren mijn twee lotgenoten. Met elkaar hebben we alle PROO meetings bijgewoond en workshops en een symposium vorm gegeven. Veel dank voor de goede samenwerking en jullie support! Martine, we hebben veel enthousiasme over onderzoek en frustraties over gamma's gedeeld. Je was een heel fijne hotelkamergenoot bij conferentiebezoeken in Milaan, Vancouver en Brussel. Vroeg in de ochtend luisterde je nog even als ik mijn presentaties wilde oefenen en na lange werkdagen sprak je me onder het genot van een drankje nog wat frisse moed in en plaatste je wat kritische noten. Na een fijne samenwerking zijn onze proefschriften nu af, we did it!

Luciana, thank you for all your support and encouragement, and your focus on esthetics. It was always nice to have coffee and non-Italian-style mensa food together. You made me happy to test children in a classroom instead of in a scanner. Wish you all the best with the scanning and the writing of your thesis!

Ook wil ik alle project-adviseurs bedanken. Peter Stiers, we spraken elkaar vooral tijdens de PROO-meetings. Ook al was je als fundamenteel onderzoeker vooral betrokken bij de neuro-kant van dit project, je hebt tijdens de bijeenkomsten veel interesse getoond en hele nuttige ideeën gedeeld over de opzet van mijn onderzoek en de resultaten. Veel dank daarvoor!

Many thanks to the international advisors John Dunlosky, Keith Thiede, and Paul Ayres. Thank you for making the symposium 'Improving Metacognitive Skills' a success. And thank you very much for all your thoughts and comments on this research project. John, when you visited us in Maastricht, I asked you if I could come to Kent for research, and you said yes! Thank you for this valuable experience, I learned a lot about research, writing, and reasoning. And of course I had fun as well, I would also like to thank all the graduate students at Kent State for that. They gave me a warm welcome, commented on my writing and took me to parties, found me a vegetarian cheesesteak, and took me to a baseball match and to rollercoasters.

Bedankt student-assistenten, zonder jullie had dit proefschrift niet bestaan! Eva heeft aan het begin van het project veel kinderen getest en data geanalyseerd. Daarna hebben Renske en Andrea een onmogelijke hoeveelheid data gescoord, ingevoerd en geanalyseerd. Online testen was niet mogelijk geweest als Eddy niet aan het programmeren was gegaan. Daarna nam Gerrit het programmeren over, hij was soms diep in de nacht nog aan de slag om de taken voor het onderzoek op tijd af te krijgen en de responsen van leerlingen te analyseren. Ik wil jullie allemaal heel hartelijk bedanken voor al jullie hulp, jullie waren onmisbaar!

Mijn werkkamer deelde ik met Ingrid, Juliette en Jonne. Zij hebben mij allemaal het goede voorbeeld gegeven door al te promoveren. Ingrid, op momenten dat ik op zoek 
was naar informatie kon jij altijd een relevant artikel opdiepen uit je grote stapel papieren. Je stond altijd klaar om mee te denken, om iets kritisch te lezen en om kanttekeningen te plaatsen bij wilde ideeën. Heel veel dank en veel succes met onderwijs, onderzoek en je net gekochte huis!

Het geeft me een veilig gevoel dat de twee dokters van onze aio-kamer achter me staan tijdens de verdediging. Juliette, jou heb ik leren kennen als een echte zelfverzekerde aanpakker, je werkte vaak door tot in de late uurtjes en combineerde je onderzoek met studie en chirurgie. Het was erg inspirerend om je als kamergenoot te hebben. We hebben leuke reizen (al dan niet onderzoek-gerelateerd) gemaakt naar Barcelona, München en Zwitserland. Ik hoop dat we dat nog vaak gaan overdoen! Fijn dat je mijn paranimf bent!

Jonne, vier volle jaren deelden wij onze werkkamer en daaruit is een bijzondere vriendschap ontstaan (keywords: menselijke factoren, laatste loodjes, lekerigheid, salades, dropjes, koffie en soep). Heel veel dank dat je er was en bent, of het nu in Randwyck, Scharn of Wittevrouwenveld is. Het was erg bijzonder om een paar maanden geleden jouw paranimf te zijn. Voordat je mij nu bij zal staan tijdens de verdediging heb je nog een andere heel grote klus, een bevalling! Heel veel geluk met je gezin en met het vinden van een droombaan! Ik kom nog vaak bij jou, Robert, Timo, Bente en de baby langs om van je espressomachine en je kookkunsten te genieten en je goede wijnen aan te breken (binnenkort delen we die weer).

Andere collega's van O\&O, ik ben erg blij dat ik bij jullie werk! Sinds een paar maanden zit ik op de vijfde, maar tijdens het werk voor dit proefschrift was de vierde verdieping mijn thuis. Fijn dat ik nog steeds bij jullie op de afdeling zit, ook al is het een andere verdieping.

Mede-aio's en ex-mede-aio's, bedankt voor jullie interesse, jullie feedback en ideeën, het delen van jullie kennis en voor de gezellige momenten! In het bijzonder wil ik de EXPED-aio's bedanken: Ellen, Jorrick, Rachelle en Katerina. Hopelijk gaan we binnenkort onze brainstorms over experimenteel onderzoek weer oppakken. Het was erg goed om ideeën te delen en super dat ons last-page plan ten uitvoer is gebracht! Hopelijk kunnen we elkaar in de toekomst nog veel inspiratie geven. Jimmie, jou wil ik bedanken voor je hulp met data-analyse.

Nu sta ik voor een nieuwe uitdaging: het ontwikkelen van de SHE Certificate Courses. Herma en Willem, fijn dat jullie me daarin bijstaan, we gaan er iets moois van maken! Daniëlle, leuk dat ik nu tegenover je zit, het is bijzonder om te zien hoe veel projecten jij gaande hebt op het werk en thuis. Ik hoop dat we nog veel productieve en gezellige dagen gaan hebben in ons gedeeld kantoor.

Nicky en Lilian, jullie verdienen een heel grote pluim vanwege het altijd klaarstaan voor mij en dit project. Voor ons druk bezochte symposium regelden jullie alles, van 
ontvangst van de gasten tot de catering. Veel dank voor de hulp bij het plannen van deze promotie. Nicky, heel knap dat je altijd weer kan toveren met de agenda van Jeroen!

Alle basisscholen en middelbare scholen waarop ik leerlingen heb getest, wat fijn dat ik bij jullie terecht kon. In het bijzonder wil ik de docenten Jan de Bres en Erwin van Dooren bedanken voor al hun steun bij rooster- en regelwerk en voor hun enthousiasme over wetenschappelijk onderzoek in onderwijs.

En er waren nog veel meer mensen die voor me klaarstonden en bij wie ik mijn ei kwijt kon als dat even nodig was. Heleen, jij heel veel voor me klaar gestaan. Je hebt zelfs dagenlang voor me achter de computer gezeten om data te scoren en te analyseren en als ik veel stress had door de bergen met data kon ik dat zelfs per mail naar je sturen! Het was erg fijn om samen te koken, te relaxen, bij te praten en te genieten van nietkunstzinnig-hoogstaande films. Met veel plezier kijk ik ook terug op onze ontspannende reizen naar Rome en naar de Oostenrijkse sneeuw. En Sam, jou wil ik ook bedanken! Jij bent al lang een bijzondere vriend voor me. Soms hadden we eigenlijk geen tijd voor elkaar als we afspraken omdat er nog te veel was blijven liggen. Dan gingen we weer met onze eigen projecten aan de slag, van in jouw atelier tot in Venetië. Gelukkig was er ook tijd voor andere dingen, ik heb heerlijk kunnen dagdromen tijdens lange autoritten met jou. Wat leuk dat je telkens weer je ideeën over leuke muziek, kunst en de zin-of-onzin van grijze gebieden waarin zwart en wit niet bestaan met me deelt. Jeroen en Martijn, bedankt voor de muzikale avonden. En iedereen van de PhD Academy, veel dank voor de gezellige borrels, feestjes en vergaderingen.

Bedankt Gerrit, Els, Renate, Erik-Jan, Janneloes, Arianne, Petricia en Gerlin, ofwel mijn familie. Als ik naar een school in een verlaten oord moest stond de auto voor me klaar. Toen ik grote tassen vol data had werd daar transport voor geregeld. Op het moment dat ik wilde kijken of de onderzoekstaken bruikbaar waren kon ik jullie gebruiken als eerste pilot-proefpersonen. Er werden zelfs allerlei buurtkinderen opgetrommeld die mee konden werken als ik mijn materialen wilde testen. Mijn vijf zusjes Renate, Janneloes, Arianne, Petricia en Gerlin, ik vind het heel bijzonder dat jullie voor mij creatief aan de slag zijn gegaan en de illustraties voor dit proefschrift hebben gemaakt. Familie, jullie waren en zijn onmisbaar! Helaas zal papa Wim niet bij de verdediging zijn. Hij is veel te vroeg overleden. Ik weet dat hij altijd hard heeft gewerkt om het mooiste van het leven te maken. Hij zou trots zijn dat ik nu mijn proefschrift ga verdedigen. De gedachte aan hem geeft mij de motivatie om te proberen veel uit dit leven te halen, ook al moet ik misschien soms even bikkelen.

Dirk, jij hebt naar me geluisterd en me (soms ongevraagd) advies gegeven om vooruit te denken en prioriteiten te stellen. Bedankt voor je relativeringsvermogen, voor het samen koken, het huishouden doen of niet doen, sporten (dankzij jouw wielrenpassie heb ik nu zelfs een racefiets), voor de gezellige uit-etentjes (laten we nog heel veel restaurantjes gaan verkennen) en voor de leuke reizen die we samen gemaakt hebben. 
Ik ben trots op je dat jij ook zo goed aan de weg aan het timmeren bent! Ik hoop dat we samen nog veel goede en gezellige tijden gaan hebben, zowel hier in Maastricht als ver van huis. 


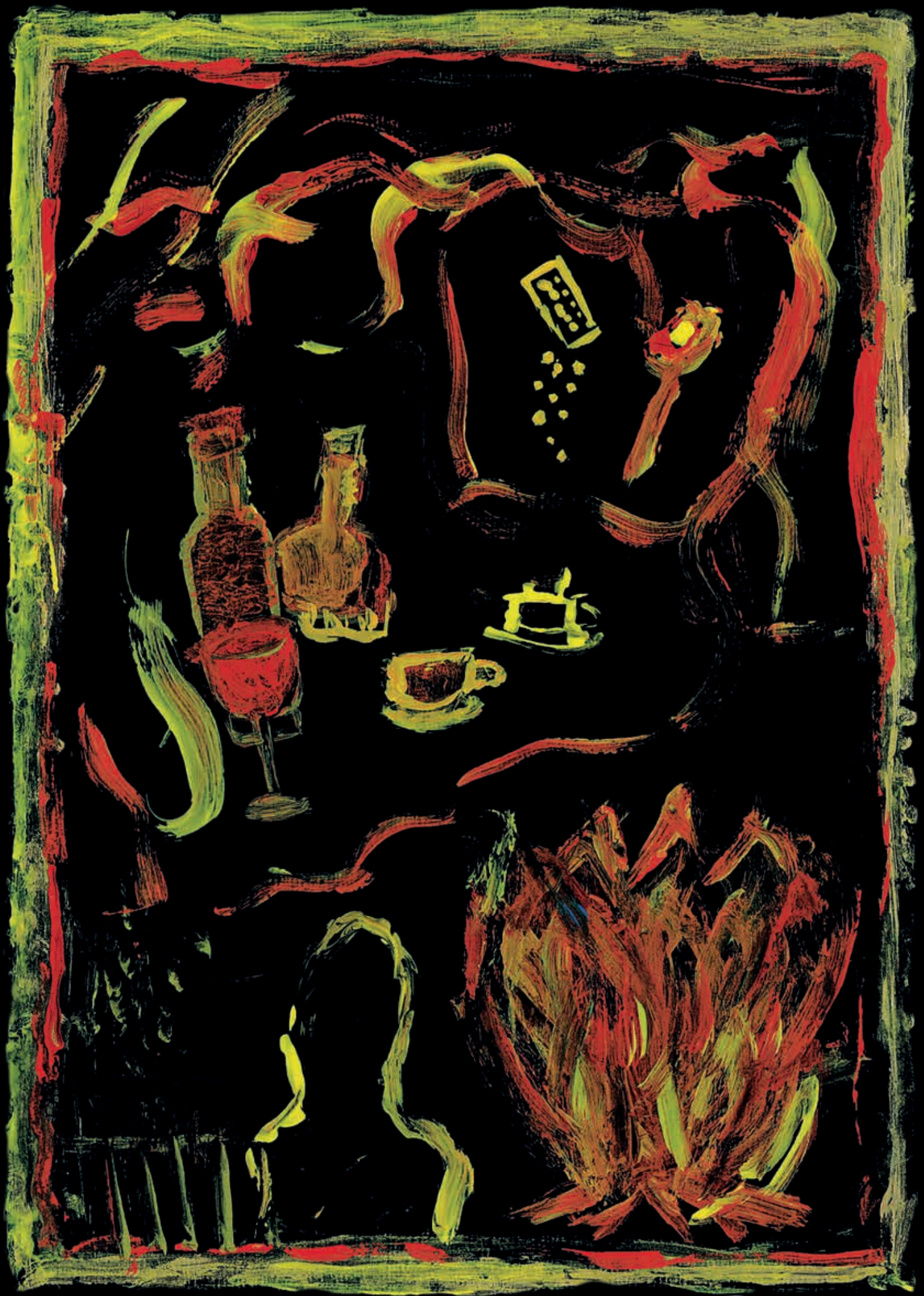




\section{Curic ulum Vitae}

Mariëtte Henrica van Loon was born in 's-Hertogenbosch in 1982. In 2001 she started studying psychology at Utrecht University. During her studies she became interested in the field of cognitive psychology, learning and memory. The last years of her studies, she went as exchange student to the Northermost Cognitive Neuroscience Group at the University of Troms $\varnothing$ in Norway. From 2004 to 2006 she worked there on research projects about memory for visual information. In August 2006, she received a Master's degree in biological and neuropsychology.

After graduation, she spent two years abroad to work and travel in North and Central America. During that time she traveled from Alaska to Belize, and worked in a skiresort, a vineyard, and as volunteer to support sustainable living.

In 2009, Mariëtte started with the PhD project at Maastricht University, this project resulted in the present dissertation. The focus of her research is on how instructions can improve learners' monitoring and regulation in educational settings. Parts of her PhD thesis were written when she was a visiting researcher at Kent State University in Ohio, USA.

Currently, Mariëtte is employed as an assistant professor at Maastricht University. Her research interests are related to metacognitive skills, self-regulated learning, judgment and decision making, instructional design, and comprehension of complex information. 


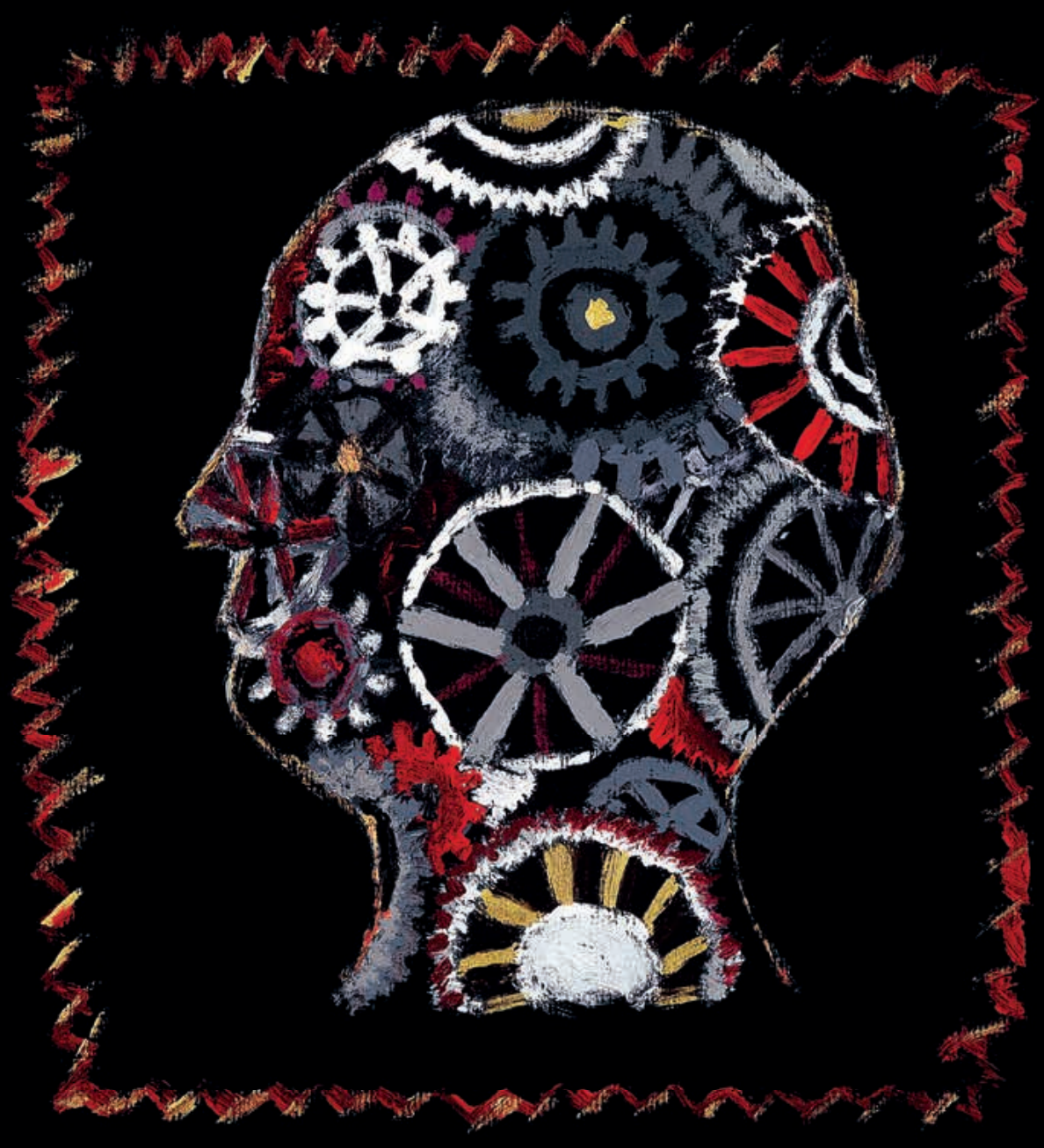




\section{List of SHE Dissertations}

The SHE Dissertation Series publishes dissertations of PhD candidates from the School of Health Professions Education (SHE) who defended their PhD theses at Maastricht University. The most recent ones are listed below. For more information go to: www.maastrichtuniversity. $\mathrm{nl} / \mathrm{she}$.

Frambach, J. M. (26-03-2014). The cultural complexity of problem-based learning across the world.

Hommes, J.E. (26-02-2014) How relations, time \& size matter in medical education.

Van der Zwet, J. (30-01-2014) Identity, Interaction and Power. Explaining the affordances of doctor-student interaction during clerkships.

Watling, C.J. (22-01-2014) Cognition, Culture, and Credibility. Deconstructing Feedback in Medical Education.

Winston, K. (12-12-2013) Remediation Theory and Practice: Transforming At-Risk Medical Students

Kamp, R.J.A. (28-11-2013) Peer Feedback to Enhance Learning in Problem-Based Tutorial Groups

Junod Perron, N. (24-10-2013) Towards a learner-centered approach to postgraduate communications skills teaching

Pratidina Susilo, A. (24-10-2013) Learning to be the Patient Advocate

The Development of a Communication Skills Course to Enhance Nurses' Contribution to the Informed Consent Process

Alves de Lima, A. (23-10-2013) Assessment of clinical competence: Reliability, Validity, Feasibility and Educational Impact of the mini-CEX

Sibbald, M. (09-10-2013) Is that your final answer? How doctors should check decisions Ladhani, Z. (05-07-2013) Competency based education and professional competencies: a study of institutional structures, perspectives and practices in Pakistan.

Jippes, M. (01-02-2013) Culture matters in medical schools: How values shape a successful curriculum change

Duvivier, R. J. (12-12-2012) Teaching and Learning Clinical Skills. Mastering the Art of Medicine

De Feijter, J.M. (09-11-2012) Learning from error to improve patient safety

Prescott, L. (09-11-2012) Ensuring the Competence of Dental Practitioners through the Development of a Workplace-Based System of Assessment 
Cilliers, F.J. (05-09-2012) The Pre-assessment Learning Effects of Consequential Assessment: Modelling how the Examination Game is Played

Spanjers, I. A.E. (05-07-2012) Segmentation of Animations: Explaining the Effects on the Learning Process and Learning Outcomes

Al-Kadri, H.M.F. (28-06-2012) Does Assessment Drive Students' Learning?

Leppink, J. (20-06-2012) Propositional manipulation for conceptual understanding of statistics

Van Zundert, M.J. (04-05-2012) Conditions of Peer Assessment for Complex Learning

Claramita, M. (30-03-2012) Doctor-patient communication in a culturally hierarchical context of Southeast Asia: A partnership approach

Kleijnen, J.C.B.M. (21-03-2012) Internal quality management and organizational values in higher education

Persoon, M.C. (19-01-2012) Learning in Urology; The influence of simulators and human factors

Pawlikowska, T.R.B. (21-12-2011) Patient Enablement; A Living Dialogue

Sok Ying Liaw, (14-12-2011) Rescuing A Patient In Deteriorating Situations (RAPIDS): A programmatic approach in developing and evaluating a simulation-based educational program

Singaram, V.S. (7-12-2011) Exploring the Impact of Diversity Factors on Problem-Based Collaborative Learning

Balslev, T. (24-11-2011) Learning to diagnose using patient video cases in paediatrics: Perceptive and cognitive processes

Widyandana, D. (19-10-2011) Integrating Pre-clinical skills training in skills laboratory and primary health care centers to prepare medical students for their clerkships

Durning, S.J. (09-09-2011) Exploring the Influence of Contextual Factors of the Clinical Encounter on Clinical Reasoning Success (Unraveling context specificity)

Govaerts, M.J.B. (08-09-2011) Climbing the Pyramid: Towards Understanding Performance Assessment

Stalmeijer, R. E. (07-07-2011) Evaluating Clinical Teaching through Cognitive Apprenticeship.

Malling, B.V.G. (01-07-2011) Managing word-based postgraduate medical education in clinical departments

Veldhuijzen, J.W. (17-06-2011) Challenging the patient-centred paradigm: designing feasible guidelines for doctor patient communication.

Van Blankenstein, F. (18-05-2011) Elaboration during problem-based, small group discussion: A new approach to study collaborative learning.

Van Mook, W. (13-05-2011) Teaching and assessment of professional behavior: Rhetoric and reality. 
De Leng, B. (8-12-2009). Wired for learning. How computers can support interaction in small group learning in higher education.

Maiorova, T. (29-05-2009). The role of gender in medical specialty choice and general practice preferences.

Bokken, L. (04-03-2009). Innovative use of simulated patients for educational purposes.

Wagenaar, A. (18-09-2008). Learning in internships. What and how students learn from experience.

Driessen, E. (25-06-2008). Educating the self-critical doctor. Using portfolio to stimulate and assess medical students' reflection.

Derkx, H. (18-06-2008). For your ears only. Quality of telephone triage at out-of-hours centres in the Netherlands.

Niessen, Th. (30-11-2007). Emerging epistemologies: making sense of teaching practice.

Budé, L. (05-10-2007). On the improvement of students' conceptual understanding in statistics education.

Niemantsverdriet, S. (26-07-2007). Learning from international internships: A reconstruction in the medical domain.

Marambe, K. (20-06-2007). Patterns of student learning in medical education - A Sri Lankan study in traditional curriculum.

Pleijers, A. (19-01-2007). Tutorial group discussion in problem-based learning.

Sargeant, J. (21-09-2006). Multi-source feedback for physician learning and change.

Dornan, T. (12-06-2006). Experience-based learning.

Wass, V. (12-05-2006). The assessment of clinical competence in high stakes examinations.

Prince, K. (21-04-2006). Problem-based learning as a preparation for professional practice. 


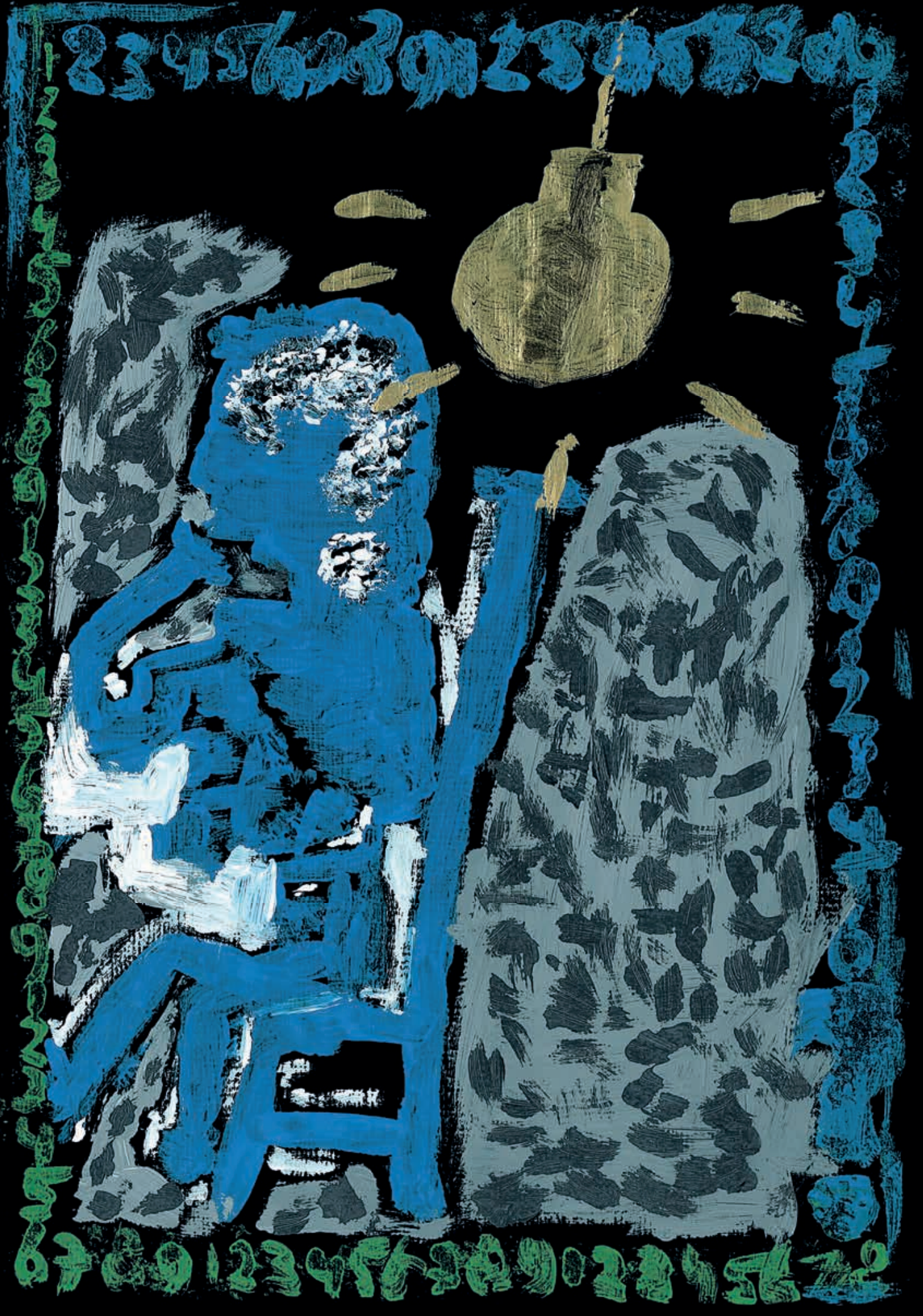




\section{List of IC O Dissertations}

In the ICO Dissertation Series the dissertations of graduate students from faculties and institutes on educational research within the ICO Partner Universities are published: Eindhoven University of Technology, Leiden University, Maastricht University, Open University of the Netherlands, University of Amsterdam, University of Twente, Utrecht University, VU University Amsterdam, and Wageningen University, and formerly University of Groningen (until 2006), Radboud University Nijmegen (until 2004), and Tilburg University (until 2002). The University of Groningen, University of Antwerp, University of Ghent, and the Erasmus University Rotterdam have been 'ICO 'Network partner' in 2010 and 2011. From 2012 onwards, these ICO Network partners are full ICO partners, and from that period their dissertations will be added to this dissertation series. The most recent dissertations of the ICO series are listed below.

207. Zitter, I.I. (04-02-2010). Designing for learning: Studying learning environments in higher professional education from a design perspective. Utrecht: Utrecht University.

208. Koopman, M. (11-02-2010). Students' goal orientations, information processing strategies and knowledge development in competence-based pre-vocational secondary education. Eindhoven: Eindhoven University of Technology.

209. Platteel, T. (11-02-2010). Knowledge development of secondary school L1 teachers on concept-context rich education in an action-research setting. Leiden: Leiden University.

210. Mittendorff, K. M. (12-03-2010). Career conversations in senior secondary vocational education. Eindhoven: Eindhoven University of Technology.

211. Moolenaar, N.M. (01-06-2010). Ties with potential: Nature, antecedents, and consequences of social networks in school teams. Amsterdam: University of Amsterdam.

212. Duijnhouwer, H. (04-06-2010). Feedback effects on students' writing motivation, process, and performance. Utrecht: Utrecht University.

213. Kessels, C.C. (30-06-2010). The influence of induction programs on beginning teachers' well-being and professional development.Leiden: Leiden University.

214. Endedijk, M.D. (02-07-2010). Student teachers' self-regulated learning. Utrecht: Utrecht University.

215. De Bakker, G.M. (08-09-2010). Allocated online reciprocal peer support as a candidate for decreasing the tutoring load of teachers. Eindhoven: Eindhoven University of Technology.

216. Groenier, M. (10-09-2010). The decisive moment: Making diagnostic decisions and designing treatments. Enschede: University of Twente.

217. Bonestroo, W.J. (24-09-2010). Planning with graphical overview: Effects of support tools on self-regulated learning. Enschede: University of Twente.

218. Vos, M.A.J. (30-09-2010). Interaction between teachers and teaching materials: On the implementation of context-based chemistry education. Eindhoven: Eindhoven University of Technology.

219. Kostons, D.D.N.M. (05-11-2010). On the role of self-assessment and task-selection skills in self-regulated learning. Heerlen: Open University of the Netherlands. 
220. Bruin-Muurling, G. (21-12-2010). The development of proficiency in the fraction domain: Affordances and constraints in the curriculum. Eindhoven: Eindhoven University of Technology.

221. Slof, B. (28-01-2011). Representational scripting for carrying out complex learning tasks. Utrecht: Utrecht University.

222. Fastré, G. (11-03-2011). Improving sustainable assessment skills in vocational education. Heerlen: Open University of the Netherlands.

223. Min-Leliveld, M.J. (18-05-2011). Supporting medical teachers' learning: Characteristics of effective instructional development. Leiden: Leiden University.

224. Van Blankenstein, F.M. (18-05-2011). Elaboration during problem-based small group discussion: A new approach to study collaborative learning. Maastricht: Maastricht University.

225. Dobber, M. (21-06-2011). Collaboration in groups during teacher education. Leiden: Leiden University.

226. Jossberger, H. (24-06-2011). Towards self-regulated learning in vocational education: Difficulties and opportunities. Heerlen: Open University of the Netherlands.

227. Schaap, H. (24-06-2011). Students' personal professional theories in vocational education: Developing a knowledge base. Utrecht: Utrecht University.

228. Kolovou, A. (04-07-2011). Mathematical problem solving in primary school. Utrecht: Utrecht University.

229. Beausaert, A.J. (19-10-2011). The use of personal developments plans in the workplace. Effects, purposes and supporting conditions. Maastricht: Maastricht University

230. Favier, T.T. (31-10-2011). Geographic information systems in inquiry-based secondary geography education: Theory and practice.Amsterdam: VU University Amsterdam.

231. Brouwer, P. (15-11-2011). Collaboration in teacher teams. Utrecht: Utrecht University.

232. Molenaar, I. (24-11-2011). It's all about metacognitive activities; Computerized scaffolding of selfregulated learning. Amsterdam: University of Amsterdam.

233. Cornelissen, L.J.F. (29-11-2011). Knowledge processes in school-university research networks. Eindhoven: Eindhoven University of Technology.

234. Elffers, L. (14-12-2011). The transition to post-secondary vocational education: Students' entrance, experiences, and attainment. Amsterdam: University of Amsterdam.

235. Van Stiphout, I.M. (14-12-2011). The development of algebraic proficiency. Eindhoven: Eindhoven University of Technology.

236. Gervedink Nijhuis, C.J. (03-2-2012) Culturally Sesitive Curriculum Development in International Cooperation Enschede: University of Twente

237. Thoonen, E.E.J. (14-02-2012) Improving Classroom Practices: The impact of Leadership School Organizational Conditions, and Teacher Factors Amsterdam: University of Amsterdam

238. Truijen, K.J.P (21-03-2012) Teaming Teachers. Exploring factors that influence effictive team functioning in a vocational education context Enschede: University of Twente

239. Maulana, R.M. (26-03-2012)Teacher-student relationships during the first year of secondary education. Exploring of change and link with motivation outcomes in The Netherlands and Indonesia. Groningen: University of Groningen

240. Lomos, C. (29-03-2012) Professional community and student achievement. Groningen: University of Groningen

241. Mulder, Y.G. (19-04-2012) Learning science by creating models Enschede: University of Twente

242. Van Zundert, M.J. (04-05-2012) Optimising the effectiveness and reliability of reciprocal peer assessment in secondary education Maastricht: Maastricht University

243. Ketelaar, E. (24-05-2012) Teachers and innovations: on the role of ownership, sense-making, and agency. Eindhoven: Eindhoven University of Technology

244. Logtenberg, A. (30-5-2012) Questioning the past. Student questioning and historical reasoning Amsterdam: University of Amsterdam

245. Jacobse, A.E. (11-06-2012) Can we improve children's thinking? Groningen: University of Groningen 
246. Leppink, J. (20-06-2012) Propositional manipulation for conceptual understanding of statistics Maastricht: Maastricht University

247. Van Andel, J (22-06-2012) Demand-driven Education. An Educational-sociological Investigation. Amsterdam: VU University Amsterdam

248. Spanjers, I.A.E. (05-07-2012) Segmentation of Animations: Explaining the Effects on the Learning Process and Learning Outcomes. Maastricht: Maastricht University

249. Vrijnsen-de Corte, M.C.W. Researching the Teacher-Researcher. Practice-based research in Dutch Professional Development Schools Eindhoven: Eindhoven University of Technology

250. Van de Pol, J.E. (28-09-2012) Scaffolding in teacher-student interaction. Exploring, measuring promoting and evaluating scaffolding Amsterdam: University of Amsterdam

251. Phielix, C. (28-09-2012) Enhancing Collaboration through Assessment \& Reflection [Samenwerking Verbeteren door middel van Beoordeling en Reflectie] Utrecht: Utrecht University

252. Peltenburg, M.C. (24-10-2012) Mathematical potential of special education students Utrecht: Utrecht University

253. Doppenberg, J.J. (24-10-2012) Collaborative teacher learning: settings, foci and powerful moments Eindhoven: Eindhoven University of Technology

254. Kenbeek, W.K. (31-10-2012) Back to the drawing board. Creating drawing or text summaries in support of System Dynamics modeling Enschede: University of Twente

255. De Feijter, J.M. (09-11-2012) Learning from error to improve patient safety Maastricht: Maastricht University

256. Timmermans, A.C. (27-11-2012) Value added in educational accountability: Possible, fair and useful? Groningen: University of Groningen

257. Van der Linden, P.W.J. (20-12-2012) A design-based approach to introducing student teachers in conducting and using research. Eindhoven: Eindhoven University of Technology

258. Noroozi, O. (11-01-2013) Fostering Argumentation-Based Computer-Supported Collaborative Learning in Higher Education Wageningen: Wageningen University

259. Bijker, M.M. (22-03-2013) Understanding the gap between business school and the workplace: Overconfidence, maximizing benefits, and the curriculum Heerlen: Open University of the Netherlands

260. Belo, N.A.H. (27-03-2013) Engaging students in the study of physics Leiden: Leiden University

261. Jong, R.J. de (11-04-2013) Student teachers' practical knowledge, discipline strategies, and the teacherclass relationship Leiden: Leiden University

262. Verberg, C.P.M. (18-04-2013) The characteristics of a negotiated assessment procedure to promote teacher learning Leiden: Leiden University

263. Dekker-Groen, A. (19-04-2013) Teacher competences for supporting students' reflection. Standards, training, and practice Utrecht: Utrecht University

264. M.H. Knol (19-04-2013). Improving university lectures with feedback and consultation. Amsterdam: University of Amsterdam

265. Diggelen, M.R. van (21-05-2013) Effects of a self-assessment procedure on VET teachers' competencies in coaching students' reflection skills Eindhoven: Eindhoven University of Technology

266. Azkiyah, S.N. (23-5-2013) The effects of Two Interventions - on Teaching Quality and Student Outcome Groningen: University of Groningen

267. Taminiau, E.M.C. (24-05-2013) Advisory Models for On-Demand Learning Heerlen: Open University of the Netherlands

268. Milliano, I.I.C.M. de (24-05-2013) Literacy development of low-achieving adolescents. The role of engagement in academic reading and writing Amsterdam: University of Amsterdam

269. Vandyck, I.J.J. (17-06-2013), Fostering Community Development in School-University Partnerships. Amsterdam: VU Universtiy Amsterdam

270. Hornstra, T.E. (17-06-2013) Motivational developments in primary school. Group-specific differences in varying learning contexts Amsterdam: University of Amsterdam 
271. Keuvelaar-Van den Bergh, L. (26-06-2013) Teacher Feedback during Active Learning: The Development and Evaluation of a Professional Development Programme. Eindhoven: Eindhoven University of Technology.

272. Meeuwen, L.W. van (06-09-13) Visual Problem Solving and Self-regulation in Training Air Traffic Control Heerlen: Open University of the Netherlands

273. Pillen, M.T. (12-09-2013) Professional identity tensions of beginning teachers Eindhoven: Eindhoven University of Technology

274. Kleijn, R.A.M. de, (27-09-2013) Master's thesis supervision. Feedback, interpersonal relationships and adaptivity Utrecht: Utrecht University

275. Bezdan, E. ( 04-10-2013) Graphical Overviews in Hypertext Learning Environments: When One Size Does Not Fit All Heerlen: Open University of the Netherlands

276. Bronkhorst, L.H. (4-10-2013) Research-based teacher education: Interactions between research and teaching Utrecht: Utrecht University

277. Popov, V. (8-10-2013) Scripting Intercultural Computer-Supported Collaborative Learning in Higher Education Wageningen: Wageningen University

278. Dolfing, R. (23-10-2013) Teachers' Professional Development in Context-based Chemistry Education. Strategies to Support Teachers in Developing Domain-specific Expertise. Utrecht: Utrecht University

279. Lucero, M.L. (21-11-2013) Considering teacher cognitions in teacher professional development: Studies involving Ecuadorian primary school teachers Ghent: Ghent University

280. Kamp, R.J.A. (28-11-2013) Peer feedback to enhance learning in problem-based tutorial groups Maastricht: Maastricht University

281. Cviko, A. (19-12-2013) Teacher Roles and Pupil Outcomes. In technology-rich early literacy learning Enschede: University of Twente 